Aus der Klinik für Hämatologie und Medizinische Onkologie

(Prof. Dr. med. L. Trümper)

der Medizinischen Fakultät der Universität Göttingen

\title{
Evaluation von Antagonisten des \\ Wnt-3a-Signalwegs in \\ diffusen großzelligen B-Zell-Lymphomen
}

\author{
INAUGURAL-DISSERTATION \\ zur Erlangung des Doktorgrades \\ der Medizinischen Fakultät der \\ Georg-August-Universität zu Göttingen
}

vorgelegt von

Patricia Take

aus

Einbeck

Göttingen 2018 
Dekan:

Prof. Dr. rer. nat. H. K. Kroemer

Referent:

Ko-Referent:

Drittreferent:
Prof. Dr. med. G. G. Wulf

Prof. Dr. rer. nat. H. D. Bastians

Datum der mündlichen Prüfung: 29. November 2018 
Hiermit erkläre ich, die Dissertation mit dem Titel „Evaluation von Antagonisten des Wnt-3a-Signalwegs in diffusen großzelligen B-Zell-Lymphomen“ eigenständig angefertigt und keine anderen als die von mir angegebenen Quellen und Hilfsmittel verwendet zu haben.

Göttingen, im November 2018

Patricia Take 


\section{Inhaltsverzeichnis}

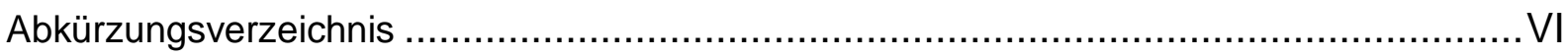

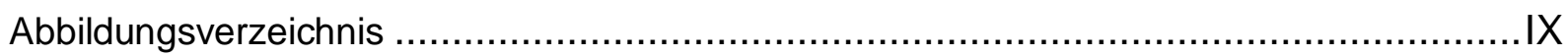

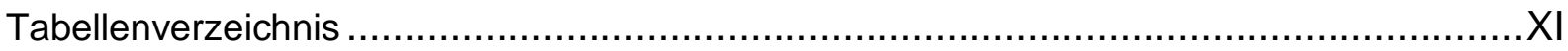

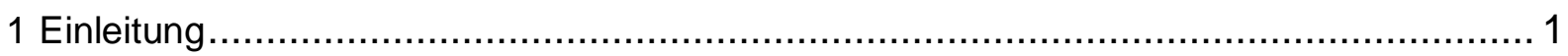

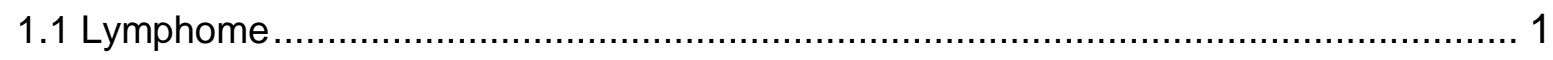

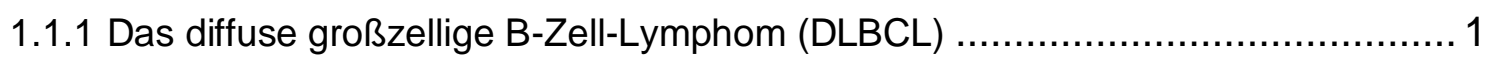

1.1.2 CD20-Expression auf B-Lymphozyten und der Einsatz von Rituximab .............. 3

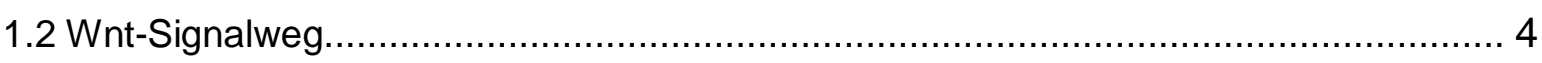

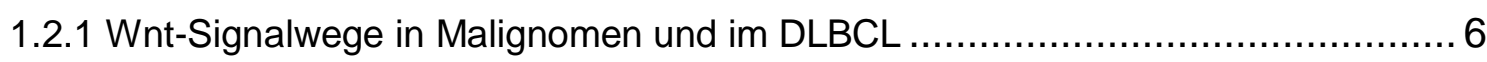

1.2.2 Regulatorische Mechanismen im Wnt-Signalweg ............................... 8

1.2.2.1 Posttranskriptionelle Palmitoylierung und Sekretion von WntMolekülen............................................................................. 8

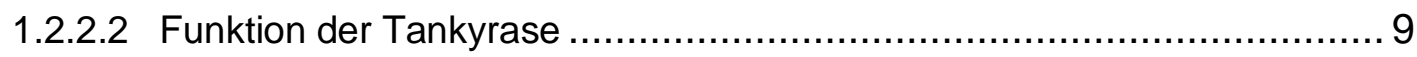

1.2.2.3 Secreted frizzled-related protein 4 (sFRP4) .............................. 10

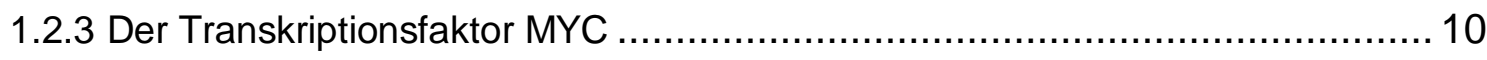

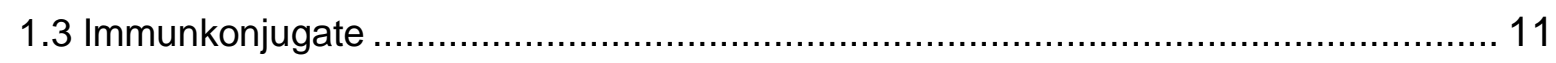

1.3.1 Bedeutung von Immunkonjugaten in der Medizin ............................... 13

1.3.2 Rituximab als Teil von Immunkonjugaten ....................................... 15

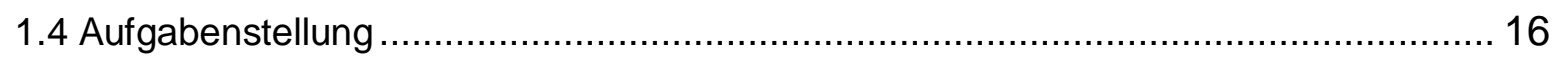

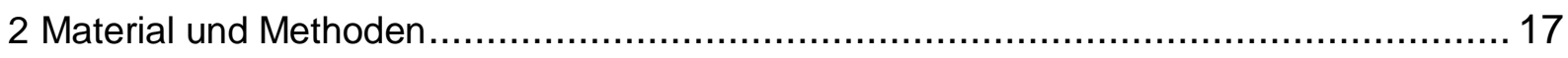

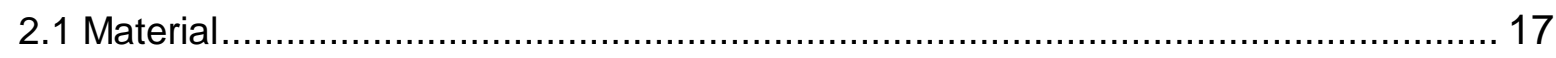

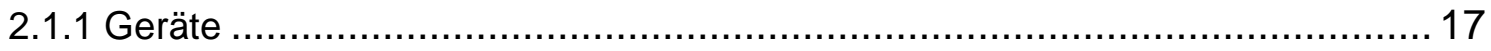

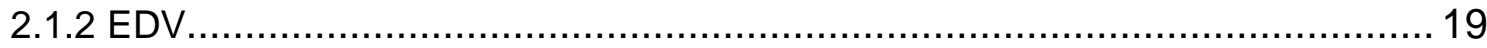

2.1.3 Verbrauchsmaterial ....................................................................... 19

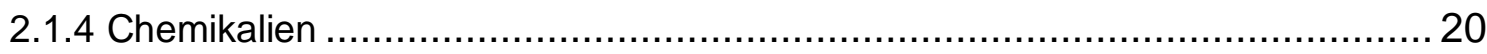

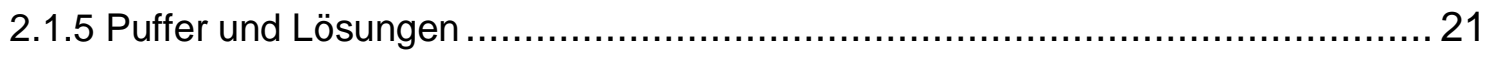




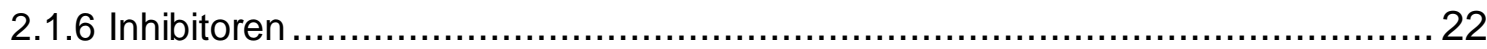

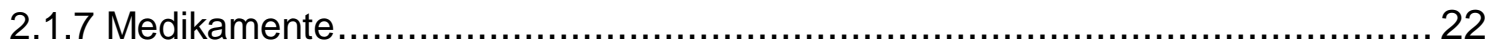

2.1.8 Wachstumsfaktoren, Zusätze für Zellmedien ...................................... 22

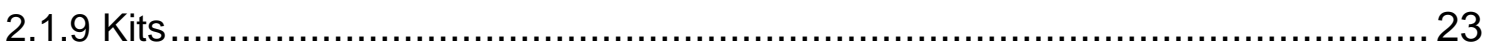

2.1.10 Proteine, Proteinaseinhibitoren und Proteinstandards .............................. 23

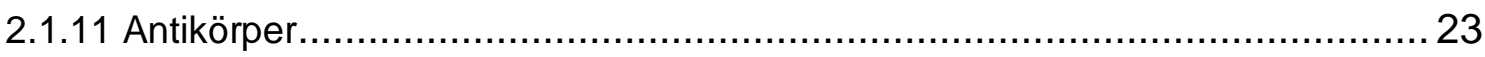

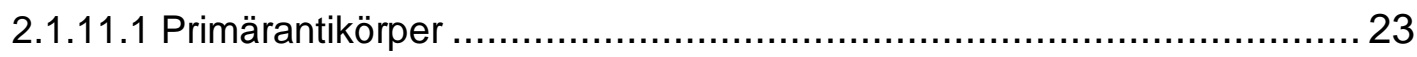

2.1.11.2 Sekundärantikörper ........................................................... 24

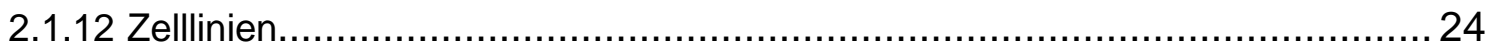

2.1.13 Zellmedien................................................................................ 24

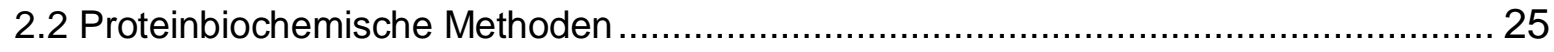

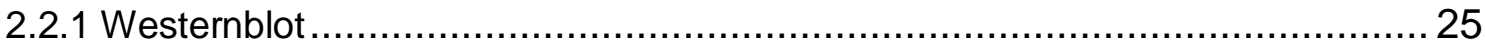

2.2.1.1 Herstellung von Zelllysaten ............................................... 25

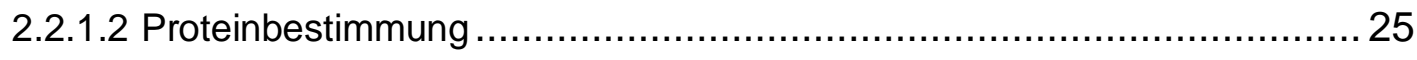

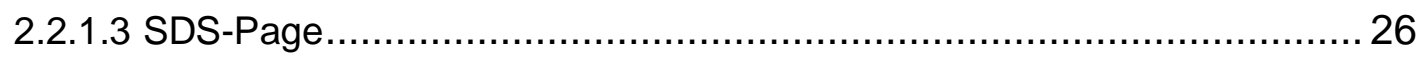

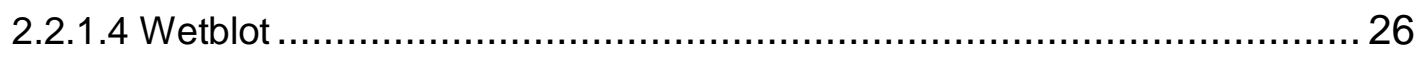

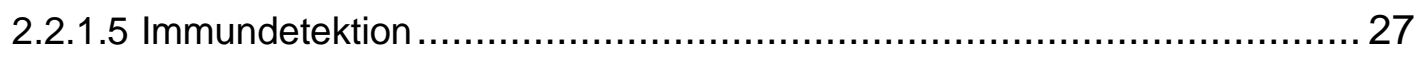

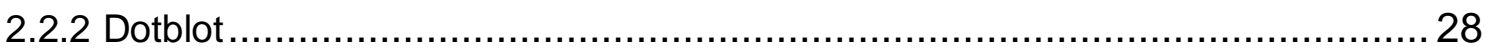

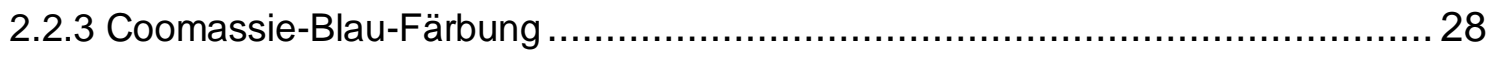

2.2.4 Herstellung eines Fusionsprodukts aus sFRP4 und CD20-bindendem

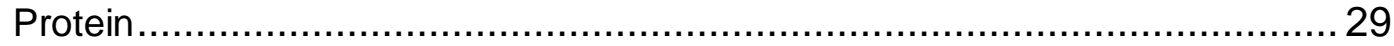

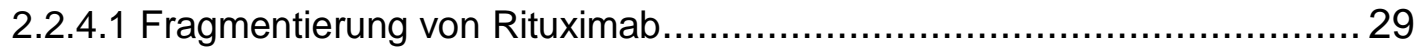

2.2.4.2 Konjugation der Proteine ...................................................... 30

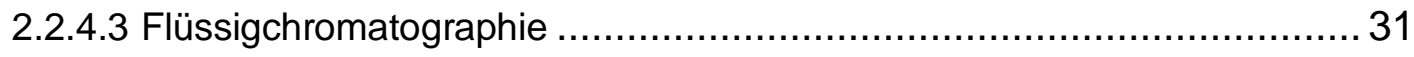

2.2.4.4 FITC-Markierung des immunologischen Konstrukts ........................ 33

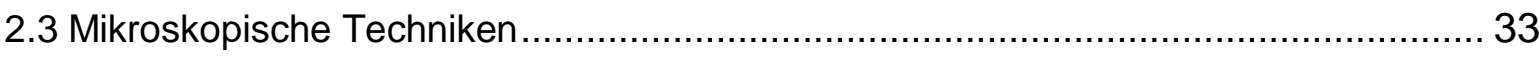

2.3.1 Trypanfärbung zur Zellzahlbestimmung...................................... 33

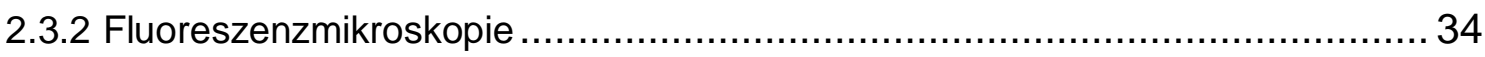




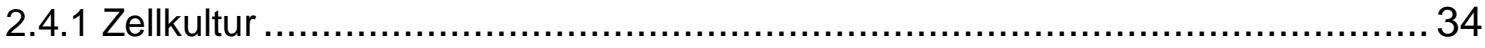

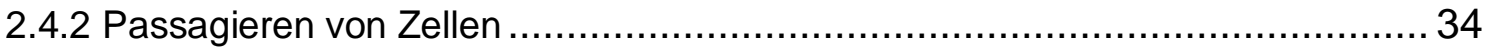

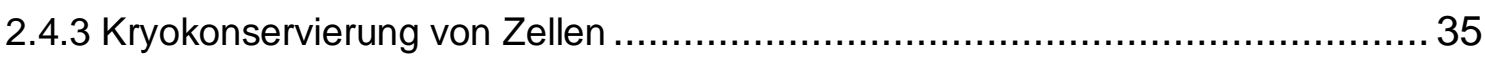

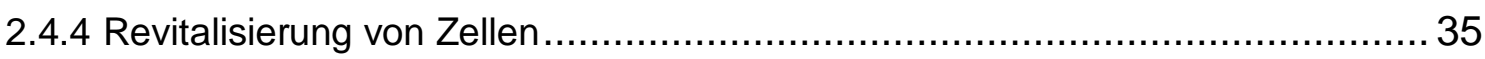

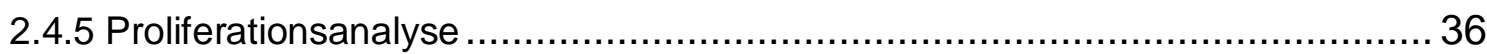

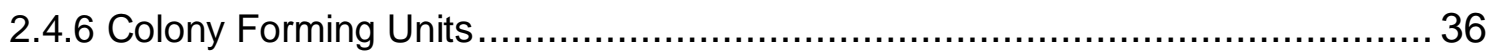

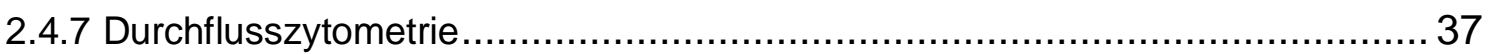

2.4.7.1 Analyse von Frizzledrezeptoren .............................................. 37

2.4.7.2 Inkubation von Lymphomzellen mit UM206 ................................. 38

2.4.7.3 Analyse der Anreicherung von sFRP4 auf Lymphomzellen mittels

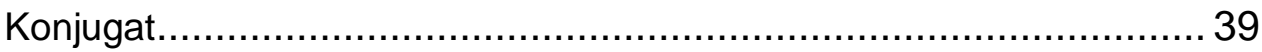

2.4.7.4 Zellzyklusanalyse.............................................................. 41

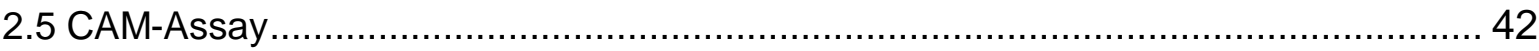

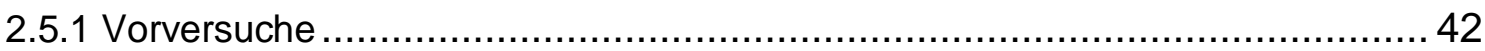

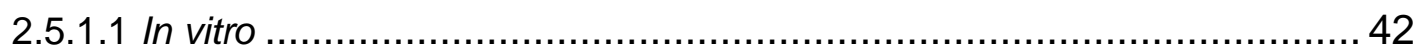

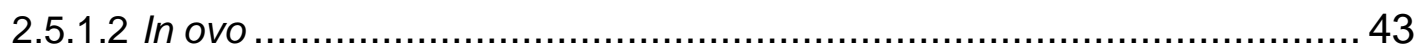

2.5.2 Anfertigen von Kryoschnitten .......................................................... 43

2.5.3 Analyse der Tumorproben im Durchflusszytometer ................................ 43

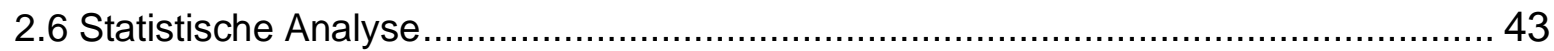

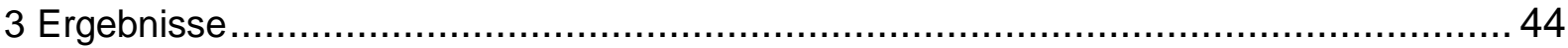

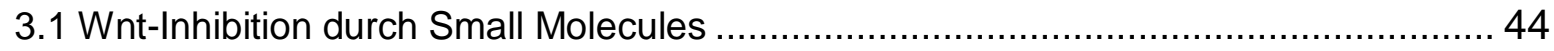

3.1.1 Inhibition des Enzyms Tankyrase durch XAV939 …............................... 45

3.1.1.1 Effekte der Wnt-Inhibition durch Stabilisierung des $\beta$-CateninDegradationskomplexes auf Klonogenität und Proliferation ................ 45

3.1.1.2 Zellzyklusanalyse unter XAV939........................................ 49

3.1.2 Inhibition des Enzyms Porcupine durch IWP-2 und C59.......................... 49

3.1.2.1 Effekte von IWP-2 und C59 auf Endabschnitt der Wnt-Signalkaskade ... 49 
3.1.2.2 Antiproliferative Effekte von IWP-2 auf Lymphomzellen .................... 52

3.1.2.3 Effekte von C59 auf Klonogenität und Zellproliferation ...................... 54

3.1.2.4 Einfluss von Porcupineinhibitoren auf die Zellzyklusprogression ...........56

3.2 UM206 als Wnt-Antagonist in Lymphomzelllinien................................................. 57

3.2.1 Expression von Frizzled-1 und Frizzled-2 auf Lymphomzelllinien................... 57

3.2.2 Effekte von UM206 auf die Zellproliferation in Abhängigkeit von Umgebungsfaktoren................................................................. 58

3.2.3 Effekte von UM206 auf die Klonogenität von Lymphomzellen .......................61

3.2.4 Expression von Frizzled-4 und Frizzled-5 auf Lymphomzelllinien....................62 62

3.2.5 Blockade von Frizzled-1, -2, -4 und -5 durch UM206 und Effekte auf die Proteinexpression der Zelle ............................................................. 63

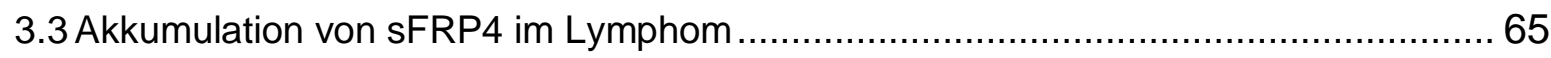

3.3.1 Herstellung eines Fusionsproteins aus sFRP4 und Rituximab- $F_{a b}-$

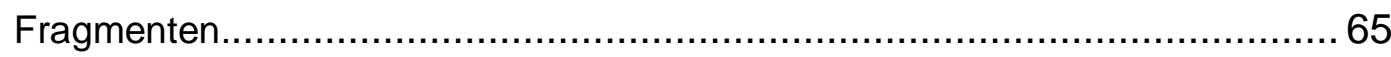

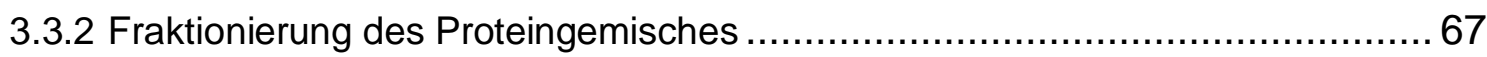

3.3.3 Bestimmung der Proteinkonzentration mittels Dotblot............................. 69

3.3.4 Detektion FITC-markierter Proteine auf Lymphomzelllinien ..........................70

3.3.5 Akkumulation von sFRP4 über CD20 sowohl in vitro als auch in ovo an Lymphomzellen ........................................................................ 71

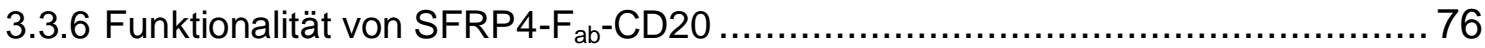

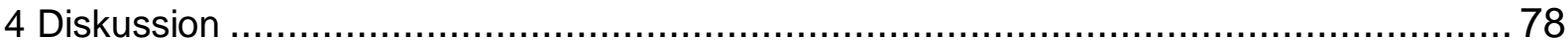

4.1 Wnt-Signalweg in DLBCL-Zelllinien und Angriffspunkte der Wnt-Inhibition................. 78

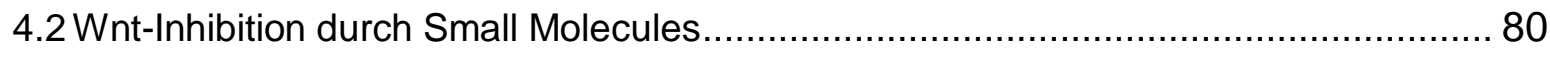

4.2.1 Small Molecules beeinflussen die Wnt-Signalkaskade in Lymphomzellen ........ 80

4.2.2 Reduktion von Zellwachstum und Klonogenität durch Small Molecules ............ 81

4.2.2.1 Effektivität der Wnt-Inhibition durch XAV939 ............................... 81

4.2.2.2 IWP-2 - Abgrenzung Wnt-spezifischer Effekte ............................ 82

4.2.2.3 Effektivität der Wnt-Inhibition durch C59 .................................... 83

4.2.3 Effekte auf die Zellzyklusprogression ............................................... 84 
4.3 Effekte der Frizzledrezeptorblockierung auf die Wnt-Signalwegübermittlung in Lymphomzellen

4.4 Potenzierung der inhibitorischen Wirkung von sFRP4 auf die Wnt-

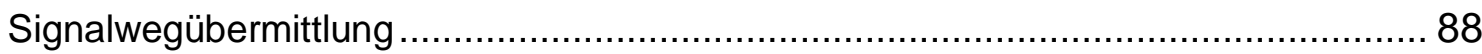

4.4.1 Entwicklung eines SFRP4-F ${ }_{a b}-C D 20-$ Immunkonjugats ............................... 88

4.4.2 Akkumulation von sFRP4 mittels SFRP4- $\mathrm{F}_{\mathrm{ab}}-\mathrm{CD} 20$ in vitro und in ovo ............ 90

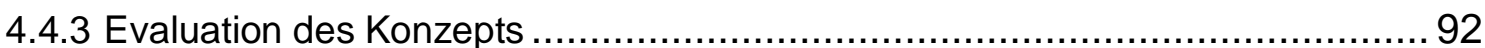

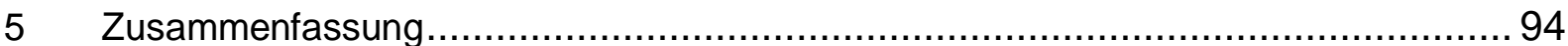

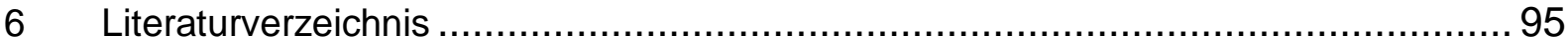




\section{Abkürzungsverzeichnis}

$\alpha$

$\mathrm{ABC}$

ADC

ADP

ANOVA

APC-Protein

Bcl-2

Bcl-6

BSA

C-

CAM

CARD

CBP

CCL3

CD

CDK

CDKN1A

CDKN1B

CFU

CK

DAPI

dest.

DLBCL

DKK

DMEM

DMF

DMSO

DNA

EBV

EDTA

$\mathrm{EZH} 2$

FACS

$F_{a b}$

$\mathrm{F}_{\mathrm{c}}$

FCS

FITC anti-

activated B-like

antibody-drug conjugate

Adenosindiphosphat

analysis of variance, Varianzanalyse

Adenomatöses-Polyposis-Coli-Protein

B-cell lymphoma 2 protein

$B$-cell lymphoma 6 protein

Rinderserumalbumin

Carboxy-

Chorion-Allantois-Membran

caspase recruitment domain

CREB binding protein, Acetyltransferase

C-C-motif Chemokin Ligand 3

cluster of differentiation

Cyclin-abhängige Kinase

CDK-Inhibitor 1A, p21

CDK-Inhibitor 1B, p27

colony forming units

Caseinkinase

4',6-Diamidin-2-phenylindol, Fluoreszenzfarbstoff für DNA destilliert

diffuses großzelliges B-Zell-Lymphom

Dickkopf

Dulbecco's modified Eagle's medium

Dimethylformamid

Dimethylsulfoxid

deoxyribonucleic acid, Desoxyribonukleinsäure

Epstein-Barr-Virus

Ethylendiamintetraessigsäure

enhancer of zeste homolog 2

fluorescence-activated cell sorting, Durchflusszytometrie

fragment antigen binding

fragment crystallisable

fetales Kälberserum

Fluoresceinisothiocyanat 


\begin{tabular}{|c|c|}
\hline FOXP1 & Forkhead Box P1 \\
\hline $\mathrm{Fz}$ & Frizzledrezeptor \\
\hline$g$ & Gewichtskraft \\
\hline G0-Phase & gap, Ruhephase \\
\hline G1-Phase & gap, präsynthetische Phase \\
\hline G2-Phase & gap, postsynthetische Phase \\
\hline GAPDH & Glycerinaldehyd-3-phosphat-Dehydrogenase \\
\hline GCB & germinal center B-like \\
\hline GSK & Glykogensynthasekinase \\
\hline $\mathrm{HCV}$ & Hepatitis-C-Virus \\
\hline HER2-neu & human epidermal growth factor receptor 2 \\
\hline HIV & Humanes Immundefizienz-Virus \\
\hline HRP & horseradish peroxidase \\
\hline IFN- $\alpha$ & Interferon- $\alpha$ \\
\hline $\lg G$ & Immunglobulin G \\
\hline IL10 & Interleukin 10 \\
\hline IMDM & Iscove's modified Dulbecco's medium \\
\hline IRF4 & interferon regulatory factor 4 \\
\hline IWP & inhibitors of Wnt-production \\
\hline $\mathrm{kDa}$ & Kilodalton \\
\hline LEF & lymphoid enhancing binding factor \\
\hline LRP & low density lipoprotein related protein \\
\hline $\mathrm{mAU}$ & milli absorbance units \\
\hline $\operatorname{miR}$ & micro RNA \\
\hline M-Phase & Mitose-Phase \\
\hline mRNA & messenger RNA \\
\hline MTS & $\begin{array}{l}\text { 3-(4,5-Dimethylthiazol-2-yl)-5-(3-carboxymethoxyphenyl)-2-(4- } \\
\text { sulfophenyl)-2H-tetrazolium }\end{array}$ \\
\hline N- & Amino- \\
\hline $\operatorname{NADP}(H)$ & Nicotinsäureamid-Adenin-Dinukleotid-Phosphat \\
\hline$N F-x B$ & nuclear factor 'kappa-light-chain-enhancer' of activated B-cells \\
\hline $\mathrm{NHL}$ & Non-Hodgkin-Lymphom \\
\hline NK-Zellen & natürliche Killerzellen \\
\hline$P$ & anorganisches Phosphat \\
\hline PBS & phosphate buffered saline, phosphatgepufferte Salzlösung \\
\hline PCA & protein-fragment complementation assay \\
\hline PE & Phycoerythrin, Fluoreszenzfarbstoff für FACS-Analysen \\
\hline
\end{tabular}




$\begin{array}{ll}\text { PES } & \text { Phenazinethosulfat } \\ \text { PFA } & \text { Paraformaldehyd } \\ \text { PI3K/AKT } & \text { Phosphatidylinositol 3-kinase/Proteinkinase B } \\ \text { PTEN } & \text { phosphatase and tensin homolog } \\ \text { rhsFRP4 } & \text { rekombinantes humanes sFRP4 } \\ \text { RNA } & \text { ribonucleic acid, Ribonukleinsäure } \\ \text { RPMI } & \text { Roswell Park Memorial Institute medium } \\ \text { SFRP } & \text { secreted frizzled-related protein } \\ \text { S-HyNic } & \text { Succinimidyl-6-hydrazin-nikotinamid } \\ \text { S-Phase } & \text { Synthesephase } \\ \text { S-S } & \text { Disulfidbindung } \\ \text { TBS-T } & \text { tris buffered saline, trisgepufferte Salzlösung mit Tween 20 } \\ \text { TCA } & \text { Trichloressigsäure } \\ \text { TCF } & \text { T-cell factor } \\ \text { TDM-1 } & \text { Trastuzumab-Emtansin } \\ \text { TP53 } & \text { Tumorsuppressor P53 } \\ \text { TrCP } & \text { transducin repeat containing protein } \\ \text { TRF1 } & \text { telomeric repeat binding factor 1 } \\ \text { WB } & \text { Westernblot } \\ & \end{array}$




\section{Abbildungsverzeichnis}

Abbildung 1: Schematische Darstellung des kanonischen Wnt-Signalwegs. .................... 6

Abbildung 2: Entstehung einer einfachen Hydrazonverbindung .................................. 12

Abbildung 3: Schematische Darstellung eines Immunkonjugats. .................................. 13

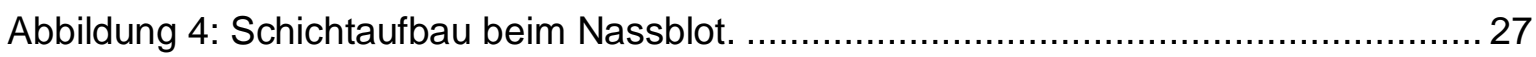

Abbildung 5: Spaltung von IgG-Molekülen durch Papain........................................... 30

Abbildung 6: Isolierung von $F_{a b}$-Fragmenten mittels einer Proteinsäule.......................... 30

Abbildung 7: Verlinkung von sFRP4 und einem $\mathrm{F}_{\mathrm{ab}}$-Fragment...................................... 31

Abbildung 8: Absorptionsverhalten von Standardproteinen bei einer Wellenlänge von

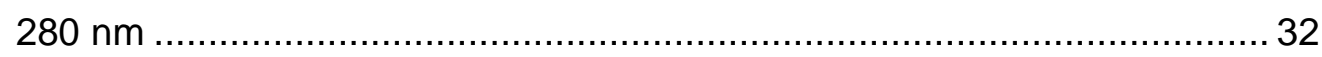

Abbildung 9: Reduktion der Tetrazoliumverbindung zu Formazan................................. 36 Abbildung 10: Zellulärer $\beta$-Catenin-Gehalt und Expression von MYC in Lymphomzelllinien.

Abbildung 11: Westernblot mit XAV939 behandelter Zellen. 46

Abbildung 12: Klonogenitätsassay mit XAV939 behandelter Zellen der Zelllinie OCI-Ly3.

Abbildung 13: Zellwachstum von OCl-Ly3 (A) und OCl-Ly1 (B) unter Behandlung mit XAV939.

Abbildung 14: Zellwachstum von U-2932 R1 (A) und U-2932 R2 (B) unter Behandlung mit XAV939.

Abbildung 15: Zellzyklusmessung mittels Durchflusszytometrie für mit XAV939 behandelte Zellen. 49

Abbildung 16: Westernblot mit IWP-2 behandelter Zellen. 50

Abbildung 17: Westernblot mit C59 behandelter Zellen. 51

Abbildung 18: Klonogenitätsassay mit IWP-2 behandelter Zellen der Zelllinie OCI-Ly3... 52 Abbildung 19: Zellwachstum von OCl-Ly3 (A) und OCl-Ly1 (B) unter Behandlung mit IWP-2.

Abbildung 20: Zellwachstum von U-2932 R1 (A) und U-2932 R2 (B) unter Behandlung mit IWP-2.

Abbildung 21: Klonogenitätsassay mit C59 behandelter Zellen der Zelllinie OCI-Ly3. ..... 54 Abbildung 22: Zellwachstum von OCI-Ly3 (A) und OCl-Ly1 (B) unter Behandlung mit C59.

Abbildung 23: Zellwachstum von U-2932 R1 (A) und U-2932 R2 (B) unter Behandlung mit C59. 55

Abbildung 24: Zellzyklusmessung mittels Durchflusszytometrie für mit IWP-2 behandelte Zellen. 
Abbildung 25: Zellzyklusmessung mittels Durchflusszytometrie für mit C59 behandelte

Zellen.

Abbildung 26: Expression von Frizzled-1 und -2 auf Lymphomzelllinien.

Abbildung 27: Proliferationsanalyse der Zelllinien OCI-Ly3 und U-2932 unter Behandlung mit UM206.

Abbildung 28: Westernblot nach 24-stündiger Inkubation mit UM206. 60

Abbildung 29: Zellzyklusanalyse nach Inkubation mit UM206.

Abbildung 30: Klonogenitätsassay mit UM206 behandelter Zellen der Zelllinie OCI-Ly3. 61

Abbildung 31: Expression von Frizzled-4 und -5 auf Lymphomzelllinien. 62

Abbildung 32: Expression von Frizzled-1, -2, -4 und -5 auf OCI-Ly1 und OCl-Ly3 nach einstündiger Inkubation mit UM206.

Abbildung 33: Expression von Frizzled-1, -2, -4 und -5 auf OCl-Ly1 und OCl-Ly3 nach 24-stündiger Inkubation mit UM206. 64

Abbildung 34: Coomassie-Färbung der Fragmentierung von Rituximab. 66

Abbildung 35: Dotblot des Fusionsprodukts SFRP4-F $\mathrm{ab}_{\mathrm{b}}-\mathrm{CD20}$ vor Fraktionierung. 67

Abbildung 36: Westernblots der SFRP4- $F_{a b}-C D 20-F r a k t i o n e n$. 68

Abbildung 37: Dotblot der Fraktionen E1-3 und F1-3. 69

Abbildung 38: CD20-Expression und Detektion FITC-markierter $F_{a b}$-Fragmente auf Lymphomzelllinien

Abbildung 39: FITC-markiertes Rituximab bindet an die Zellmembran von Lymphomzellen.

Abbildung 40: Durchflusszytometrische Analyse von SU-DHL-4 nach Inkubation mit sFRP4 und SFRP4-Fab-CD20-Fusionsprodukt.

Abbildung 41: Durchflusszytometrische Analyse von SU-DHL-4 nach Inkubation mit Rituximab und SFRP4-F $\mathrm{ab}_{\mathrm{a}}-\mathrm{CD} 20$-Fusionsprodukt. 73

Abbildung 42: Detektion von SFRP4- $\mathrm{F}_{\mathrm{ab}}-\mathrm{CD} 20$ in ovo. 74

Abbildung 43: Durchflusszytometrische Analyse von SFRP4- $F_{a b}-C D 20$ auf

Primärtumorproben. 75

Abbildung 44: Klonogenitätsassay nach Präinkubation mit SFRP4- $\mathrm{F}_{\mathrm{ab}}-\mathrm{CD} 20$. 


\section{Tabellenverzeichnis}

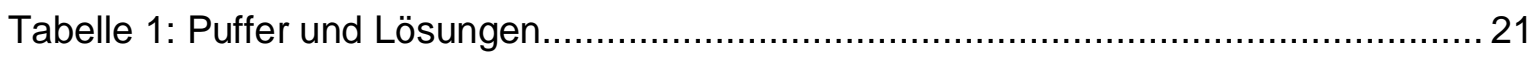

Tabelle 2: Primärantikörper. ............................................................................. 23

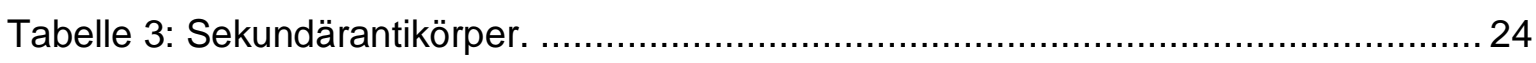

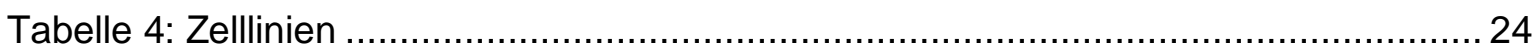

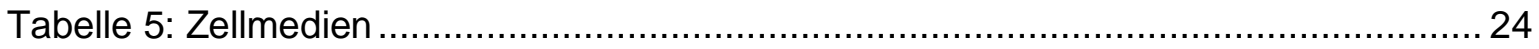

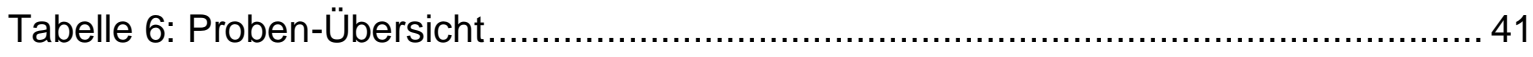

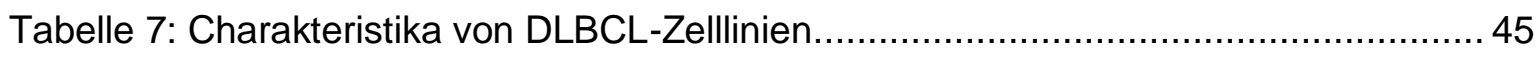

Tabelle 8: Durchflusszytometrische Analyse der Expression von Frizzled-1 und -2 auf Lymphomzelllinien...................................................................... 58

Tabelle 9: Durchflusszytometrische Analyse der Expression von Frizzled-4 und -5 auf

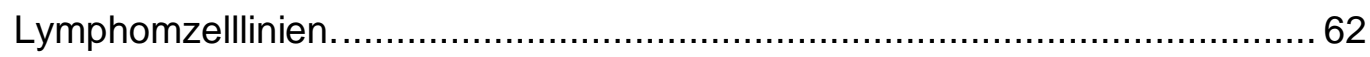

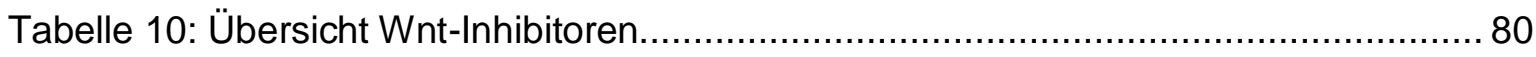




\section{Einleitung}

\subsection{Lymphome}

Lymphome sind Neoplasien des lymphatischen Systems, die in die Gruppen der Hodgkin- und der Non-Hodgkin-Lymphome unterteilt werden, wobei letztere ca. $90 \%$ aller Lymphome ausmachen (Shankland et al. 2012). Das Non-HodgkinLymphom (NHL) betrifft etwas häufiger Männer als Frauen und zeigt die größte Inzidenz in Nordamerika und Australien (Torre et al. 2015). Inzidenz sowie Mortalität sind zunehmend - zwischen 2008 und 2012 ist die Zahl der Neuerkrankungen um $8 \%$ auf 385.000 Fälle und die Zahl der Todesfälle um 4 \% auf 199.700 Fälle weltweit angestiegen (Jemal et al. 2011; Torre et al. 2015).

Das NHL geht zu 85-90\% aus B-Zellen und zu 10-15\% aus T- oder NK-Zellen hervor (Shankland et al. 2012). Im Rahmen der physiologischen Immunantwort kommt es bei der Reifung und Aktivierung der B-Zellen im Lymphfollikel zu Proliferation und somatischer Hypermutation, wodurch diese Zellen bei Verlust von Kontrollmechanismen oder Fehlregulation prädestiniert für das Entstehen bösartiger Erkrankungen sind. Die Entartung kann in allen Stadien der B-ZellEntwicklung entstehen, was zur klinischen Heterogenität der Erkrankung beiträgt. Klinisch unterscheidet man die indolenten von den aggressiven $\mathrm{NHL}$, wobei das in der Arbeit näher untersuchte diffuse großzellige B-Zell-Lymphom (DLBCL) der Gruppe aggressiver Lymphome angehört (WHO et al. 2008).

\subsubsection{Das diffuse großzellige B-Zell-Lymphom (DLBCL)}

In der Gruppe der NHL stellt das diffuse großzellige B-Zell-Lymphom weltweit mit einem Anteil von 30-40 \% den häufigsten Subtyp dar (Lenz und Staudt 2010). Das mittlere Erkrankungsalter liegt bei etwa 70 Jahren (Smith et al. 2011), wobei Patienten häufig durch Lymphknotenschwellung und B-Symptomatik mit Gewichtsverlust, Nachtschweiß und Fieber auffallen. Für die Entstehung des DLBCLs sind verschiedene Risikofaktoren beschrieben worden. Dazu gehören eine immunsuppressive Therapie (Opelz und Dohler 2004), Infektionen mit HCV (de Sanjose et al. 2008), HIV und EBV (WHO et al. 2008), aber auch Autoimmunerkrankungen (Ekstrom Smedby et al. 2008) und eine positive Familienanamnese (Wang et al. 2007). 
Wie schon die große Gruppe der NHL ist auch die Subgruppe der DLBCL von morphologischer, biologischer und klinischer Heterogenität geprägt (WHO et al. 2008). Genexpressionsanalysen haben allerdings gezeigt, dass sich die DLBCL unabhängig von der bestehenden morphologischen Heterogenität in zwei große Subtypen unterscheiden lassen. Grundlage dieser Einteilung ist gemäß des cellof-origin-Konzepts der Differenzierungsgrad und das damit einhergehende Expressionsmuster der B-Zelle, aus der die Tumorzellen hervorgegangen sind. Die erste Subgruppe ist durch Expression typischer Keimzentrumsmarker wie CD10 gekennzeichnet, weshalb diese Lymphome als germinal center B-cell-like DLBCL (GCB) bezeichnet werden (Alizadeh et al. 2000). Gene der physiologischen Keimzentrumsreaktion, wie $B C L 6$, spielen hierbei pathogenetisch eine wichtige Rolle: Als transkriptioneller Repressor inhibiert BCL-6 Inhibitoren des Zellzyklus wie p21 und p27, wodurch der Zellzyklus stimuliert wird. Daneben vermindert BCL-6 durch Suppression von TP53 die Induktion von Apoptose als Zellantwort auf DNA-Schädigung (Phan und Dalla-Favera 2004; Shaffer et al. 2000). Weitere charakteristische onkogene Mechanismen der GCB-Lymphome stellen z. B. eine Überexpression des anti-apoptotischen BCL2-Gens durch die Translokation $\mathrm{t}(14 ; 18)$ (q32;q21), eine Aktivierung des PI3K/AKT-Signalwegs durch PTEN-Deletionen oder miR-17-92 Amplifikationen (Lenz et al. 2008b; Xiao et al. 2008; Zhang et al. 2011) und auch spezifische somatische Mutationen wie z. B. im EZH2-Gen dar (Morin et al. 2010). Im Gegensatz zu den GCB-Lymphomen weisen die Lymphome der zweiten Gruppe ein Expressionsmuster auf, das dem Muster von aktivierten reifen B-Zellen ähnlich ist. Sie werden als activated B-celllike DLBCL $(A B C)$ bezeichnet und weisen charakteristischerweise genetische Alterationen auf, die mit einem stetig aktivierten NF-xB-Signalweg einhergehen, so z. B. aktivierende Mutationen im CARD11-Gen oder chronische Aktivierung des B-Zell-Rezeptors durch CD79A- oder CD79B-Mutationen (Alizadeh et al. 2000; Davis et al. 2010; Lenz et al. 2008a).

Die Subgruppen unterscheiden sich klinisch im Ansprechen auf die Therapie. So haben Patienten mit GCB mit einer 5-Jahresüberlebensrate von $76 \%$ eine signifikant bessere Prognose als Patienten mit $A B C$ und einer 5Jahresüberlebensrate von nur $16 \%$ (Alizadeh et al. 2000). 
Auch wenn ein Großteil der Patienten mit DLBCL dank des Chemotherapieschemas R-CHOP (Kombination aus Rituximab, Cyclophosphamid, Hydroxydaunorubicin, Oncovin und Prednisolon) progressionsfreie Überlebensraten von über zehn Jahren erreicht, erleiden $30-40 \%$ der Patienten mit DLBCL nach initialer Chemotherapie ein Rezidiv oder eine Progression der Erkrankung. Die Prognose dieser Patienten ist deutlich schlechter, so überleben $70 \%$ der Patienten weniger als 48 Monate (Coiffier et al. 2010). Daher ist es nötig, weitere Erkenntnisse über die Tumorbiologie und Inhibitionsmöglichkeiten der onkogenen Signalwege zu gewinnen und so Strategien zur Behandlung von DLBCL zu entwickeln.

\subsubsection{CD20-Expression auf B-Lymphozyten und der Einsatz von Rituximab}

Auf der Membranoberfläche von Zellen können Proteine mittels Antikörpern detektiert werden, die sich aufgrund biochemischer und funktioneller Eigenschaften zu Gruppen, den sogenannten Clusters of Differentiation (CD) zusammenfassen lassen. Derzeit sind über 300 CD-Antigene beschrieben worden, von denen einige allein oder in Kombination spezifisch für eine Zellart oder für eine bestimmte Entwicklungsstufe einer Zellreihe sind und damit als Marker dienen können (Engel et al. 2015).

Für B-Lymphozyten sind zahlreiche CD-Antigene untersucht. Zu diesen gehören CD19, CD20 und CD22, welche spezifisch auf B-Zellen zu finden sind. CD20 ist ein Transmembranprotein, dessen Expressionsdichte im Laufe der Entwicklung der B-Zellen zunimmt. Auf frühen Vorläufer-B-Zellen des Knochenmarks ist das Antigen noch nicht zu finden, spätere Vorstufen exprimieren CD20 bereits und das Antigen ist schließlich auf allen reifen B-Zellen vorhanden, bis es im Rahmen der Plasmazell-Differenzierung zur Herabregulation kommt (Tedder und Engel 1994). CD20 ist an der Aktivierung und Proliferation von B-Zellen beteiligt (Tedder et al. 1985) und kann als Ionenkanal den Calciumstrom über die Zellmembran regulieren (Bubien et al. 1993). Das Oberflächenprotein CD20 scheint zudem eine wichtige Rolle in der T-Zell-unabhängigen Immunantwort zu spielen (Kuijpers et al. 2010).

CD20 wird sowohl von gesunden als auch von malignen B-Zellen exprimiert. Auch der überwiegende Teil der DLBCL besitzt dieses Oberflächenantigen (Freedman et al. 1985), was mit dem Einsatz des anti-CD20-Antikörpers Rituximab 
therapeutisch genutzt wird (Maloney et al. 1994). 1997 wurde Rituximab als erster monoklonaler Antikörper für die Therapie des Non-Hodgkin-Lymphoms in den USA zugelassen, ein Jahr später folgte die Zulassung in Europa und heute gehört der Antikörper in Kombination mit einer Chemotherapie nach dem CHOP-Protokoll zur Erstlinientherapie aggressiver B-Zell-Lymphome, was gegenüber alleiniger CHOP-Chemotherapie zu einer signifikanten Verbesserung des progressionsfreien Überlebens und Gesamtüberlebens führt (Coiffier et al. 2010; Grillo-Lopez et al. 2002). Mechanistisch folgt einer Bindung des Antikörpers an das CD20 einer B-Zelle eine Aktivierung des Komplementsystems, was zur Opsonierung der betroffenen Zelle oder direkt zur Lyse führen kann. Das $F_{c}$-Fragment aktiviert zudem natürliche Killerzellen, die ebenfalls durch Lyse oder Apoptoseinduktion den Tod der Zielzelle herbeiführen (Glennie et al. 2007). Darüber hinaus scheint die Bindung an CD20 zur Schwächung verschiedener antiapoptotisch wirkender Signale zu führen, wodurch die Zellen eine erhöhte Chemosensibilität zeigen (Motta et al. 2010).

\subsection{Wnt-Signalweg}

Für die adäquate Entwicklung eines Lebewesens sind viele Steuerungs- und Kontrollmechanismen von essentieller Bedeutung. Die Signalwege, die während der Entwicklung eine wichtige Rolle spielen, sind ebenso im adulten Organismus an Wachstumsvorgängen oder auch dem programmierten Zelltod beteiligt. Geraten die Regulationsmechanismen außer Kontrolle, kann dies zu unkontrolliertem Zellwachstum führen - Krebs entsteht.

Der im Mittelpunkt dieser Arbeit stehende Wnt-Signalweg ist einer dieser Signalwege, der eine Vielzahl biologischer Vorgänge kontrolliert und durch extrazelluläre Moleküle reguliert wird. Der Wnt-Signalweg spielt eine essentielle Rolle in der Morphogenese aller Metazoen und wurde ursprünglich in Drosophila beschrieben (Siegfried und Perrimon 1994). Wnt-Moleküle sind von Zellen ungebunden oder auf Exosomen in den Extrazellulärraum freigegebene Proteine, die über kurze Distanz mittels Konzentrationsgradienten interzelluläre Kommunikation vermitteln und Zelldifferenzierung, Gewebshomöostase und Zellproliferation regulieren (Gross et al. 2012; Koch et al. 2014; Willert und Nusse 1998). Zur Zeit sind 19 WNT-Gene sowie 10 Gene für Frizzledrezeptoren bekannt (Clevers und Nusse 2012; Wang et al. 2016). 
Grundsätzlich wird der kanonische vom nicht-kanonischen Wnt-Signalweg unterschieden. Letzterer ist $\beta$-Catenin-unabhängig und nimmt Einfluss auf zytoplasmatische Effekte wie Zellpolarität und Calciumhaushalt, wodurch wiederum andere Zellvorgänge reguliert werden (Niehrs 2012).

Der kanonische Signalweg ist durch den second messenger $\beta$-Catenin charakterisiert, der die Genexpression beeinflusst. $\beta$-Catenin ist in der Zelle einem stetigen Regulationsprozess unterworfen. In Abwesenheit von Wnt-Stimulation wird $\beta$-Catenin an einen Degradationskomplex gebunden, welcher aus Axin1/2, der Glykogensynthasekinase 3, der Caseinkinase 1a und dem AdenomatösesPolyposis-Coli-(APC-)Protein besteht. Die Kinasen phosphorylieren gebundenes $\beta$-Catenin am N-Terminus, was wiederum zur Ubiqitinierung des Proteins durch $\beta$ TrCP (Teil eines E3-Ubiquitinligasekomplexes) und anschließendem Abbau über Proteasomen führt (Clevers und Nusse 2012). Binden dagegen Wnt-Moleküle an den Frizzledrezeptor und die Corezeptoren LRP5 oder LRP6, so werden letztere Dishevelled-abhängig von der Glykogensynthasekinase 3 und anderen Kinasen phosphoryliert. Durch diese Phosphorylierung entsteht an LRP5/6 eine Bindestelle für Axin. Durch die Bindung von Axin an LRP5/6 wird der Degradationskomplex an die Zellmembran rekrutiert. $\beta$-Catenin bleibt dabei an den Degradationskomplex gebunden, kann aber nicht mehr vom Proteasom abgebaut werden. Der Komplex ist damit gesättigt und kann kein weiteres $\beta$-Catenin binden. Neu synthetisiertes $\beta$ Catenin akkumuliert im Zytoplasma und steht als aktiver Transkriptionsfaktor zur Verfügung (Li et al. 2012).

Das Wnt-Signal an der Zelloberfläche führt nicht nur zu einer Akkumulation von $\beta$ Catenin, sondern setzt auch eine Signalkaskade in Gang, an deren Ende die Phosphorylierung des freien $\beta$-Catenins am C-Terminus durch die Junkinase 2 steht. Durch diese Modulation kann $\beta$-Catenin in den Nucleus migrieren, als Coaktivator an den lymphoid enhancing-binding factor (LEF) und an den T-cell factor (TCF) binden und die Genexpression verändern (Kim et al. 2013; Valkenburg et al. 2011). Zu den Zielgenen dieser Kaskade gehören MYC, CCND1 und AXIN2 (He et al. 1998; Jho et al. 2002; Tetsu und McCormick 1999). 


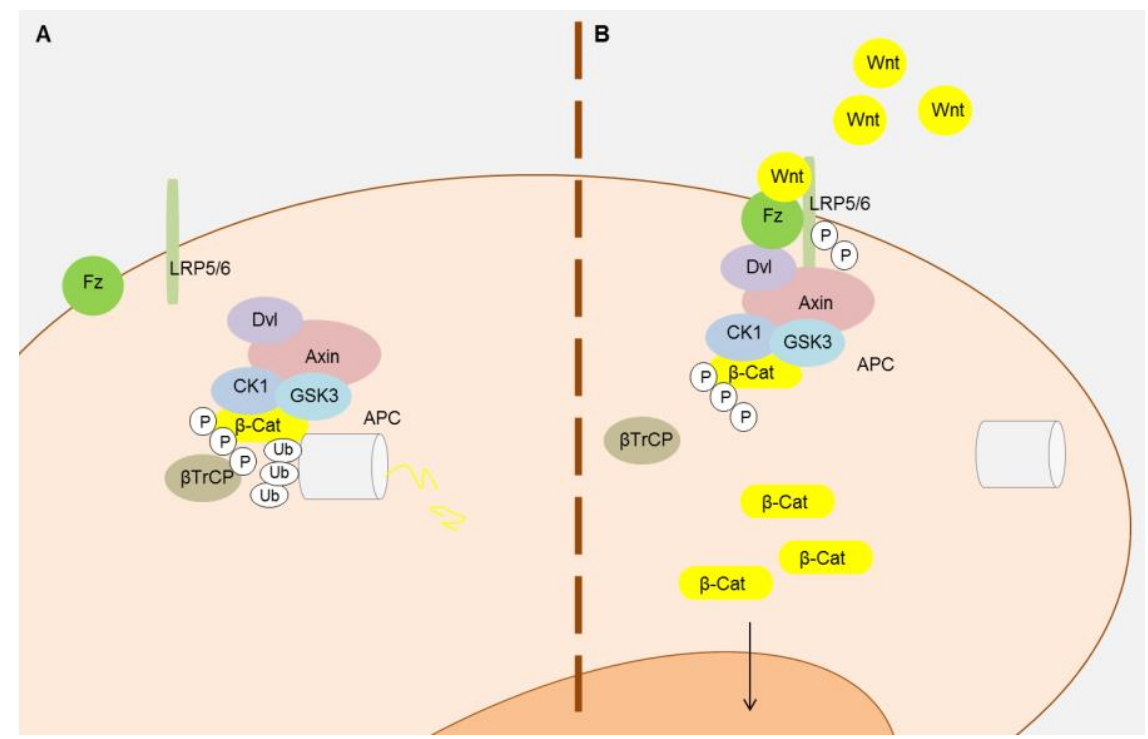

Abbildung 1: Schematische Darstellung des kanonischen Wnt-Signalwegs. A: Bei fehlendem Wnt-Signal bindet der Degradationskomplex $\beta$-Catenin, was zu dessen Phosphorylierung und anschließender Ubiquitinierung führt. Es kommt zum Abbau von $\beta$-Catenin im Proteasom. B: Binden Wnt-Moleküle an den Frizzledrezeptor sowie an die Corezeptoren LRP5 oder 6, werden letztere phosphoryliert. Dadurch kommt es zu einer Interaktion zwischen Corezeptor und Degradationskomplex, wodurch wiederum die Ubiquitinierung sowie der Abbau von $\beta$-Catenin verhindert werden. Neu synthetisiertes $\beta$-Catenin steht nun für die Migration in den Nucleus zur Verfügung. Abkürzungen: Fz: Frizzledrezeptor, LRP: low-density-lipoprotein-related-Protein, Dvl: Dishevelled, GSK3: Glykogensynthasekinase 3, CK1: Caseinkinase 1a, APC: AdenomatösesPolyposis-Coli-Protein, $\beta$-Cat: $\beta$-Catenin, $\beta$ TrCP: $\beta$-Transducin-repeats-containing-Protein. Nach Clevers und Nusse 2012.

\subsubsection{Wnt-Signalwege in Malignomen und im DLBCL}

Die Bedeutung von Veränderungen des Wnt-Signalwegs mit resultierender Fehlregulation ist für zahlreiche Tumoren gezeigt worden. Dabei können relevante Aberrationen direkt Komponenten des Signalwegs oder aber indirekt dessen Regulatoren betreffen.

Schon lange ist eine Verbindung zwischen Wnt und der Entwicklung von Brustkrebs bekannt (Tsukamoto et al. 1988). Eine Aktivierung des Signalwegs geht dabei mit einem schlechteren Überleben der Patientinnen einher (Khramtsov et al. 2010). Eines der häufigsten Beispiele für Mutationen im Wnt-Signalweg ist der funktionelle Verlust des Tumorsuppressorproteins APC im Kolonkarzinom, der zu einer Fehlregulation von $\beta$-Catenin führt und damit zur Tumorgenese beiträgt (Bienz und Clevers 2000; Kinzler et al. 1991). Mutationen von AXIN sind ebenfalls 
im Kolonkarzinom, aber auch im hepatozellulären Karzinom oder im Medulloblastom gefunden worden (Salahshor und Woodgett 2005).

Darüber hinaus stellt der Wnt-Signalweg eine Komponente in der Entstehung und Progression von Non-Hodgkin-Lymphomen dar, die für verschiedene Subtypen beschrieben worden ist (Bellei et al. 2004; Gelebart et al. 2008). Speziell für DLBCL ergaben sich in den vergangenen Jahren zunehmend Hinweise auf eine pathogenetische Relevanz des kanonischen Wnt-Signalwegs: Ge et al. beschrieben an einer chinesischen Kohorte von 30 DLBCL-Patienten eine signifikant höhere Expression und nukleäre Lokalisation von $\beta$-Catenin im Vergleich zu reaktivem Lymphdrüsengewebe und sahen eine Korrelation zwischen $\beta$-Catenin-Expression und fortgeschrittenem klinischem Stadium der Erkrankung ( $\mathrm{Ge}$ et al. 2012). Folgende Arbeiten ergaben zudem Erkenntnisse über Mechanismen, die den kanonischen Wnt-Signalweg im DLBCL aktivieren: Walker et al. identifizierten den Transkriptionsfaktor FOXP1, dessen Expression bekanntlich mit einer schlechteren Prognose assoziiert ist, als Verstärker der $\beta$ Catenin-abhängigen Transkription: In der Promotorregion von Ziel-Genen des Wnt-Signalwegs bilden FOXP1, CBP, $\beta$-Catenin und TCF7L2 einen Komplex, in dem FOXP1 die Acetylierung von $\beta$-Catenin durch CBP augmentiert und dadurch zu einer verstärkten Transkription dieser Zielgene führt. Genamplifikation oder Translokation von FOXP1 führen somit zu einer Potenzierung kanonischen WntSignalings und zu einer signifikanten Verschlechterung der Prognose (Gascoyne und Banham 2017; Walker et al. 2015). Eine weitere Arbeit, die die Relevanz kanonischen Wnt-Signalings im DLBCL unterstreicht, wurde 2016 von Bognar et al. veröffentlicht: In einer systematischen Untersuchung onkogener CARD11Mutationen, die eine der häufigsten somatischen Mutationen in ABC-DLBCL darstellt, wurden massenspektrometrisch Bindungspartner von CARD11 untersucht und eine Rekrutierung von $\beta$-Catenin und dem Abbau-Komplex aus APC, Axin1, CK1 $\alpha$ und GSK3 $\beta$ nachgewiesen. Dies führt zu einer Stabilisierung von $\beta$-Catenin und augmentierter TCF/LEF-abhängiger Transkription bei WntStimulation mit konsekutiv verstärkter Expression von IL10 und Suppression von anti-tumoralem CCL3, wodurch ein tumorprotektives Milieu geschaffen wird (Bognar et al. 2016). Auch Vorarbeiten unserer eigenen Arbeitsgruppe unterstrichen die Relevanz von Wnt-Molekülen im Mikromilieu von Lymphomen: In DLBCL-Zelllinien wurde eine Subpopulation mit Tumorstammzelleigenschaften 
(sogenannte Side Population) nachgewiesen, die sich durch Klonogenität und Chemoresistenz ausweist. Diese Subpopulation unterliegt einer dynamischen Regulation, die maßgeblich von Stimulatoren des kanonischen Wnt-Signalwegs augmentiert und von epigenetischer Suppression von Wnt-Antagonisten gefördert wird (Koch et al. 2014). Dieses Grundprinzip wurde auch durch Koivala et al. gestützt: Die Arbeitsgruppe untersuchte die Wirkungsweise der Rituximabtherapie auf molekulargenetischer Ebene und konnte zeigen, dass das Therapieansprechen von Lymphomzellen unter anderem von einer verstärkten Transkription des Wnt-Inhibitors Dickkopf-1 (Dkk-1) abhängig ist (Koivula et al. 2011).

Auf den hohen Stellenwert des Wnt-Zielgens MYC in der Tumorgenese wird in Kapitel 1.2.3 eingegangen.

\subsubsection{Regulatorische Mechanismen im Wnt-Signalweg}

Die Aktivität des Wnt-Signalwegs wird endogen auf verschiedenen Ebenen reguliert und bietet damit auch zahlreiche Ansatzpunkte für eine exogene Durchbrechung der Signalkaskade. Die in diesem Kontext für die vorliegende Arbeit relevanten Mechanismen werden im Folgenden beschrieben.

\subsubsection{Posttranskriptionelle Palmitoylierung und Sekretion von Wnt- Molekülen}

Bildungsort der Wnt-Moleküle ist das endoplasmatische Retikulum, wo auch das Enzym Porcupine lokalisiert ist. Porcupine gehört zur Familie der membrangebundenen O-Acyltransferasen und überträgt Lipidketten auf Moleküle wie Wnt (sogenannte Palmitoylierung) (Kadowaki et al. 1996). Nach dieser Modifikation gelangt Wnt über den Golgiapparat weiter durch die Zelle und wird schließlich mittels der Transportmoleküle Wntless und Evi zur Zelloberfläche befördert und dort u. a. auf Exosomen sezerniert (Clevers und Nusse 2012; Gross et al. 2012). An der Zielzelle binden die Wnt-Moleküle im Wesentlichen an Frizzledrezeptoren, deren Familie zu den Transmembranrezeptoren gehört. Sie besitzen cysteinreiche Regionen an der Extrazellularseite, an die Wnt binden kann (Bhanot et al. 1996; Niehrs 2012). Diese Bindung sowie die weitere Interaktion mit den Corezeptoren LRP5 und LRP6 kann ebenso wie die Sekretion nur bei vorhandenem Acylrest stattfinden (Janda et al. 2012; Takada et al. 2006). Die Palmitoylierung von Wnt ist demnach sowohl für die Sekretion als auch für die Aktivität des Moleküls 
essentiell, sodass durch Inhibition von Porcupine zwei wichtige Komponenten der frühen Schritte im Wnt-Signalweg gestört werden. Ob neben Porcupine noch andere Acyltransferasen an der Lipidmodifikation beteiligt sind, ist nicht ausreichend geklärt (Saito-Diaz et al. 2013).

Im Rahmen dieser Arbeit sollte nun die Effektivität der Porcupineinhibitoren IWP-2 und C59 hinsichtlich der Wnt-Inhibition in Lymphomzellen untersucht werden. Chen et al. identifizierten mit den inhibitors of Wnt-production (IWP) eine Gruppe von Molekülen, die in der Lage waren, die Aktivität von Porcupine zu inhibieren. Zu dieser Gruppe gehört das kleine Molekül IWP-2 (Chen et al. 2009), welches Porcupine vermutlich am aktiven Zentrum angreift (Dodge et al. 2012). C59 ist ein von Novartis entwickeltes Acetamid, dessen wirkungsvolle Wnt-Inhibition bereits in Brustkrebszellen beschrieben wurde (Proffitt et al. 2013).

\subsubsection{Funktion der Tankyrase}

Für die Funktionstüchtigkeit des $\beta$-Catenin-Degradationskomplexes ist Axin der limitierende Faktor, da es die Komponente mit der geringsten Konzentration in der Zelle darstellt (Lee et al. 2003). Eine Veränderung des Axinlevels wirkt sich damit direkt auf die Konzentration des second messengers aus. Ein Enzym, das die Axinkonzentration beeinflussen kann, ist die Tankyrase, die zu den Poly-ADPRibose-Polymerasen gehört (Smith et al. 1998) und in Form der zwei Subtypen Tankyrase 1 und 2 vorkommt (Kaminker et al. 2001). Die beiden Subtypen haben weitestgehend überlappende Funktionen (Hsiao und Smith 2008). Im WntSignalweg ist die durch beide Tankyrasen katalysierte Poly-ADP-Ribosylierung von Axin1 und Axin2 bedeutend. Axin wird in ribosyliertem Zustand ubiquitiniert und durch Proteasomen abgebaut (Huang et al. 2009). Eine aktive Tankyrase limitiert damit das für den Degradationskomplex zur Verfügung stehende Axin und hat somit Einfluss auf die Aktivität der Endstrecke des Wnt-Signalwegs. Neue Erkenntnisse zeigen, dass die Tankyrase auch mit APC interagiert und dadurch ebenfalls die Aktivität des Degradationskomplexes beeinflusst (Croy et al. 2016).

Der Inhibitor XAV939 wirkt indirekt auf den second messenger des WntSignalwegs, indem durch die Hemmung der Tankyrase der Axinabbau vermindert und damit der Degradationskomplex von $\beta$-Catenin stabilisiert wird (Huang et al. 2009). 


\subsubsection{Secreted frizzled-related protein 4 (sFRP4)}

Die Familie der secreted frizzled-related proteins (sFRPs) gehört zu den natürlichen Wnt-Antagonisten. Es handelt sich dabei um Glykoproteine mit einer den Frizzledrezeptoren nahezu homologen Struktur, insbesondere des für die Wnt-Bindung notwendigen cysteinreichen Bereichs, jedoch ohne TransmembranDomäne (Jones und Jomary 2002). Grundsätzlich können sFRPs auf zwei Wegen zu einer Antagonisierung des Wnt-Signalwegs führen: Zum einen kann eine Interaktion zwischen sFRPs und Wnt-Molekülen erfolgen (Wawrzak et al. 2007), zum anderen können sFRPs an die Frizzledrezeptoren binden und diese damit für die Wnt-Moleküle blockieren (Bafico et al. 1999). Dabei kann sowohl der kanonische als auch der nicht-kanonische Wnt-Signalweg beeinflusst werden (Surana et al. 2014). Speziell für sFRP4 konnte gezeigt werden, dass es eine direkte Bindung mit Wnt-3a eingehen und damit die Effekte des kanonischen WntSignalwegs antagonisieren kann (Constantinou et al. 2008). Das SFRP4-Gen befindet sich auf Chromosom 7, besteht aus 346 Aminosäuren und hat zahlreiche Funktionen (Jones und Jomary 2002). Im onkologischen Kontext wurden u. a. antiproliferative Effekte im Prostata- (Horvath et al. 2007), Ovarial- (Jacob et al. 2012) und Endometriumkarzinom (Carmon und Loose 2008) gefunden. Jüngste Ergebnisse unserer Arbeitsgruppe ergaben, dass SFRP4 im DLBCL durch Promotormethylierung inaktiviert ist und bei Reaktivierung einen antiproliferativen Effekt hat (Koch et al. 2014). Bei bösartigen Erkrankungen ist zudem eine hohe Expression von SFRP4 für ein gutes Ansprechen auf Chemotherapeutika relevant (Saran et al. 2012).

Ein weiterer Wnt-Antagonist ist UM206, ein von Laeremans et al. beschriebenes Peptid, das aufgrund seiner Wnt-3a-homologen Struktur an Frizzledrezeptoren binden und in kardialem Gewebe Wnt-antagonistische Wirkungen erzielen kann (Laeremans et al. 2011). Damit stört der Inhibitor den Wnt-Signalweg auf einer sehr frühen Ebene. In Lymphomzellen wurde der Einsatz von UM206 bislang nicht untersucht.

\subsubsection{Der Transkriptionsfaktor MYC}

Das MYC-Gen ist eines der Zielgene des kanonischen Wnt-Signalwegs. $\beta$-Catenin bindet LEF- und TCF-abhängig an die Promoterregion des MYC-Gens, wodurch die Expression aktiviert wird (He et al. 1998). Das Protein MYC ist ein wichtiger 
Transkriptionsfaktor, der die Expression zahlreicher Gene beeinflussen kann (Patel et al. 2004). Zielgene sind vor allem solche, die für die Zellproliferation, Zelldifferenzierung und Apoptose sowie die hämatologische Homöostase bedeutend sind (Hoffman et al. 2002). So werden Cyclin D2 und die Cyclinabhängige Kinase 4 (CDK4) durch MYC induziert, was eine Progression der Zelle in der G1-Phase des Zellzyklus bewirkt (Bouchard et al. 1999; Hermeking et al. 2000). Zugleich sequestrieren diese Proteine den Zellzyklusinhibitor p27 (Bouchard et al. 2001). Durch beide Effekte wird die Zellproliferation gesteigert. Des Weiteren wird die Expression von CDKN1A durch MYC unterdrückt (Coller et al. 2000). CDKN1A codiert für das Protein p21, das die Cyclin-abhängigen Kinasen und damit die Zellzyklusaktivität inhibiert (Harper et al. 1993). Dies sind nur wenige Bespiele für Wirkungen von MYC. Betrachtet man diese biologischen Effekte, wird deutlich, dass MYC in wichtige Prozesse der Zellregulation eingreift und eine fehlerhafte Expression Störungen in der Homöostase mit sich bringt: MYC ist ein Protoonkogen.

Eine Überexpression dieses Gens ist für zahlreiche Malignome beschrieben worden (Nesbit et al. 1999). Diese kann zum Beispiel aufgrund von Translokationen oder Amplifikationen des Gens vorliegen. Beide Mechanismen sind auch im DLBCL zu finden. So weisen ca. 10\% der DLBCL eine MYCTranslokation auf (Savage et al. 2009) und auch die Genamplifikation konnte nachgewiesen werden (Rao et al. 1998; Stasik et al. 2010). Daneben kommt eine verstärkte MYC-Aktivität aber auch in DLBCL ohne die genannten genetischen Veränderungen vor (Kluk et al. 2012). Hier kommt eine Dysregulation der Transkription sowie von Posttranskriptionsvorgängen in Frage (Meyer und Penn 2008). Eine verstärkte MYC-Expression geht in DLBCL mit einer schlechteren Prognose einher (Rimsza et al. 2008).

\subsection{Immunkonjugate}

Immunkonjugate sind kovalente Verbindungen aus einem Antikörper oder einem Antikörperfragment und einem weiteren Molekül, welches meist als Funktionsträger fungiert. Der Antikörper dient dazu, eine spezifische Bindung mit einer gewünschten Zielstruktur einzugehen, wodurch auch das an inn gekoppelte Molekül an eben diese Zielstruktur gelangt. Hier kann letzteres seine Funktion erfüllen und zum Beispiel als Radionuklid oder Toxin wirken (Kreitman 2006). 
Durch diese gezielte Lokalisation von Substanzen kann es möglich sein, eine sehr hohe Dosis einer Substanz am Zielort zu erreichen, während gesundes Gewebe nur wenig oder keine Wirkungen erfährt. Werden Antikörper ausgewählt, die mittels ihres $F_{c}$-Fragments das Immunsystem selbst aktivieren können, kann zudem der therapeutische Effekt von Immunkonjugaten potenziert werden (Perez et al. 2014).

Bei der Herstellung von Immunkonjugaten ist neben der Wahl von Antikörper und Funktionsmolekül auch die Bindung zwischen diesen beiden Komponenten besonders zu berücksichtigen. Eine stabile Verlinkung ist essentiell, denn die Bindung darf nicht vorzeitig enzymatisch oder spontan spaltbar sein, um den Transport des Moleküls zum Zielort zu gewährleisten. Bewährt haben sich Hydrazonverbindungen, die zwischen einem Aldehyd oder einem Keton und einem Hydrazin gebildet werden. Diese Bindung bleibt in der Zellumgebung relativ stabil, ist aber säurelabil, sodass sie durch Hydrolyse im sauren Milieu der Lysosomen gespalten werden kann. Das funktionelle Molekül wird somit in der Zelle freigesetzt und kann zum Beispiel als Zytostatikum wirken (Hamann et al. 2002).

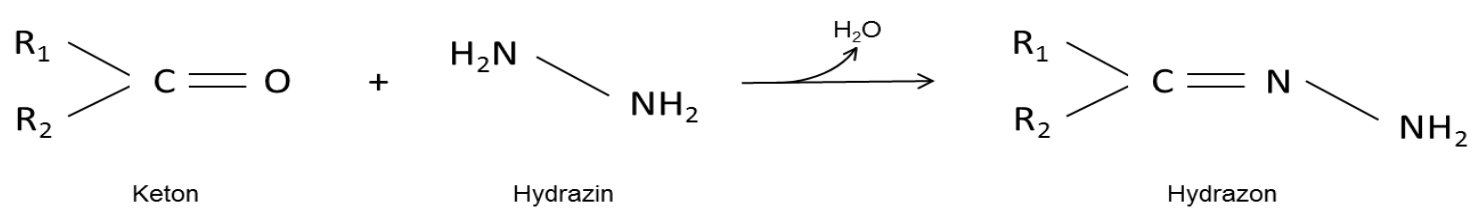

Abbildung 2: Entstehung einer einfachen Hydrazonverbindung. Reaktion eines Ketons mit einem Hydrazin zu einem Hydrazon. R=Rest.

Andere Möglichkeiten sind Peptid-Verlinkungen, die nicht durch das saure Milieu in Lysosomen, sondern durch die lysosomalen Proteasen enzymatisch gespalten werden (Doronina et al. 2003). Darüber hinaus können auch die freien Thiolgruppen eines Antikörpers, die durch Reduktion der Disulfidbrücken zwischen den vier Ketten entstehen, als Ausgangspunkt einer Konjugation verwendet werden, indem eine neue Disulfidbrücke zwischen Antikörper und Funktionsmolekül ausgebildet wird. Diese kann im Tumorgewebe wiederum durch Glutathion reduziert werden, wodurch das funktionelle Molekül freigesetzt wird (Jaracz et al. 2005). Neben diesen genannten cleavable linkings gibt es auch noncleavable-linkings. Dabei bleiben Antikörper und Funktionsträger miteinander verbunden, der Antikörper wird aber in der Zelle abgebaut, sodass nur das 
Funktionsmolekül verbleibt (Perez et al. 2014). Als Verknüpfung kann dabei zum Beispiel ein Thioether dienen (Lewis Phillips et al. 2008).

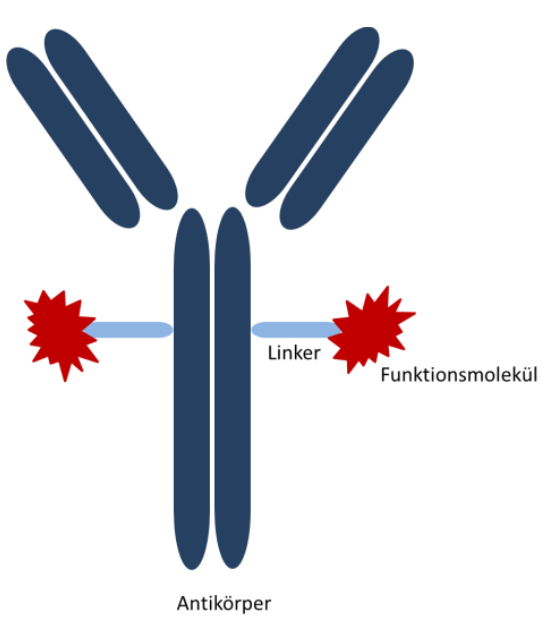

\author{
Abbildung 3: Schematische Darstellung \\ eines Immunkonjugats. Der monoklonale \\ Antikörper ist über einen Linker mit einem \\ Funktionsmolekül verbunden.
}

Probleme bei der Entwicklung und dem Einsatz von Immunkonjugaten sind eine zu geringe Potenz des - in der Regel zytotoxischen - Funktionsmoleküls, eine zu geringe Selektivität des Zielantigens oder Instabilität der Verlinkung (Perez et al. 2014). In der Vergangenheit war auch die Immunogenität von zum Beispiel murinen Antikörpern als Bestandteil der Immunkonjugate limitierend, was jedoch mittlerweile durch den nahezu ausschließlichen Einsatz von humanisierten oder humanen Antikörpern minimiert werden kann (Diamantis und Banerji 2016).

\title{
1.3.1 Bedeutung von Immunkonjugaten in der Medizin
}

„Zauberkugeln“ - ein therapeutisches Konzept, das Paul Ehrlich Ende des 19. Jahrhunderts nach seiner Entdeckung der Seitenkettentheorie postulierte, könnte mit dem Einsatz von Immunkonjugaten in die Realität umgesetzt werden (Strebhardt und Ullrich 2008). Immunkonjugate eröffnen die Möglichkeit, besonders hohe Dosen einer Substanz selektiv zum Fokus einer Erkrankung zu transportieren und gleichzeitig den restlichen Körper und das gesunde Gewebe mit nur geringer Dosis zu belasten und damit vor Nebenwirkungen zu schützen. Vor allem Therapien maligner Krankheitsbilder könnten mit einer solchen spezifischen Therapie revolutioniert werden. Dies erklärt das enorme Interesse an der Entwicklung von Immunkonjugaten bzw. antibody-drug conjugates (ADCs) (Perez et al. 2014). Für einige Erkrankungen sind bereits in therapeutischer Zielsetzung Immunkonjugate entwickelt worden. Gemtuzumab-Ozogamicin ist ein solches Präparat, das in der Behandlung der akuten myeloischen Leukämie eingesetzt werden kann. Es besteht aus einem anti-CD33-Antikörper und dem sehr potenten Zellgift Calicheamicin. CD33 befindet sich auf Blasten, wodurch das 
Immunkonjugat gezielt an die malignen Zellen binden kann. Nach Internalisierung der Verbindung kann Calicheamicin seine Wirkung entfalten: Die Zelle stirbt (Bross et al. 2001). Gemtuzumab-Ozogamicin erhielt 2000 in den USA als erstes Immunkonjugat überhaupt unter dem Handelsnamen Mylotarg® die Zulassung, wurde jedoch zehn Jahre später wegen nicht nachweisbarer Verbesserung des Gesamtüberlebens sowie unerwünschter Nebenwirkungen, wie dem vermehrten Auftreten von Neutropenien und der venösen okklusiven Leberkrankheit, wieder vom Markt genommen (Ricart 2011).

Für die Therapie des Hodgkin-Lymphoms wurde das Immunkonjugat Brentuximab Vedotin entwickelt. Diese aus dem Antikörper anti-CD30 und dem Zytostatikum Monomethyl-Auristatin-E bestehende Substanz ist als Salvage-Therapie bei Rezidiv eines Hodgkin-Lymphoms oder eines systemischen anaplastischen großzelligen Lymphoms zugelassen (Francisco et al. 2003; Senter und Sievers 2012). Ein anderes zugelassenes Medikament aus der Gruppe der ADCs ist TDM1, eine aus Trastuzumab und dem Mitosehemmstoff Emtansin bestehende Substanz, die bei HER2-neu-positivem Mammakarzinom eingesetzt werden kann (Verma et al. 2012).

Als Beispiel für die spezifische Radiotherapie mittels Immunkonjugat ist Tositumomab zu nennen. Es handelt sich dabei um eine Verbindung, die gegen das Antigen CD20 gerichtet und mit dem Radioisotop lod-131 beladen ist. Es kann in der Therapie des Non-Hodgkin-Lymphoms eingesetzt werden (Srinivasan und Mukherji 2011). Ein ebenfalls gegen CD20 gerichtetes und radioaktiv wirkendes Immunkonjugat ist Ibritumomab-Tiuxetan mit dem Handelsnamen Zevalin $\AA_{\text {. }}$ Tiuxetan ist ein Chelator, der Yttrium-90 bindet, sodass bei Gabe von Zevalin® CD20-tragende Zellen mittels radioaktiver Strahlung zerstört werden (Witzig et al. 2002).

Neben diesen radionuklid- und toxinbasierten Immunkonjugaten gibt es noch andere Möglichkeiten, Immunkonjugate therapeutisch einzusetzen. So können RNA-Polymerase-Inhibitoren wie alpha-Amanitin an Antikörper geknüpft und zur Zielzelle transportiert werden, die die RNA-Produktion und damit den Stoffwechsel der malignen Zellen beeinträchtigen (Moldenhauer et al. 2012). Über den therapeutischen Rahmen hinaus können Immunkonjugate auch zu diagnostischen Zwecken genutzt werden. So kann zum Beispiel in der Szintigraphie ein radioaktiv 
markierter und gegen ein Leukozytenantigen gerichteter Antikörper für die Darstellung von Entzündungsherden oder ein Antikörper gegen ein malignes Antigen zur Krebsdiagnostik verwendet werden (Das et al. 2002).

Zurzeit befinden sich zahlreiche weitere Immunkonjugate sowohl für hämatologische Neoplasien als auch für solide Tumoren in der frühen Phase von klinischen Studien (Diamantis und Banerji 2016; Lambert 2013) und es ist anzunehmen, dass diese Substanzen die Zukunft der Krebstherapie prägen werden.

\subsubsection{Rituximab als Teil von Immunkonjugaten}

Trotz des erfolgreichen Einsatzes von Rituximab in der Therapie des NonHodgkin-Lymphoms sprechen nicht alle Patienten optimal auf die Behandlung an (Coiffier et al. 2010), was bei einigen Wissenschaftlern das Interesse weckte, Varianten des Antikörpers zu entwickeln, um die Therapie noch effektiver werden zu lassen. Die Arbeitsgruppe um Xuan entwickelte ein Fusionsprodukt aus Rituximab und Interferon- $\alpha$ (IFN- $\alpha$ ). IFN- $\alpha$ stimuliert das Immunsystem, wirkt bei systemischer Applikation aber toxisch. Die Konjugation von IFN- $\alpha$ an Rituximab erlaubt die Kumulation des Zytokins an den malignen B-Zellen, was im Mausmodell eine Regression des Tumors bewirkte (Xuan et al. 2010). Eine Verknüpfung zwischen Rituximab und dem Proteinsynthesehemmer Saporin-S6 wurde von Polito et al. vorgenommen. Das entstandene Immunkonjugat wirkte auf Non-Hodgkin-Lymphomzellen stark zytotoxisch und proapoptotisch (Polito et al. 2004). Der kombinierte Einsatz von Rituximab und anti-CD22-Antikörpern zeigte in einigen Studien gute Wirksamkeit in der Therapie des Non-Hodgkin-Lymphoms (Leonard et al. 2008) und führte zu der Idee, einen gegen beide Antigene gerichteten Antikörper zu entwickeln. Tuscano et al. stellten einen solch bispezifischen Antikörper aus Rituximab und dem Anti-CD22-Antikörper HB22.7 her. Im Xenograft-Experiment verlängerte das Fusionsprodukt im Vergleich zur Behandlung mit der Kombination aus beiden einzelnen Antikörpern das Überleben signifikant (Tuscano et al. 2011).

Des Weiteren gab es mehrere Ansätze, Rituximab mit Radionukliden zu verbinden (Aurlien et al. 2000; Knop et al. 2004). So konnte zum Beispiel eine Kopplung des Alpha-Strahlers Thorium-227 an Rituximab gute Ergebnisse bezüglich der 
Tumorregression im Tiermodell erzielen, ohne relevante Schädigungen anderer Gewebe hervorzurufen (Dahle et al. 2010; Dahle et al. 2007).

\subsection{Aufgabenstellung}

Eine pathologische Aktivierung des Wnt-Signalwegs ist ein treibender onkogener Mechanismus in einer Vielzahl maligner Erkrankungen. Das wachsende Verständnis der regulierenden Mechanismen führte zur Entwicklung zahlreicher sogenannter Small Molecules als Wnt-Inhibitoren, die auf verschiedene Komponenten dieser regulierenden Mechanismen abzielen. In bereits publizierten Arbeiten über die funktionelle Relevanz des Wnt-Signalwegs in Lymphomen wurden einige dieser Inhibitoren eingesetzt und unterstrichen das Grundprinzip, dass deregulierte Wnt-Signalwegaktivierung Ziel einer neuen Tumortherapie sein könnte. Die Wirkungen dieser Inhibitoren wurden bis jetzt jedoch nicht vergleichend untersucht, sodass Strategien zu einer optimierten Therapie unklar sind. In dieser Arbeit sollten verschiedene Inhibitionsmechanismen in DLBCLZellen anhand folgender Verfahren evaluiert werden:

1) Vergleichende Untersuchung verschiedener Inhibitoren im Hinblick auf die Effektivität in der Unterbrechung des Wnt-Signalwegs

2) Analyse von Proliferations- und Zellzyklusprogression sowie der Klonogenität von DLBCL-Zelllinien unter verschiedenen Wnt-Inhibitoren

3) Entwicklung eines Immunkonjugats zur molekular gezielten WntSignalweginhibition 


\section{Material und Methoden}

\subsection{Material}

\subsubsection{Geräte}

Absaugsystem Vacusafe comfort

ASID Reagenzglas Mischer Rotation Automix 1

BD FACSCanto II Flow Cytometer

Chromatographie-Anlage Äkta Purifier UPC 10

Chromatographie-Säulen Superdex 200 10/300 GL

Dampfsterilisator Varioklav

Edelstahlkästen für CFU-Inkubation

Feinwaage Sartorius AC 210 P

Flockeneismaschine AF100

Gefrierbehälter Mr. Frosty

Gefrierschrank $-80^{\circ} \mathrm{C}$ : Forma 88000 series Freezer

Gefrierschrank -20 C

Horizontalrotierer Rotamax 120

Inkubatoren

Brutschrank BSS 300 MP GTFS

$\mathrm{CO}_{2}$-Inkubator HERACELL240

$\mathrm{CO}_{2}$-Inkubator Labotect C200

Wärmeschrank

Kryostat Microm HM560

Laborwaage Sartorius PT 600

Magnetrührer IKAMAG RCT

Metallblockthermostat

Mikroplatten-Reader Infinite 200pro

Mikroskope

ApoTome, Fluoreszenzmikroskop
INTEGRA Biosciences, Fernwald, Deutschland

ASID Bonz\&Sohn, Unterschleißheim, Deutschland

BD Biosciences, Heidelberg, Deutschland

GE Healthcare Europe, Freiburg, Deutschland

GE Healthcare Europe, Freiburg, Deutschland

$\mathrm{H}+\mathrm{P}$ Labortechnik AG, Oberschleißheim, Deutschland

Fine Science Tools, Heidelberg,

Deutschland

Sartorius, Göttingen, Deutschland

Scotsman Ice Systems - Frimont S.P.A., Mailand, Italien

Thermo Scientific, Braunschweig, Deutschland

Thermo Scientific, Braunschweig, Deutschland

Liebherr, Bierbach, Deutschland

Heidolph, Bremen, Deutschland

Grumbach Brutgeräte, Asslar, Deutschland

Thermo Scientific, Braunschweig,

Deutschland

Labotect, Göttingen, Deutschland

Heraeus Instruments, Hanau, Deutschland

Thermo Scientific, Braunschweig, Deutschland

Sartorius, Göttingen, Deutschland

IKA, Staufen, Deutschland

Liebisch, Bielefeld, Deutschland

Tecan, Crailsheim, Deutschland

Zeiss, Jena, Deutschland 
AxioVert 100, inverses Lichtmikroskop

Stemi SV 11, Auflichtmikroskop

NanoDrop ND-1000 Spektrometer

Neubauer-Zählkammer; 0,0025mm²

pH-Meter $\mathrm{pH} 211$

Pinzetten und Scheren

anatomische Pinzette, gerade

Mikroskopierschere, gefedert

Splitterpinzette, gerade

Pipetten

Einfach-Pipetten: Research Plus, $2 \mu \mathrm{l}$, $10 \mu \mathrm{l}, 200 \mu \mathrm{l}, 1000 \mu \mathrm{l}$

Mehrkanalpipetten: Finnpipette, 5-

$50 \mu \mathrm{l}$ und $50-300 \mu \mathrm{l}$

Multipette plus

Pipettierhilfe Pipetus

Reinwasseraufbereitungsanlage Sartorius arium basic

Rollenmischgerät RM5

Schüttelwasserbad 1083

Sterilbank SterilGARD III Advance

Vortex Genie 2

Wasserbad

Wipptisch, SSL4 (Stuart)

Westernblot-Apparatur

XCell SureLock Mini-Cell

XCell I Blot Module

Zentrifugen

Biofuge 13

Multifuge 3L-R

Tischzentrifuge Centrifuge 5415 D
Zeiss, Jena, Deutschland

Zeiss, Jena, Deutschland

Thermo Scientific, Braunschweig, Deutschland

Heidolph, Bremen, Deutschland

Hanna Instruments, Kehl am Rhein, Deutschland

Fine Science Tools, Heidelberg, Deutschland

Fine Science Tools, Heidelberg, Deutschland

Fine Science Tools, Heidelberg, Deutschland

Eppendorf, Hamburg, Deutschland

Thermo Labsystems, Egelsbach, Deutschland

Eppendorf, Hamburg, Deutschland

Hirschmann, Eberstadt, Deutschland

Sartorius, Göttingen, Deutschland

Glaswarenfabrik Hecht, Sondheim v. d. Rhön, Deutschland

Gesellschaft für Labortechnik, Burgwedel, Deutschland

The Baker Company, Sanford, USA

Scientific Industries Inc., New York, USA

Köttermann Labortechnik, Hänigsen, Deutschland

Barloworld Scientific, Staffordshire, UK

Invitrogen, Karlsruhe, Deutschland

Invitrogen, Karlsruhe, Deutschland

Heraeus Instruments, Hanau, Deutschland

Heraeus Instruments, Hanau, Deutschland

Eppendorf AG, Hamburg, Deutschland 


\subsubsection{EDV}

Adobe Photoshop 7

AxioVision Software

BD Facs Diva Software

FlowJo

GraphPad Prism 6

i-control - Microplate Reader Software

ImageJ

ImageReader LAS 4000 Pro V 2.1

Microsoft Office 2010

Microsoft Windows 7

Nanodrop-Software ND-1000 V3.8.1

\subsubsection{Verbrauchsmaterial}

Amicon Ultra-2 ml Centrifugal Filters

Combitips, steril; $2,5 \mathrm{ml}$

Deckgläschen, 18x24 mm

Durapore Kunstseidenpflaster, 2,5 cm

Einmalkanülen, steril, $30 \mathrm{G}$

Falcon Round Bottom 5mL, 12x75mm

Falcon Tubes $15 \mathrm{ml}, 50 \mathrm{ml}$

Hybond ${ }^{\mathrm{IM}} \mathrm{C}$ Nitrocellulosemembran

Kryoboxen

Kryoröhrchen 1,8 ml

Meliseptol Desinfektionsmittel

Objektträger

Omnifix40 Solo, Einmal-Insulinspritzen für U40 Insulin (1 ml / 40 I.E.)

Parafilm

Pasteurpipetten $150 \mathrm{~mm}$

Petrischalen $35 \mathrm{~mm}$

Pipettenspitzen

$10 \mu \mathrm{l}, 200 \mu \mathrm{l}, 1000 \mu \mathrm{l}$

Reagiergefäß

$0,5 \mathrm{ml}, 1,5 \mathrm{ml}, 2,0 \mathrm{ml}$

Rotilabor Spritzenfilter

$0,22 \mu \mathrm{m}, 0,45 \mu \mathrm{m}$
Adobe Systems Inc., San José, USA

Zeiss, Jena, Deutschland

BD Biosciences, Heidelberg, Deutschland

FlowJo, LLC, Ashland, USA

GraphPad Software Inc., La Jolla, USA

Tecan, Crailsheim, Deutschland

Wayne Rasband, NIH, USA

FujiFilm, Düsseldorf, Deutschland

Microsoft, Redmond, USA

Microsoft, Redmond, USA

Thermo Scientific, Braunschweig, Deutschland

Merck, Darmstadt, Deutschland

Eppendorf, Hamburg, Deutschland

Menzel-Gläser, Braunschweig,

Deutschland

3M, Neuss, Deutschland

B. Braun, Melsungen, Deutschland

BD Biosciences, Heidelberg, Deutschland

Sarstedt, Nümbrecht, Deutschland

Amersham Biosciences, UK

Ratiolab, Dreieich, Deutschland

Thermo Scientific, Braunschweig, Deutschland

B. Braun, Melsungen, Deutschland

Menzel-Gläser, Braunschweig, Deutschland

B. Braun, Melsungen, Deutschland

Bermis, Neenah, USA

Brand, Wertheim, Deutschland

Greiner Bio-One, Frickenhausen, Deutschland

Sarstedt, Nümbrecht, Deutschland

Sarstedt, Nümbrecht, Deutschland

Roth, Karlsruhe, Deutschland 
Sekuroka-Entsorgungsbeutel

serologische Pipette

$2 \mathrm{ml}, 5 \mathrm{ml}, 10 \mathrm{ml}, 25 \mathrm{ml}$

Skalpell

Spritzen $5 \mathrm{ml}, 10 \mathrm{ml}$

TSK-Supra Sonderkanülen 2x70mm

Zellkultur-Platten, 12-well

Zellkultur-Platten, 96-well, flat bottom

Zellkultur-Flaschen

$25 \mathrm{~cm}^{2}, 75 \mathrm{~cm}^{2}, 175 \mathrm{~cm}^{2}$

Zellsieb $70 \mu \mathrm{m}$

\subsubsection{Chemikalien}

Ampuwa

Beta-Mercaptoethanol

CellTiter $96 \AA$ AQueous One Solution

Proliferation Assay

Certipur buffer solution 4.00 (Zitronensäure, Natriumhydroxid, Chlorwasserstoff)

Certipur buffer solution 7.00

(Dinatriumhydrogenphosphat,

Kaliumdihydrogenphosphat)

Coomassie Brillantblau R-250 Puder

$\mathrm{D}(+)$-Saccharose

Dimethylsulfoxid Hybri-Max, sterile-filtered

Dithiothreitol DTT $(0,1 \mathrm{M})$

Essigsäure

Ethanol 99\%

Ethylendiamintetraessigsäure (EDTA)

FACS Clean

FACS Flow

Glycerin

Hoechst 33342

Kaliumchloridlösung, $3 \mathrm{~mol} / \mathrm{l}$

Luminata $^{\mathrm{TM}}$ Crescendo Western HRP

Substrate

Magermilchpulver

Matrigel Basement Membrane Matrix

Methanol

Methylcellulose
Roth, Karlsruhe, Deutschland

Sarstedt, Nümbrecht, Deutschland

Feather Safety Razor Co., Osaka, Japan

BD Biosciences, Heidelberg, Deutschland

TSK Laboratory, LH Oirschot, Niederlande

Greiner Bio-One, Frickenhausen,

Deutschland

Sarstedt, Nümbrecht, Deutschland

Sarstedt, Nümbrecht, Deutschland

BD Biosciences, Heidelberg, Deutschland

Fresenius, Bad Homburg, Deutschland

Gibco, Life Technologies, Karlsruhe, Deutschland

Promega Corporation, Madison, USA

Merck, Darmstadt, Deutschland

Merck, Darmstadt, Deutschland

Serva, Heidelberg, Deutschland

Roth, Karlsruhe, Deutschland

Sigma-Aldrich, Steinheim, Deutschland

Invitrogen, Karlsruhe, Deutschland

Merck, Darmstadt, Deutschland

Walter CMP, Kiel, Deutschland

Sigma-Aldrich, Steinheim, Deutschland

BD Biosciences, Heidelberg, Deutschland

BD Biosciences, Heidelberg, Deutschland

Sigma-Aldrich, Steinheim, Deutschland

Sigma-Aldrich, Steinheim, Deutschland

Merck, Darmstadt, Deutschland

Merck, Darmstadt, Deutschland

Roth, Karlsruhe, Deutschland

BD Biosciences, Heidelberg, Deutschland

J.T. Baker, Griesheim, Deutschland

R\&D Systems, Wiesbaden-Nordenstadt, Deutschland 
Natriumazid

Natriumchlorid $(\mathrm{NaCl})$

Nonidet P40

Paraformaldehyd

PBS (phosphate buffered saline)

Ponceau-Rot

Roti-Mount FluorCare DAPI

Roti-Quant Universal Reagenz 1

Roti-Quant Universal Reagenz 2

Salzsäure, $37 \%$

Tissue-Tek O.C.T. Compound

Trichloressigsäure

Tris-(hydroxymethyl)-aminomethan (Tris)

Tris-Glycin-SDS-Gele, 8-16 \%; 1,0 mm

Tris-Glycin-SDS-Laufpuffer (10x)

Tris-Glycin-SDS-Probenpuffer $(2 x)$

Tris-Glycin-Transferpuffer (25x)

TritonX

Trypanblau 0,4 \% in PBS

Trypsin (1:250)/EDTA-Lösung (0,5\%/0,2\%) (10x)

Tween 20 Sigma Ultra

Wasserbadschutz Akasolv Aqua Care
Roth, Karlsruhe, Deutschland

Roth, Karlsruhe, Deutschland

AppliChem, Darmstadt, Deutschland

Serva, Heidelberg, Deutschland

Sigma-Aldrich, Steinheim, Deutschland

Roth, Karlsruhe, Deutschland

Roth, Karlsruhe, Deutschland

Roth, Karlsruhe, Deutschland

Roth, Karlsruhe, Deutschland

Roth, Karlsruhe, Deutschland

Sakura Finetek, Alphen am Rhein, Niederlande

Sigma-Aldrich, Steinheim, Deutschland

Roth, Karlsruhe, Deutschland

Anamed, Bieberau, Deutschland

Anamed, Bieberau, Deutschland

Anamed, Bieberau, Deutschland

Anamed, Bieberau, Deutschland

Sigma-Aldrich, Steinheim, Deutschland

Sigma-Aldrich, Steinheim, Deutschland

Biochrom AG, Berlin, Deutschland

Sigma-Aldrich, Steinheim, Deutschland

Carl Roth $\mathrm{GmbH}+\mathrm{Co}$. KG, Karlsruhe, Deutschland

\subsubsection{Puffer und Lösungen}

\begin{tabular}{|l|l|}
\hline Blocklösung (Blotto) & $100 \mathrm{ml}$ TBS-T \\
& $5 \mathrm{~g}$ Magermilchpulver \\
\hline Coomassie-Blau-Lösung (0,1 \%) & $500 \mathrm{ml}$ dest. $\mathrm{H}_{2} \mathrm{O}$ \\
& $400 \mathrm{ml}$ Ethanol \\
& $100 \mathrm{ml}$ Essigsäure \\
& $1 \mathrm{~g}$ Coomassie Brillantblau R-250 \\
\hline Entfärberlösung 1 & dest. $\mathrm{H}_{2} \mathrm{O}$ \\
& $25 \% \mathrm{Methanol}$ \\
& $5 \% \mathrm{CH}_{3} \mathrm{COOH}$ \\
\hline Entfärberlösung 2 & dest. $\mathrm{H}_{2} \mathrm{O}$ \\
& $10 \% \mathrm{Methanol}$ \\
\hline Glycerinwasser & $5 \% \mathrm{CH}_{3} \mathrm{COOH}$ \\
\hline & dest. $\mathrm{H}_{2} \mathrm{O}$ \\
& $1 \% \mathrm{Glycerin}^{2}$ \\
\hline
\end{tabular}




\begin{tabular}{|c|c|}
\hline Lysepuffer, $\mathrm{pH} 7,5$ & $\begin{array}{l}150 \mathrm{mM} \mathrm{NaCl} \\
50 \mathrm{mM} \text { Tris } \\
2 \mathrm{mM} \text { EDTA } \\
1 \% \mathrm{NP} 40 \\
1 \% \text { TritonX }\end{array}$ \\
\hline Paraformaldehyd $4 \%$ & $\begin{array}{l}100 \mathrm{ml} \text { PBS (1x) } \\
4 \mathrm{~g} \text { PFA }\end{array}$ \\
\hline PBS (phosphate buffered saline), $\mathrm{pH} 7,4$ & $\begin{array}{l}\text { dest. } \mathrm{H}_{2} \mathrm{O} \\
137 \mathrm{mM} \mathrm{NaCl} \\
10 \mathrm{mM} \text { Phosphat }\left(\mathrm{HPO}_{4}{ }^{2-} \text { und } \mathrm{H}_{2} \mathrm{PO}_{4}{ }^{-}\right) \\
2,7 \mathrm{mM} \mathrm{KCl}\end{array}$ \\
\hline Ponceau S (0,5 \%) & $\begin{array}{l}100 \mathrm{ml} \text { dest. } \mathrm{H}_{2} \mathrm{O} \\
1 \mathrm{ml} \text { Essigsäure } \\
0,5 \mathrm{~g} \text { Ponceau-Rot }\end{array}$ \\
\hline Puffer für Äkta-Anlage, $\mathrm{pH} 7,4$ & $\begin{array}{l}150 \mathrm{mM} \mathrm{NaCl} \\
20 \mathrm{mM} \text { Tris }\end{array}$ \\
\hline TBS (tris buffered saline), $\mathrm{pH} 7,6$ & $\begin{array}{l}\text { dest. } \mathrm{H}_{2} \mathrm{O} \\
20 \mathrm{mM} \text { Tris } \\
137 \mathrm{mM} \mathrm{NaCl}\end{array}$ \\
\hline TBS-T, pH 7,6 & $\begin{array}{l}\text { TBS } \\
0,1 \% \text { Tween } 20\end{array}$ \\
\hline Tris-Puffer, $\mathrm{pH} 8,8$ & $\begin{array}{l}1 \mathrm{mmol} / \mathrm{l} \text { Tris } \\
\text { steril-filtriert }(0,22 \mu \mathrm{m})\end{array}$ \\
\hline
\end{tabular}

Tabelle 1: Puffer und Lösungen. Zur Einstellung des pH-Werts wurde $37 \%$ ige Salzsäure verwendet.

\subsubsection{Inhibitoren}

C59, Porcupine-Inhibitor

IWP-2, Porcupine-Inhibitor

UM206, Wnt-Antagonist

XAV939, Tankyrase-Inhibitor

\subsubsection{Medikamente}

Rituximab (MabThera®) abcam, Cambridge, USA

Sigma-Aldrich, Steinheim, Deutschland

Laeremans et al., 2011

Tocris Bioscience, Bristol, UK

Roche, Mannheim, Deutschland

\subsubsection{Wachstumsfaktoren, Zusätze für Zellmedien}

fetales Kälberserum (FCS)

Penicillin-Streptomycin $(10.000 \mathrm{U} / \mathrm{ml}$ $10.000 \mu \mathrm{g} / \mathrm{ml}$ )
Sigma-Aldrich, Steinheim, Deutschland

Gibco, Life Technologies, Karlsruhe, Deutschland 


\subsubsection{Kits}

FluoroTag FITC Conjugation Kit

Pierce $F_{a b}$ Micro Preparation Kit

Solulink Protein-Protein Conjugation Kit
Sigma-Aldrich, Steinheim, Deutschland

Pierce Biotechnology, Rockford, USA

Solulink Inc., San Diego, USA

\subsubsection{Proteine, Proteinaseinhibitoren und Proteinstandards}

PageRuler Plus Prestained Protein Ladder

Phosphataseinhibitor PhosSTOP

Proteaseinhibitor Complete, Mini, EDTA-free

Recombinant Human sFRP-4

Rinderserumalbumin (BSA)
Pierce Biotechnology, Rockford, USA

Roche, Mannheim, Deutschland

Roche, Mannheim, Deutschland

Hölzel, Köln, Deutschland

Serva, Heidelberg, Deutschland

\subsubsection{Antikörper}

\subsubsection{Primärantikörper}

\begin{tabular}{|c|c|c|c|c|}
\hline \multirow[t]{2}{*}{ Antikörper } & \multirow[t]{2}{*}{$\begin{array}{l}\text { Spezies und } \\
\text { Klon }\end{array}$} & \multicolumn{2}{|c|}{ Verdünnung } & \multirow[t]{2}{*}{ Herkunft } \\
\hline & & WB & FACS & \\
\hline Anti- $\beta$-Catenin & Maus \#610153 & $1: 2.000$ & & $\begin{array}{l}\text { BD Biosciences, Heidelberg, } \\
\text { Deutschland }\end{array}$ \\
\hline Anti-CD20-FITC & Maus \#302304 & & $1: 50$ & BioLegend, London, UK \\
\hline Anti-MYC & $\begin{array}{l}\text { Kaninchen \#Y69 } \\
\text { (ab32072) }\end{array}$ & $1: 10.000$ & & abcam, Cambridge, UK \\
\hline Anti-Frizzled-1 & $\begin{array}{l}\text { Kaninchen } \\
\text { \#AP12394 }\end{array}$ & $1: 1.000$ & $1: 25$ & $\begin{array}{l}\text { Acris Antibodies, Herford, } \\
\text { Deutschland }\end{array}$ \\
\hline Anti-Frizzled-2 & $\begin{array}{l}\text { Kaninchen } \\
\text { \#orb100745 }\end{array}$ & $1: 100$ & $1: 50$ & Biorbyt, Cambridge, UK \\
\hline Anti-Frizzled-4 & $\begin{array}{l}\text { Kaninchen } \\
\text { \#B5723 }\end{array}$ & $1: 1.000$ & $1: 25$ & $\begin{array}{l}\text { LifeSpan Biosciences, Seattle, } \\
\text { USA }\end{array}$ \\
\hline Anti-Frizzled-5 & $\begin{array}{l}\text { Kaninchen } \\
\text { \#C30356 }\end{array}$ & $1: 1.000$ & $1: 25$ & $\begin{array}{l}\text { LifeSpan Biosciences, Seattle, } \\
\text { USA }\end{array}$ \\
\hline Anti-GAPDH & $\begin{array}{l}\text { Kaninchen } \\
\# 14 \text { C10 }\end{array}$ & $1: 1.000$ & & $\begin{array}{l}\text { Cell Signaling Technology, } \\
\text { Frankfurt a. M., Deutschland }\end{array}$ \\
\hline $\begin{array}{l}\text { Anti-Rituximab- } \\
\text { FITC }\end{array}$ & Ratte \#MB2A4 & $1: 1.000$ & $1: 20$ & $\begin{array}{l}\text { Bio-Rad AbD Serotec, Kidlington, } \\
\text { UK }\end{array}$ \\
\hline Anti-sFRP4 & Ziege \#AF1827 & $1: 100$ & & $\begin{array}{l}\text { R\&D Systems, Wiesbaden- } \\
\text { Nordenstadt, Deutschland }\end{array}$ \\
\hline Anti-sFRP4 & $\begin{array}{l}\text { Kaninchen } \\
\text { \#HPA009712 }\end{array}$ & & $1: 10$ & $\begin{array}{l}\text { Sigma-Aldrich, Steinheim, } \\
\text { Deutschland }\end{array}$ \\
\hline Anti-Wnt-3a & Ratte \#217804 & $1: 1.000$ & & $\begin{array}{l}\text { R\&D Systems, Wiesbaden- } \\
\text { Nordenstadt, Deutschland }\end{array}$ \\
\hline
\end{tabular}

Tabelle 2: Primärantikörper. Angegebene Verdünnungen für Westernblot (WB) wurden mit TBS-

$T$, Verdünnungen für Durchflusszytometrie (FACS) mit PBS vorgenommen. 


\subsubsection{Sekundärantikörper}

\begin{tabular}{|l|l|l|l|l|}
\hline \multicolumn{1}{|c|}{ Antikörper } & \multicolumn{1}{|c|}{ Spezies } & \multicolumn{2}{c|}{ Verdünnung } & \multicolumn{1}{c|}{ Herkunft } \\
\hline & & WB & FACS & \\
\hline Anti-goat IgG-HRP & Esel \#sc-2020 & $1: 10.000$ & & $\begin{array}{l}\text { Santa Cruz Biotechnology, Inc., } \\
\text { Heidelberg, Germany }\end{array}$ \\
\hline $\begin{array}{l}\text { Anti-rabbit IgG- } \\
\text { HRP }\end{array}$ & Esel \#sc-2313 & $1: 10.000$ & & $\begin{array}{l}\text { Santa Cruz Biotechnology, Inc., } \\
\text { Heidelberg, Germany }\end{array}$ \\
\hline $\begin{array}{l}\text { Anti-mouse IgG- } \\
\text { HRP }\end{array}$ & Ziege \#sc-2005 & $1: 10.000$ & & $\begin{array}{l}\text { Santa Cruz Biotechnology, Inc., } \\
\text { Heidelberg, Germany }\end{array}$ \\
\hline Anti-rabbit IgG-PE & Ziege \#sc-3739 & $1: 100$ & $\begin{array}{l}\text { Santa Cruz Biotechnology, Inc., } \\
\text { Heidelberg, Germany }\end{array}$ \\
\hline Anti-rat IgG-HRP & Ziege \#sc-2006 & $1: 10.000$ & & $\begin{array}{l}\text { Santa Cruz Biotechnology, Inc., } \\
\text { Heidelberg, Germany }\end{array}$ \\
\hline
\end{tabular}

Tabelle 3: Sekundärantikörper. Angegebene Verdünnungen für Westernblot (WB) wurden mit TBS-T, Verdünnungen für Durchflusszytometrie (FACS) mit PBS vorgenommen.

\subsubsection{Zelllinien}

\begin{tabular}{|c|c|c|c|}
\hline Zelllinie & Charakteristika & Herkunft & Referenz \\
\hline HeLa & Zervixkarzinom & DSMZ & (Scherer et al. 1953) \\
\hline OCl-Ly1 & $\begin{array}{l}\text { B-Zellen, DLBCL } \\
\text { (GCB) }\end{array}$ & DSMZ & (Tweeddale et al. 1987) \\
\hline OCl-Ly3 & $\begin{array}{l}\text { B-Zellen, DLBCL } \\
\text { (ABC) }\end{array}$ & DSMZ & (Tweeddale et al. 1987) \\
\hline SU-DHL-4 & $\begin{array}{l}\text { B-Zellen, DLBCL } \\
\text { (GCB) }\end{array}$ & DSMZ & (Epstein et al. 1976) \\
\hline $\begin{array}{l}\text { U-2932 Wildtyp, } \\
\text { Subtypen R1, R2 }\end{array}$ & $\begin{array}{l}\text { B-Zellen, DLBCL } \\
\text { (ABC) }\end{array}$ & DSMZ & $\begin{array}{l}\text { (Amini et al. 2002), } \\
\text { (Quentmeier et al. 2013) }\end{array}$ \\
\hline
\end{tabular}

\section{Tabelle 4: Zelllinien}

\subsubsection{Zellmedien}

\begin{tabular}{|l|l|l|}
\hline \multicolumn{1}{|c|}{ Medium } & \multicolumn{1}{|c|}{ Zusätze } & Hersteller des Mediums \\
\hline DMEM High Glucose $(4,5 \mathrm{~g} / \mathrm{l})$ & $\begin{array}{l}10 \% \mathrm{FCS}, 100 \mathrm{U} / \mathrm{ml} \text { Penicillin } \\
+100 \mu \mathrm{g} / \mathrm{ml} \text { Streptomycin }\end{array}$ & $\begin{array}{l}\text { Gibco, Life Technologies, } \\
\text { Karlsruhe, Deutschland }\end{array}$ \\
\hline IMDM & $\begin{array}{l}20 \% \mathrm{FCS}, 100 \mathrm{U} / \mathrm{ml} \text { Penicillin } \\
+100 \mu \mathrm{g} / \mathrm{ml} \text { Streptomycin }\end{array}$ & $\begin{array}{l}\text { Gibco, Life Technologies, } \\
\text { Karlsruhe, Deutschland }\end{array}$ \\
\hline $\begin{array}{l}\text { RPMI Medium 1640 (1x) }+ \\
\text { GlutaMAX }\end{array}$ & $\begin{array}{l}10 \% \mathrm{FCS}, 100 \mathrm{U} / \mathrm{ml} \text { Penicillin } \\
+100 \mu \mathrm{g} / \mathrm{ml} \text { Streptomycin }\end{array}$ & $\begin{array}{l}\text { Gibco, Life Technologies, } \\
\text { Karlsruhe, Deutschland }\end{array}$ \\
\hline Panserin-401 & Keine & $\begin{array}{l}\text { Pan Biotech, Regensburg, } \\
\text { Deutschland }\end{array}$ \\
\hline
\end{tabular}

Tabelle 5: Zellmedien 


\subsection{Proteinbiochemische Methoden}

\subsubsection{Westernblot}

Zum Nachweis von Proteinen wurden Zelllysate mittels NatriumdodecylsulfatPolyacrylamidgelelektrophorese (SDS-Page) aufgetrennt. SDS löst sowohl Sekundär- als auch Tertiärstrukturen von Proteinen und überdeckt deren Eigenladung, wodurch die Proteine konstante Ladungen aufweisen. Somit wandern sie im elektrischen Feld lediglich in Abhängigkeit von ihrer Größe. Die aufgetrennten Proteine wurden anschließend mittels Elektroblotting auf eine Membran transferiert und letztlich immunologisch sichtbar gemacht.

\subsubsection{Herstellung von Zelllysaten}

Zur Herstellung von Zelllysaten wurden $10^{6}$ Zellen in ein Reagiergefäß überführt und zentrifugiert (10 min, $400 \times \mathrm{g}, 20^{\circ} \mathrm{C}$ ). Der Überstand wurde verworfen, das Zellpellet mit $500 \mu \mathrm{l}$ PBS resuspendiert und anschließend erneut zentrifugiert (10 min, $400 \times g, 20^{\circ} \mathrm{C}$ ). Nachdem dieser Überstand ebenfalls verworfen worden war, wurde das Pellet mit $50 \mu \mathrm{l}$ Lysepuffer (Zusammensetzung s. Tab. 1), dem zuvor Protease- und Phosphataseinhibitoren frisch zugesetzt worden waren, resuspendiert und für 2-3 h auf Eis gelagert, wobei die Lysate regelmäßig mittels Vortex resuspendiert wurden. Anschließend wurde die Suspension $30 \mathrm{~min}$ bei $9450 \times g$ und $4^{\circ} \mathrm{C}$ zentrifugiert, wodurch sich der Zelldebris im Pellet sammelte. Die gewünschten Proteine verblieben im Überstand, der nun in ein neues Reagiergefäß überführt und bei $-80^{\circ} \mathrm{C}$ gelagert werden konnte. Bei Verwendung wurden die Proben auf Eis aufgetaut.

\subsubsection{Proteinbestimmung}

Um die Proteinkonzentration der Zelllysate mittels PCA-verstärkter Biuret-Reaktion zu bestimmen, wurde eine BSA-Verdünnungsreihe zur Kalibrierung der Extinktionswerte genutzt. Dazu wurden in einer 96-well-Platte jeweils Triplikate aufsteigender BSA-Konzentrationen $\quad(0 \mathrm{mg} / \mathrm{ml} ; \quad 0,125 \mathrm{mg} / \mathrm{ml} ; \quad 0,25 \mathrm{mg} / \mathrm{ml}$; $0,5 \mathrm{mg} / \mathrm{ml}$ und $1 \mathrm{mg} / \mathrm{ml}$ ) pipettiert (Verdünnung mit Ampuwa, Gesamtvolumen $50 \mu l)$. Die zu bestimmenden Proben wurden mit Ampuwa 1:10 verdünnt und ebenso mit einem Gesamtvolumen von $50 \mu \mathrm{l}$ pro Vertiefung in Duplikaten aufgetragen. Anschließend wurden zu jeder Probe $100 \mu$ von frisch hergestelltem Roti-Quant-Reagenz hinzugefügt (Reagenz 1 : Reagenz $2=15: 1$ ). Nach einer Inkubation von $30 \mathrm{~min}$ bei $37^{\circ} \mathrm{C}$ konnte die Extinktion bei $490 \mathrm{~nm}$ mittels 
Mikroplatten-Reader gemessen, die Standardgerade durch die BSA-Werte ermittelt und so die Proteinkonzentration der einzelnen Proben bestimmt werden. Mithilfe der Proteinkonzentration konnte nun das für $25 \mu \mathrm{g}$ Protein benötigte Volumen der Proben errechnet werden.

\subsubsection{SDS-Page}

Für die Elektrophorese wurden Tris-Glycin-SDS-Gele mit einem Gradienten von 8$16 \%$ und Tris-Glycin-SDS-Laufpuffer verwendet. Im Gel werden die Proteine aus den Zelllysaten nach Anlegen der Spannung entsprechend ihrer Größe aufgetrennt, wobei für spätere Vergleichbarkeit darauf zu achten ist, dass in jede Tasche die gleiche Proteinmenge aufgetragen wird. In dieser Arbeit wurden stets mindestens $25 \mu \mathrm{g}$ verwendet. Die in die Taschen zu pipettierenden Proben wurden so hergestellt, dass sich ein Endvolumen von $20 \mu \mathrm{l}$ ergab. Dieses Volumen setzte sich aus $9 \mu$ Ladepuffer (2x), $1 \mu$ DTT (10x) und entsprechend errechnetem Lysatvolumen zusammen. Mit Ampuwa wurden die Proben auf $20 \mu \mathrm{l}$ aufgefüllt. Die so hergestellten Proben wurden vor dem Auftragen noch einmal gemischt, zwecks Denaturierung der Proteine für $5 \mathrm{~min}$ bei $95^{\circ} \mathrm{C}$ inkubiert und kurz zentrifugiert $(10 \mathrm{sec}, 16.100 \mathrm{xg}$ ). Während der Denaturierung wurde die Elektrophorese-Apparatur XCell SureLock Mini-Cell zusammengebaut. Pro Durchlauf konnten zwei Gele eingespannt werden; wurde nur ein Gel verwendet, wurde ein Platzhalter genutzt. Vor Verwendung wurden die Taschen des Gels mit Laufpuffer (1x, Verdünnung mit dest. $\mathrm{H}_{2} \mathrm{O}$ ) gespült, um Luftbläschen zu entfernen. Für die spätere Größenbestimmung der Proteinbanden wurden in mindestens eine der Taschen $3 \mu$ l eines Molekulargewichtsstandards (PageRuler Plus Prestained Protein Ladder) aufgetragen. In die restlichen Taschen wurden vorsichtig und langsam die Proben pipettiert, und die Elektrophorese wurde für ca. $30 \mathrm{~min}$ bei $30 \mathrm{~V}$ begonnen, um ein Sammeln der Proteine zu ermöglichen. Sobald die Lauffront gut zu erkennen war, wurde die Spannung zuerst auf $50 \mathrm{~V}$, dann $70 \mathrm{~V}$ und schließlich für weitere $2 \mathrm{~h}$ auf $100 \mathrm{~V}$ erhöht.

\subsubsection{Wetblot}

Mit dem System XCell II Blot Module wurden die im Gel aufgetrennten Proteine mittels Wetblot auf die Nitrocellulosemembran übertragen. Dazu wurden Schwämme, Blotting-Papiere und die Membran in Transferpuffer (1x, Verdünnung mit dest. $\mathrm{H}_{2} \mathrm{O}$ ) angefeuchtet und beim Zusammenbau der Kammer von der Anode 
zur Kathode wie folgt gestapelt: drei Schwämme, zwei Blotting-Papiere, Gel, Membran, zwei Blotting-Papiere, drei Schwämme. Für zwei Gele ergab sich Folgendes: zwei Schwämme, ein Blotting-Papier, Gel 1, Membran 1, ein BlottingPapier, zwei Schwämme, ein Blotting-Papier, Gel 2, Membran 2, ein BlottingPapier, zwei Schwämme (Abb. 4). Luft wurde durch kräftiges Aneinanderdrücken entfernt. Der Transfer erfolgte eine Stunde bei einer Spannung von $30 \mathrm{~V}$.

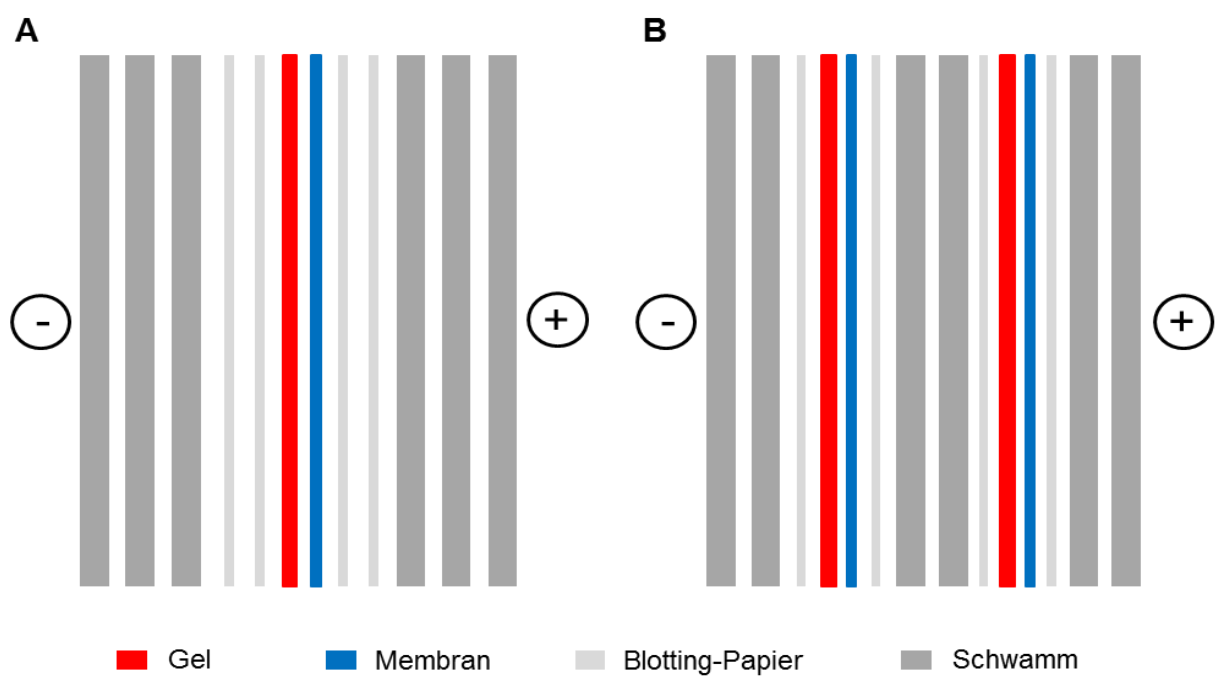

Abbildung 4: Schichtaufbau beim Nassblot. A: Bloteinsatz für ein Gel. B: Bloteinsatz für zwei Gele.

\subsubsection{Immundetektion}

Nach Ablauf des Blots wurde die Membran aus der Kammer genommen, mit Ponceaurotlösung für ca. zwei Minuten gefärbt, danach kurz mit TBS-T gewaschen, um Reste der Farblösung zu entfernen, und anschließend bei Raumtemperatur für eine Stunde in $5 \%$ Milchpulverlösung geschwenkt, um freie Proteinbindungsstellen zu blockieren. Anschließend wurde die Membran über Nacht bei $4^{\circ} \mathrm{C}$ mit dem Primärantikörper (Verdünnungen s. Tab. 2) in einem geschlossenen Gefäß unter ständigem Schwenken inkubiert. Am Folgetag wurde nach 5 Waschgängen à 10 min mit TBS-T die Inkubation mit dem Sekundärantikörper (Verdünnung 1:10.000) für eine Stunde bei Raumtemperatur durchgeführt, daran schlossen sich erneut 5 Waschgänge à $10 \mathrm{~min}$ an. Alle Vorgänge erfolgten auf einem Wipptisch und bei Raumtemperatur. Letztlich wurde die Membran bei Raumtemperatur für eine Minute mit Entwicklerlösung (Luminata Crescendo Western HRP Substrate) benetzt, in eine Folie überführt und die 
Chemilumineszenz wurde mittels LAS-4000 und der Software Image Reader LAS4000 detektiert, wobei die Expositionszeit je nach Signalstärke variieren konnte.

\subsubsection{Dotblot}

Bei einem Dotblot werden Proteine nativ in einer Verdünnungsreihe auf eine Nitrocellulosemembran aufgetragen. Bei diesem Experiment können Proteinlösungen quantifiziert werden, indem eine Positivkontrolle mit bekannter Konzentration parallel aufgetragen wird.

Die Ausgangslösung wurde jeweils in sechs Schritten 1:1 mit PBS verdünnt, sodass sich insgesamt je sieben Proben ergaben, die punktförmig auf die Membran pipettiert wurden; dazu wurden je $2 \mu \mathrm{l}$ verwendet. Nachdem die Auftragungsstellen getrocknet waren, wurde die Membran bei Raumtemperatur für $2 \mathrm{~h}$ in $5 \%$ Milchpulverlösung geschwenkt, um freie Proteinbindungsstellen zu blockieren. Anschließend wurde die Membran über Nacht bei $4^{\circ} \mathrm{C}$ mit dem Primärantikörper (Verdünnungen wie WB, Tab. 2) in einem geschlossenen Gefäß unter ständigem Schwenken inkubiert. Am Folgetag wurde nach 5 Waschgängen à 10 min mit TBS-T die Inkubation mit dem Sekundärantikörper (Verdünnung 1:10.000) für eine Stunde bei Raumtemperatur durchgeführt, daran schlossen sich erneut 5 Waschgänge à $10 \mathrm{~min}$ an. Letztlich wurde die Membran bei Raumtemperatur für eine Minute mit Entwicklerlösung benetzt, in eine transparente Folie gelegt und die Chemilumineszenz wurde mittels LAS-4000 und der Software Image Reader LAS-4000 detektiert.

\subsubsection{Coomassie-Blau-Färbung}

Zur Größenbestimmung von Proteinen eines Proteingemischs wurde eben dieses durch eine SDS-Page getrennt. Im Anschluss können die Proteinbanden im Gel durch eine Coomassie-Blau-Färbung sichtbar gemacht werden, da sich der Farbstoff Coomassie-Brillant-Blau unspezifisch an basische und aromatische Seitenketten von Proteinen lagert.

Für die Elektrophorese wurden Tris-Glycin-SDS-Gele mit einem Gradienten von 8$16 \%$ und Tris-Glycin-SDS-Laufpuffer verwendet. Vor Verwendung wurden die Taschen des Gels mit Laufpuffer (1x, Verdünnung mit dest. $\mathrm{H}_{2} \mathrm{O}$ ) gespült, um Luftbläschen zu entfernen. Die in die Taschen zu pipettierenden Proben wurden so hergestellt, dass sich ein Endvolumen von $20 \mu \mathrm{l}$ ergab, welches sich im 
Verhältnis 1:1 aus Ladepuffer und Proteinlösung zusammensetzt. Die Proben wurden ggf. mit Ampuwa aufgefüllt. Für die spätere Größenbestimmung der Proteinbanden wurden in mindestens eine der Taschen $3 \mu \mathrm{l}$ eines Molekulargewichtsstandards (PageRuler Plus Prestained Protein Ladder) aufgetragen. Die Elektrophorese wurde in der Elektrophorese-Apparatur XCell SureLock Mini-Cell für ca. 30 min bei $30 \mathrm{~V}$ begonnen und langsam auf $100 \mathrm{~V}$ für $2 \mathrm{~h}$ gesteigert.

Das Gel wurde anschließend für mindestens $2 \mathrm{~h}$ bei $37^{\circ} \mathrm{C}$ unter Schütteln mit Coomassie-Blau-Lösung (Tab. 1) gefärbt. Um ein Austrocknen des Gels zu verhindern, wurde das Gefäß abgedeckt. Bei deutlich sichtbar gefärbten Proteinbanden wurde mit dem Entfärben begonnen, hierzu wurde ebenfalls bei $37^{\circ} \mathrm{C}$ und unter Schütteln zu Beginn eine Lösung aus $25 \%$ Methanol und $5 \%$ Essigsäure verwendet. Nach zwei bis drei Spülvorgängen wurde das Entfärben mit einer Lösung aus $10 \%$ Methanol und $5 \%$ Essigsäure fortgeführt. Anhand der Banden konnte nun abgelesen werden, welches Molekulargewicht die Proteine der jeweils aufgetragenen Probe besitzen. Das Gel wurde in $1 \%$ Glycerin bei Raumtemperatur gelagert.

\subsubsection{Herstellung eines Fusionsprodukts aus sFRP4 und CD20-bindendem Protein}

Ziel war es, aus dem Wnt-Antagonisten sFRP4 und dem antigenbindenden Fragment $\left(F_{a b}\right)$ von Rituximab ein konjugiertes Protein herzustellen.

\subsubsection{Fragmentierung von Rituximab}

Rituximab liegt in Form von IgG-Molekülen vor (MabThera ${ }^{\circledR}$, Produktinformation). Mit Hilfe des Pierce $F_{a b}$ Micro Preparation Kits wurden die Antikörper durch das Enzym Papain zu je einem $F_{c^{-}}$und zwei $F_{a b}$-Fragmenten gespalten. Letztere wurden zur weiteren Verarbeitung isoliert.

In der Vorbereitung wurden $4 \mathrm{mg}$ Rituximab über eine Säule entsalzt und anschließend mit Papain für $6 \mathrm{~h}$ bei $37^{\circ} \mathrm{C}$ in einer weiteren Säule unter Schwenken inkubiert. 


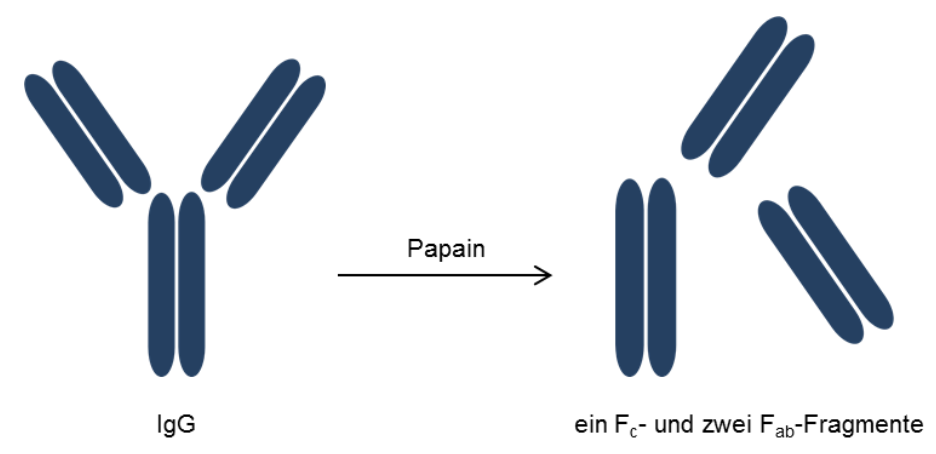

Abbildung 5: Spaltung von IgG-Molekülen durch Papain.

Nach Verdau wurde die Inkubationssäule vierfach ausgewaschen und von jeder Waschfraktion wurden $10 \mu \mathrm{l}$ für eine SDS-Page abgenommen. Die Waschfraktionen wurden dann in eine weitere Säule überführt, die mittels eines enthaltenen Proteins IgG und $F_{c}$-Fragmente binden konnte. In weiteren Waschschritten blieben IgG und $F_{c}$-Fragmente damit in der Säule gebunden, während die $F_{a b}$-Fragmente im Durchlauf gesammelt werden konnten. Auch von diesen Waschfraktionen wurden je $10 \mu \mathrm{l}$ in einer SDS-Page aufgetragen.

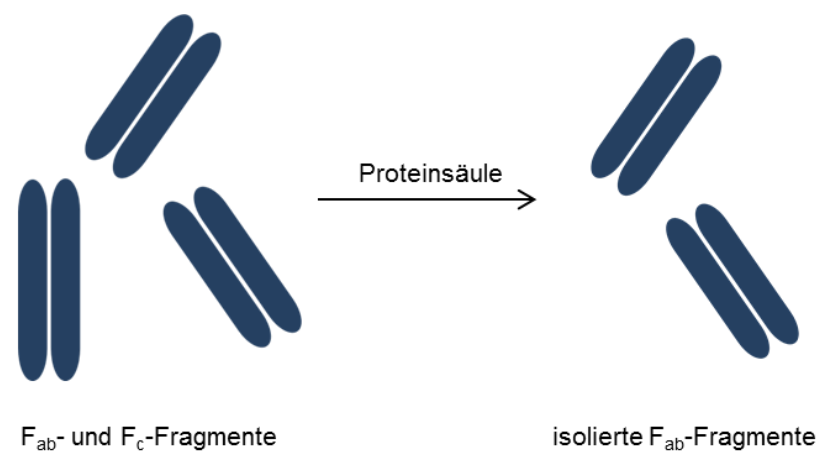

Abbildung 6: Isolierung von $\mathrm{F}_{\mathrm{ab}}$-Fragmenten mittels einer

Proteinsäule.

Die $\mathrm{F}_{\mathrm{ab}}$-Fragmente wurden bei der Trennung in PBS überführt und bei $4^{\circ} \mathrm{C}$ bis zur weiteren Verwendung gelagert. Das Experiment wurde nach dem vorliegenden Protokoll von Pierce Technology durchgeführt, dem detaillierte Schritte zu entnehmen sind.

\subsubsection{Konjugation der Proteine}

Für die Konjugation wurden das Solulink Protein-Protein Conjugation Kit und das zugehörige Protokoll verwendet.

$50 \mu \mathrm{g}$ rekombinantes sFRP4 wurden in $50 \mu$ Ampuwa gelöst und anschließend mit in DMF gelöstem Succinimidyl-4-formyl-benzamid (S-4FB) verlinkt. 
$120 \mu \mathrm{F} \mathrm{Fab}_{\mathrm{ab}}$-Fragmente wurden zwecks Entsalzung in $130 \mu \mathrm{l}$ Modification-Puffer überführt. Die $F_{a b}$-Fragmente wurden anschließend mit in DMF gelöstem Succinimidyl-6-hydrazin-nikotinamid (S-HyNic) verlinkt.

Nach dreistündiger Inkubation bei Raumtemperatur unter Schwenken wurden sowohl die nun verlinkten sFRP4-Moleküle als auch die nun verlinkten $F_{a b}$ Fragmente erneut über Entsalzungssäulen geführt, wodurch überschüssiges Linkermaterial entfernt wurde. Das entstandene Linkerverhältnis wurde mittels Nanodrop bestimmt und schließlich wurden die Lösungen im Verhältnis 2:1 gemischt. Um die Konjugation zu unterstützen, wurde TurboLink-Puffer hinzugefügt. Nach dreistündiger Inkubation bei Raumtemperatur wurde das Konjugationsgemisch wieder entsalzt und in PBS gelagert. Das Experiment wurde nach dem vorliegenden Protokoll von Solulink durchgeführt, dem detaillierte Schritte zu entnehmen sind.

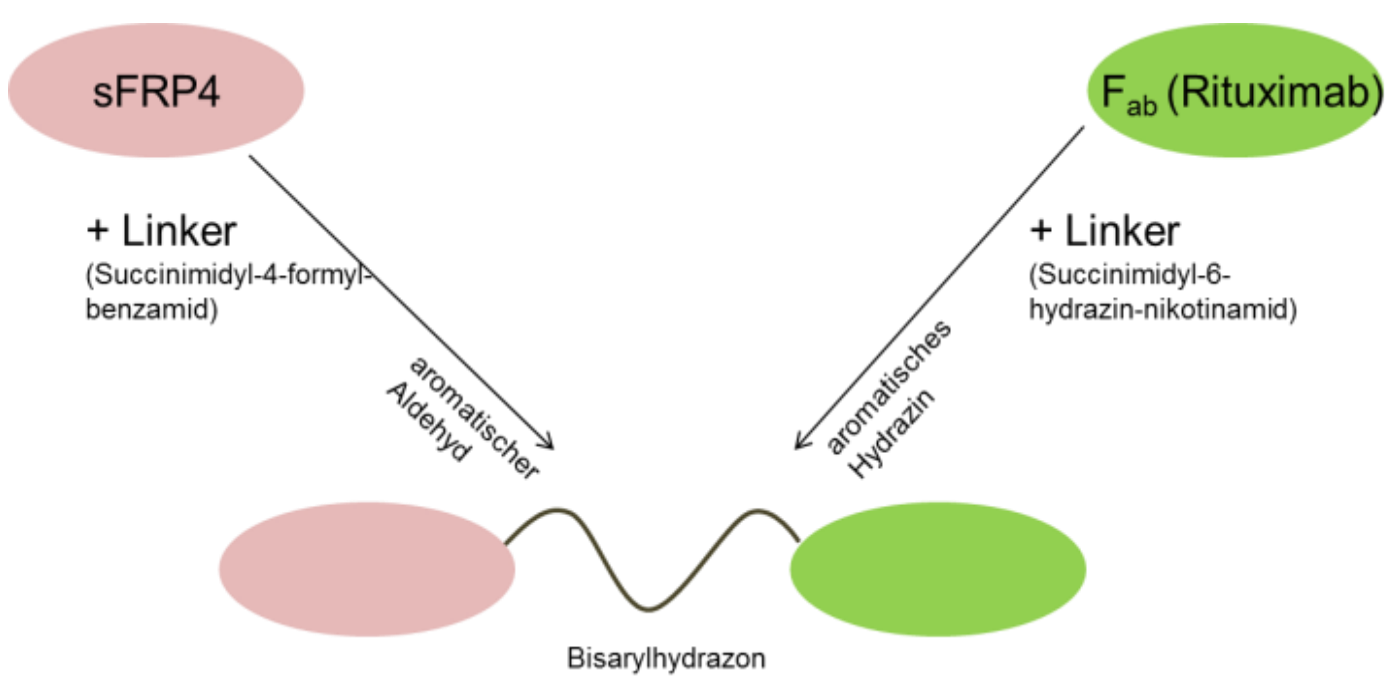

Abbildung 7: Verlinkung von sFRP4 und einem $\mathbf{F}_{\mathbf{a b}}$-Fragment. Die Edukte wurden zunächst jeweils an einen Linker gekoppelt. Diese beiden Linker reagierten wiederum zu einem Hydrazon, welches eine stabile Verbindung zwischen sFRP4 und $\mathrm{F}_{\mathrm{ab}}$-Fragment darstellt.

Im Rahmen dieser Arbeit wurden fünf Fusionsreaktionen durchgeführt und die dabei entstandenen Produkte mit K1 bis K5 bezeichnet.

\subsubsection{Flüssigchromatographie}

Bei der Fusion entstand ein Gemisch aus Edukten und Produkt. Um das Produkt zu isolieren, wurde eine Aufreinigung des Gemisches mittels Flüssigchromatographie vorgenommen. Dabei wurde das Trennprinzip des Größenausschlusses verwendet, bei dem das Proteingemisch nach dem Molekular- 
gewicht aufgetrennt wird. Bei einem Durchlauf passieren zuerst die Proteine mit hohem Molekulargewicht das System, es folgen mittelschwere und schließlich niedermolekulare Proteine. Während des Durchlaufs wird die Absorption der Probe bei einer Wellenlänge von $280 \mathrm{~nm}$ gemessen. Hierbei macht man sich die unterschiedliche Absorptionsfähigkeit der verschiedenen Proteine zunutze, was in Form von Peaks dargestellt wird; je stärker die Absorption, desto höher der Peak. Die einzelnen Peaks repräsentieren die getrennten Proteine, welche sich somit voneinander abgrenzen lassen. Ist bei Proteinen das Molekulargewicht bekannt, können bei einem Gemisch aus Standardproteinen die Absorptionspeaks dem entsprechenden Molekulargewicht zugeordnet werden (Abb. 8). Wird nun im Folgenden ein Durchlauf mit einer Lösung durchgeführt, die das zu isolierende Protein enthält, von dem jedoch nur das Gewicht bekannt ist, kann aufgrund des Molekulargewichts rückgeschlossen werden, in welcher Fraktion sich das gewünschte Protein befinden muss. Nach diesem Prinzip wurde in Zusammenarbeit mit dem Zentrum Biochemie (Klaus Neifer, Biochemie, Göttingen) das Proteingemisch dieser Arbeit aufgetrennt. Dabei wurde das Material in einzelne Fraktionen aufgeteilt, von denen die Fraktionen, die das gewünschte Produkt enthielten, für weitere Experimente verwendet wurden.

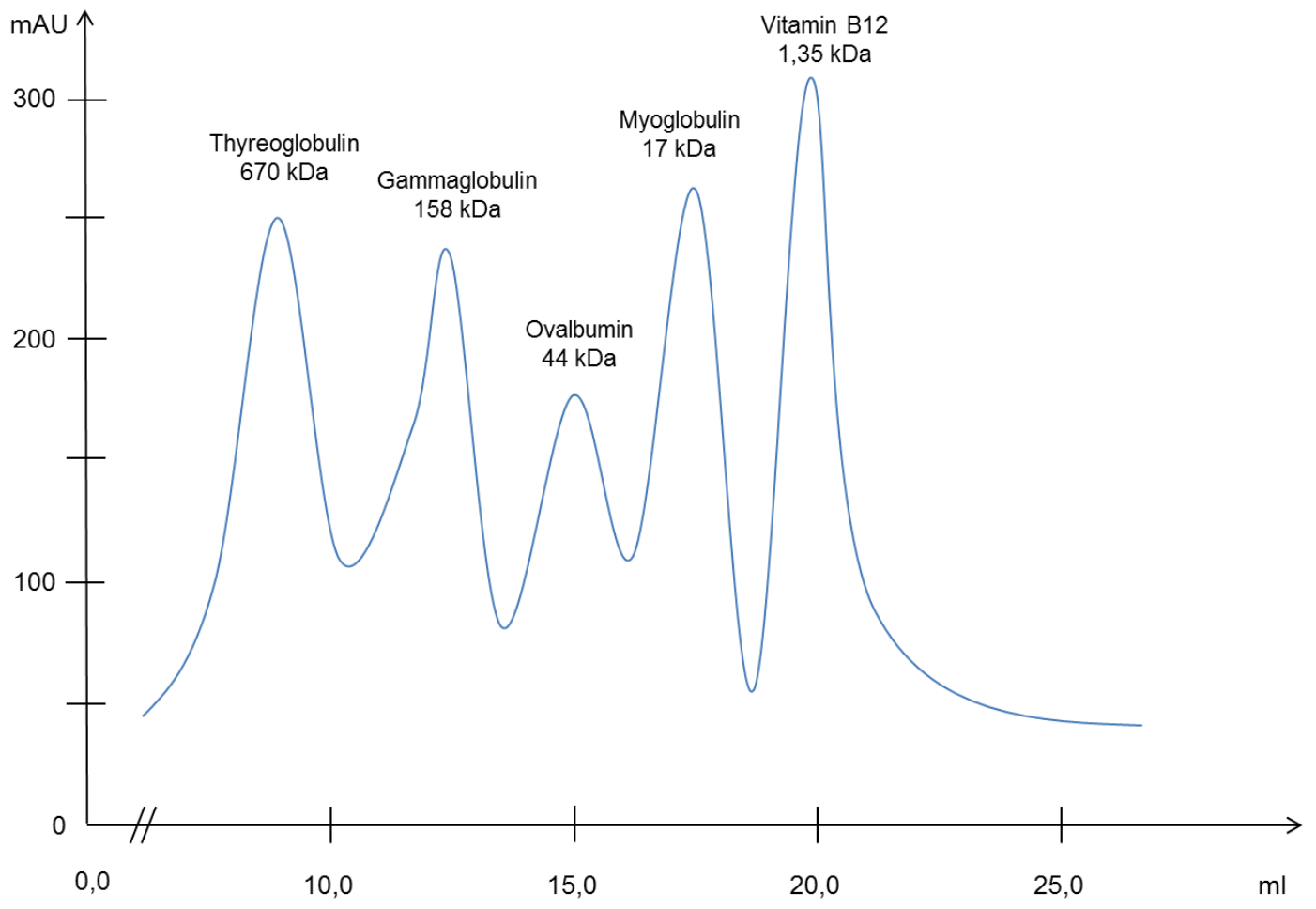

Abbildung 8: Absorptionsverhalten von Standardproteinen bei einer Wellenlänge von 280 nm (nach Datasheet Superdex-Säulen, GE Healthcare). 


\subsubsection{FITC-Markierung des immunologischen Konstrukts}

Für die Fluoreszenzmikroskopie der Gefrierschnitte aus dem CAM-Assay und für Analysen am Durchflusszytometer wurde das immunologische Konstrukt mit Fluoresceinisothiocyanat (FITC) markiert. Die Durchführung der Markierung orientierte sich am Protokoll des Kits FluoroTag FITC Conjugation von SigmaAldrich. Die nötige Konzentrationsbestimmung der Proteinlösung erfolgte durch Abschätzung des Ergebnisses vom entsprechenden Dotblot. Die Konjugation wurde so durchgeführt, dass Protein und FITC im Verhältnis 1:10 eingesetzt wurden. Die genauen Schritte sind dem Protokoll zu entnehmen. Nach erfolgter Verlinkung wurde (UV-Vis) die erfolgreiche Markierung mittels Nanodrop überprüft und das FITC-Konjugat anschließend bis zur weiteren Verwendung bei $4{ }^{\circ} \mathrm{C}$ lichtgeschützt gelagert.

\subsection{Mikroskopische Techniken}

\subsubsection{Trypanfärbung zur Zellzahlbestimmung}

Zur Bestimmung der Zellzahl kann eine kleine Probe der Zellkultur mit Trypanblau gefärbt und anschließend mittels der Neubauer-Zählkammer mikroskopisch ausgezählt werden.

Der Inhalt der Zellkulturflasche wurde in ein Falconröhrchen überführt und bei $300 \times g$ für 5 min bei $20^{\circ} \mathrm{C}$ zentrifugiert. Der Überstand wurde verworfen und das Zellpellet je nach Größe in 5 bis $10 \mathrm{ml}$ frisches Medium aufgenommen. Aus dieser Zellsuspension wurden $10 \mu \mathrm{l}$ in eine 96-well-Platte überführt und mit $90 \mu \mathrm{l}$ Trypanblau gefärbt. Von dem entstandenen Gemisch wurden wenige Mikroliter in eine Kammer der Neubauer-Zählkammer pipettiert und die äußeren vier Quadranten wurden ausgezählt. Dabei wurden nur vitale, das heißt sich hell abzeichnende, Zellen berücksichtigt. Unter Berücksichtigung der 1:10 Verdünnung und der Auszählung von vier Quadranten konnte die Zellzahl pro $\mathrm{ml}$ nach folgender Formel berechnet werden:

$$
\frac{\text { Zellzahl }}{4} * 10 * 10^{\wedge} 4
$$

Wurden zudem ebenfalls die toten, das heißt dunkelblau gefärbten, Zellen gezählt, so konnte der Anteil toter Zellen ermittelt und die Eignung der Zellkultur für Experimente bestimmt werden (geeignet, wenn $>90 \%$ vital). 


\subsubsection{Fluoreszenzmikroskopie}

Die wie in 2.5.2 beschrieben hergestellten Kryoschnitte wurden mit dem Eindeckmedium Roti-Mount FluorCare DAPI versehen und mit einem Deckgläschen abgedeckt. Anschließend erfolgte die mikroskopische Untersuchung mit dem Fluoreszenzmikroskop ApoTome und der Software AxioVision. Dabei wurden Aufnahmen in bis zu 40-facher Vergrößerung angefertigt. Die Objektträger wurden bei $4{ }^{\circ} \mathrm{C}$ und Dunkelheit gelagert.

\subsection{Zellbiologische Methoden}

\subsubsection{Zellkultur}

In der Zellkultur wurden alle Arbeiten unter einer Sterilbank durchgeführt, alle verwendeten Materialien wurden vor Gebrauch autoklaviert bzw. mit Meliseptol oder $70 \%$ Ethanol desinfiziert. Die Zellkultivierung erfolgte bei $37^{\circ} \mathrm{C}$ und $5 \% \mathrm{CO}_{2}$ mit wassergesättigter Atmosphäre. Alle Medien wurden vor Verwendung auf $37^{\circ} \mathrm{C}$ erwärmt.

\subsubsection{Passagieren von Zellen}

Die Zelllinien OCI-Ly1 und OCl-Ly3 wurden in Iscove's modified Dulbecco's medium (IMDM) mit 4,5 mg/ml D-Glucose, $584 \mu \mathrm{g} / \mathrm{ml}$ L-Glutamin und 5,958 mg/ml HEPES kultiviert. Dem Medium wurden $20 \%$ durch Hitze inaktiviertes fetales Kälberserum, $100 \mathrm{U} / \mathrm{ml}$ Penicillin sowie $100 \mu \mathrm{g} / \mathrm{ml}$ Streptomycin zugegeben.

Die Kultivierung der Zelllinien SU-DHL-4, U-2932, U-2932 R1 und U-2932 R2 erfolgte in Roswell Park Memorial Institute medium (RPMI) 1640 (1x) + GlutaMAXI, welches $2 \mathrm{mg} / \mathrm{ml} \mathrm{D-Glucose}$ und $446 \mu \mathrm{g} / \mathrm{ml}$ L-Alanyl-Glutamin enthielt. Hier wurden dem Medium $10 \%$ durch Hitze inaktiviertes fetales Kälberserum, $100 \mathrm{U} / \mathrm{ml}$ Penicillin sowie $100 \mu \mathrm{g} / \mathrm{ml}$ Streptomycin zugefügt.

Das Passagieren der Zellen erfolgte je nach Zelldichte alle zwei bis drei Tage. Dazu wurden die Zellen mit dem Medium in ein Falconröhrchen überführt und bei $300 \times g$ für 5 min zentrifugiert. Der Überstand wurde abgenommen und das Zellpellet mit frischem Medium resuspendiert. Für Erhaltungskulturen wurden Zellen in Flaschen mit einer Fläche von $75 \mathrm{~cm}^{2}$ und zur Vorbereitung von Experimenten Flaschen mit einer Fläche von $175 \mathrm{~cm}^{2}$ kultiviert. Dabei wurde die Zellkonzentration bei der Zelllinie OCl-Ly1 auf ca. $2 \times 10^{6}$ Zellen pro $\mathrm{ml}$, bei OClLy3 auf ca. $1 \times 10^{6}$ Zellen pro $\mathrm{ml}$ und bei den restlichen Zelllinien auf ca. $5 \times 10^{5}$ 
Zellen pro ml eingestellt. Für die Bestimmung der Zellkonzentration wurden die Zellen bei jedem Passagiervorgang, wie in 2.3.1 beschrieben, gezählt, was zugleich die Bestimmung der Vitalität erlaubte.

Die adhärente Zellinie HeLa wurde in Dulbecco's modified Eagle medium (DMEM) mit $4,5 \mathrm{mg} / \mathrm{ml}$ Glucose kultiviert. Dem Medium wurden $10 \%$ durch Hitze inaktiviertes fetales Kälberserum, $100 \mathrm{U} / \mathrm{ml}$ Penicillin sowie $100 \mu \mathrm{g} / \mathrm{ml}$ Streptomycin zugegeben. Das Passagieren der Zellen erfolgte alle zwei Tage. Hierzu wurde das Medium abgenommen und der Flaschenboden mit $5 \mathrm{ml}$ Trypsin/EDTA (0,05\%/ 0,02\%) beschichtet. Nach 2-3 min Inkubation bei $37^{\circ} \mathrm{C}$ konnten die Zellen, durch leichtes Klopfen unterstützt, vom Flaschenboden gelöst werden. Zur Inaktivierung des Trypsins wurden $5 \mathrm{ml}$ Medium hinzugegeben und der gesamte Flascheninhalt wurde bei $300 \times g 5$ min in einem Falcon zentrifugiert. Nach Verwerfen des Überstandes wurde das Zellpellet mit frischem Medium resuspendiert und ca. ein Drittel der Suspension wurde in eine neue Zellkulturflasche gegeben.

\subsubsection{Kryokonservierung von Zellen}

In regelmäßigen Abständen wurden Zellen eingefroren, um sie bei Bedarf wieder frisch in Kultur nehmen zu können.

Die Zellsuspension wurde bei $300 \times g$ für 5 min bei $20^{\circ} \mathrm{C}$ zentrifugiert und der Überstand wurde verworfen. Für die Kryokonservierung wurde reines FCS mit $10 \%$ DMSO versetzt. In diesem Kryomedium wurden bis zu $10^{7}$ Zellen in $1 \mathrm{ml}$ aufgenommen und in Kryoröhrchen überführt. Anschließend wurden die Kryoröhrchen in einem mit Propanol gefüllten Einfriercontainer (Mr. Frosty) langsam heruntergekühlt und letztlich bei $-80^{\circ} \mathrm{C}$ eingefroren.

\subsubsection{Revitalisierung von Zellen}

Zur Revitalisierung eingefrorener Zellen wurde ein Kryoröhrchen zügig aufgetaut und der Inhalt des Röhrchens in $10 \mathrm{ml}$ frisches Medium gegeben. Die Suspension wurde bei $300 \times g$ für 5 min bei $20^{\circ} \mathrm{C}$ zentrifugiert und der Überstand wurde abgenommen. Dies diente dem Entfernen von toxischem DMSO. Das Zellpellet wurde in $5 \mathrm{ml}$ frischem Medium gelöst und in eine Zellkulturflasche $\left(25 \mathrm{~cm}^{2}\right)$ gegeben. Die Zellen wurden im weiteren Verlauf beobachtet und nach Anzeichen der Proliferation passagiert. 


\subsubsection{Proliferationsanalyse}

Das proliferative Verhalten der Zelllinien unter Einfluss verschiedener Substanzen wurde mittels CellTiter 96® AQueous One Solution Proliferation Assay gemessen. Dieser Assay beruht auf dem Prinzip, dass vitale Zellen im Rahmen des normalen Metabolismus NADPH bzw. NADH produzieren, welches die im Reagenz enthaltene Tetrazoliumverbindung 3-(4,5-Dimethylthiazol-2-yl)-5-(3-carboxymethoxyphenyl)-2-(4-sulfophenyl)-2H-tetrazolium (MTS) reduziert, wobei wiederum eine Verbindung entsteht, die Formazan enthält. Formazan ist im Medium löslich und absorbiert Licht der Wellenlänge $490 \mathrm{~nm}$. Die Absorption ist dabei direkt proportional zur Anzahl vitaler Zellen. Der Elektronentransport wird bei dieser Reaktion über Phenazinethosulfat (PES) vermittelt, welches ebenfalls im Reagenz enthalten ist.

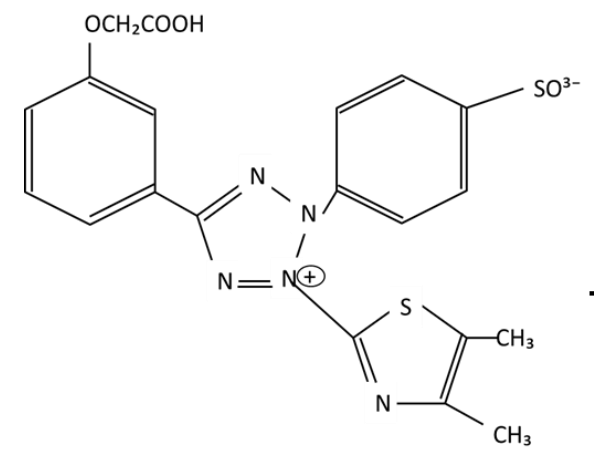

MTS
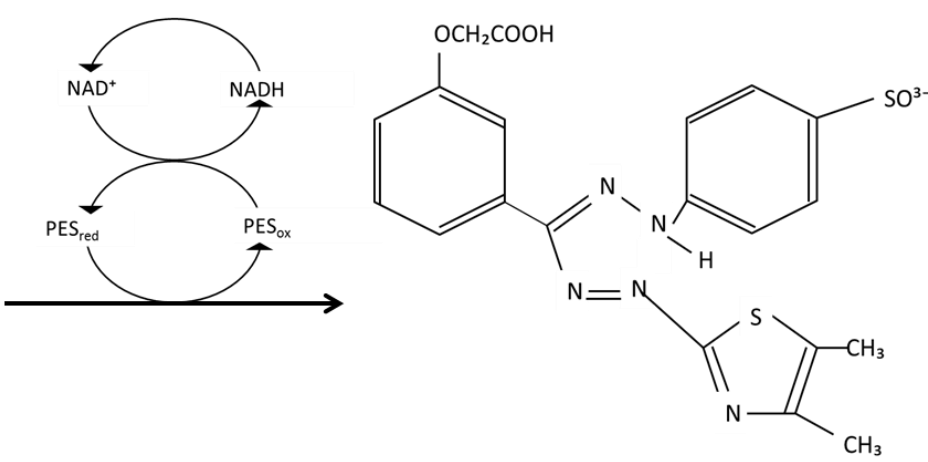

Formazan

Abbildung 9: Reduktion der Tetrazoliumverbindung zu Formazan. Als Reduktionsmittel dient NADH bzw. NADPH aus dem Zellmetabolismus. Nach Promega, Protokoll.

In 96-well-Platten wurden 10.000 Zellen in $100 \mu \mathrm{l}$ Medium pro Vertiefung ausplattiert und nach 24, 48 und 72 h $20 \mu \mathrm{l}$ des Reagenz hinzugegeben. Nach 150 min Inkubation bei $37^{\circ} \mathrm{C}$ wurde die Extinktion mit dem Mikroplatten-Reader Infinite 200pro und der Software i-control gemessen, wobei die Messwellenlänge $490 \mathrm{~nm}$ und die Referenzwellenlänge $655 \mathrm{~nm}$ betrug. Die Subtraktion der Extinktionswerte wurde errechnet und der Anteil vitaler Zellen ermittelt.

\subsubsection{Colony Forming Units}

Das klonale Verhalten von Zellen unter Zugabe verschiedener Substanzen wurde mittels Colony Forming Units untersucht. Dazu wurden 1000 Zellen in einem Volumen von $1 \mathrm{ml}$ Methylcellulose in einer Petrischale mit einer Fläche von $9,62 \mathrm{~cm}^{2}$ ausplattiert. 
Die bei $-20^{\circ} \mathrm{C}$ gelagerte Methylcellulose wurde über Nacht bei $4{ }^{\circ} \mathrm{C}$ aufgetaut. Zur Durchmischung der Inhaltsstoffe wurde das Medium vor Durchführung des Experiments kräftig geschüttelt und anschließend eine Stunde bei Raumtemperatur stehen gelassen, um die beim Schütteln entstandenen Luftbläschen aufsteigen zu lassen. Für jede Petrischale wurden $800 \mu \mathrm{l}$ bläschenfreie Methylcellulose und $200 \mu$ Zelllösung mit einer Konzentration von 5000 Zellen pro $\mathrm{ml}$ zuerst gemischt und anschließend mittels EinmalInsulinspritzen sowie Sonderkanülen ausplattiert. Wurden den Platten Substanzen hinzugefügt, so wurden diese jeweils zuvor als Tropfen auf den Plattenboden pipettiert.

Die Ansätze wurden für $10-21$ Tage bei $37^{\circ} \mathrm{C}$ und $5 \% \mathrm{CO}_{2}$ inkubiert. Zur Vermeidung von Transpiration und damit verbundener Austrocknung des Mediums wurden die Platten während der Inkubation in Metallkästen aufbewahrt. Sobald die Kontrollansätze gut abgrenzbare Kolonien bildeten, wurden die Platten mit der Kamera LAS-4000 und der Software Image Reader LAS-4000 fotografiert und einzeln mit Hilfe des Auflichtmikroskops Stemi SV 11 von Zeiss ausgezählt.

\subsubsection{Durchflusszytometrie}

Die Durchflusszytometrie ermöglicht es, Zellen nach Größe und Granularität zu sortieren, wodurch verschiedene Zellpopulationen voneinander abgegrenzt werden können. Zudem können Oberflächenmoleküle markiert und im FACS detektiert werden, was Aussagen über die Expression von zum Beispiel Rezeptoren oder anderen Proteinen auf der Zelloberfläche erlaubt. Des Weiteren ist es möglich, die DNA im Nucleus anzufärben, anhand der Signalstärke den DNA-Gehalt einzuordnen und auf den Zellzyklus rückzuschließen.

\subsubsection{Analyse von Frizzledrezeptoren}

Als Grundlage für das Verständnis der Interaktion von UM206 und Frizzledrezeptoren wurde die Expression eben dieser Rezeptoren auf verschiedenen Lymphomzelllinien u. a. mittels FACS-Analyse untersucht.

Dazu wurden $10^{6}$ Zellen in $1 \mathrm{ml}$ Panserin aufgenommen, mit PBS gewaschen und bei $400 \times g$ für 10 min zentrifugiert. Nach Verwerfen des Überstandes wurde das Zellpellet in $300 \mu \mathrm{l}$ PBS aufgenommen und die entstandene Zellsuspension auf sechs Reagiergefäße aufgeteilt. $Z u$ je einem Ansatz wurden die primären 
Antikörper gegen die Frizzledrezeptoren 1, 2, 4 und 5 hinzugefügt (Verdünnungen s. Tab. 2). Ein Ansatz diente als Kontrolle, dem lediglich der Sekundärantikörper im nachfolgenden Schritt zugefügt wurde. Eine Probe blieb unbehandelt. Die Inkubation erfolgte $2 \mathrm{~h}$ auf Eis, anschließend wurden die Proben mit $450 \mu \mathrm{l}$ PBS zum Waschen vermischt, bei $400 \times g$ für 10 min zentrifugiert und der Überstand wurde verworfen. Für den zweiten Waschvorgang wurden nun je $500 \mu \mathrm{l}$ PBS hinzugegeben und es wurde erneut bei $400 \times g$ für $10 \mathrm{~min}$ zentrifugiert. Der Überstand wurde abgenommen und der PE-markierte Sekundärantikörper (Antirabbit IgG-PE) in einer Verdünnung von 1:100 und einem Volumen von $100 \mu \mathrm{l}$ jeweils zu den Proben für 30 min abgedunkelt und auf Eis hinzugegeben. Nach dieser Inkubation wurde erneut mit je $500 \mu \mathrm{l}$ PBS gewaschen und bei $400 \times g$ für 10 min zentrifugiert, bevor jede Probe in $200 \mu \mathrm{l}$ PBS aufgenommen und in FACSRöhrchen überführt wurde. Die Detektion erfolgte am Durchflusszytometer BD FACSCanto II mit der BD Facs Diva Software.

\subsubsection{Inkubation von Lymphomzellen mit UM206}

Die Bindung des Peptids UM206 an Frizzledrezeptoren wurde in einer FACSAnalyse untersucht. Dazu wurden für zwei Ansätze jeweils $10^{6}$ Zellen in $1 \mathrm{ml}$ Panserin aufgenommen. Zu einem Ansatz wurde UM206 in einer vermutlich sättigenden Konzentration von $1000 \mathrm{nM}$ zugefügt. Beide Ansätze wurden $1 \mathrm{~h}$ bzw. $24 \mathrm{~h}$ auf Eis inkubiert. Die Zellen wurden anschließend bei $400 \times \mathrm{g}$ für $10 \mathrm{~min}$ zentrifugiert, nach Verwerfen des Überstandes wurden sie mit $500 \mu \mathrm{l}$ PBS gewaschen und erneut zentrifugiert. Nach erneutem Verwerfen des Überstandes wurden zu dem nichtbehandelten Ansatz $300 \mu \mathrm{l}$ PBS zugefügt und die entstandene Zellsuspension auf sechs Reagiergefäße aufgeteilt. $\mathrm{Zu}$ je einem Ansatz wurden Antikörper gegen die Frizzledrezeptoren 1, 2, 4 und 5 hinzugefügt. Ein Ansatz diente als Kontrolle, dem lediglich der Sekundärantikörper im nachfolgenden Schritt zugefügt wurde. Eine Probe blieb unbehandelt. Die mit UM206 behandelten Zellen wurden in $250 \mu \mathrm{l}$ aufgenommen und auf fünf Reagiergefäße aufgeteilt, wobei auch hier eine Probe als Sekundärantikörperkontrolle diente und die restlichen vier mit den jeweiligen Antikörpern gegen Frizzledrezeptoren versetzt wurden. Die Hinzugabe der Primärantikörper und das weitere Vorgehen entsprechen dem Protokoll des Kapitels 2.4.7.1 und sind diesem zu entnehmen. 


\subsubsection{Analyse der Anreicherung von sFRP4 auf Lymphomzellen mittels Konjugat}

Mittels des hergestellten Konjugats soll eine Anreicherung von sFRP4 an der Zellmembran erzielt werden. Um zu zeigen, dass sFRP4 über das Antigenbindende Fragment von Rituximab an die Zelloberfläche gebunden wird, wurden FACS-Analysen durchgeführt. Tabelle 6 dient der Übersicht über die eingesetzten Proben dieses Experiments. Es ist zu berücksichtigen, dass die eingesetzten Fusionsprodukte bereits zuvor mit FITC markiert wurden. Durch die Waschschritte wurde die Konzentration ca. 5-fach verdünnt und mit 2 ng/ $\mu$ l kalkuliert.

$3 \times 10^{7}$ Zellen wurden mit PBS gewaschen und nach Zentrifugation bei $300 \times g$ für 5 min bei Raumtemperatur und anschließender Abnahme des Überstandes in $3 \mathrm{ml}$ 4 \% PFA-Lösung 10 min fixiert. Danach wurden je $100 \mu \mathrm{l}$ der Zelllösung in 28 Reagiergefäße pipettiert und zu jedem Ansatz wurden $500 \mu \mathrm{l}$ PBS als Waschvorgang gegeben. Die Zellen wurden bei 400 x g für 10 min zentrifugiert. Im Folgenden wurden zehn Zellpellets (für Kontrollansätze und Rituximab-Inkubation) in je $25 \mu \mathrm{l}$ PBS aufgenommen. Je zwei Zellpellets wurden in $25 \mu$ der fünf Konjugatlösungen aufgenommen und von den restlichen acht Zellpellets wurden je zwei mit verschiedenen Konzentrationen von rekombinantem sFRP4 versetzt

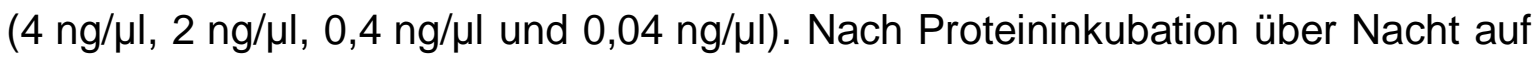
Eis unter Schwenken wurden die Proben am Folgetag mit je $500 \mu \mathrm{l}$ PBS gewaschen, bei $400 \times g$ für $10 \mathrm{~min}$ zentrifugiert und der Überstand wurde abgenommen. Für $4 \mathrm{~h}$ wurde ein Teil der Proben mit dem Primärantikörper antisFRP4 (Verdünnung 1:10) bei Raumtemperatur inkubiert (Tab. 6). Die restlichen Proben wurden mit PBS behandelt. Nach erneutem Waschen und Zentrifugieren wurden die Zellen für 45 min bei Raumtemperatur mit dem Sekundärantikörper (Verdünnung 1:100) behandelt. Die Kontrollproben und die Ansätze für die Rituximab-Proben wurden erneut mit dem entsprechenden Volumen PBS behandelt. Anschließend wurden die Zellen gewaschen, zentrifugiert, der Überstand wurde verworfen und das Zellpellet in $200 \mu$ l gelöst, wovon jeweils $100 \mu \mathrm{l}$ in FACS-Röhrchen überführt wurden. Jedes FACS-Röhrchen wurde mit $100 \mu \mathrm{l}$ PBS aufgefüllt und die Detektion erfolgte am Durchflusszytometer BD FACSCanto II mit der BD Facs Diva Software. 
Im Anschluss wurden je zwei der nur mit PBS behandelten Proben mit Rituximab in den Konzentrationen $0,4 \mathrm{ng} / \mu \mathrm{l}, 4 \mathrm{ng} / \mu \mathrm{l}$ und $40 \mathrm{ng} / \mu \mathrm{l}$ und einem Volumen von $25 \mu \mathrm{l}$ für $2 \mathrm{~h}$ bei Raumtemperatur inkubiert. Nach erfolgter Inkubation wurden die Proben mit $500 \mu \mathrm{l}$ PBS gewaschen, bei $400 \times g$ für 10 min zentrifugiert und der Überstand wurde verworfen. Die Zellpellets wurden in je $200 \mu \mathrm{l}$ PBS aufgenommen. $\mathrm{Zu}$ je einer Probe der nun mit Rituximab behandelten Ansätze sowie zu den restlichen $100 \mu \mathrm{l}$ der bereits mit sFRP4 bzw. mit einem Konjugat behandelten Proben wurde im nächsten Schritt der FITC-markierte Antikörper antiRituximab in einer Verdünnung von 1:20 hinzugegeben. Für die Kontrollen wurden eine Solo-Probe sowie je eine der Rituximab-Proben weiterhin nur mit PBS behandelt. Einer Solo-Probe wurde der Antikörper anti-Rituximab zugefügt. Die Proben wurden über Nacht auf Eis inkubiert. Am Folgetag wurden die Proben mit PBS gewaschen, zentrifugiert und der Überstand wurde verworfen. Das Zellpellet wurde in $200 \mu$ PBS aufgenommen und die Detektion sowohl des PE- als auch des FITC-Signals erfolgte am Durchflusszytometer BD FACSCanto II mit der BD Facs Diva Software. Dieser zweite Schritt hatte das Ziel, in der Durchflusszytometrie doppelt positiv markierte Zellen darzustellen, um zu zeigen, dass sowohl sFRP4 als auch Elemente von Rituximab an die Zelloberfläche gebunden sind. 


\begin{tabular}{|c|c|c|c|}
\hline Probe & Protein & Detektion Tag 1 & Detektion Tag 2 \\
\hline 1. & Solo & & \\
\hline 2. & Solo & & Anti-Rituximab-FITC \\
\hline 3. & Solo & PE-Sekundär-AK & \\
\hline 4. & Solo & Anti-sFRP4 + PE-Sekundär-AK & Anti-Rituximab-FITC \\
\hline 5. & Rituximab $40 \mathrm{ng} / \mu \mathrm{l}$ & & \\
\hline 6. & Rituximab $40 \mathrm{ng} / \mu \mathrm{l}$ & & Anti-Rituximab-FITC \\
\hline 7. & Rituximab $4 \mathrm{ng} / \mu \mathrm{l}$ & & \\
\hline 8. & Rituximab $4 \mathrm{ng} / \mu \mathrm{l}$ & & Anti-Rituximab-FITC \\
\hline 9. & Rituximab $0,4 \mathrm{ng} / \mu \mathrm{l}$ & & \\
\hline 10. & Rituximab 0,4 ng/ $\mu \mathrm{l}$ & & Anti-Rituximab-FITC \\
\hline 11. & sFRP4 $4 \mathrm{ng} / \mu \mathrm{l}$ & PE-Sekundär-AK & \\
\hline 12. & sFRP4 $4 \mathrm{ng} / \mu \mathrm{l}$ & Anti-sFRP4 + PE-Sekundär-AK & Anti-Rituximab-FITC \\
\hline 13. & sFRP4 $2 \mathrm{ng} / \mu \mathrm{l}$ & PE-Sekundär-AK & \\
\hline 14. & sFRP4 $2 \mathrm{ng} / \mu \mathrm{l}$ & Anti-sFRP4 + PE-Sekundär-AK & Anti-Rituximab-FITC \\
\hline 15. & sFRP4 0,4 ng/ $\mu \mathrm{l}$ & PE-Sekundär-AK & \\
\hline 16. & sFRP4 0,4 ng/ $\mu \mathrm{l}$ & Anti-sFRP4 + PE-Sekundär-AK & Anti-Rituximab-FITC \\
\hline 17. & sFRP4 0,04 ng/ $\mu \mathrm{l}$ & PE-Sekundär-AK & \\
\hline 18. & sFRP4 0,04 ng/ $\mu \mathrm{l}$ & Anti-sFRP4 + PE-Sekundär-AK & Anti-Rituximab-FITC \\
\hline 19. & Konjugat 1 & PE-Sekundär-AK & \\
\hline 20. & Konjugat 1 & Anti-sFRP4 + PE-Sekundär-AK & Anti-Rituximab-FITC \\
\hline 21. & Konjugat 2 & PE-Sekundär-AK & \\
\hline 22. & Konjugat 2 & Anti-sFRP4 + PE-Sekundär-AK & Anti-Rituximab-FITC \\
\hline 23. & Konjugat 3 & PE-Sekundär-AK & \\
\hline 24. & Konjugat 3 & Anti-sFRP4 + PE-Sekundär-AK & Anti-Rituximab-FITC \\
\hline 25. & Konjugat 4 & PE-Sekundär-AK & \\
\hline 26. & Konjugat 4 & Anti-sFRP4 + PE-Sekundär-AK & Anti-Rituximab-FITC \\
\hline 27. & Konjugat 5 & PE-Sekundär-AK & \\
\hline 28. & Konjugat 5 & Anti-sFRP4 + PE-Sekundär-AK & Anti-Rituximab-FITC \\
\hline
\end{tabular}

\section{Tabelle 6: Proben-Übersicht}

\subsubsection{Zellzyklusanalyse}

Für die Zellzyklusanalyse wurden $5 \times 10^{4}$ bis $10^{5}$ Zellen in $100 \mu$ Medium in FACSRöhrchen überführt. Für das Anfärben der DNA wurde der DNA-Farbstoff Hoechst 33342 mit einer Stammlösungskonzentration von $50 \mu \mathrm{g} / \mathrm{ml}$ verwendet, von der ebenfalls $100 \mu \mathrm{l}$ in die FACS-Röhrchen überführt wurden, sodass sich ein finales Volumen von $200 \mu \mathrm{l}$ und eine Hoechst-33342-Konzentration von $25 \mu \mathrm{g} / \mathrm{ml}$ ergaben. Nach 30 min Inkubation bei $37^{\circ} \mathrm{C}$ erfolgte die Zellzyklusmessung mittels Durchflusszytometrie. 


\subsection{CAM-Assay}

Die Anreicherung des Konjugats im Tumor in ovo wurde mittels Chorio-AllantoisMembran-(CAM-)Assay untersucht. Der CAM-Assay ist ein etabliertes In-vivoVerfahren als Alternative zum Tiermodell (Rosenbruch 1994). Er eignet sich zur Anzüchtung von Tumorgewebe und bietet den Vorteil, dass das Wachstum des Tumors makroskopisch sichtbar ist. Zudem verursachen Injektionen keinen Schmerz, da die Gefäße der CAM nicht innerviert sind (Rosenbruch 1994).

Befruchtete Hühnereier wurden bei $37^{\circ} \mathrm{C}$ und einer Luftfeuchtigkeit von $70 \%$ inkubiert. Am dritten Tag nach Inkubationsbeginn wurden die Eier vorsichtig fenestriert und die Öffnungen anschließend mit Cellotape verschlossen. Es folgte die weitere Inkubation. Am zehnten Tag wurden Tumorzellen auf die sichtbare Allantoismembran transplantiert. Hierzu wurden pro Membran ca. $65 \mu \mathrm{l}$ Matrigel mit einer Zellsuspension von $5 \times 10^{6}$ Zellen in $35 \mu \mathrm{l}$ Medium gemischt. Das Gemisch aus Matrigel und Zellsuspension wurde auf eine Petrischale getropft und 30 min bei $37^{\circ} \mathrm{C}$ inkubiert, um der Masse eine erhöhte Viskosität zu verleihen. Anschließend wurde der Tropfen mit einer Pipette auf die Allantoismembran übertragen. Bei sich entwickelndem, makroskopisch gut sichtbarem Tumor, der in der Laufzeit des Assays von Membrangefäßen neovaskularisiert und versorgt worden ist, wurde die intravenöse Gabe von Rituximab, Rituximabfragmenten und Konjugaten durchgeführt. Die Proteine waren zuvor jeweils mit FITC markiert worden. Nach $24 \mathrm{~h}$ wurden die Tumoren geerntet und halbiert. Eine Hälfte der Tumoren wurde für Kryoschnitte, die andere für eine FACS-Analyse präpariert.

\subsubsection{Vorversuche}

\subsubsection{In vitro}

Um die Anreicherung von FITC-markierten Proteinen auf der Zellmembran zunächst in vitro zu testen, wurden $5 \times 10^{6}$ Zellen mit FITC-markierten Proteinen für eine Stunde bei Raumtemperatur inkubiert. Als Positivkontrolle diente ein FITCmarkierter Antikörper gegen CD20 in der Verdünnung von 1:50. Die Zellen wurden nach der Inkubation mit $500 \mu \mathrm{l}$ PBS gewaschen, bei $400 \mathrm{xg}$ für $10 \mathrm{~min}$ zentrifugiert und nach Verwerfen des Überstandes in $200 \mu \mathrm{l}$ PBS aufgenommen. Die Zellsuspension wurde in FACS-Röhrchen überführt und das FITC-Signal wurde am Durchflusszytometer BD FacsCanto II mit der BD Facs Diva Software detektiert. 


\subsubsection{In ovo}

Zur Vermeidung einer großen Anzahl von Versuchen im Eimodell wurden vor der Injektion des sFRP4-Konstrukts Vorversuche durchgeführt, die dazu dienten, die Injektion eines FITC-markierten Proteins in das Venensystem der Chorio-AllantoisMembran und die Anreicherung dieses Proteins im implantierten Tumor zu etablieren und den Erfolg des Verfahrens sicherzustellen. Dazu wurden $60 \mu \mathrm{g}$ Rituximab mit FITC markiert und injiziert. Der Tumor wurde am Folgetag geerntet, es wurden Kryoschnitte hergestellt (2.5.2) und Aufnahmen mit dem Fluoreszenzmikroskop ApoTome und der Software AxioVision aufgenommen (2.3.2).

\subsubsection{Anfertigen von Kryoschnitten}

Für die Kryoschnitte wurden die Tumoren für 10 min in 4 \% PFA-Lösung fixiert, dann mit PBS gespült und anschließend 2 h in $10 \%$ Saccharose gelagert. Danach wurden die Gewebestücke in $30 \%$ Saccharose überführt und $7 \mathrm{~h}$ bei $4^{\circ} \mathrm{C}$ gelagert. Die so vorbereiteten Tumoren wurden über Nacht bei $-80^{\circ} \mathrm{C}$ in Tissue Tek eingebettet gelagert und am Folgetag wurden mit dem Kryostat Microm HM560 bei einer Temperatur von $-20{ }^{\circ} \mathrm{C}$ Kryoschnitte mit einer Dicke von $3 \mu \mathrm{m}$ hergestellt.

\subsubsection{Analyse der Tumorproben im Durchflusszytometer}

Für die FACS-Analyse wurden die Tumoren direkt nach der Ernte mit einem Skalpell zerkleinert und in PBS auf Eis gelagert. Das Gewebe wurde durch ein Zellsieb gegeben und die entstandene Suspension zentrifugiert (300 x g, $5 \mathrm{~min}$, $\left.20^{\circ} \mathrm{C}\right)$. Der Überstand wurde verworfen, das Pellet in $300 \mu \mathrm{l}$ PBS aufgenommen und in FACS-Röhrchen überführt. Die Detektion erfolgte am Durchflusszytometer BD FACSCanto II mit der BD Facs Diva Software.

\subsection{Statistische Analyse}

Für die statistische Auswertung wurde die einfaktorielle ANOVA eingesetzt, die es erlaubt, den Einfluss eines variablen Faktors auf den Ausgang eines Experiments mit verschiedenen Gruppen zu vergleichen. Für die statistische Auswertung der Proliferationsanalysen wurde die zweifaktorielle ANOVA eingesetzt, um die Auswirkung zweier variabler Faktoren zu messen. Im Anschluss folgte jeweils der Bonferroni-Post-Test. Zur Berechnung der statistischen Daten und zur graphischen Darstellung wurde die Software GraphPad Prism 6 verwendet. 


\section{Ergebnisse}

\subsection{Wnt-Inhibition durch Small Molecules}

Die Rolle von Mutationen des Wnt-Signalwegs wurde insbesondere im Kolon-, Mamma- sowie auch im Prostatakarzinom beschrieben (Valkenburg et al. 2011). Die Erkenntnisse führten dazu, dass zahlreiche sogenannte kleine Moleküle (small molecules) gegen verschiedenste Strukturen und Ebenen des Signalwegs entwickelt wurden. Im Rahmen dieser Arbeit sollte untersucht werden, welche Strategie der Wnt-Inhibition im Lymphom die stärkste Effektivität zeigt. Dazu wurden Lymphomzellinien mit verschiedenen Inhibitoren inkubiert und deren Effektivität wurde mittels Proliferations- und Zellzyklusanalysen sowie Klonogenitätsassays untersucht.

Für die Experimente wurden als Modell die Zelllinien OCI-Ly3 und OCI-Ly1 sowie U-2932 mit den beiden Subpopulationen R1 und R2 ausgewählt. Bei OCl-Ly3 und U-2932 R1 ist im Westernblot ein hoher Gehalt an $\beta$-Catenin nachweisbar, während in den Zelllinien OCI-Ly1 und U-2932 R2 kaum $\beta$-Catenin nachzuweisen war (Abb. 10).

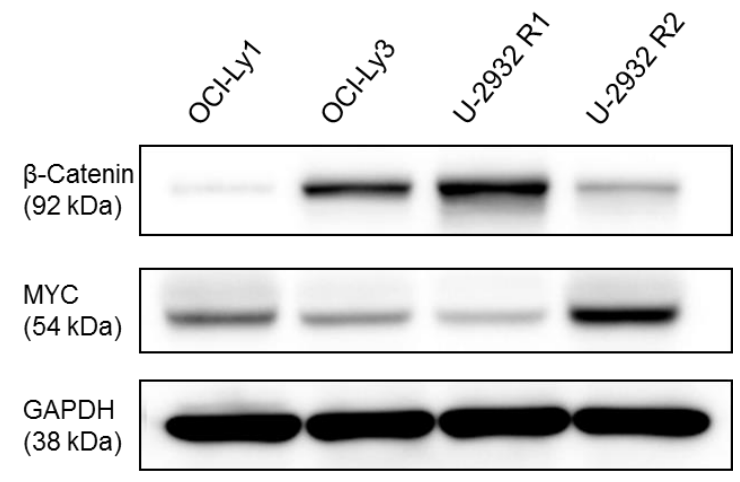

Abbildung 10: Zellulärer $\beta$-Catenin-Gehalt und Expression von MYC in Lymphomzelllinien. OCl-Ly3 sowie U-2932 $\mathrm{R} 1$ zeigten hohe $\beta$-Catenin- und niedrige MYC-Level, für OCl-Ly1 und U-2932 R2 konnte dagegen ein hoher MYC-Level bei geringem $\beta$-Catenin-Gehalt nachgewiesen werden.

OCl-Ly3 zeigt keine Translokation oder genomische Amplifikation des Protoonkogens MYC, während OCl-Ly1 eine Amplifikation von MYC besitzt (Mehra et al. 2002). Entsprechend zeigte sich im Westernblot ein hoher MYCLevel für OCI-Ly1. Der Klon R1 der Zelllinie U-2932 wies einen geringen MYCLevel auf, wohingegen der Klon R2, für den die Translokation $t(8 ; 14)(q 24 ; q 32)$ beschrieben worden ist (Quentmeier et al. 2013), einen hohen MYC-Gehalt zeigte. 


\begin{tabular}{|l|c|c|c|c|}
\hline \multicolumn{1}{|c|}{ Zelllinie } & OCl-Ly1 & OCl-Ly3 & U-2932 R1 & U-2932 R2 \\
\hline $\boldsymbol{\beta}$-Catenin-Gehalt & niedrig & hoch & hoch & niedrig \\
\hline MYC-Translokation & - & - & - & $\mathrm{t}(8 ; 14)$ \\
\hline MYC-Amplifikation & + & - & - & - \\
\hline
\end{tabular}

Tabelle 7: Charakteristika von DLBCL-Zelllinien.

\subsubsection{Inhibition des Enzyms Tankyrase durch XAV939}

\subsubsection{Effekte der Wnt-Inhibition durch Stabilisierung des $\beta$-Catenin- Degradationskomplexes auf Klonogenität und Proliferation}

Zur Verifizierung des Inhibitionsmechanismus wurden mit XAV939 inkubierte Lymphomzellen der Zelllinien OCI-Ly3 und U-2932 mittels Westernblot (Kapitel 2.2.1) auf den zellulären $\beta$-Catenin-Gehalt sowie die Expression von MYC hin untersucht. Die Inkubation der Zellen erfolgte hierzu über $24 \mathrm{~h}$ in serumfreiem Medium.

In der Immundetektion zeigte sich für OCI-Ly3 nach Behandlung mit XAV939 ab einer Konzentration von $10 \mu \mathrm{M}$ eine konzentrationsabhängige Abnahme des $\beta$ Catenin-Gehalts. Eine noch deutlichere Abnahme war bei MYC zu verzeichnen. Bei einer Konzentration von $10 \mu \mathrm{M}$ XAV939 waren im Vergleich zur DMSOKontrolle nur noch $13,5 \%$ des Proteins vorhanden, ab $20 \mu \mathrm{M}$ war MYC nahezu nicht mehr nachweisbar. Für die Zelllinie U-2932 wurden die beiden Subpopulationen R1 und R2 separat untersucht. In behandelten Zellen des Subtyps R1 sank der MYC-Gehalt ab einer Konzentration von $10 \mu \mathrm{M}$ XAV939 deutlich, bei den mit XAV939 behandelten Zellen des Subtyps R2 konnte keine Veränderung nachgewiesen werden. 

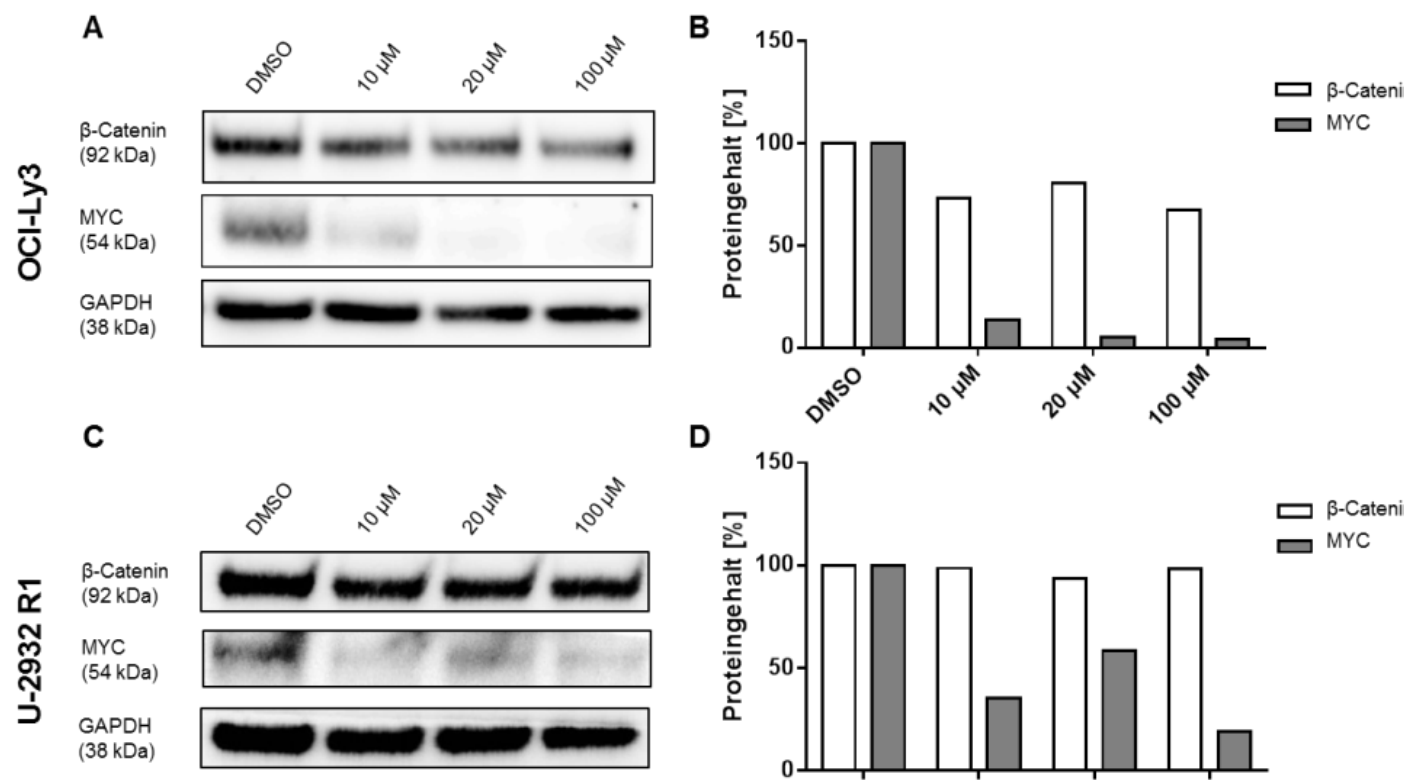

D
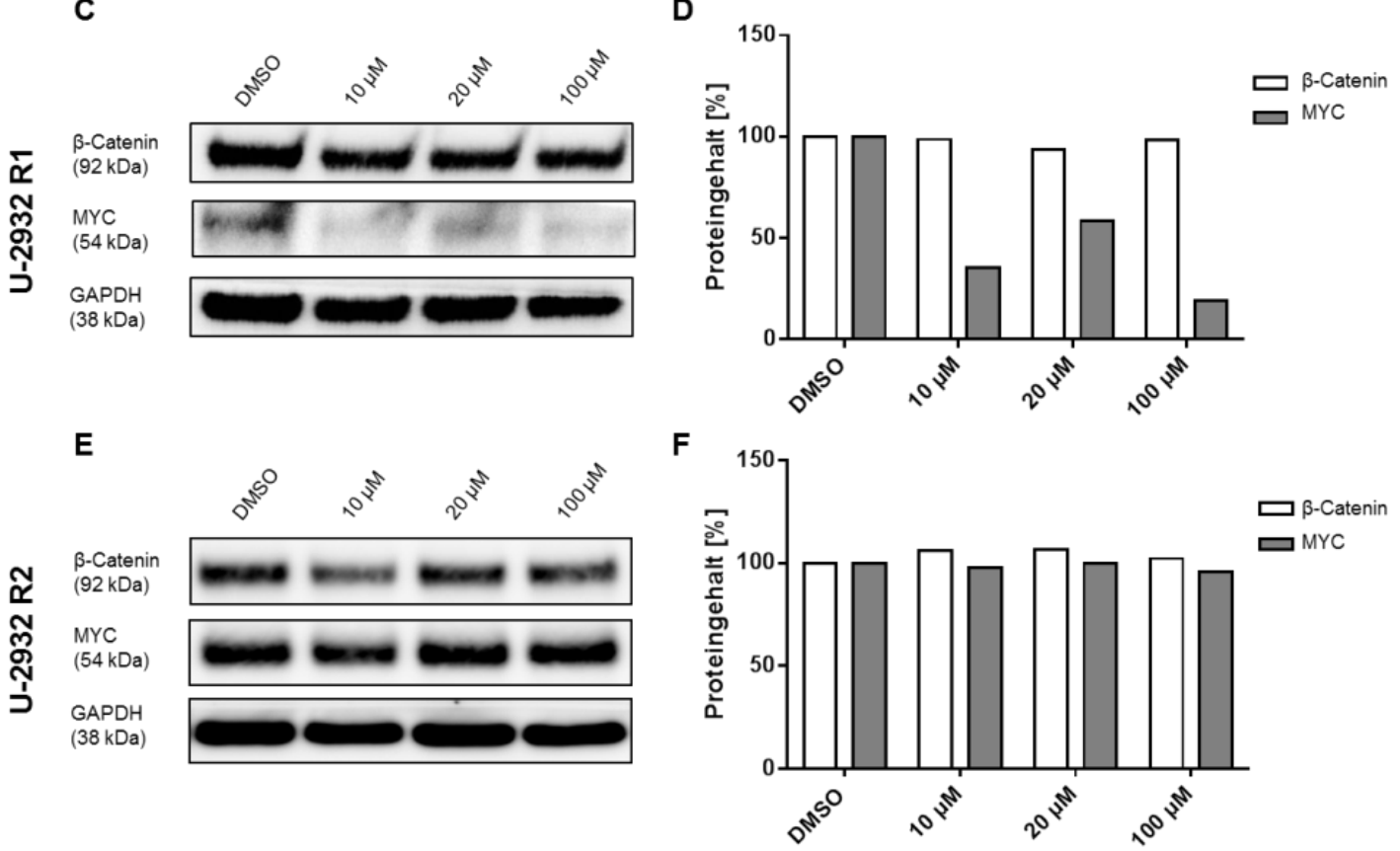

Abbildung 11: Westernblot mit XAV939 behandelter Zellen. A und B: OCl-Ly3. C und D: U-2932 R1. E und F: U-2932 R2. A, C und E: Immundetektion der Proteine $\beta$-Catenin und MYC. GAPDH diente als Ladekontrolle. B, D und F: Quantifizierung des $\beta$-Catenin- und MYC-Gehalts. Angaben in Prozent bezogen auf die DMSO-Kontrolle nach Normierung auf die jeweilige GAPDHBande. Das Protein MYC wurde in den Zelllinien OCI-Ly3 und U-2932 R1 nach Behandlung mit XAV939 weniger stark exprimiert. Eine Abnahme des zellulären $\beta$-Catenin-Gehalts ergab sich für die Zelllinie OCI-Ly3. Bei der Zelllinie U-2932 R2 führte XAV939 zu keiner Suppression von MYC.

Im Westernblot konnte damit gezeigt werden, dass XAV939 den Wnt-Signalweg in Lymphomzellen unterbrechen, aber bei Zellen, die eine MYC-Translokation aufweisen, keinen Einfluss auf die Expression von MYC ausüben kann.

Im nächsten Schritt wurden Klonogenitätsassays für die Zelllinie OCl-Ly3 durchgeführt, die Aufschluss darüber geben sollten, ob die Behandlung mit dem Inhibitor die Klonogenität einschränken oder sogar aufheben kann. Im Gegensatz zu den U-2932-Zelllinien, die bei Aussaat vereinzelter Zellen nicht in der Lage sind, autonom zu proliferieren, weist die Zelllinie OCI-Ly3 autonomes Wachstum 
einzelner Zellen mit Ausbildung von Kolonien auf. Die Durchführung des Experiments erfolgte wie in Kapitel 2.4.6 beschrieben. Bei einem einmaligen Zusatz von XAV939 in einer Konzentration von $10 \mu \mathrm{M}$ zu Zellen der Zelllinie OCILy3 ging die Anzahl an Kolonien auf $59 \%(p<0,001)$ und bei Gabe von $20 \mu \mathrm{M}$ auf $30 \%(p<0,0001)$ zurück.

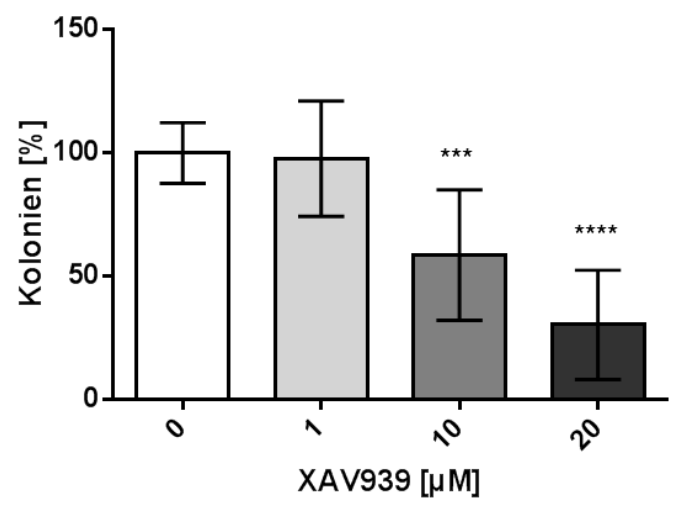

Abbildung 12: Klonogenitätsassay mit XAV939 behandelter Zellen der Zelllinie OCI-Ly3. Dargestellt sind Mittelwerte und Standardabweichungen von drei unabhängigen Ansätzen bezogen auf die DMSO-Kontrolle $(0 \mu \mathrm{M})$ in Prozent. Die Klonogenität einzeln ausgesäter Zellen wurde bereits durch die Behandlung mit XAV939 in einer Konzentration von $10 \mu \mathrm{M}$ signifikant vermindert. Unter $20 \mu \mathrm{M}$ konnten nur noch weniger als ein Drittel der Kolonien gezählt werden. Statistische Testung mittels One-way ANOVA $\left({ }^{* * *} p<0,001 ;{ }^{* * * *} p<0,0001\right)$.

Für Proliferationsanalysen bei Wnt-Inhibition durch XAV939 wurden nun die Zelllinie OCI-Ly3 sowie die Subtypen R1 und R2 der Zelllinie U-2932 mit der Substanz in einer Konzentration von bis zu $20 \mu \mathrm{M}$ behandelt. Dabei wurde die Proliferation nach 24, 48 und $72 \mathrm{~h}$ mittels MTS-Assays gemessen (Kapitel 2.4.5). Die Zelllinie OCI-Ly1 wurde zusätzlich als Negativkontrolle untersucht.

Für OCl-Ly3 zeigte sich nach einer Inkubation über $72 \mathrm{~h}$ mit XAV939 in einer Konzentration von $10 \mu \mathrm{M}$ eine signifikante Hemmung des Wachstums um $35 \%$ Punkte (Abb. 13, p<0,0001). Eine Steigerung der Konzentration auf $20 \mu \mathrm{M}$ XAV939 führte zu einem Einbruch des Wachstums um $42 \%$-Punkte ( $p<0,0001)$. Für die als Negativkontrolle eingesetzte Zelllinie OCI-Ly1 konnte keine signifikante Proliferationshemmung gemessen werden. 

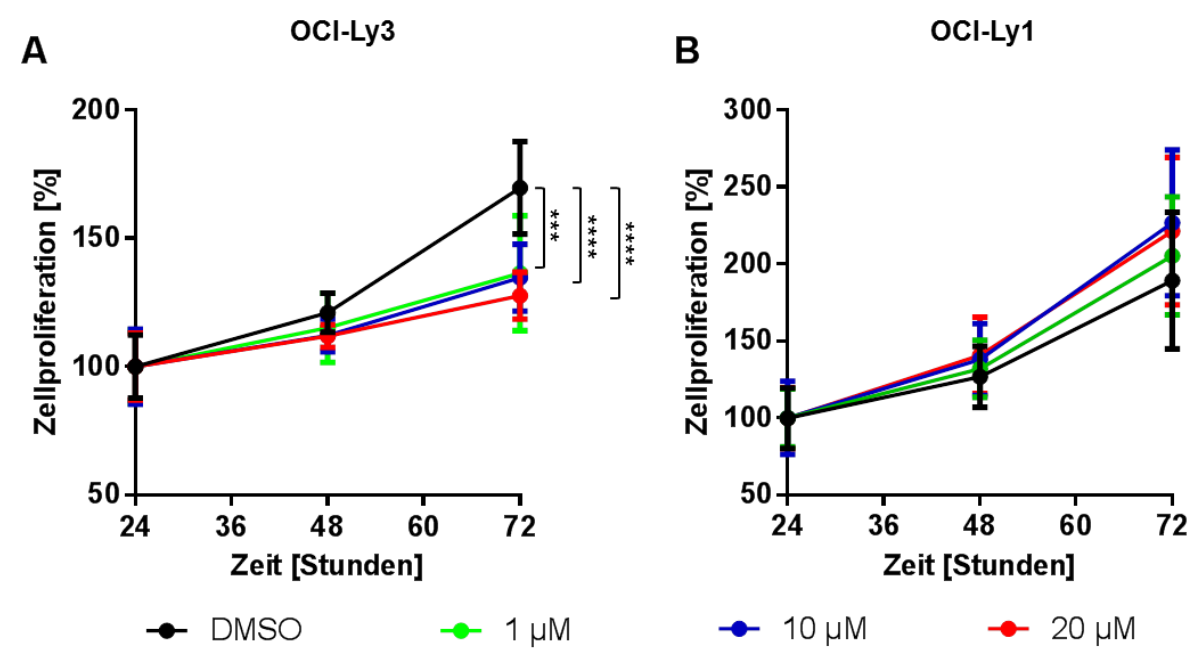

Abbildung 13: Zellwachstum von OCl-Ly3 (A) und OCl-Ly1 (B) unter Behandlung mit XAV939. DMSO diente als Kontrolle. XAV939 wurde in den Konzentrationen 1, 10 und $20 \mu \mathrm{M}$ eingesetzt. Dargestellt sind Mittelwerte und Standardabweichungen für $n=3$. Das Wachstum der Zelllinie OCI-Ly3 wurde für alle Konzentrationen von XAV939 signifikant gehemmt. OCI-Ly1 diente als Negativkontrolle. Statistische Auswertung mittels Two-way ANOVA (*** $p<0,001$; **** $p<0,0001)$.

Vergleicht man die erhobenen Proliferationsdaten für die Subpopulationen von U-2932, fällt auf, dass die Subpopulation R1 nach Behandlung mit XAV939 in einer Konzentration von $20 \mu \mathrm{M}$ ein vermindertes Wachstum zeigte, während der Inhibitor keinen Effekt auf Zellen der Subpopulation R2 besaß (Abb. 14).
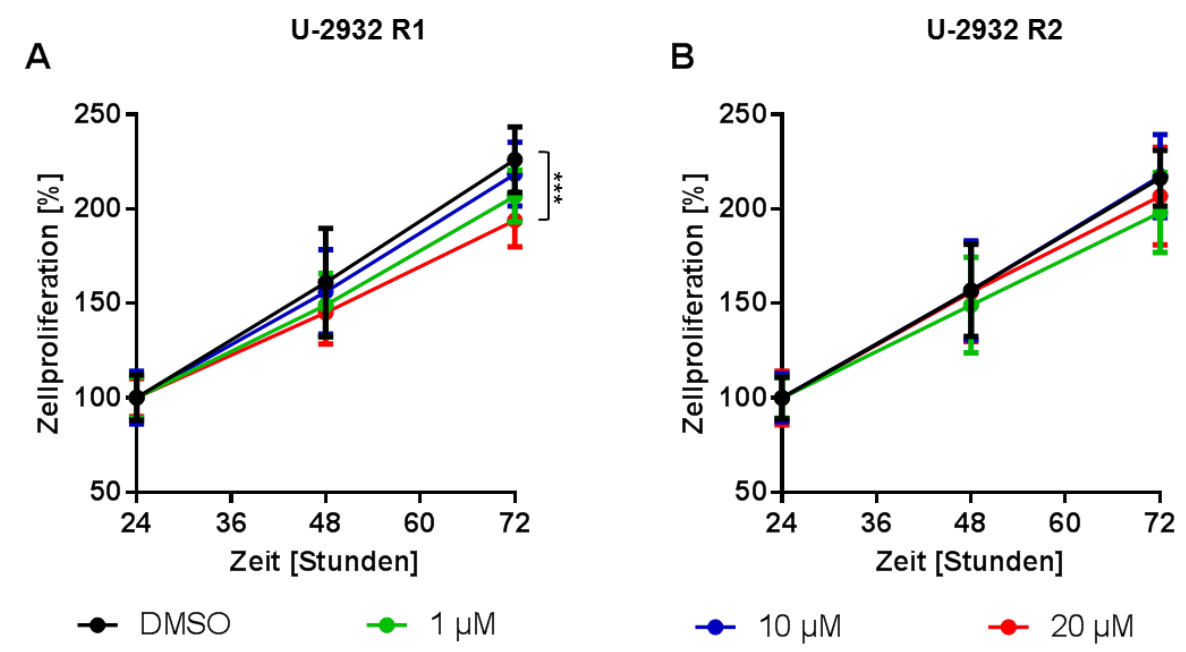

Abbildung 14: Zellwachstum von U-2932 R1 (A) und U-2932 R2 (B) unter Behandlung mit XAV939. DMSO diente als Kontrolle. XAV939 wurde in den Konzentrationen 1, 10 und $20 \mu \mathrm{M}$ eingesetzt. Dargestellt sind Mittelwerte und Standardabweichungen für $n=3$. Für Zellen des Subtyps R1 konnte eine Wachstumshemmung bei Behandlung mit $20 \mu \mathrm{M}$ XAV939 nachgewiesen werden. Statistische Auswertung mittels Two-way ANOVA $\left(^{* * *} p<0,001\right)$. 


\subsubsection{Zellzyklusanalyse unter XAV939}

Die Proliferationseigenschaften unter XAV939 wurden mittels Zellzyklusanalyse untersucht (Kapitel 2.4.7.4). Wurden die Zellen der Zelllinie OCI-Ly3 einmalig mit $10 \mu \mathrm{M}$ XAV939 behandelt, ließ sich nach 72-stündiger Inkubation ein um $6 \%$ Punkte erniedrigter Anteil der sich in der G0/G1-Phase befindlichen Zellpopulation nachweisen $(p<0,05)$. Dies entspricht etwa der Anteilssteigerung in der G2/MPhase, die jedoch ohne Signifikanz blieb. Der Anteil an Zellen in der S-Phase blieb dagegen sowohl über die Zeit als auch unter Behandlung konstant.

Für die Zelllinie U-2932 konnte eine signifikante Verschiebung von G0/G1 zu G2/M für R1 gemessen werden. Für R2 konnten keine Veränderungen in der Zellzyklusanalyse nachgewiesen werden.
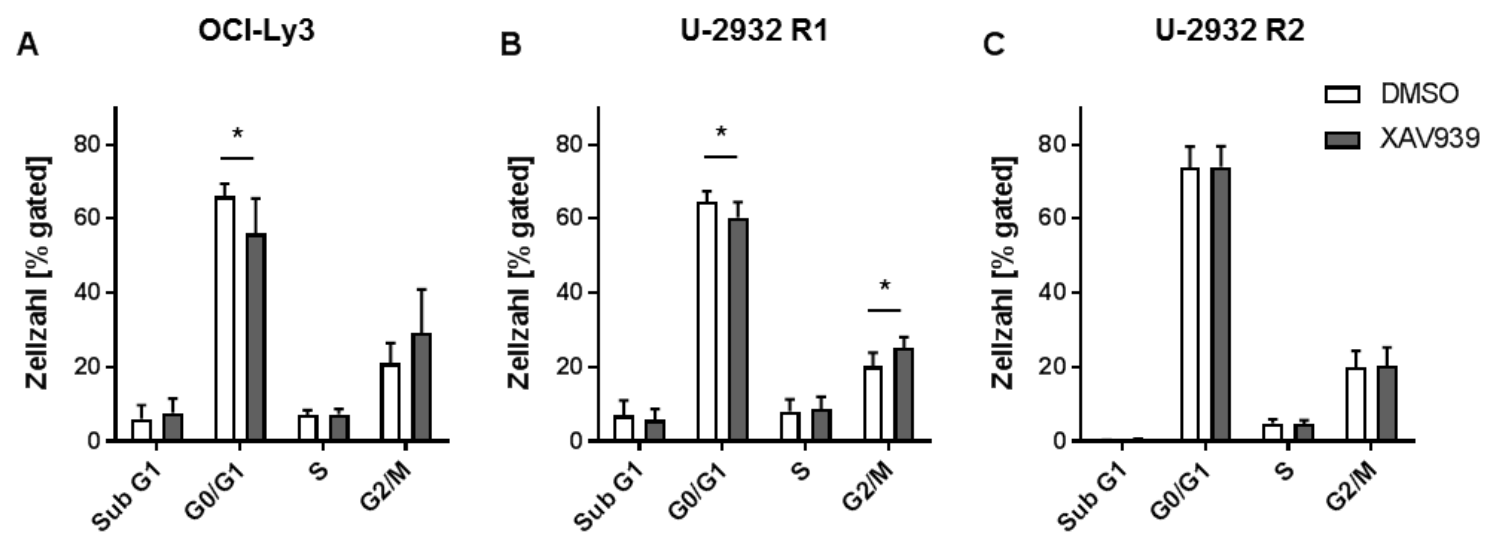

Abbildung 15: Zellzyklusmessung mittels Durchflusszytometrie für mit XAV939 behandelte Zellen. A: OCI-Ly3. B: U-2932 R1. C: U-2932 R2. XAV939 wurde in einer Konzentration von $10 \mu \mathrm{M}$ zu den Zellen gegeben, DMSO diente als Kontrolle. Dargestellt sind Mittelwerte und Standardabweichungen für $\mathrm{n}=3$ nach einer Inkubationszeit von $72 \mathrm{~h}$. Mit XAV939 behandelte U2932 R1-Zellen zeigten eine Populationsverschiebung von G0/G1 hin zu G2/M. Statistische Testung mittels One-way ANOVA (* $p<0,05)$.

\subsubsection{Inhibition des Enzyms Porcupine durch IWP-2 und C59}

\subsubsection{Effekte von IWP-2 und C59 auf Endabschnitt der Wnt-Signalkaskade}

Zunächst wurde der Wirkmechanismus der Porcupineinhibitoren untersucht. Wie zuvor bereits für XAV939 wurden mittels Westernblot die Proteine $\beta$-Catenin und MYC in Zelllysaten von mit IWP-2 und C59 behandelten Zellen bestimmt (Kapitel 2.2.1). Dazu wurden die Inhibitoren für $24 \mathrm{~h}$ in aufsteigenden Konzentrationen und unter serumfreien Wachstumsbedingungen zu Zellen der Zelllinien OCI-Ly3 und U-2932 gegeben. 
Die Immundetektion zeigte für IWP-2 in allen Konzentrationen einen konstant bleibenden zellulären $\beta$-Catenin-Gehalt sowohl bei OCl-Ly3 als auch bei U-2932 R1 und R2. Eine Veränderung ergab sich dagegen im Gehalt des Endstreckenproteins MYC (Abb. 16). Im Vergleich zur Kontrolle zeigte sich für OCl-Ly3 bei $25 \mu \mathrm{M}$ IWP-2 eine Abnahme der Proteinmenge auf $19 \%$. Auch schon $5 \mu \mathrm{M}$ ließen den MYC-Gehalt auf weniger als ein Drittel sinken. Die Zelllinie U-2932 R1 zeigte im Proteingehalt ebenfalls einen Abfall von 70-80 \% bei Behandlung mit IWP-2 in Konzentrationen zwischen 5 und $25 \mu \mathrm{M}$. U-2932 R2 erwies sich bezüglich des MYC-Gehalts als resistent.
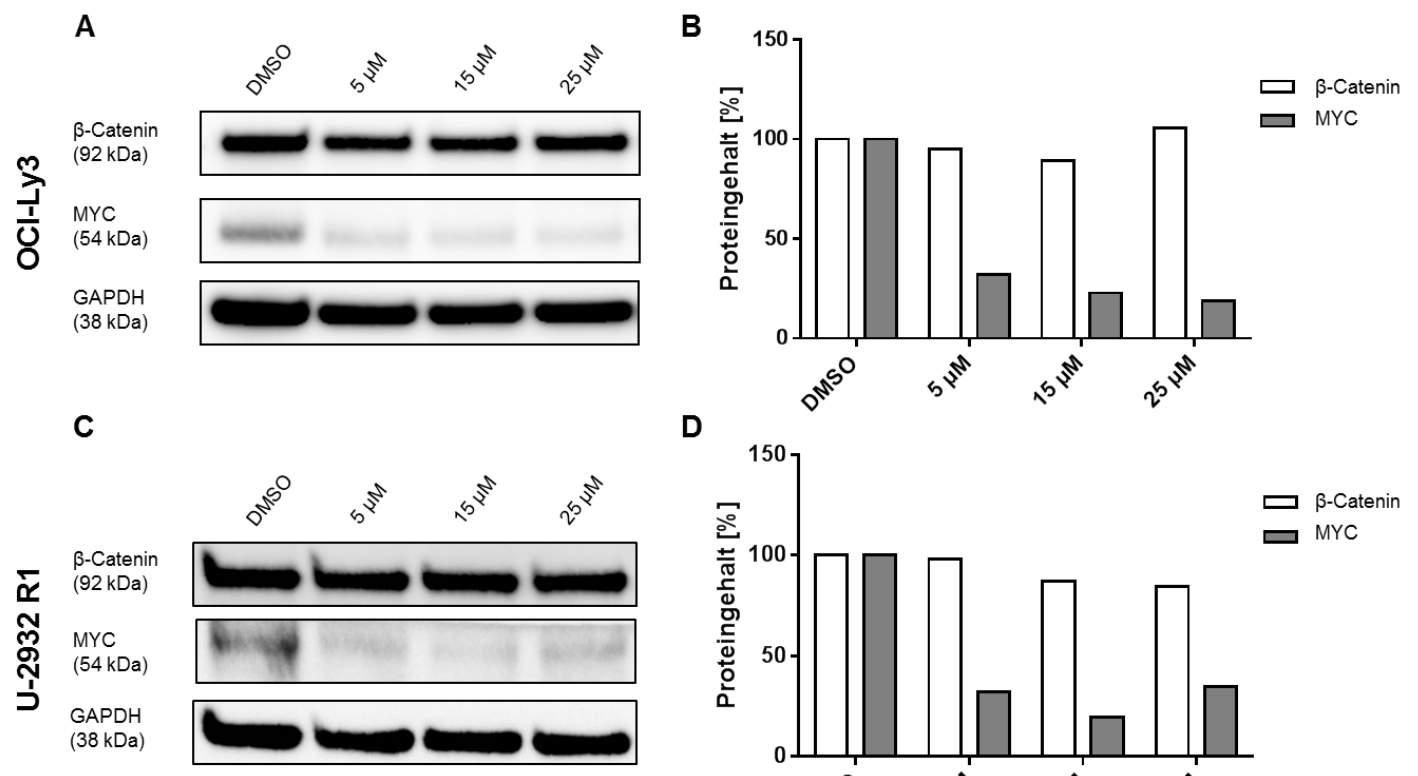

D
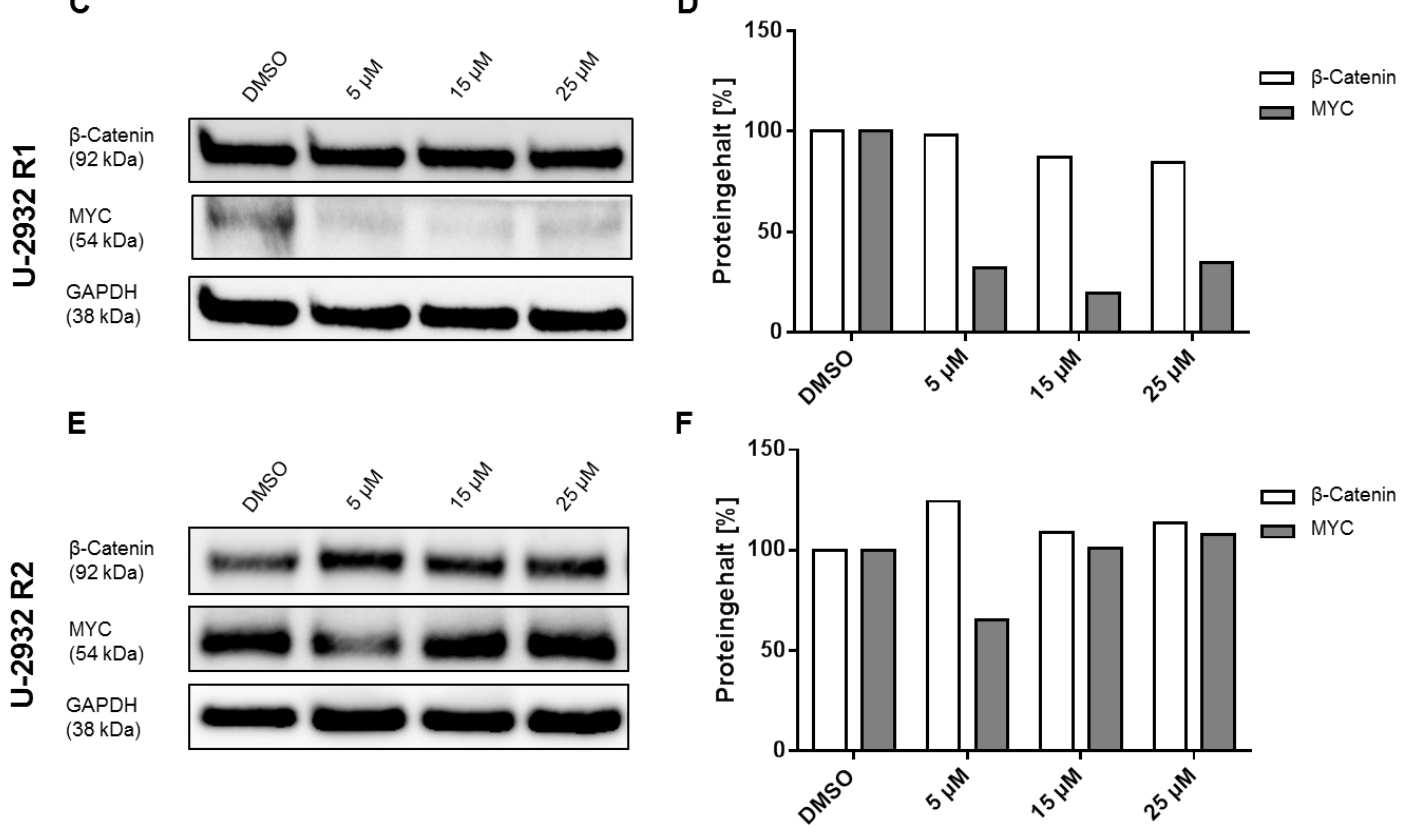

Abbildung 16: Westernblot mit IWP-2 behandelter Zellen. A und B: OCl-Ly3. C und D: U-2932 R1. E und F: U-2932 R2. A, C und E: Immundetektion der Proteine $\beta$-Catenin und MYC. GAPDH diente als Ladekontrolle. B, D und F: Quantifizierung des $\beta$-Catenin- und MYC-Gehalts. Angaben in Prozent bezogen auf die DMSO-Kontrolle nach Normierung auf die jeweilige GAPDH-Bande. Während der zelluläre $\beta$-Catenin-Gehalt in allen Zelllinien nahezu konstant blieb, konnte sowohl für OCl-Ly3 als auch für U-2932 R1 eine deutliche Abnahme des Gehalts von MYC detektiert werden. 
Mit C59 behandelte Zellen zeigten im Westernblot eine ähnliche Veränderung der Proteinmengen wie die mit IWP-2 behandelten Zellen: Der zelluläre $\beta$-CateninGehalt blieb nahezu konstant, wohingegen MYC bei den behandelten Zellen der Zellinien OCI-Ly3 und U-2932 R1 in geringerem Maße im Zelllysat detektierbar war (Abb. 17). Für OCl-Ly3 fiel im Vergleich zur Kontrolle der Gehalt auf ca. $60 \%$ bei mittleren Konzentrationen und bis auf $45 \%$ bei der maximal eingesetzten Konzentration von $5000 \mathrm{nM}$ C59. Bei U-2932 R1 war ebenfalls eine Abnahme zu messen. Bereits bei Zusatz von nur $100 \mathrm{nM}$ C59 sank die Proteinmenge um ein Drittel, bei 1000 nM um $44 \%$ und für die höchste Konzentration fiel MYC um mehr als $60 \%$. Im Gegensatz dazu hatte der Inhibitor C59 keinen Einfluss auf den MYC-Gehalt der Subpopulation R2.

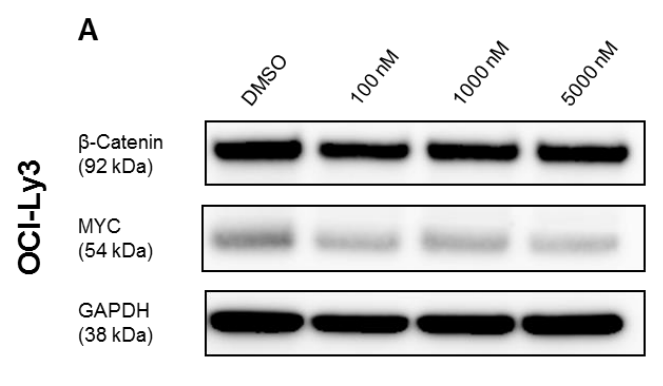

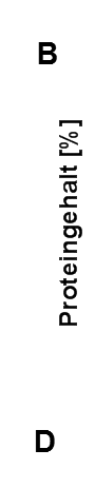
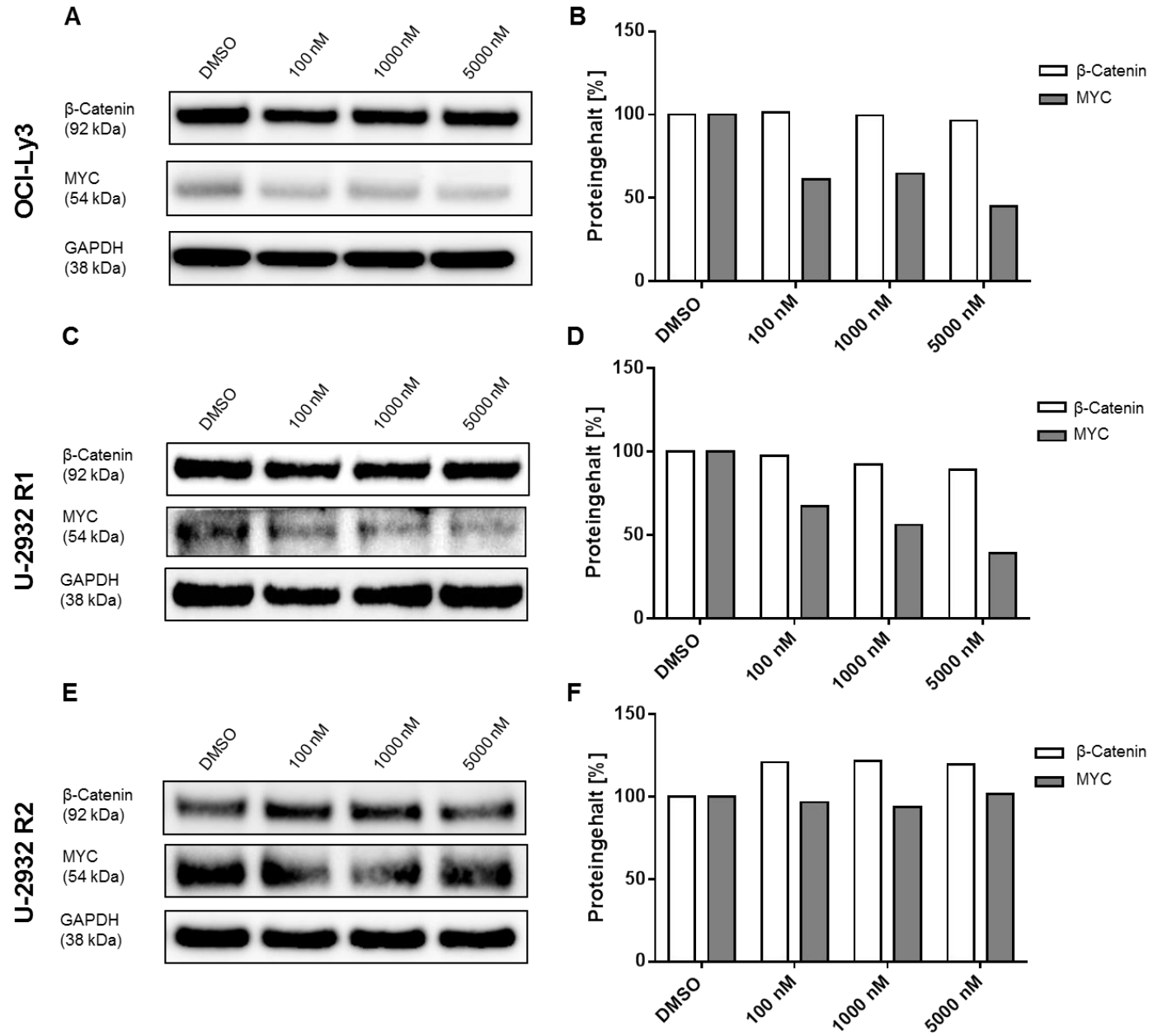

Abbildung 17: Westernblot mit C59 behandelter Zellen. A und B: OCl-Ly3. C und D: U-2932 R1. E und F: U-2932 R2. A, C und E: Immundetektion der Proteine $\beta$-Catenin und MYC. GAPDH diente als Ladekontrolle. B, D und F: Quantifizierung des $\beta$-Catenin- und MYC-Gehalts. Angaben in Prozent bezogen auf die DMSO-Kontrolle nach Normierung auf die jeweilige GAPDH-Bande. Mit aufsteigender Konzentration von C59 zeigten sich für OCI-Ly3 und U-2932 R1 ein konstanter $\beta$ Catenin- und ein abnehmender MYC-Gehalt. U-2932 R2 zeigte keine veränderten Proteinmengen. 


\subsubsection{Antiproliferative Effekte von IWP-2 auf Lymphomzellen}

Die erwarteten inhibitorischen Effekte von IWP-2 wurden an der Zelllinie OCl-Ly3 im Klonogenitätsassay untersucht. Hierzu wurden erneut Zellen ausgesät und einmalig mit dem Inhibitor behandelt (Kapitel 2.4.6). Hinsichtlich der Klonogenität ließ sich kein Effekt von IWP-2 nachweisen.

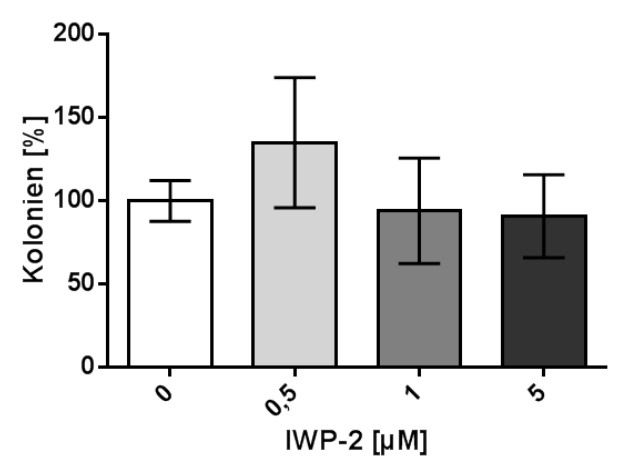

Abbildung 18: Klonogenitätsassay mit IWP-2 behandelter Zellen der Zelllinie OCI-Ly3. Abgebildet sind Mittelwerte und Standardabweichungen von drei unabhängigen Ansätzen bezogen auf die DMSO-Kontrolle $(0 \mu \mathrm{M})$. Es zeigte sich keine Einschränkung der Klonogenität. Statistische Auswertung mittels One-way ANOVA.

Im nächsten Schritt sollte das Zellwachstum unter Behandlung mit IWP-2 untersucht werden. Dazu wurden Zellen mit dem Inhibitor in aufsteigender Konzentration inkubiert und mittels MTS-Assay wurde das proliferative Verhalten analysiert (Kapitel 2.4.5). Dabei ergab sich, dass die Zelllinie OCI-Ly3 nach 72stündiger Behandlung mit IWP-2 in einer Konzentration von $20 \mu \mathrm{M}$ im Zellwachstum um 25\%-Punkte signifikant gehemmt wurde ( $p<0,001$, Abb. 19). Die erneut als Negativkontrolle dienende Zelllinie OCI-Ly1 zeigte keine signifikanten Veränderungen im Proliferationsverhalten. 

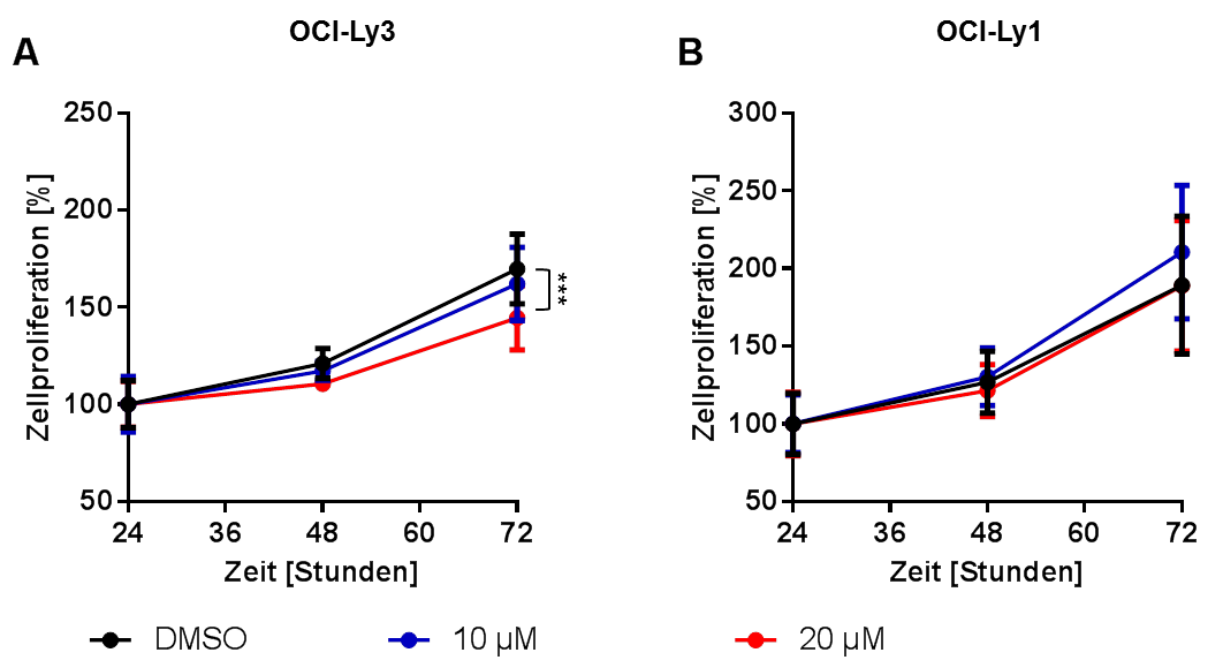

Abbildung 19: Zellwachstum von OCl-Ly3 (A) und OCl-Ly1 (B) unter Behandlung mit IWP-2. DMSO diente als Kontrolle. IWP-2 wurde in den Konzentrationen 10 und $20 \mu \mathrm{M}$ eingesetzt. Dargestellt sind Mittelwerte und Standardabweichungen für $n=3$. Das Wachstum von OCI-Ly3 war signifikant eingeschränkt. Statistische Auswertung mittels Two-way ANOVA ( $\left.{ }^{* \star *} p<0,001\right)$.

Für die Subpopulationen R1 und R2 der Zellinie U-2932 ergab die statistische Testung weder für $10 \mu \mathrm{M}$ noch $20 \mu \mathrm{M}$ IWP-2 eine signifikante Proliferationseinschränkung.

A

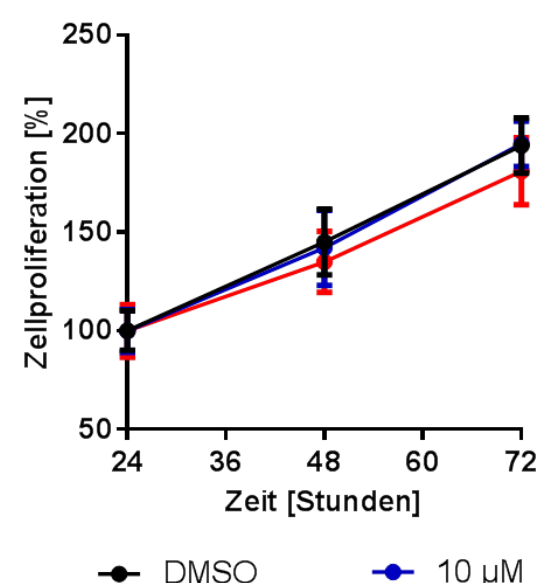

B

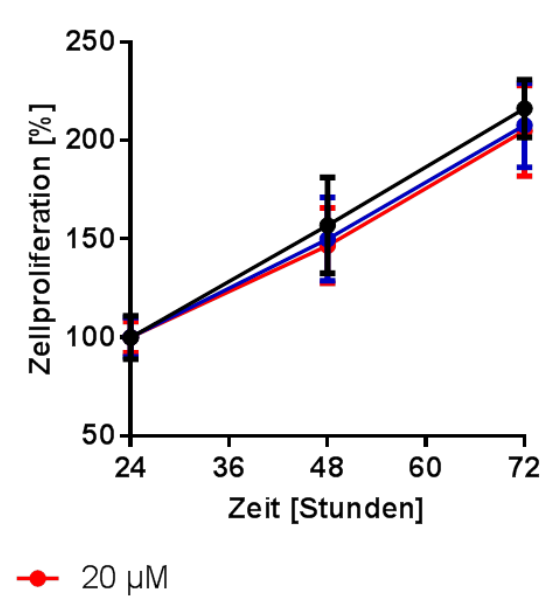

Abbildung 20: Zellwachstum von U-2932 R1 (A) und U-2932 R2 (B) unter Behandlung mit IWP-2. DMSO diente als Kontrolle. IWP-2 wurde in den Konzentrationen 10 und $20 \mu \mathrm{M}$ eingesetzt. Dargestellt sind Mittelwerte und Standardabweichungen für $n=3$. Eine Wachstumshemmung konnte für keine der beiden Zellpopulationen gemessen werden. Statistische Auswertung mittels Two-way ANOVA ergab keine signifikanten Differenzen. 


\subsubsection{Effekte von C59 auf Klonogenität und Zellproliferation}

Auch für den Inhibitor C59 wurden Klonogenität und Zellproliferation untersucht. Bei der Frage nach dem Einfluss auf die Klonogenität von Tumorzellen ergab sich, dass C59 in einer Konzentration von $1000 \mathrm{nM}$ in der Lage war, das Koloniewachstum von OCl-Ly3 um mehr als $50 \%$ zu mindern $(p<0,0001)$.

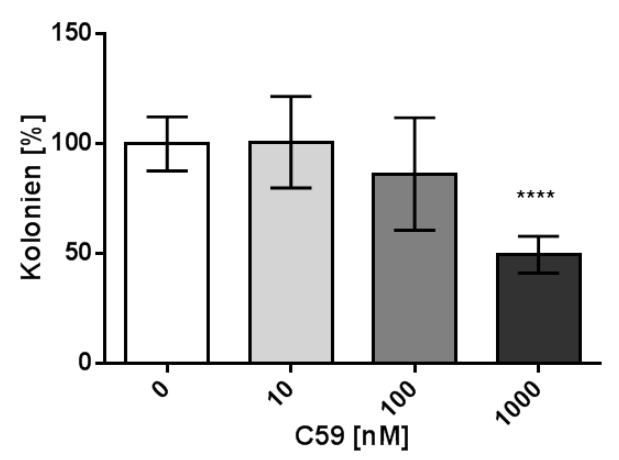

Abbildung 21: Klonogenitätsassay mit C59 behandelter Zellen der Zelllinie OCI-Ly3. Abgebildet sind Mittelwerte und Standardabweichungen von drei unabhängigen Ansätzen bezogen auf die DMSO-Kontrolle $(0 \mathrm{nM})$. Für die Konzentration von $1000 \mathrm{nM}$ wurde eine deutliche Reduktion der Kolonienzahl ermittelt. Statistische Auswertung mittels One-way ANOVA $\left({ }^{* * * *} p<0,0001\right)$.

Des Weiteren wurde auch die Effektivität des Inhibitors C59 in der Proliferationshemmung untersucht. Dazu wurden erneut Zellen mit C59 in Konzentrationen von 10 bis $1000 \mathrm{nM}$ inkubiert und nach 24, 48 und $72 \mathrm{~h}$ wurden MTS-Assays durchgeführt (Kapitel 2.4.5). OCl-Ly3 zeigte nach einer Inkubationszeit von $72 \mathrm{~h}$ eine signifikante Wachstumsinhibition von $37 \%$-Punkten $(p<0,05)$. Geringere Konzentrationen hatten keinen Einfluss auf das Zellwachstum. Die Negativkontrolle OCl-Ly1 zeigte kein verändertes Wachstumsverhalten unter dem Inhibitor. 
A

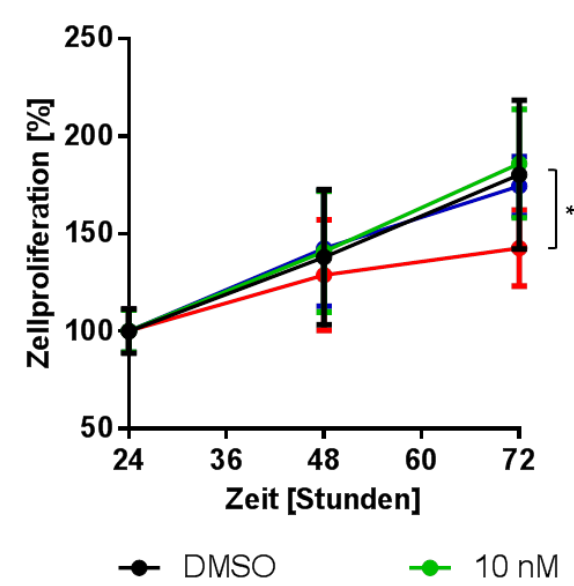

B

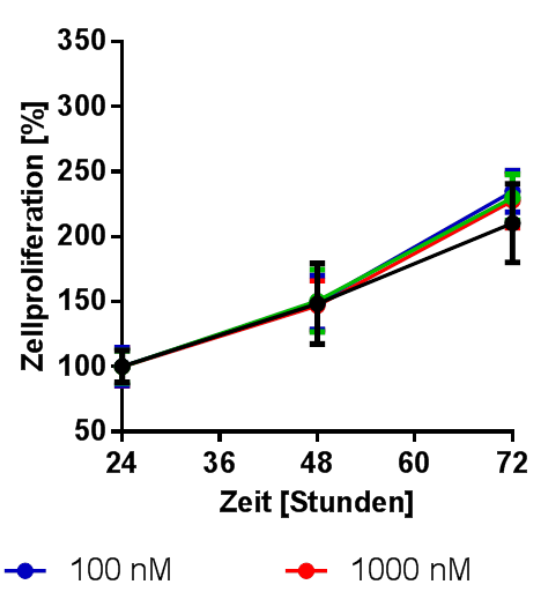

Abbildung 22: Zellwachstum von OCl-Ly3 (A) und OCI-Ly1 (B) unter Behandlung mit C59. DMSO diente als Kontrolle. C59 wurde in den Konzentrationen 10, 100 und 1000 nM eingesetzt. Dargestellt sind Mittelwerte und Standardabweichungen für $n=3$. Das Wachstum von OCl-Ly3 wurde unter $1000 \mathrm{nM}$ signifikant gehemmt. Mit C59 behandelte Zellen der Zellinie OCI-Ly1 konnten nicht beeinflusst werden. Statistische Auswertung mittels Two-way ANOVA ( $\left.{ }^{*} p<0,05\right)$.

Für die Zelllinie U-2932 erzielte die Inkubation mit C59 keine Effekte bezüglich der Zellproliferation (Abb. 23).

A

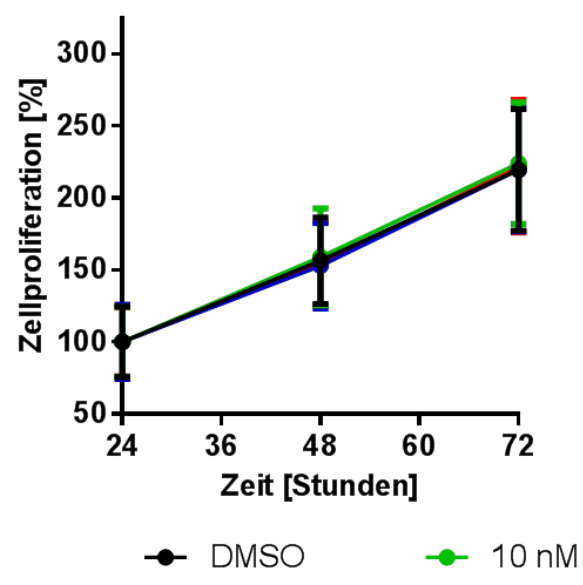

B

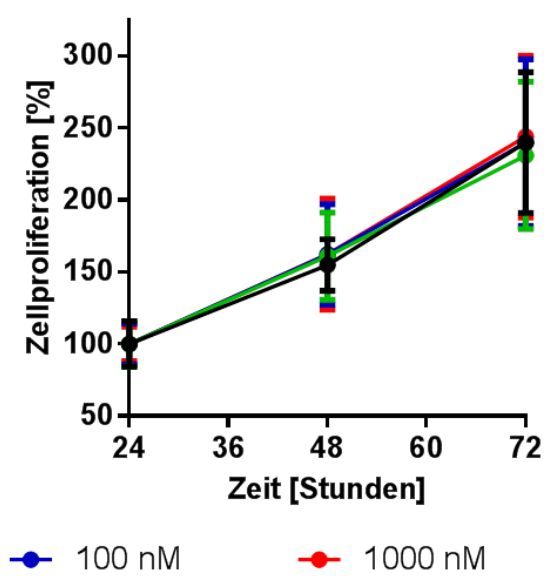

Abbildung 23: Zellwachstum von U-2932 R1 (A) und U-2932 R2 (B) unter Behandlung mit C59. DMSO diente als Kontrolle. C59 wurde in den Konzentrationen 10, 100 und $1000 \mathrm{nM}$ eingesetzt. Dargestellt sind Mittelwerte und Standardabweichungen für $n=3$. Die Zelllinien erwiesen sich als resistent. Statistische Auswertung mittels Two-way ANOVA ergab keine signifikanten Differenzen. 


\subsubsection{Einfluss von Porcupineinhibitoren auf die Zellzyklusprogression}

In Abbildung 24 sind jeweils drei unabhängige Messungen zur Zellzyklusbestimmung (Kapitel 2.4.7.4) für die Zelllinien OCl-Ly3 sowie U-2932 R1 und R2 dargestellt. Die Zellen wurden über $72 \mathrm{~h}$ mit dem Inhibitor IWP-2 in einer Konzentration von $20 \mu \mathrm{M}$ kultiviert. In der durchflusszytometrischen Bestimmung des Zellzyklus resultierten keine signifikanten Unterschiede zwischen dem Kontrollansatz und den behandelten Zellen für OCl-Ly3 und U-2932 R2, für die Subpopulation R1 ließ sich eine Abnahme der G0/G1-Population nachweisen.
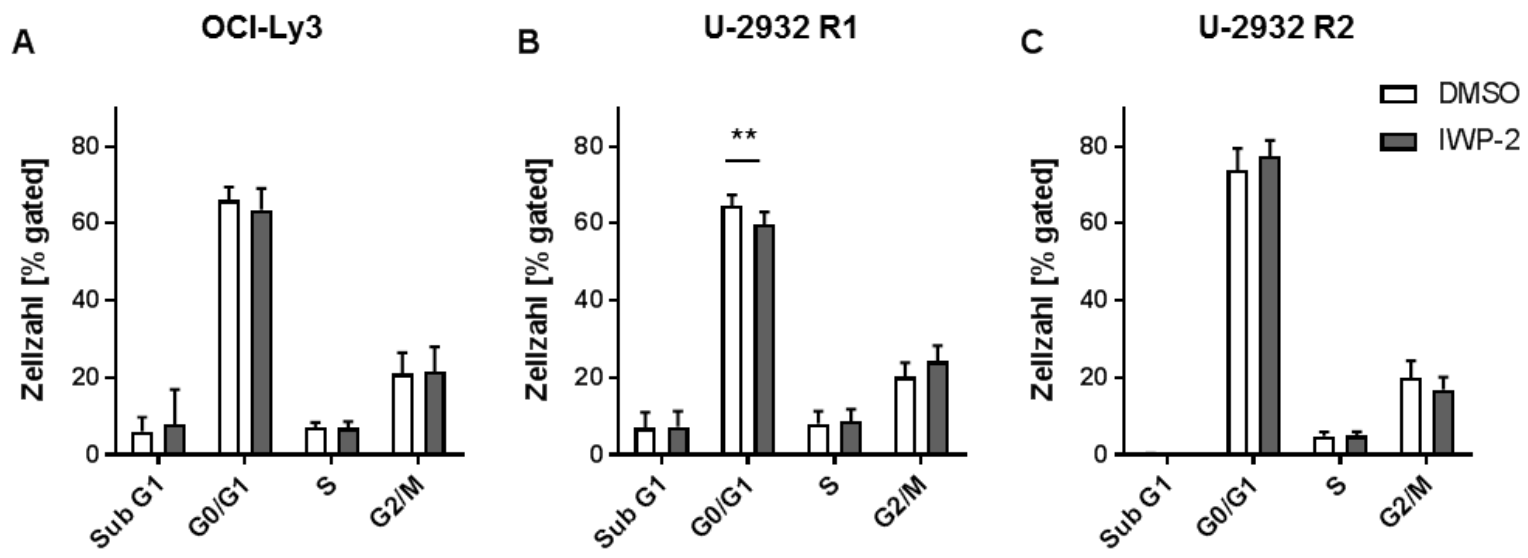

Abbildung 24: Zellzyklusmessung mittels Durchflusszytometrie für mit IWP-2 behandelte Zellen. A: OCI-Ly3. B: U-2932 R1. C: U-2932 R2. IWP-2 wurde in einer Konzentration von $20 \mu \mathrm{M}$ zu den Zellen gegeben, DMSO diente als Kontrolle. Dargestellt sind Mittelwerte und Standardabweichungen für $\mathrm{n}=3$ nach einer Inkubationszeit von $72 \mathrm{~h}$. In der statistischen Auswertung mittels One-way ANOVA ließen sich signifikante Differenzen für U-2932 R1 nachweisen ( ${ }^{* *} p<0,01$ ).

Abbildung 25 zeigt die Ergebnisse der Zellzyklusanalyse für die gleichen Zelllinien nach Inkubation mit C59 in einer Konzentration von $1000 \mathrm{nM}$ über $72 \mathrm{~h}$. Es ergaben sich keine Veränderungen in den Zellpopulationen. 
A

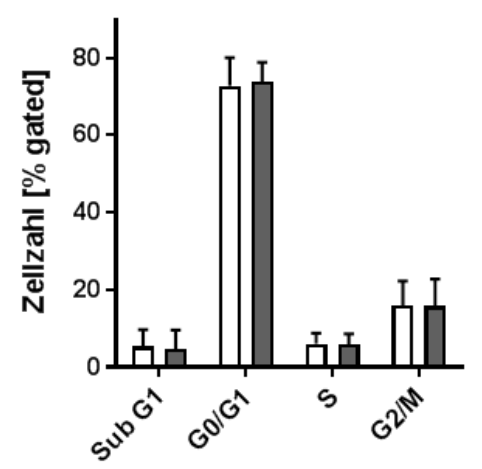

B

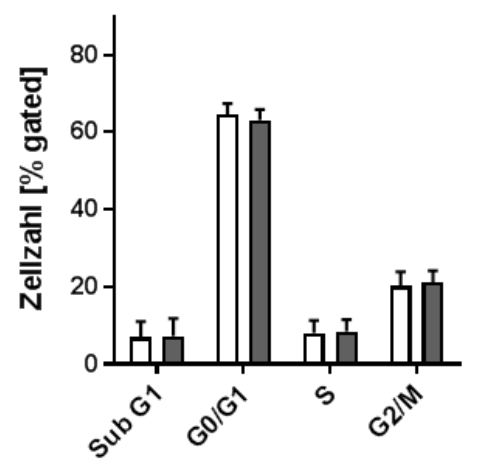

C

U-2932 R2

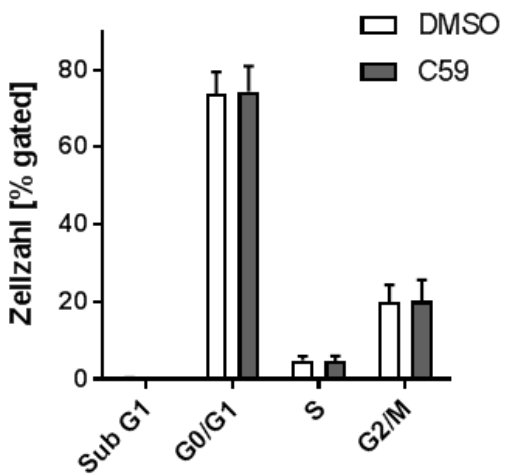

Abbildung 25: Zellzyklusmessung mittels Durchflusszytometrie für mit C59 behandelte Zellen. A: OCl-Ly3. B: U-2932 R1. C: U-2932 R2. C59 wurde in einer Konzentration von 1000 nM zu den Zellen gegeben, DMSO diente als Kontrolle. Dargestellt sind Mittelwerte und Standardabweichungen für $n=3$ nach einer Inkubationszeit von $72 \mathrm{~h}$. Statistische Auswertung mittels One-way ANOVA ergab keine signifikanten Differenzen.

\subsection{UM206 als Wnt-Antagonist in Lymphomzelllinien}

In dieser Arbeit sollte mechanistisch durch Quantifizierung des zellulären $\beta$ Catenin-Gehalts und der Expression von MYC analysiert werden, inwieweit die Gabe von UM206 auch in Lymphomen antagonistische Effekte zeigt. Funktionell wurde UM206 in vitro mittels Wachstums- und Zellzyklusanalysen sowie Klonogenitätsassays untersucht.

\subsubsection{Expression von Frizzled-1 und Frizzled-2 auf Lymphomzelllinien}

Als Nachweis der Expression der Frizzledrezeptoren 1 und 2 auf Lymphomzelllinien wurden zunächst verschiedene Zelllinien mittels Westernblot (Kapitel 2.2.1) untersucht und dabei eine heterogene Expression der Proteine auf den Zelllinien detektiert. HeLa-Zellen dienten als Positivkontrolle.

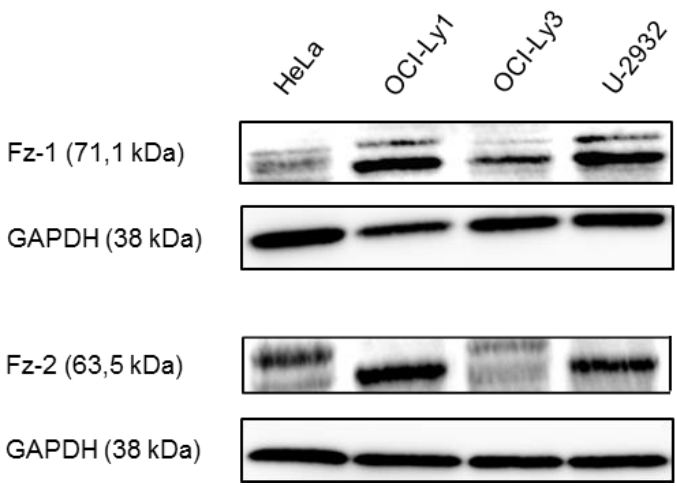

Abbildung 26: Expression von Frizzled-1 und -2 auf Lymphomzelllinien. Frizzled-1 und -2 werden heterogen auf DLBCLZelllinien exprimiert. Doppelbanden sind durch Glykosylierung der Proteine bedingt. 
Die getesteten Zelllinien exprimierten die Frizzledrezeptoren mäßig bis stark. Im Vergleich konnten bei OCI-Ly1 und U-2932 hohe Expressionsniveaus von Frizzled-1 und -2 detektiert werden, während OCl-Ly3 ein mittleres Expressionsniveau zeigte.

Für diese drei Zelllinien wurden die Frizzledrezeptoren 1 und 2 zusätzlich in der Durchflusszytometrie analysiert (Kapitel 2.4.7.1). Die gemessenen Fluoreszenzintensitäten der zu bestimmenden Proben wurden mit dem Signal der Kontrolle verglichen (Tabelle 8). Die Ergebnisse zeigen, dass sich die Frizzledrezeptorexpression auch in der Durchflusszytometrie erfassen lässt.

\begin{tabular}{|l|l|l|l|}
\hline Zelllinie & Frizzledrezeptor & $\begin{array}{c}\text { Mittlere relative } \\
\text { Fluoreszenzintensität }\end{array}$ & Standardabweichung \\
\hline OCl-Ly1 & Fz-1 & $472 \%$ & 3,16 \\
\hline & Fz-2 & $315 \%$ & 1,65 \\
\hline OCl-Ly3 & Fz-1 & $195 \%$ & 0,70 \\
\hline & Fz-2 & $202 \%$ & 1,42 \\
\hline U-2932 & Fz-1 & $224 \%$ & 0,70 \\
\hline & Fz-2 & $144 \%$ & 0,36 \\
\hline
\end{tabular}

Tabelle 8: Durchflusszytometrische Analyse der Expression von Frizzled-1 und -2 auf Lymphomzelllinien.

\subsubsection{Effekte von UM206 auf die Zellproliferation in Abhängigkeit von Umgebungsfaktoren}

Wie bereits ausgeführt, ist der Wnt-Signalweg u. a. für die Regulation von Wachstumsprozessen von Bedeutung. Um das Wachstumsverhalten von Lymphomzelllinien unter Einfluss von UM206 zu analysieren, wurden Zellen der Zelllinien OCI-Ly3 und U-2932 für 24 und $48 \mathrm{~h}$ mit dem Peptid inkubiert und mittels MTS-Assay analysiert (Kapitel 2.4.5). Da die Arbeitsgruppe um Laeremans Proliferationsanalysen unter reduzierten Wachstumsbedingungen durchgeführt hat, wurden auch in dieser Arbeit Analysen sowohl unter optimalen Wachstumsbedingungen als auch unter serumfreien Bedingungen vorgenommen. Zusätzlich wurde das Peptid dabei in linearer und geknickter Struktur verwendet. Letztere wird durch eine durch Oxidation des Moleküls entstehende Disulfidbrücke hervorgerufen und inhibiert die biologische Aktivität der Substanz (Laeremans et al. 2011). 
Wurden die Zellen in serumfreiem Panserin kultiviert, konnte nach $24 \mathrm{~h}$ für Zellen der Zelllinie OCI-Ly3, die mit UM206 in linearer Form behandelt worden waren, im Vergleich zur Kontrolle eine signifikante Proliferationshemmung um $11 \%$ erzielt werden (Abb. 27, $p<0,001$ ). Dagegen ergaben die Proliferationsanalysen nach $48 \mathrm{~h}$ sowie die Messungen zu beiden Zeitpunkten unter serumhaltigen Bedingungen nach statistischer Testung mittels One-Way ANOVA weder einen Inhibitions- noch einen Stimulationseffekt. UM206 mit ausgebildeter Disulfidbrücke (in Abb. 27 als S-S bezeichnet) beeinflusste das Wachstum nicht. Für die Zelllinie U-2932 konnte unter serumfreien Bedingungen nach 24 h Inkubation mit UM206 in linearer Struktur eine Proliferationshemmung um $20 \%$ erreicht werden $(p<0,001)$, Inkubation der Zellen mit dem geknickten Peptid inhibierte die Proliferation um $13 \%(p<0,05)$. Nach $48 \mathrm{~h}$ war keine Veränderung im Wachstumsverhalten nachweisbar. Unter serumhaltigen Wachstumsbedingungen zeigten sich sowohl nach 24 als auch nach $48 \mathrm{~h}$ statistisch signifikante Differenzen im Wachstum von weniger als $10 \%$.
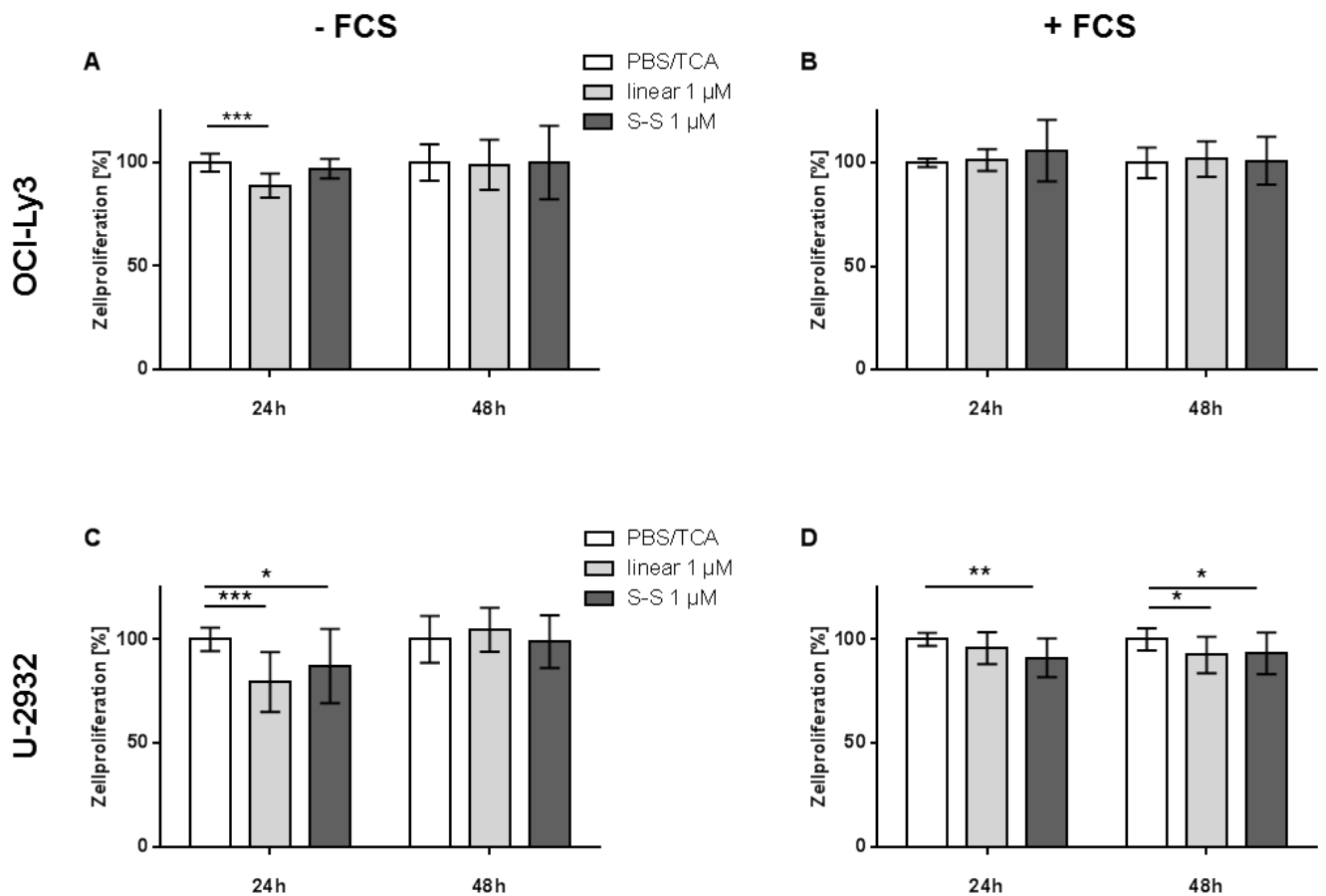

\begin{abstract}
Abbildung 27: Proliferationsanalyse der Zelllinien OCl-Ly3 (A und B) und U-2932 (C und D) unter Behandlung mit UM206. A und C: serumfreie Wachstumsbedingungen. B und D: serumhaltige Wachstumsbedingungen. Dargestellt sind Mittelwerte und Standardabweichungen der Zellproliferation nach 24- bzw. 48-stündiger Inkubation mit UM206 für $n=3$ in Prozent. PBS $/$ TCA $=0,1 \%$ Trichloressigsäure in PBS. S-S = Disulfidform von UM206. Auswertungen mittels One-way ANOVA $\left({ }^{*} p<0,05 ;{ }^{* *} p<0,01 ;{ }^{* \star *} p<0,001\right)$.
\end{abstract}


Bisher wurde lediglich gezeigt, dass die Inkubation mit UM206 das Wachstum von Lymphomzellen inhibieren kann. Um die Inhibition des Wnt-Signalwegs durch UM206 zu verifizieren, wurden Zellen der Zellinien OCI-Ly3 und U-2932 mit UM206 in einer Konzentration von $1 \mu \mathrm{M}$ serumfrei über $24 \mathrm{~h}$ behandelt, anschließend lysiert und die downstream-Proteine $\beta$-Catenin und MYC mittels Immunreaktion detektiert (Kapitel 2.2.1). Es ließ sich keine Änderung des Proteingehalts feststellen.

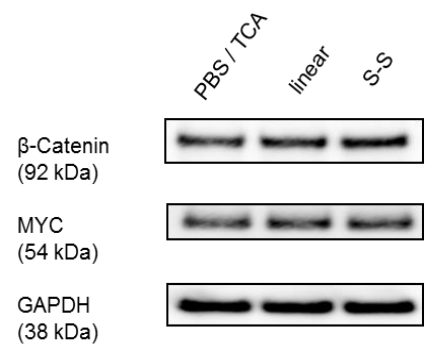

OCl-Ly3

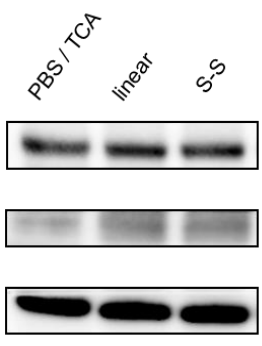

U-2932
Abbildung 28: Westernblot nach 24stündiger Inkubation mit UM206. Ladungskontrolle: GAPDH. S-S = Disulfidform von UM206. Beide Zelllinien zeigten keine Veränderung in der Expression von $\beta$-Catenin oder MYC. Auf eine Quantifizierung der Ergebnisse wurde daher verzichtet.

Des Weiteren wurden Zellzyklusanalysen durchgeführt, um das Verhalten der Zelle unter UM206 zu beobachten. Dazu wurden Zellen der Zelllinien OCI-Ly3 und U-2932 erneut mit dem Peptid inkubiert, mit dem DNA-Farbstoff Hoechst 33342 angefärbt und anschließend im Durchflusszytometer detektiert (Kapitel 2.4.7.4). Abbildung 29 zeigt, dass das Zellzyklusverhalten durch die Behandlung mit UM206 nach 24 h für die getesteten Zelllinien unverändert blieb. 

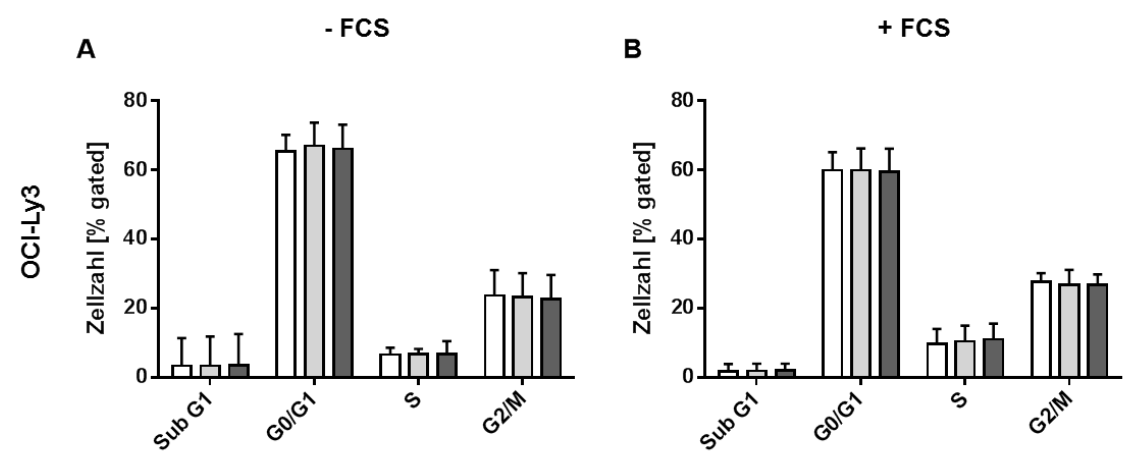

C

D
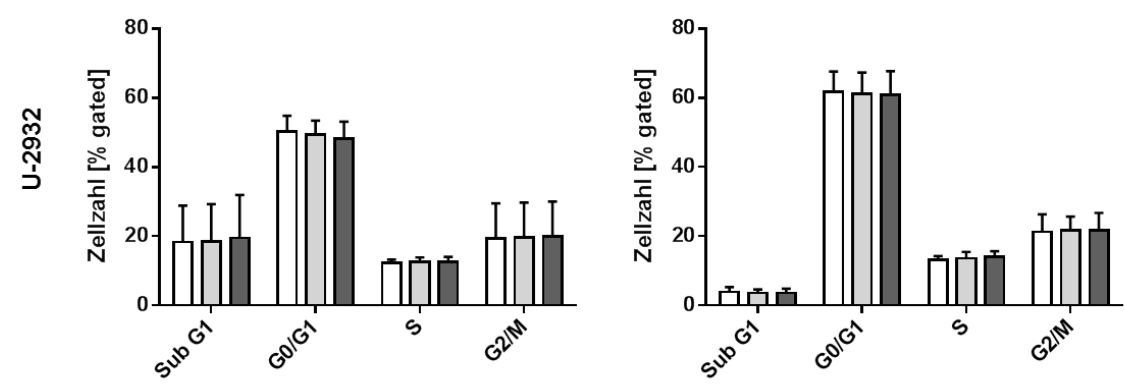

$\square$ PBS/TCA $\square$ linear $1 \mu \mathrm{M} \square \mathrm{S}-\mathrm{S} 1 \mu \mathrm{M}$

Abbildung 29: Zellzyklusanalyse nach Inkubation mit UM206. A und B: OCl-Ly3. C und D: U2932. A und C: serumfreie Wachstumsbedingungen. B und D: serumhaltige Wachstumsbedingungen. Dargestellt sind Mittelwerte und Standardabweichungen für $n=3$. Das Peptid UM206 wurde sowohl in linearer als auch geknickter Form in einer Konzentration von je $1 \mu \mathrm{M}$ eingesetzt. Statistische Testung mittels One-way ANOVA ergab keine signifikanten Differenzen.

\subsubsection{Effekte von UM206 auf die Klonogenität von Lymphomzellen}

Um eine Aussage über das klonale Verhalten der Zelllinie OCI-Ly3 unter UM206 treffen zu können, wurden Zellen unter Zusatz des Peptids sowohl in linearer als auch in oxidierter Form in Konzentrationen von 10 bis $1000 \mathrm{nM}$ in Methylcellulose ausplattiert (Kapitel 2.4.6). Die Mittelwerte und Standardabweichungen aus drei Wiederholungen des Experiments sind in Abbildung 30 dargestellt. Es lässt sich aufgrund streuender Messwerte keine eindeutige Aussage über die Wirkung von UM206 auf das klonale Verhalten von Zellen treffen.

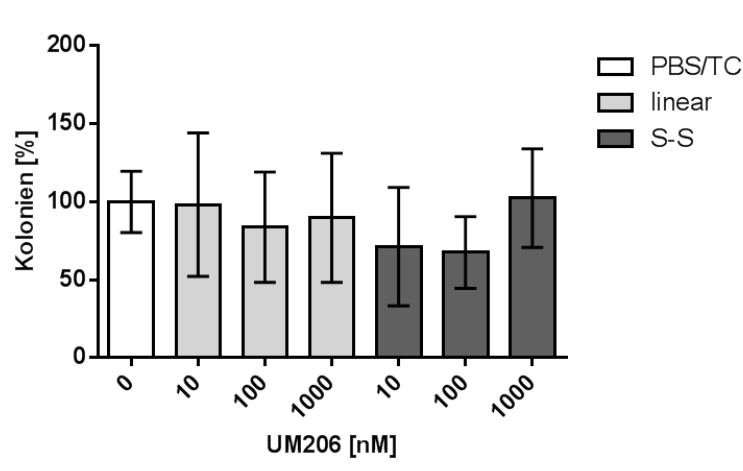

Abbildung 30: Klonogenitätsassay mit UM206 behandelter Zellen der Zelllinie OCI-Ly3. Dargestellt sind Mittelwerte und Standardabweichungen von drei unabhängigen Ansätzen bezogen auf die Kontrolle in Prozent. Die Mittelwerte bewegten sich zwischen 70 und $100 \%$. Statistische Testung mittels One-way ANOVA, keine signifikanten Differenzen nachweisbar. 


\subsubsection{Expression von Frizzled-4 und Frizzled-5 auf Lymphomzelllinien}

Um zu analysieren, warum UM206 in Lymphomzelllinien keine relevante Inhibition des kanonischen Wnt-Signalwegs erzielen konnte, wurden die Zellen mittels Westernblot auf die Expression von Frizzled-4 und -5 hin untersucht. Von Laeremans et al. wurde gezeigt, dass UM206 auch an diese Rezeptoren binden, jedoch keine Aktivitätsunterdrückung bewirken kann (Laeremans et al. 2011).

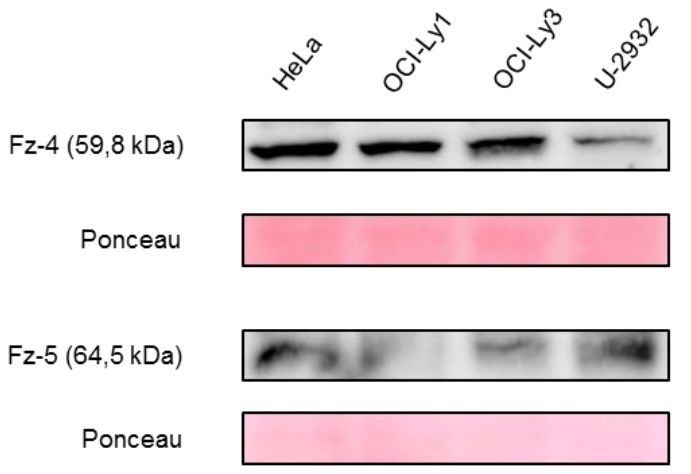
Abbildung 31: Expression von Frizzled-4 und $\mathbf{- 5}$ auf Lymphomzelllinien. Ebenso wie die Proteine Frizzled-1 und -2 konnten auch die Proteine Frizzled-4 und -5 auf allen Zelllinien detektiert werden.

OCl-Ly1 und OCl-Ly3 zeigten ein deutlich höheres Expressionsniveau für Frizzled-4 als U-2932. Bei Frizzled-5 verhielt es sich nahezu reziprok: U-2932 zeigte die stärkste Expression, OCI-Ly1 und OCI-Ly3 mäßige Niveaus.

Ebenso wie für Frizzled-1 und -2 wurden auch für Frizzled-4 und -5 Analysen in der Durchflusszytometrie für die genannten Zelllinien durchgeführt. In Tabelle 9 sind die mittleren Fluoreszenzintensitäten in Bezug auf die Kontrolle aufgeführt. OCl-Ly1 zeigt im Vergleich zu den beiden anderen Zelllinien die stärkste Expression der Rezeptoren. Insgesamt waren die Intensitäten für Frizzled-4 und -5 stärker als die gemessenen Signale für Frizzled-1 und -2.

\begin{tabular}{|l|l|l|l|}
\hline Zelllinie & Frizzledrezeptor & $\begin{array}{c}\text { Mittlere relative } \\
\text { Fluoreszenzintensität }\end{array}$ & Standardabweichung \\
\hline OCI-Ly1 & Fz-4 & $1005 \%$ & 2,13 \\
\hline & Fz-5 & $895 \%$ & 5,66 \\
\hline OCl-Ly3 & Fz-4 & $562 \%$ & 2,86 \\
\hline & Fz-5 & $307 \%$ & 1,25 \\
\hline U-2932 & Fz-4 & $522 \%$ & 2,07 \\
\hline & Fz-5 & $328 \%$ & 0,58 \\
\hline
\end{tabular}

Tabelle 9: Durchflusszytometrische Analyse der Expression von Frizzled-4 und -5 auf Lymphomzelllinien. 


\subsubsection{Blockade von Frizzled-1, -2, -4 und -5 durch UM206 und Effekte auf die Proteinexpression der Zelle}

Nachdem sich eine starke Expression von Frizzled-4 und -5 auf Lymphomzelllinien gezeigt hatte, sollte nun untersucht werden, ob das Peptid UM206 an diese Rezeptoren binden kann. Dazu wurden die Rezeptoren von Lymphomzellen nach kurzer Inkubation mit UM206 erneut mittels Durchflusszytometrie detektiert. Zusätzlich wurde untersucht, ob die Zellen nach 24-stündiger Inkubation ein verändertes Proteinmuster zeigten. Bei beiden Experimenten wurde ein indirektes Nachweisverfahren genutzt, indem zum einen die Signalstärke fluoreszenzmarkierter Frizzledrezeptoren von nicht behandelten Zellen und zum anderen die Signalstärke der Rezeptoren von mit UM206 behandelten Zellen detektiert wurde (Kapitel 2.4.7.2). Bei letzteren wurde eine geringere Signalintensität erwartet, sofern die Antikörperbindungsstellen zuvor durch UM206 blockiert werden konnten. Für die Experimente wurden die Zelllinien OCI-Ly1 und OCI-Ly3 ausgewählt.
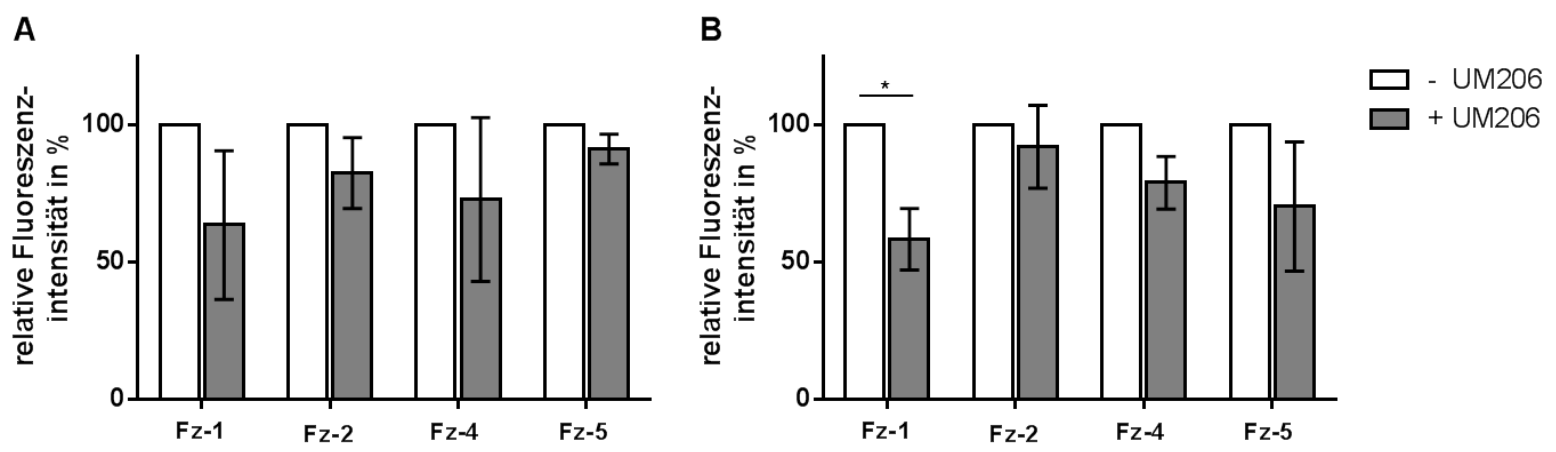

Abbildung 32: Expression von Frizzled-1, -2, -4 und -5 auf OCl-Ly1 und OCl-Ly3 nach einstündiger Inkubation mit UM206. A: OCI-Ly1. B: OCI-Ly3. Dargestellt sind mittlere relative Fluoreszenzintensitäten von mit UM206 behandelten Zellen in Prozent bezogen auf die Kontrolle. Als Kontrolle diente die Signalintensität von unbehandelten Zellproben. Diese wurde für jede individuelle Messung gleich $100 \%$ gesetzt. Aus den ermittelten Fluoreszenzwerten der behandelten Zellen wurden der Mittelwert und die Standardabweichung gebildet $(n=3)$. Nach einstündiger Inkubation mit UM206 konnten die hier untersuchten Frizzledrezeptoren nur noch in vermindertem Maße detektiert werden. Statistische Auswertung mittels One-way ANOVA $\left({ }^{*} p<0,05\right)$.

Es ließ sich zeigen, dass nach einstündiger Inkubation mit UM206 die Frizzledrezeptoren auf der Zelloberfläche im Vergleich zur Oberfläche von unbehandelten Zellen in geringerem Maße detektierbar waren (Abb. 32). In der statistischen Auswertung mittels One-way ANOVA zeigte sich bei der Zelllinie OCl-Ly3 die 
größte Differenz für Frizzled-1 mit einer signifikanten Signalabnahme von über $40 \% \quad(p<0,05)$, gefolgt von Frizzled-5 mit einer Abnahme von $30 \%$, hier allerdings ohne nachweisbare Signifikanz. Bei OCl-Ly1 konnte keine signifikante Abnahme des Fluoreszenzsignals nachgewiesen werden, jedoch lässt sich eine ähnliche Tendenz erkennen.

Im nächsten Schritt sollte analysiert werden, ob sich das Rezeptormuster der Zelle durch die Behandlung mit UM206 verändert. Dazu wurde das Experiment mit einer 24-stündigen Inkubationszeit wiederholt.
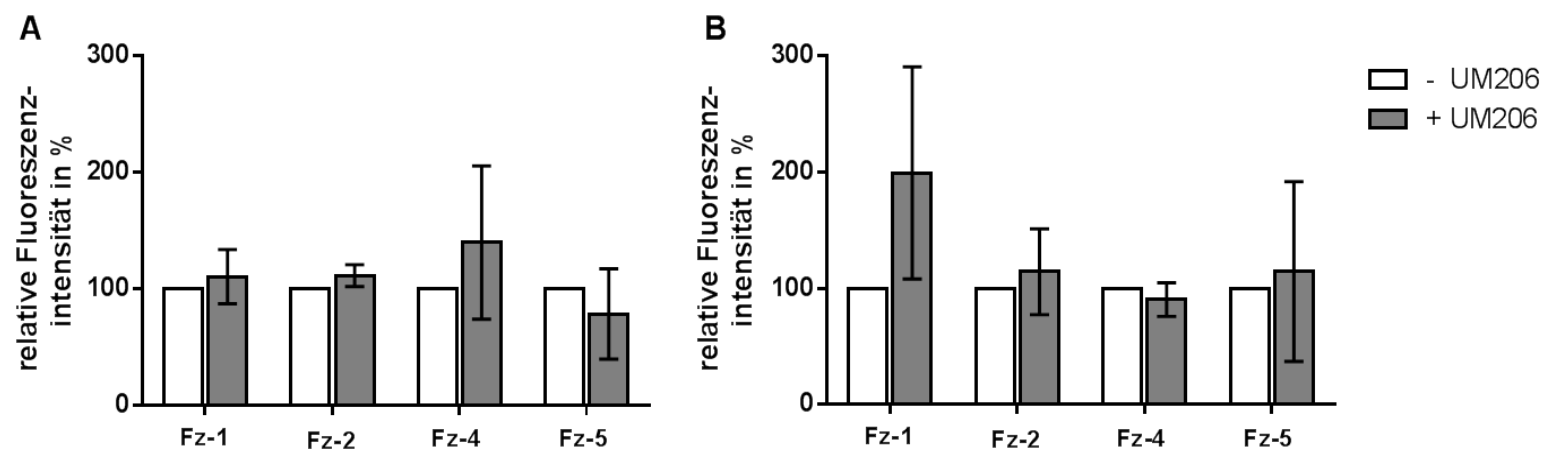

Abbildung 33: Expression von Frizzled-1, -2, -4 und -5 auf OCl-Ly1 und OCl-Ly3 nach 24-stündiger Inkubation mit UM206. A: OCI-Ly1. B: OCI-Ly3. Dargestellt sind mittlere relative Fluoreszenzintensitäten von mit UM206 behandelten Zellen in Prozent bezogen auf die Kontrolle. Als Kontrolle diente die Signalintensität von unbehandelten Zellproben. Diese wurde für jede individuelle Messung gleich $100 \%$ gesetzt. Aus den ermittelten Fluoreszenzwerten der behandelten Zellen wurden der Mittelwert und die Standardabweichung gebildet $(n=3)$. Nach 24stündiger Inkubation mit UM206 konnten die hier untersuchten Frizzledrezeptoren im Vergleich zur Kontrolle wieder in gleichem Maße oder verstärkt detektiert werden. In der statistischen Auswertung mittels One-way ANOVA konnten keine signifikanten Differenzen nachgewiesen werden.

Die Messungen zeigten, dass alle gemessenen Frizzledrezeptortypen auf behandelten Zellen nach $24 \mathrm{~h}$ mindestens das Niveau der unbehandelten Zellen erreicht haben (Abb. 33). Bei der Zelllinie OCl-Ly3 zeigte sich für Frizzled-1 und bei der Zelllinie OCI-Ly1 für Frizzled-4 eine Zunahme des Fluoreszenzsignals über das Expressionsniveau der unbehandelten Zellen hinaus, die allerdings in der One-way ANOVA nicht statistisch signifikant ausfiel. Vergleicht man die nach $1 \mathrm{~h}$ gemessenen Werte mit den Werten nach $24 \mathrm{~h}$, zeigt sich für Frizzled-1 eine signifikante Zunahme der Rezeptorexpression bei OCI-Ly3 ( $<<0,05)$. 


\subsection{Akkumulation von sFRP4 im Lymphom}

In Vorarbeiten der Arbeitsgruppe konnte gezeigt werden, dass die Expression von sFRP4 in Side-Population-Zellen von DLBCL-Zelllinien durch Hypermethylierung supprimiert ist und SFRP4 durch Antagonisierung kanonischen Wnt-Signalwegs die Proliferation und Klonogenität von DLBCL-Zellen inhibiert. Daher sollte nun sFRP4 an $\mathrm{F}_{\mathrm{ab}}$-Fragmente des CD20-Antikörpers Rituximab gekoppelt und somit über ein SFRP4-Fab-CD20-Konjugat eine Akkumulation von SFRP4 im Lymphomgewebe erzielt werden, um so eine effektive Wnt-Inhibition erreichen zu können.

\subsubsection{Herstellung eines Fusionsproteins aus sFRP4 und Rituximab- $\mathrm{F}_{a b^{-}}$ Fragmenten}

Für die Fusion wurden die antigenbindenden Anteile von Rituximab benötigt, sodass in einem ersten Schritt Rituximab durch Papain in seine Fragmente zerlegt wurde. Dazu wurde wie in Kapitel 2.2.4.1 beschrieben vorgegangen. Bei Papain handelt es sich um eine Thiolprotease, welche Immunglobuline $G$ in der HingeRegion spaltet. Entsprechend entstehen aus einem $\lg G$ ein $F_{c^{-}}$und $z w e i F_{a b}$ Fragmente. Während des Experiments wurden zu mehreren Zeitpunkten Proben entnommen und für eine SDS-Page mit anschließender Coomassiefärbung verwendet (Kapitel 2.2.1.3 und 2.2.3). Nach Papainverdau konnten in den Waschfraktionen die einzelnen Bestandteile von Rituximab nachgewiesen werden. Die Bestandteile wurden mittels einer Proteinsäule aufgetrennt, sodass letztlich isolierte $F_{a b}$-Fragmente in den Durchlauffraktionen 1 und 2 sowie übrige Bestandteile in den Auswaschfraktionen 3 und 4 detektiert werden konnten (Abb. $34)$. 
A

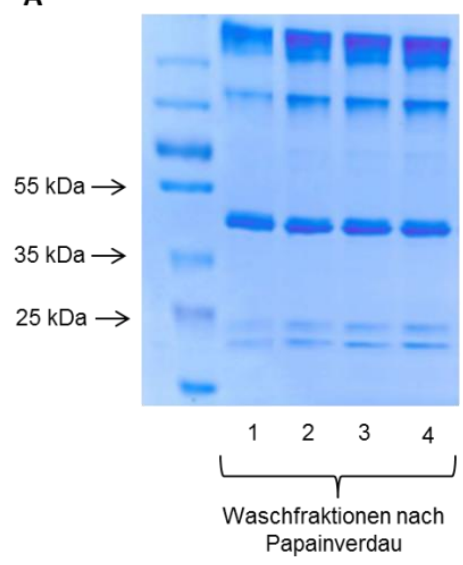

B

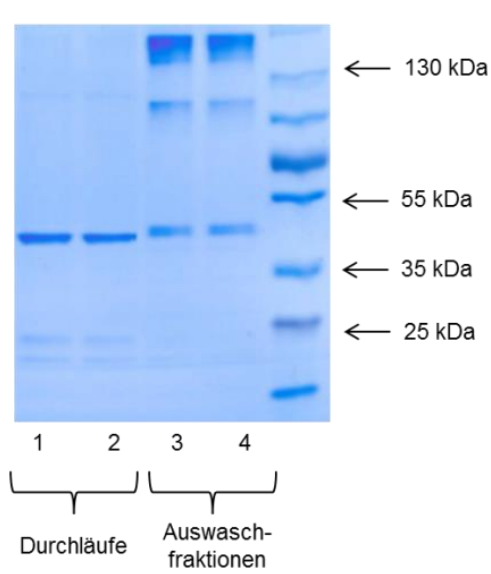

Abbildung 34: Coomassie-Färbung der Fragmentierung von Rituximab. A: Proben der vier Waschfraktionen nach Proteinverdau, aber vor Auftrennung des Gemisches. B: Ergebnis nach Auftrennung. Für die Auftrennung wurden die Waschfraktionen 1 und 2 zusammengefügt und durch das IgG- bzw. $F_{c}$-bindende Protein aufgetrennt. Ebenso wurde mit den Waschfraktionen 3 und 4 verfahren. In den Durchlauffraktionen (1 und 2) konnten isolierte $F_{a b}$-Fragmente (50 kDa), in den Auswaschfraktionen ( 3 und 4) nicht verdaute $\operatorname{lgG}$ (150 kDa), schwere Ketten (100 kDa) und $\mathrm{F}_{\mathrm{c}^{-}}$ Fragmente $(50 \mathrm{kDa})$ detektiert werden. Eine Doppelbande im Bereich von $25 \mathrm{kDa}$ wurde durch einzelne leichte Ketten hervorgerufen.

Die somit erfolgreich isolierten $\mathrm{F}_{\mathrm{ab}}$-Fragmente wurden in einem weiteren Schritt mit rekombinantem sFRP4 verlinkt (Kapitel 2.2.4.2). Dabei entstand aus sFRP4 und dem Linkermolekül Succinimidyl-4-formyl-benzamid ein stabiler aromatischer Aldehyd und aus $F_{a b}$-Molekülen und dem Linker Succinimidyl-6-hydrazinnikotinamid ein stabiles aromatisches Hydrazin. Über Aldehyd und Hydrazin konnte wiederum eine Brücke in Form eines Hydrazons ausgebildet werden.

Um mittels Immundetektion das Ergebnis der Fusion zu analysieren, aber die reduzierenden Bedingungen einer SDS-Page zu umgehen, wurde ein Dotblot angefertigt (Kapitel 2.2.2). Dazu wurden sowohl das Fusionsprodukt (SFRP4-FabCD20) als auch die Edukte in Verdünnungsschritten auf vier Nitrocellulosemembranen aufgetragen und immunologisch detektiert. Die Inkubation mit den dabei eingesetzten sekundären Antikörpern diente der Überprüfung unspezifischer Bindung dieser Antikörper an die aufgetragenen Proteine. Die mit anti-sFRP4 inkubierte Membran ergab sowohl für die Positivkontrolle als auch für die Zeile des Fusionsproduktes ein Signal (Abb. 35). In Zusammenschau mit der Kontrollmembran ist das positive Ergebnis in der $F_{a b}$-Zeile auf den sekundären Antikörper (anti-goat) zurückzuführen. Nach Inkubation mit anti-Fab-Rituximab 
ließen sich Signale in der Positivkontrolle ( $F_{a b}$-Fragmente) und ebenfalls in der Zeile des Fusionsproduktes detektieren.

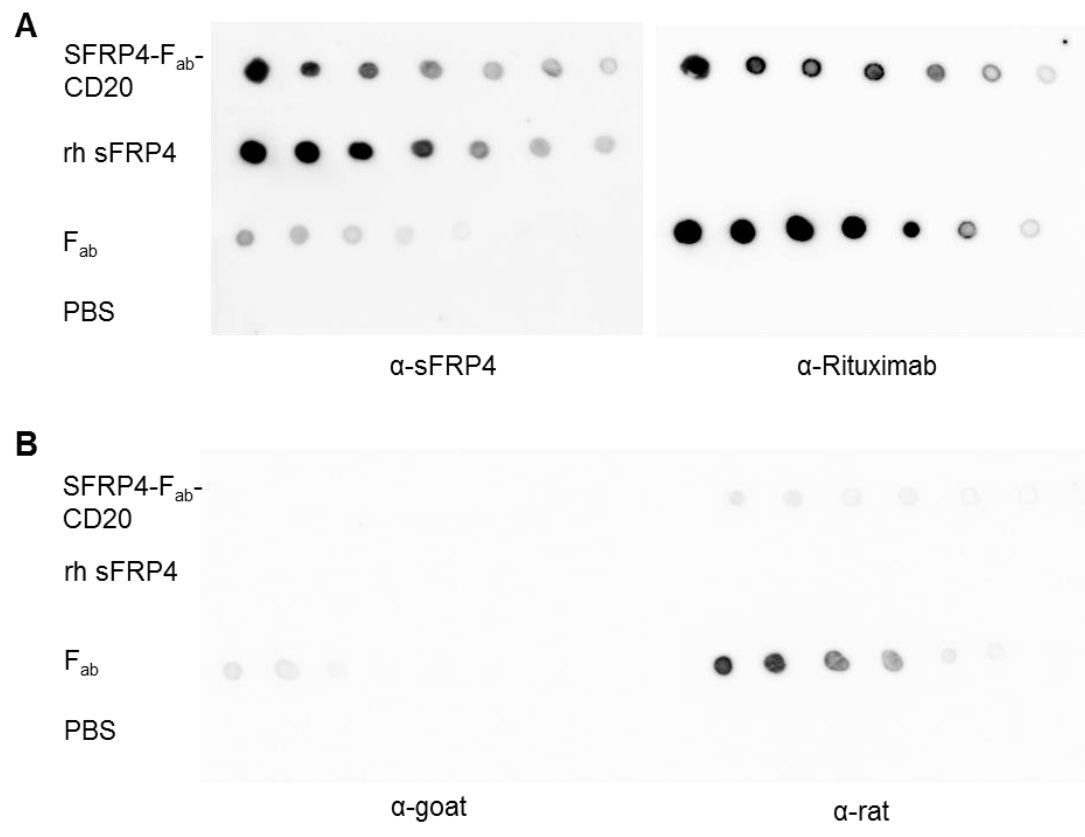

Abbildung 35: Dotblot des Fusionsprodukts SFRP4- Fab $_{a-C D 20}$ vor Fraktionierung. A: Immundetektion nach Inkubation mit den Primärantikörpern anti-sFRP4 sowie anti-Rituximab und Kopplung entsprechender Sekundärantikörper. B: Sekundärantikörper-Kontrollen für den Nachweis unspezifischer Bindungen. Anti-goat ist der zugehörige Sekundärantikörper zu antisFRP4, anti-rat ist der zugehörige Sekundärantikörper zu anti-Rituximab. In der Probe des Fusionsproduktes konnten sowohl sFRP4 als auch Rituximab detektiert werden. Positivkontrollen: rekombinantes sFRP4 und $\mathrm{F}_{\mathrm{ab}}$-Fragmente. Negativkontrolle: PBS (Lösungsmittel).

\subsubsection{Fraktionierung des Proteingemisches}

Im Dotblot wurde gezeigt, dass sowohl sFRP4 als auch $F_{a b}$-Fragmente im Konjugationsgemisch enthalten waren, jedoch ist diese Methode nicht geeignet, auch die erfolgreiche Verlinkung der beiden Edukte zu verifizieren.

Um das Produkt SFRP4- $F_{a b}-C D 20$ von den Edukten zu isolieren, wurde das gesamte Gemisch deshalb mittels Flüssigchromatographie aufgetrennt (Kapitel 2.2.4.3). Von den dabei hergestellten Fraktionen wurden Stichproben ausgewählt, die in einem ersten Schritt mittels Ultrafiltration (Amicon Ultra-2ml Centrifugal Filters) konzentriert werden mussten, da sie durch die Chromatographie stark verdünnt worden waren. Von diesen Fraktionen (Abb. 36, Lanes $A-G$ ) wurden mittels Westernblot die Proteine sFRP4 (Abb. 36, A) und Rituximab (Abb. 36, B) detektiert. Wie den Westernblots zu entnehmen ist, befand sich in den Fraktionen $\mathrm{E}$ und $\mathrm{F}$ ein Protein, das sowohl sFRP4 als auch Rituximab enthielt und eine 
Masse von ca. $90 \mathrm{kDa}$ aufwies. In den Kontrollen, die zugleich die Edukte darstellten, lag auf dieser Höhe keine Bande vor, sodass sich in diesen Fraktionen mutmaßlich das gewünschte Produkt SFRP4- $F_{a b}-C D 20$ befand. Für anti-Rituximab ist das Produkt als Bande sichtbar, auf der anti-SFR4-Membran ist es dagegen durch höhermolekulare Produkte versteckt und als Bande nicht abgrenzbar. Der Westernblot wurde wie in Kapitel 2.2.1 beschrieben durchgeführt.

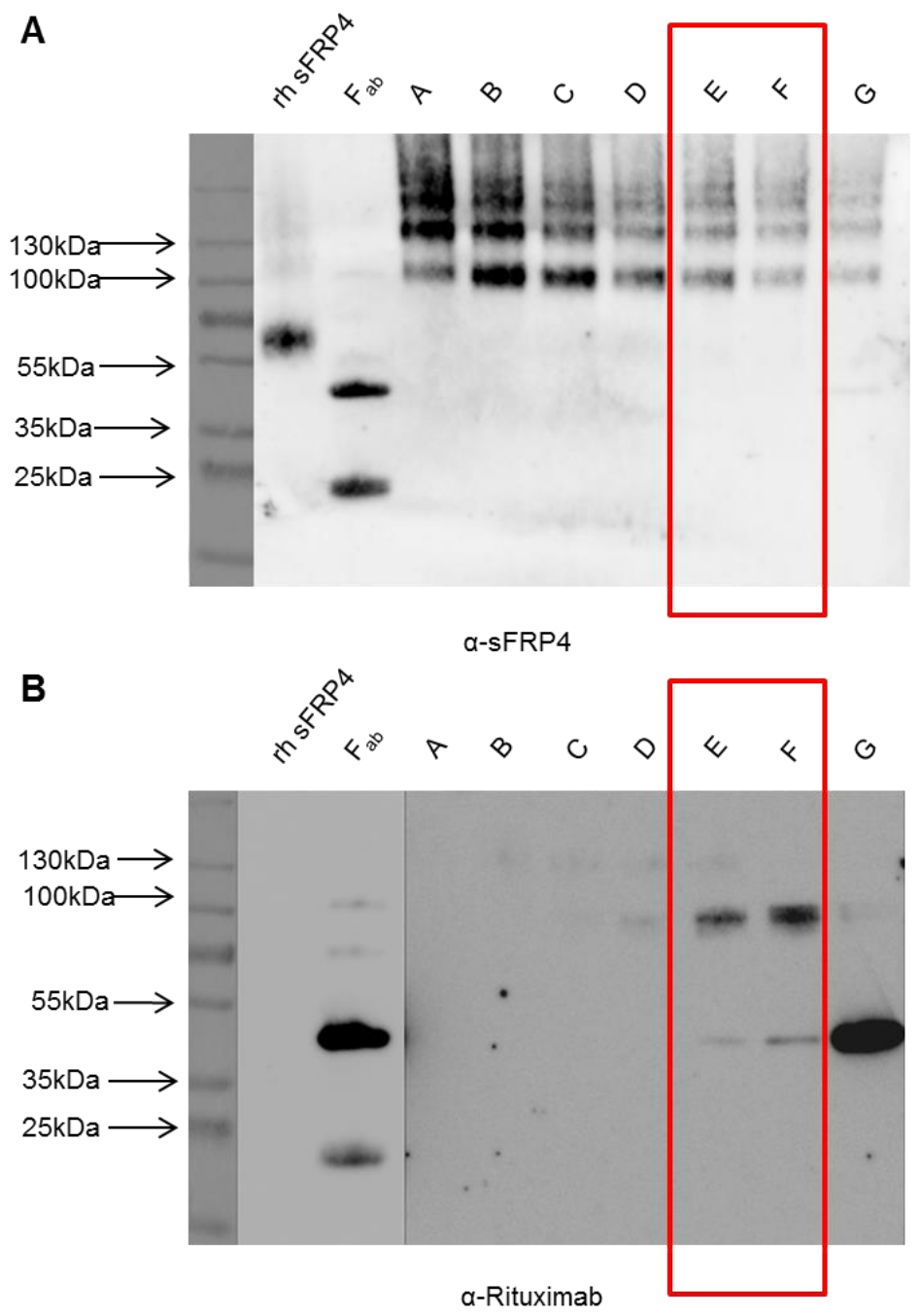

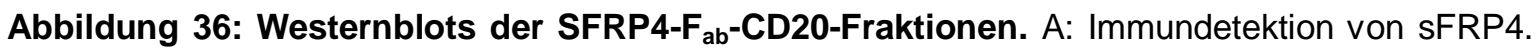
B: Immundetektion von Rituximab. Wegen unterschiedlicher Signalintensität wurden Teile des Westernblots zusammengeschnitten. In den Lanes E und F konnte ein Protein detektiert werden, das nicht mit den Edukten identisch war, aber von den Antikörpern gegen sowohl sFRP4 als auch Rituximab erkannt wurde. 


\subsubsection{Bestimmung der Proteinkonzentration mittels Dotblot}

Um weitere Experimente durchführen zu können, war es notwendig, die Konzentration des Fusionsproduktes zu bestimmen. Verschiedene Methoden wurden hierbei getestet, jedoch erwiesen sich weder die Nanodrop-Messung noch die Proteinbestimmung mittels Biuretreaktion (Rotiquant) oder der Bradfordmethode (Pierce $660 \mathrm{~nm}$ Protein Assay) als geeignet. Um trotzdem eine gute Näherung für die Konzentration zu erhalten, wurde erneut ein Dotblot durchgeführt (Kapitel 2.2.2). Nach dem Ergebnis der Westernblots in Kapitel 3.3.2 wurden die Fraktionen der Stichproben $E$ und $F$ sowie die jeweiligen Nachbarfraktionen für die Durchführung dieses Dotblots ausgewählt. Für die Konzentrationsbestimmung wurde sFRP4 in einer Verdünnungsreihe bekannter Konzentration aufgetragen.

A

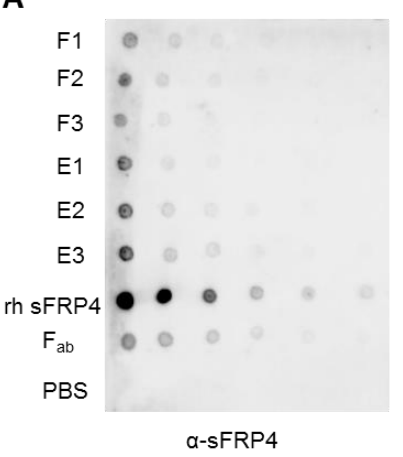

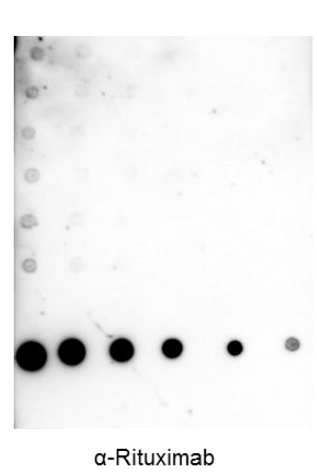

B

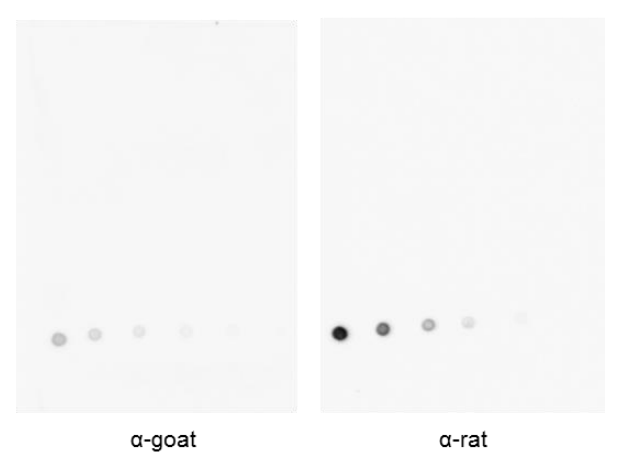

Abbildung 37: Dotblot der Fraktionen E1-3 und F1-3. A: Immundetektion nach Inkubation mit den Primärantikörpern anti-sFRP4 sowie anti-Rituximab und Kopplung entsprechender Sekundärantikörper. B: Sekundärantikörper-Kontrollen für den Nachweis unspezifischer Bindungen. In den sechs aufgetragenen Fraktionen des Fusionsproduktes konnte sowohl mit anti-sFRP4 als auch mit anti-Rituximab ein Signal detektiert werden. Die Sekundärantikörper gingen eine schwache unspezifische Bindung mit $F_{a b}$-Fragmenten ein. Positivkontrollen: rekombinantes sFRP4 und $F_{a b}$ Fragmente. Negativkontrolle: PBS (Lösungsmittel).

Die Ausgangskonzentration von sFRP4 im Dotblot betrug $50 \mu \mathrm{g} / \mathrm{ml}$. Ebenso wie alle anderen Proben wurde die sFRP4-Lösung in den weiteren Schritten 1:1 verdünnt. Vergleicht man nun die Ausgangskonzentrationen der Fraktionen mit der Verdünnungsreihe von sFRP4, so können diese annähernd zwischen der zweiten und dritten Verdünnungsstufe eingeordnet werden. Damit ergab sich für die Konjugatlösung eine kalkulierte Konzentration von 9,375 $\mu \mathrm{g} / \mathrm{ml}$. 


\subsubsection{Detektion FITC-markierter Proteine auf Lymphomzelllinien}

Das hergestellte Protein SFRP4-F $\mathrm{F}_{a b}$-CD20 sollte für weitere Experimente FITCmarkiert werden. Um zum einen eben diese FITC-Markierung (Kapitel 2.2.4.4) zu testen und um zum anderen sicherzustellen, dass die $F_{a b}$-Fragmente ähnlich gut wie Rituximab an CD20 binden konnten, wurden $F_{a b}$-Fragmente sowie Rituximab mit FITC markiert, Lymphomzellen in vitro mit jeweils 2,5 $\mu \mathrm{g}$ der FITC-markierten Proteine inkubiert und schließlich das Signal im Durchflusszytometer detektiert (Kapitel 2.5.1.1). Abbildung 38 B zeigt eine repräsentative Messung der Zelllinie SU-DHL-4. Als Positivkontrolle diente ein FITC-markierter anti-CD20-Antikörper und als Negativkontrolle wurden mit PBS behandelte Zellen eingesetzt. In allen zu bestimmenden Proben ließen sich sowohl CD20 als auch $F_{a b}$-Fragmente nachweisen. Die Zelllinie OCl-Ly3 zeigte nach Inkubation mit dem FITCmarkierten anti-CD20-Antikörper zwar ebenfalls ein positives Signal, jedoch war dieses deutlich schwächer als bei SU-DHL-4 (Abb. 38 A). Daher wurde hier auf eine Inkubation mit $F_{a b}$-Fragmenten sowie Rituximab verzichtet.
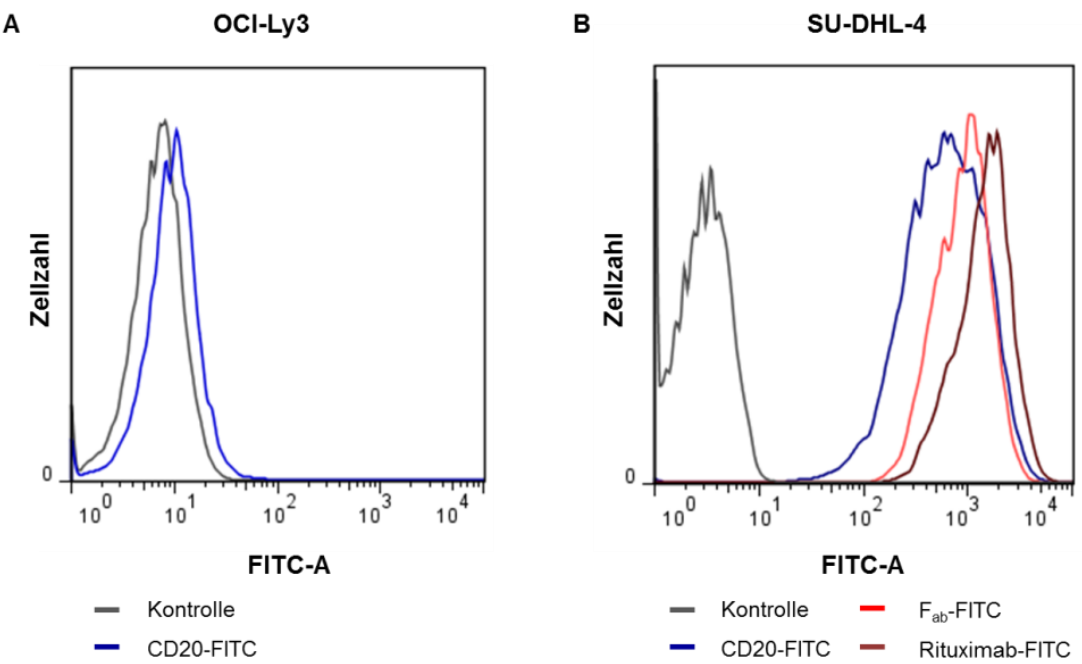

Abbildung 38: CD20-Expression und Detektion FITC-markierter $F_{a b}$-Fragmente auf Lymphomzelllinien. A: Auf der Oberfläche von OCI-Ly3 ließ sich CD20 nur schwach nachweisen. $B$ : Detektion von an CD20 gebundenen FITC-markierten $F_{a b}$-Fragmenten auf SU-DHL-4. Als Negativkontrolle dienten unbehandelte Zellen (grau). Die Positivkontrolle ist blau dargestellt. Die mit $F_{a b}$-Fragmenten und Rituximab behandelten Proben zeigen ein deutlich positives FITC-Signal.

Im nächsten Schritt wurde zur Validierung der geplanten In-ovo-Methode FITCmarkiertes Rituximab im CAM-Assay eingesetzt. Dazu wurden, wie in Kapitel 2.5 beschrieben, $60 \mu \mathrm{g}$ Rituximab-FITC in eine Vene der Allantoismembran injiziert und nach $24 \mathrm{~h}$ wurde der Tumor geerntet. Für die Kontrolle wurde das äquivalente 
Volumen PBS injiziert. Nach der Ernte wurden von den Gewebestücken Kryoschnitte angefertigt (Kapitel 2.5.2) und das Lymphomgewebe mittels Fluoreszenzmikroskopie untersucht.

A

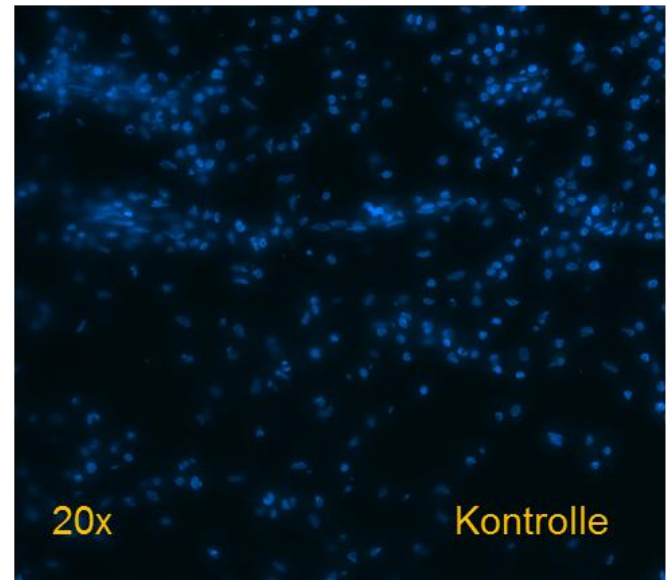

B

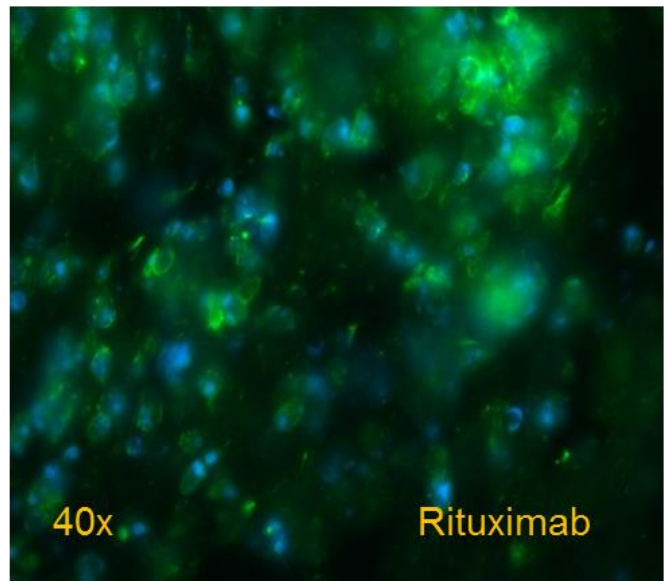

Abbildung 39: FITC-markiertes Rituximab bindet an die Zellmembran von Lymphomzellen. A: unbehandeltes Tumorgewebe. B: Tumor nach Injektion von Rituximab-FITC. DAPI-gefärbte DNA stellt sich blau dar, das FITC-Signal erscheint grün.

\subsubsection{Akkumulation von SFRP4 über CD20 sowohl in vitro als auch in ovo an Lymphomzellen}

Für die folgenden Experimente wurde das Fusionsprodukt SFRP4-Fab-CD20 mit FITC markiert (Kapitel 2.2.4.4). Durch die Waschschritte wurde SFRP4-F ${ }_{a b}$ CD20 stark verdünnt (ca. 5-fach), sodass für die folgenden Experimente eine Konzentration der Stammlösung von $2 \mu \mathrm{g} / \mathrm{ml}$ kalkuliert wurde. Im Anschluss an die FITC-Markierung wurden für die Analyse in der Durchflusszytometrie, wie in Kapitel 2.4.7.3 beschrieben, SU-DHL-4-Zellen mit sFRP4 und dem Fusionsprodukt inkubiert. Nach der Proteininkubation wurden die Proben mit dem primären Antikörper anti-sFRP4 behandelt und die Bindung dieses Antikörpers wurde über einen PE-markierten sekundären Antikörper sichtbar gemacht. Das PE-Signal wurde im Durchflusszytometer detektiert, wobei die in Abbildung 40 gezeigten Intensitäten gemessen wurden. Die mit dem Fusionsprodukt behandelten Zellen wiesen dabei stärkere Signalintensitäten auf als die mit löslichem sFRP4 inkubierten Zellen. Zur anschaulichen Darstellung und für einen direkten Vergleich zeigt Abbildung 40 B einzelne Messungen im Overlay. Hierzu wurden neben der Kontrolle eine Probe mit löslichem sFRP4 und eine Probe mit dem Fusionsprodukt ausgewählt. Beide Substanzen wurden in einer Konzentration von $2 \mathrm{ng} / \mu \mathrm{l}$ eingesetzt. Die behandelten Proben zeigten jeweils zwei Zellpopulationen, wobei 
die erste Gruppe dem Kontrollpeak entsprach, sodass angenommen werden kann, dass sich auch in den behandelten Proben eine kleine Zellpopulation ohne gebundenes Protein befand. Die zweite Population beider Proben lag dagegen im positiven Fluoreszenzbereich, wobei die Verschiebung für das Fusionsprodukt größer war. Über den PE-markierten Sekundärantikörper konnte hier die Anreicherung von sFRP4 an diesen Zellen sichtbar gemacht werden.

A

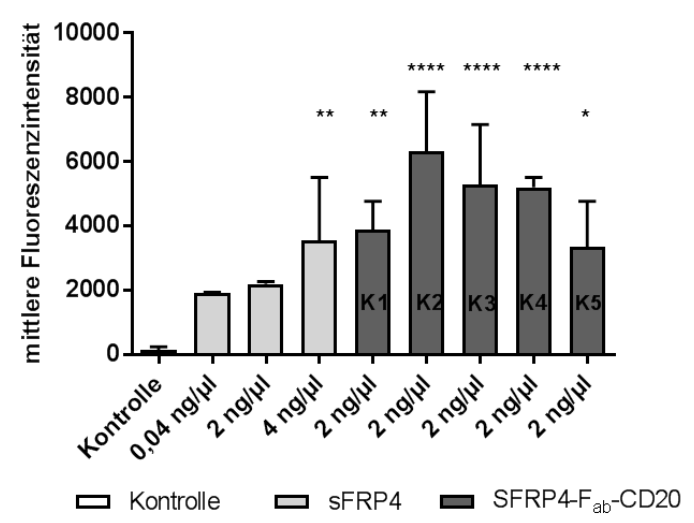

B

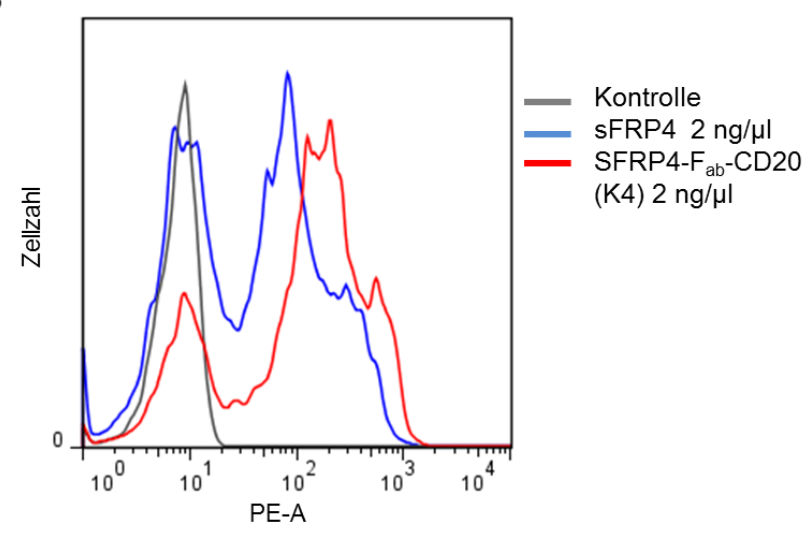

Abbildung 40: Durchflusszytometrische Analyse von SU-DHL-4 nach Inkubation mit sFRP4

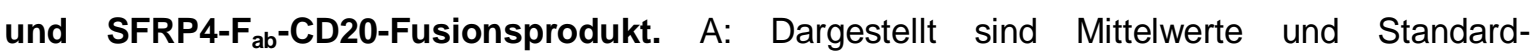
abweichungen der PE-Signalintensität von drei unabhängigen Messungen. Für jedes Protein wurde eine eigene Sekundärantikörper-Kontrolle mitgeführt. Das PE-Signal dieser Kontrolle wurde vom Signal der zu bestimmenden Probe abgezogen. Als Negativkontrolle und zur Einstellung der Messung dienten mit PBS behandelte Zellen. SFRP4 wurde in Konzentrationen von 0,04 $\mathrm{ng} / \mu \mathrm{l}$, $2 \mathrm{ng} / \mu \mathrm{l}$ und $4 \mathrm{ng} / \mu \mathrm{l}$ eingesetzt. Das Fusionsprodukt SFRP4- $\mathrm{F}_{\mathrm{ab}}-\mathrm{CD} 20$ wurde in fünf Proben (K1-K5) jeweils in einer Konzentration von $2 \mathrm{ng} / \mu \mathrm{l}$ eingesetzt. Die Signalintensitäten der Proben entsprachen der Signalintensität der $4 \mathrm{ng} / \mu \mathrm{l}$-Probe von sFRP4 oder waren stärker. B: Beispielhafte Darstellung einzelner Messungen. Die Fluoreszenzintensität verschiebt sich sowohl für lösliches

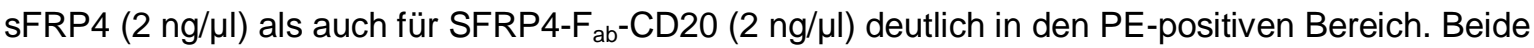
Proben zeigten neben dem PE-positiven Peak auch eine Zellpopulation, die der Negativkontrolle entspricht. SFRP4- $F_{a b}-C D 20$ zeigt im Vergleich zu löslichem sFRP4 eine deutlich stärkere Verschiebung in den positiven Fluoreszenzbereich und weniger sFRP4-negative Zellen. Statistische Auswertung mittels One-way ANOVA ( $\left.p<0,05 ;{ }^{* *} p<0,01 ;{ }^{* * *} p<0,0001\right)$.

Da das Fusionsprodukt FITC-markiert vorlag, wurde in der Durchflusszytometrie simultan das FITC-Signal der Probe detektiert, welches jedoch sehr schwach war. Um ein deutlicheres Ergebnis zu erzielen, wurden die Proben daher über Nacht mit dem Antikörper anti- $\mathrm{F}_{\mathrm{ab}}$-Rituximab-FITC inkubiert und am Folgetag wurde das FITC-Signal erneut gemessen. Da der Antikörper die Bindung von Rituximab bzw. Rituximab- $F_{a b}$-Fragmenten sichtbar macht, sollte so nachgewiesen werden, dass 
das Fusionsprodukt an die Zelloberfläche gebunden vorliegt. Als Positivkontrollen dienten Zellen, die vor der Antikörperinkubation für $2 \mathrm{~h}$ mit aufsteigenden Konzentrationen von Rituximab behandelt worden waren.

Für die mit dem Fusionsprodukt behandelten Proben konnte eine mittlere Fluoreszenzintensität gemessen werden. Zur Veranschaulichung zeigt Abbildung $41 \mathrm{~B}$ beispielhafte Messungen im Overlay. Hierzu wurden neben der Negativkontrolle eine Rituximab-Probe mit einer Konzentration von $40 \mathrm{ng} / \mu \mathrm{l}$ und eine Probe von K4 des SFRP4-Fab-CD20-Fusionsproduktes mit der kalkulierten Konzentration von $2 \mathrm{ng} / \mu \mathrm{l}$ ausgewählt. Insgesamt konnte gezeigt werden, dass Rituximab erwartungsgemäß an die Lymphomzellen band und damit ein deutlich positives Signal detektiert werden konnte. Die Zellen, die mit dem Fusionsprodukt SFRP4-F $F_{a b}-C D 20$ behandelt wurden, zeigten ein mäßiges, aber dennoch ebenfalls positives FITC-Signal, sodass davon ausgegangen werden kann, dass das Fusionsprodukt an die Zelloberfläche gebunden vorlag.

A

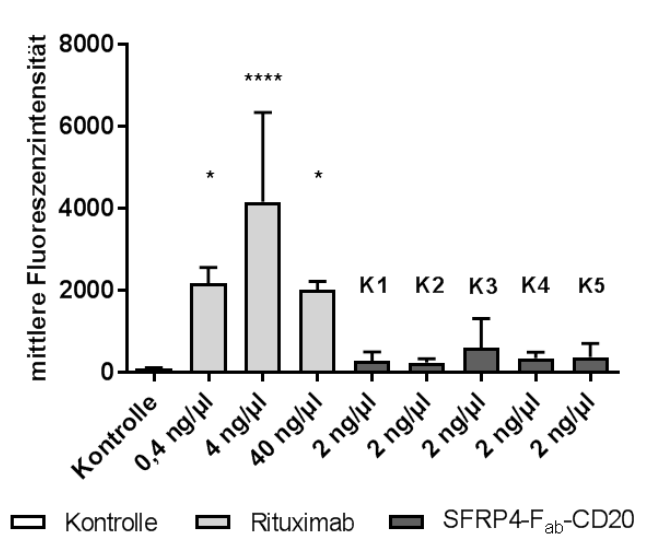

B

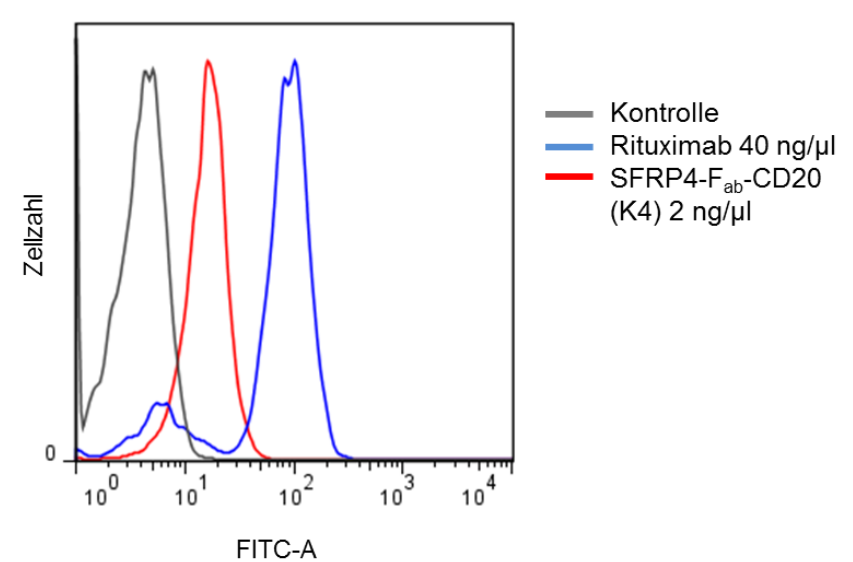

Abbildung 41: Durchflusszytometrische Analyse von SU-DHL-4 nach Inkubation mit

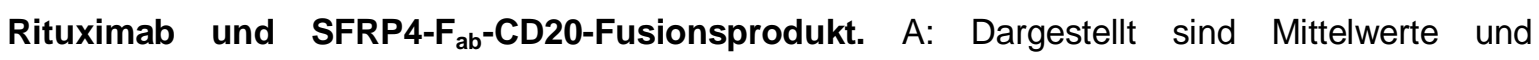
Standardabweichungen der FITC-Signalintensität von drei unabhängigen Messungen. Das FITCSignal der jeweiligen Antikörperkontrolle wurde vom Signal der zu bestimmenden Probe abgezogen. Als Negativkontrolle und zur Einstellung der Messung dienten mit PBS behandelte Zellen. Es wurden 40, 4 und 0,4 ng/ $\mu$ l Rituximab eingesetzt. Das Fusionsprodukt SFRP4- $\mathrm{ab}_{\mathrm{ab}}-\mathrm{CD} 20$ wurde in fünf Proben (K1-K5) jeweils in einer Konzentration von $2 \mathrm{ng} / \mu \mathrm{l}$ eingesetzt. B: Beispielhafte Darstellung einzelner Messungen. Die Fluoreszenzintensität verschiebt sich sowohl für SFRP4- $\mathrm{F}_{\mathrm{ab}}$ CD20 $(2 \mathrm{ng} / \mu \mathrm{l})$ als auch für Rituximab $(40 \mathrm{ng} / \mu \mathrm{l})$ in den FITC-positiven Bereich. Statistische Auswertung mittels One-way ANOVA $\left({ }^{*} p<0,05 ;{ }^{* * *} p<0,0001\right)$.

Nach erfolgreicher Anreicherung des Fusionsprodukts in vitro wurde die Akkumulation nun im CAM-Assay untersucht. Wie in Kapitel 2.5 beschrieben 
wurden Zellen der Zelllinie SU-DHL-4 auf die Allantoismembran transplantiert und nach Ausbildung eines gut sichtbaren Tumors wurde $1 \mu \mathrm{g}$ des hergestellten Konjugats SFRP4-F $\mathrm{ab}_{\mathrm{b}} \mathrm{CD20}$ in eine Vene der Allantoismembran injiziert. Für die Positivkontrollen wurden unterschiedliche Mengen an $F_{a b}$-Fragmenten bzw. Rituximab, für die Negativkontrolle wurde das entsprechende Volumen $(500 \mu \mathrm{l})$ PBS injiziert. Nach $24 \mathrm{~h}$ wurden die Tumoren geerntet, von den Gewebestücken Kryoschnitte angefertigt (Kapitel 2.5.2) und diese mittels Fluoreszenzmikroskopie untersucht. Im Vergleich zur Kontrolle erscheint nach Proteingabe die Zellmembran der Tumorzellen deutlich grün, sodass von einer Akkumulation des Proteins im Tumor ausgegangen werden kann.

A

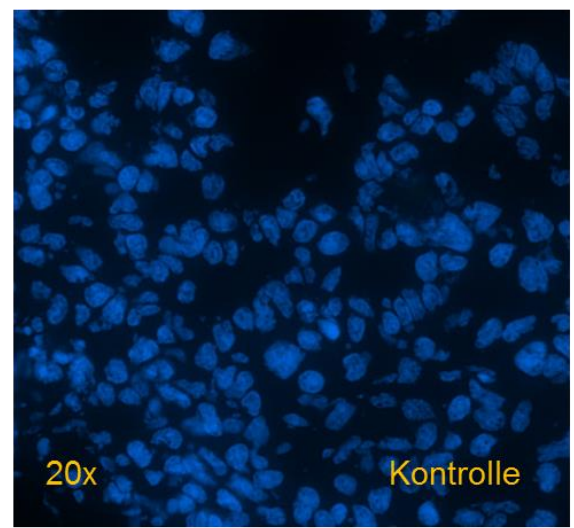

C

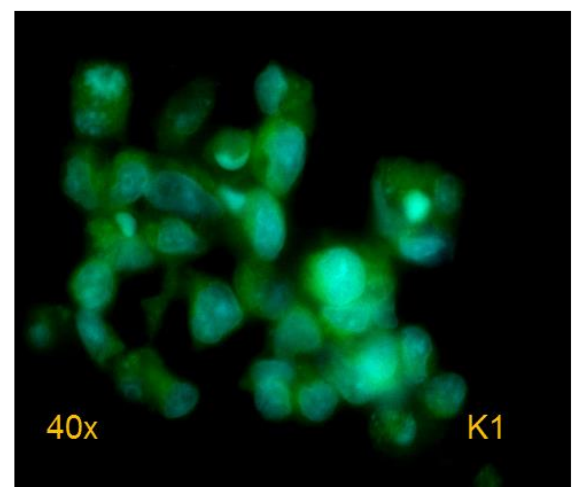

B

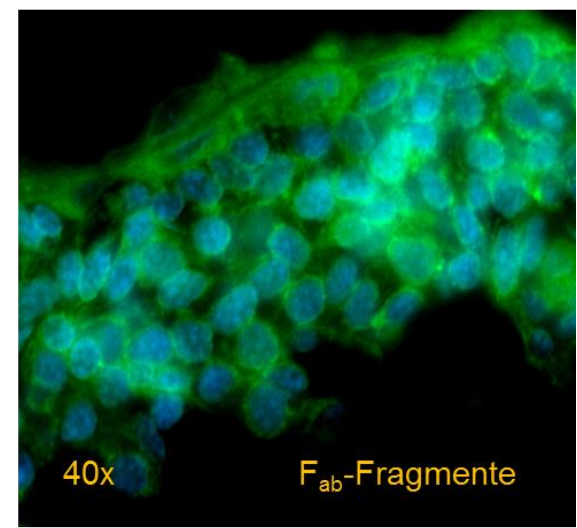

D

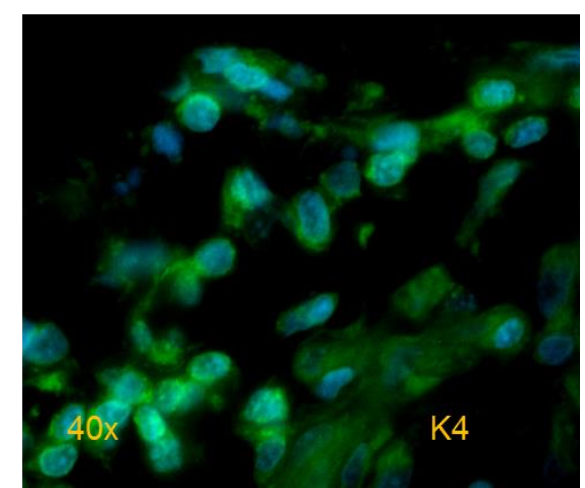

Abbildung 42: Detektion von SFRP4-F $F_{a b}-C D 20$ in ovo. $24 \mathrm{~h}$ nach Injektion FITC-markierter Proteine wurden die Tumoren geerntet und Kryoschnitte angefertigt. Die Zellkerne färben sich durch den DNA-färbenden Farbstoff DAPI blau an. In den behandelten Tumoren zeigte sich eine deutlich FITC-positive Membran (grün), was die Anreicherung von $F_{a b}$-Fragmenten ( $B$, Positivkontrolle mit $2 \mu \mathrm{g}$ ) sowie zwei ausgewählten Konjugationsprodukten K1 und K4 (C und D) an der Zellmembran nachweist.

Ein Teil des Tumorgewebes wurde nach der Ernte für eine Analyse am Durchflusszytometer verwendet. Die Proben wurden dazu, wie in Kapitel 2.5.3 beschrieben, vorbereitet und es wurde das FITC-Signal gemessen. In 
Abbildung $43 \mathrm{~A}$ ist eine deutlich konzentrationsabhängige Fluoreszenzintensität der Positivkontrollen dargestellt. Wurde der Tumor mit nur 1-2 $\mu \mathrm{g} \mathrm{F}_{\mathrm{ab}}$-Fragmenten behandelt, konnte kaum ein Unterschied zur Negativkontrolle nachgewiesen werden, ab $50 \mu \mathrm{g} \mathrm{F}_{\mathrm{ab}}$-Fragmenten wurde das FITC-Signal deutlich positiv. Für die mit dem Fusionsprodukt behandelten Tumoren zeigte sich die Intensität heterogen (Abb. 43 B). Zur beispielhaften Darstellung in Abbildung $43 \mathrm{C}$ wurde eine Probe ausgewählt, die mit dem SFRP4-F ${ }_{a b}-C D 20-F u s i o n s p r o d u k t ~ K 4$ behandelt worden war, da diese in der Gesamtschau eine mittlere Fluoreszenzintensität zeigte (vgl. Abb. 43 B). Als Positivkontrolle diente eine Probe mit $50 \mu \mathrm{g} \mathrm{Fab}_{\mathrm{ab}}$-Fragmenten.

A

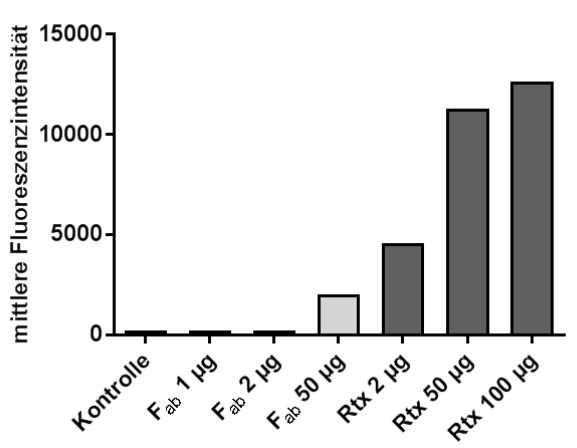

B

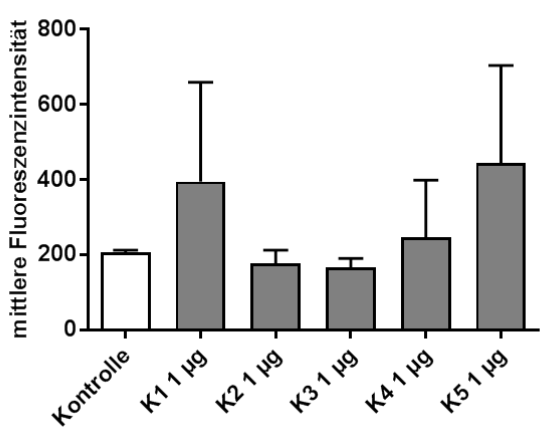

C

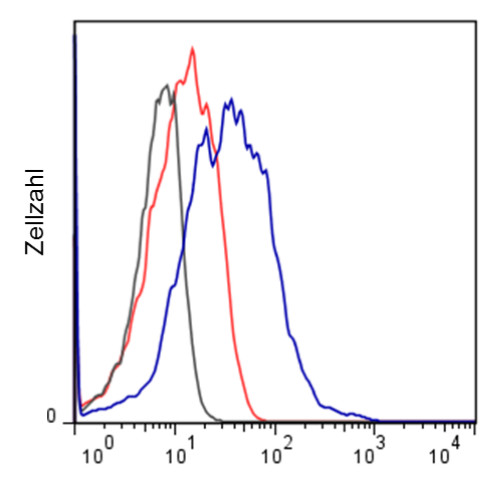

FITC-A

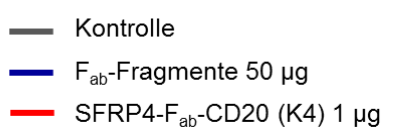

Abbildung 43: Durchflusszytometrische Analyse von SFRP4-F ${ }_{a b}-C D 20$ auf Primärtumorproben. Die Tumoren wurden zerkleinert und die einzelnen Zellen mittels Durchflusszytometrie analysiert. A: Positivkontrollen mit FITC-markierten $F_{a b}$-Fragmenten $\left(F_{a b}\right)$ und Rituximab (Rtx). B: Mittlere Fluoreszenzintensität der Tumoren, die mit FITC-markiertem SFRP4$\mathrm{F}_{\mathrm{ab}}$-CD20 (K1-K5) behandelt wurden. C: Beispielhafte Darstellung einer Messung für das Fusionsprodukt (K4).

Die Positivkontrollen zeigten jeweils eine konzentrationsabhängige Signalintensität im Durchflusszytometer (A). Die Signalintensität der mit SFRP4- $F_{a b}-C D 20$ behandelten Proben zeigte sich heterogen (B). C zeigt als Beispiel die Signalintensität der Negativkontrolle (grau), Positivkontrolle (blau) und einer ausgewählten Probe mit SFRP4- Fab $-\mathrm{CD} 20$ (rot) im Vergleich. 


\subsubsection{Funktionalität von SFRP4- $F_{a b}-C D 20$}

Die Funktionalität des Fusionsproduktes SFRP4-F ${ }_{a b}-C D 20$ sollte in einem Klonogenitätsassay an Zellen der Zelllinien SU-DHL-4 und OCl-Ly3 untersucht werden. Dazu wurde die Methode aus Kapitel 2.4.6 in abgewandelter Form

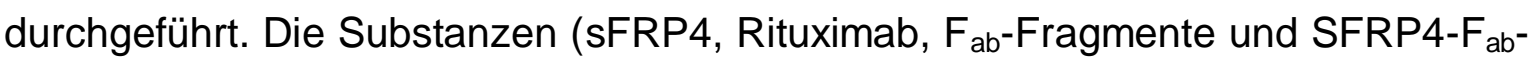
CD20 der Ansätze K1 bis K4) wurden nicht in der Methylcellulose ausplattiert, sondern die Zellen wurden $24 \mathrm{~h}$ vor Ansatz des Assays in einer 96-well-Platte ausgesät und mit den Proteinen inkubiert. Nach $24 \mathrm{~h}$ wurden die Zellen gewaschen, mit Methylcellulose gemischt und schließlich ausplattiert. Diese Modifikation des Verfahrens wurde durchgeführt, um nur die über CD20 an die Zellmembran gebundenen Proteine im Assay zu testen. Wären die Substanzen direkt der Methylcellulose zugegeben worden, wäre kein Unterschied zwischen der Bindung von löslichem sFRP4 und dem Konstrukt zu erwarten. Die Ergebnisse des Assays sind in Abbildung 44 gezeigt. Die Analyse des Ansatzes K5 war aus technischen Gründen nicht möglich.

Für SU-DHL-4 konnte im Vergleich zur Kontrolle eine signifikante Reduktion an Kolonien für $10 \mathrm{ng} / \mu$ l Rituximab erzielt werden (Abb. $44 \mathrm{~A}$ und $\mathrm{B}, \mathrm{p}<0,0001$ ). Präinkubation mit löslichem sFRP4 zeigte eine tendenziell konzentrationsabhängige Einschränkung der Klonogenität ohne nachweisbare Signifikanz. Für eine Konzentration von 0,5 ng/ $\mu$ ergab sich eine Differenz von $12 \%$ im Vergleich zur Kontrolle. Dieser Wert entspricht der mittleren Reduktion an Kolonien, die auch

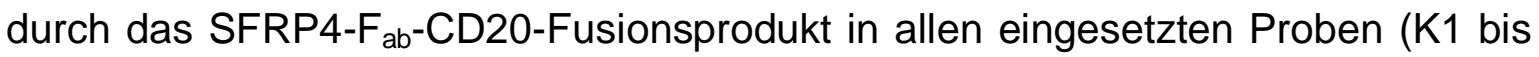
K4) erzielt werden konnte. Damit deutet sich zwar ein Effekt durch die Behandlung mit dem in dieser Arbeit hergestellten SFRP4- $F_{a b}-C D 20$ an, jedoch konnte die durch die verstärkte Akkumulation von SFRP4 erwartete verminderte Klonogenität der Zellen im Vergleich zu löslichem sFRP4 nicht nachgewiesen werden.

Bei der Zellinie OCl-Ly3, die im Gegensatz zu SU-DHL-4 eine deutlich schwächere CD20-Expression (vgl. Abb. 38), aber keine genomische Veränderung der $M Y C$-Expression zeigt, ergab sich ein interessantes Resultat (Abb. $44 \mathrm{C}$ ): Während weder Rituximab noch $F_{a b}$-Fragmente eine relevante Wirkung auf die Anzahl an Kolonien hatten und lösliches sFRP4 lediglich eine Reduktion von $11,1 \%$ in der höchsten Konzentration von $1 \mathrm{ng} / \mu$ l erzielen konnte, riefen die vier eingesetzten Fusionsprodukte K1 bis K4 unterschiedliche 
Ergebnisse hervor. K1 bis K3 schränkten die Klonogenität nur gering ein, dagegen fiel bei dem Fusionsprodukt K4 eine deutliche Reduktion der Kolonien von 58,4 \% für die mit dieser Substanz behandelten Proben auf (Abb. $44 \mathrm{C}$ und $\mathrm{D}$, $p<0,0001$ ). Dies lässt darauf schließen, dass bei der Fusion von sFRP4 und $F_{a b}{ }^{-}$ Fragmenten mit dem Produkt K4 eine Substanz entstanden ist, die mittels der Akkumulation von sFRP4 über das Oberflächenprotein CD20 potent ist, das Wachstum von Kolonien signifikant zu unterdrücken.

A

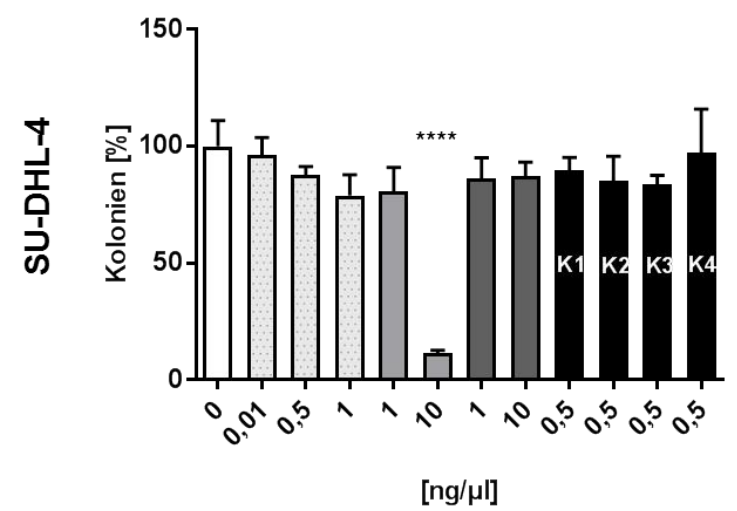

C

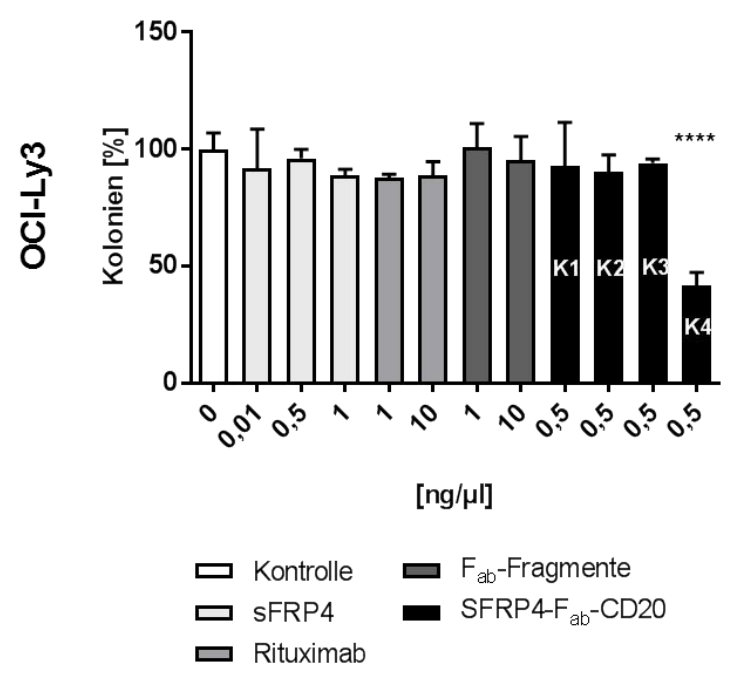

B

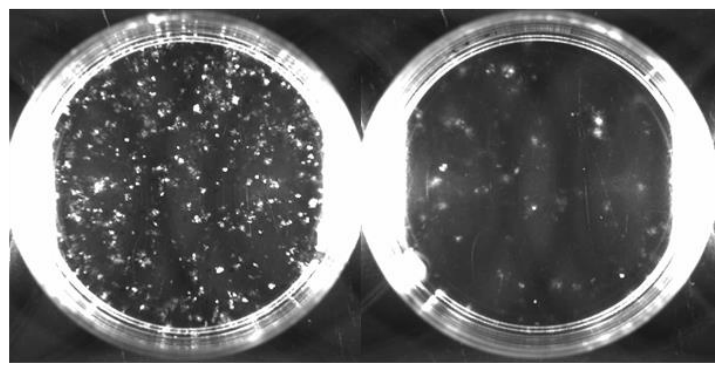

Kontrolle

$10 \mathrm{ng} / \mu \mathrm{l}$ Rituximab

D

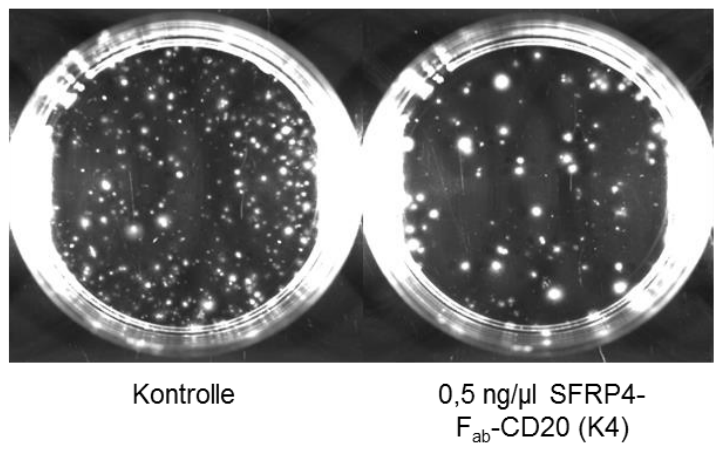

Abbildung 44: Klonogenitätsassay nach Präinkubation mit SFRP4-F ${ }_{a b}-C_{20}$. A und B: SU-DHL-4. C und D: OCl-Ly3. Dargestellt sind Mittelwerte und Standardabweichungen von Triplikaten. Die Fusionsprodukte SFRP4-F ${ }_{a b}-C D 20$ wurden in einer Konzentration von 0,5 ng/ $\mu$ l eingesetzt. A: Für SU-DHL-4 ergab sich eine signifikante Hemmung des Koloniewachstums für $10 \mathrm{ng} / \mu \mathrm{l}$ Rituximab. SFRP4 in Form des Fusionsproduktes konnte eine verminderte Anzahl an Kolonien erzielen, die der Reduktion unter löslichem sFRP4 in der gleichen Konzentration entsprach. B: Koloniewachstum von SU-DHL-4 unter 10 ng/ $\mu$ l Rituximab im Vergleich zur Kontrolle. C: Der Einsatz von K4 zeigte für die Zelllinie OCl-Ly3 eine Hemmung der Klonogenität um fast $60 \%$ und damit eine vielfache Reduktion im Vergleich zu löslichem sFRP4 in gleicher Konzentration. D: Koloniewachstum von OCl-Ly3 unter 0,5 ng/ $\mu$ l SFRP4-F ${ }_{a b}-C D 20$ (K4) im Vergleich zur Kontrolle. Statistische Auswertung mittels One-way ANOVA ( $\left.{ }^{\star \star \star *} p<0,0001\right)$. 


\section{Diskussion}

Patienten mit einem diffusen großzelligen B-Zell-Lymphom können eine Behandlung in kurativer Zielsetzung erhalten. Bei einem Teil der Patienten zeigt sich die Erkrankung jedoch refraktär, oder es kommt zur Ausbildung von Rezidiven, was mit einer ungünstigen Prognose einhergeht (Coiffier et al. 2010). Ein Grund für dieses sehr unterschiedliche Therapieansprechen ist in der Heterogenität der Lymphome zu suchen, denn durch genetische Aberrationen können Tumoren der etablierten Behandlung nicht zugänglich sein und sich daher in der Prognose deutlich unterscheiden (Alizadeh et al. 2000). Diese Problematik in der Therapie des DLBCL erfordert weitere Erkenntnisse der Biologie der Lymphomzellen sowie die Entwicklung individueller Therapieschemata.

Der Wnt-Signalweg stellt eine genetische Komponente dar, dessen onkogenes Potential in zahlreichen Malignomen nachgewiesen worden ist (Clevers und Nusse 2012). Vorarbeiten legen auch im DLBCL eine besondere Bedeutung nahe (Koch et al. 2014; Walker et al. 2015). Ein Teil der DLBCL-Tumoren weist eine Überexpression des Onkogens MYC auf, was mit einer schlechteren Prognose einhergeht (Rimsza et al. 2008). Nur bei einem kleinen Anteil dieser DLBCL beruht die MYC-Überexpression auf genetischen Alterationen (Savage et al. 2009; Stasik et al. 2010). Für die übrigen MYC-high-level-DLBCL kann die Hypothese aufgestellt werden, dass MYC - als zentrales Zielgen und Mediator vom kanonischen Wnt-Signalweg- möglicherweise einer Regulation durch Wnt-Aktivität unterliegt. Der gezielte Eingriff in den Wnt-Signalweg könnte daher Ansatzpunkt neuer Therapien sein. Dabei bietet die Signalkaskade unterschiedliche Ebenen, die einer Inhibition zugänglich sind. Es liegen bereits einige Ergebnisse zur Inhibition einzelner Schritte des Signalwegs vor. Ziel dieser Arbeit war es, die verschiedenen Wnt-Inhibitionsmöglichkeiten in DLBCL-Zellen hinsichtlich ihrer Effektivität zu untersuchen und zu evaluieren.

\subsection{Wnt-Signalweg in DLBCL-Zelllinien und Angriffspunkte der Wnt-Inhibition}

Grundlage der Arbeit war der Nachweis des Wnt-Signalwegs in verschiedenen DLBCL-Zelllinien. Mittels Immunoblot konnte gezeigt werden, dass OCI-Ly1, OCILy3 und beide Subtypen von U-2932 sowohl $\beta$-Catenin als auch MYC in 
unterschiedlichem Maße exprimieren und damit als Modelle für Untersuchungen des Signalwegs dienen können (Abb. 10). Insbesondere die Zelllinie U-2932 ist als Modellsystem von hoher Relevanz: Es konnte gezeigt werden, dass die Zelllinie aus zwei Subklonen besteht, die sich durch die Überexpression von entweder BCL-6 (R1) oder MYC (R2) unterscheiden, wobei die MYC-Expression im R2-Klon auf einer Translokation $\mathrm{t}(8 ; 14)(\mathrm{q} 24 ; \mathrm{q} 32)$ beruht (Quentmeier et al. 2013). Auch für OCI-Ly1 ist eine MYC-Genamplifikation bekannt, was sich in einem hohen Expressionslevel widerspiegelt (Mehra et al. 2002). Dahingegen weisen OCl-Ly3 und U-2932 R1 keine bekannten genetischen Alterationen von MYC auf. In Übereinstimmung mit bisherigen Publikationen weisen v. a. die Zelllinien OCl-Ly3 und U-2932 eine starke Expression von $\beta$-Catenin auf (Bognar et al. 2016). Interessanterweise zeigt Abbildung 10, dass die Expression von $\beta$-Catenin in $\mathrm{U}$ 2932 vor allem in dem R1-Klon nachzuweisen war. Dies legt ein inverses Verhältnis der Nacheisbarkeit von $\beta$-Catenin auf Proteinebene und der vermehrten, deregulierten Expression von MYC nahe. Dieser Befund könnte an einer größeren Kohorte von Zelllinien sowie an Proben aus klinischen Kohorten auf eine signifikante negative Korrelation überprüft werden.

Für die Untersuchung verschiedener Inhibitoren eignen sich im Hinblick auf die Effektivität in der Durchbrechung des Wnt-Signalwegs folglich OCI-Ly3 und U2932 R1 besonders, da keine genetischen Alterationen des Wnt-Mediators MYC vorliegen und mit $\beta$-Catenin und MYC zwei downstream-Komponenten als Nachweis von aktivem Wnt-Signalweg detektierbar sind. Für OCI-Ly1 und U-2932 R2 kann bei genetischer Alteration von MYC eine Unabhängigkeit vom exogenen Wnt-Signal postuliert und die Hypothese aufgestellt werden, dass bei stetiger downstream-Stimulation die Inhibition des Wnt-Signalwegs durch die in Tabelle 10 genannten Angriffspunkte keinen Einfluss zeigt. Die Zelllinie U-2932 war darüber hinaus als Modell interessant, da bei Untersuchung der beiden Subpopulationen R1 und R2 der Einfluss der MYC-Translokation des Klons R2 im Vergleich zum Klon R1 analysiert werden konnte. Mit den genannten vier Zelllinien war es zudem möglich, sowohl Vertreter der ABC- (OCI-Ly3 und U-2932) als auch der GCBDLBCL (OCl-Ly1) zu untersuchen.

Wie bereits in Vorarbeiten gezeigt (Koch et al. 2014), konnte auch in dieser Arbeit durch Proliferationsanalysen und Klonogenitätsassays nachgewiesen werden, 
dass es grundsätzlich effektiv ist, den Wnt-Signalweg in DLBCL zu inhibieren, wobei die eingesetzten Substanzen in unterschiedlichem Maße wirkungsvoll waren. Die in dieser Arbeit evaluierten Wnt-Inhibitoren greifen vor allem auf frühen Ebenen des Wnt-Signalwegs an (Tab. 10).

\begin{tabular}{|l|l|l|}
\hline Inhibitor & Angriffspunkt & Erwarteter Effekt \\
\hline XAV939 & Tankyrase & $\beta$-Catenin $\downarrow$ \\
\hline IWP-2 & Porcupine & Produktion/ Aktivität von Wnt-Molekülen $\downarrow$ \\
\hline C59 & Porcupine & Produktion/ Aktivität von Wnt-Molekülen $\downarrow$ \\
\hline UM206 & Frizzledrezeptoren & $\begin{array}{l}\text { Blockade der Wnt-Rezeptoren an der } \\
\text { Zielzelle }\end{array}$ \\
\hline sFRP4 & Wnt-Molekül/-Rezeptor & Wnt-Bindung am Rezeptor $\downarrow$ \\
\hline
\end{tabular}

Tabelle 10: Übersicht Wnt-Inhibitoren.

\subsection{Wnt-Inhibition durch Small Molecules}

\subsubsection{Small Molecules beeinflussen die Wnt-Signalkaskade in Lymphomzellen}

Für die Zelllinien OCI-Ly3 und U-2932 R1 konnte sowohl nach Inkubation mit dem Tankyraseinhibitor XAV939 als auch mit den Porcupineinhibitoren IWP-2 und C59 im Westernblot eine Wnt-Inhibition nachgewiesen werden (Abb. 11, 16, 17). Dabei zeigten alle drei Inhibitoren ein ähnliches Resultat: der MYC-Gehalt war deutlich reduziert, während sich der $\beta$-Catenin-Level nur mäßig bis gar nicht verringerte. $\beta$ Catenin stellt im Wnt-Signalweg den second messenger dar und kommt in der Zelle in zwei Formen vor: nukleäres $\beta$-Catenin, welches als aktiver Transkriptor die Genexpression beeinflussen kann, und zelluläres $\beta$-Catenin, das inaktiv im Zytoplasma vorliegt. Der Unterschied zwischen beiden Formen besteht im Phosphorylierungszustand: aktives $\beta$-Catenin ist am C-Terminus, inaktives $\beta$ Catenin am N-Terminus phosphoryliert. Für inaktives $\beta$-Catenin ergaben sich Hinweise, dass es in der Zelle in Aggresomen abgelagert wird (Sukhdeo et al. 2012). Daher ist es möglich, dass sich bei Wnt-Inhibition der Gesamtgehalt an $\beta$ Catenin in der Zelle nur wenig verändert, aber eine Verschiebung von aktivem zu inaktivem Protein stattfindet. Eine Unterscheidung zwischen beiden Formen ist durch den hier eingesetzten Antikörper nicht möglich, sodass die Detektion das gesamte zelluläre $\beta$-Catenin abbildet, wodurch folglich keine abschließenden Aussagen über die Aktivität des Wnt-Signalwegs möglich sind. Für den hier 
nahezu konstanten $\beta$-Catenin-Gehalt kommen demnach zwei Erklärungsansätze in Betracht: Zum einen ist eine Ineffektivität der Inhibitoren zu diskutieren, zum anderen kommt die fehlende Differenzierung von aktivem und inaktivem, aber noch in der Zelle befindlichem, $\beta$-Catenin bei der Antikörperdetektion in Frage. Dass die Inhibitoren keinen Effekt ausüben konnten, ist bei detektierter Reduktion des MYC-Gehalts unwahrscheinlich. Diese Hypothese wird durch Untersuchungen anderer Arbeitsgruppen gestützt. So zeigten Huang et al. mittels Luciferase-Assay eine Abnahme der Wnt-Aktivität in HEK293- sowie in Kolonkarzinomzellen unter Inkubation mit XAV939 (Huang et al. 2009). Gleiches haben Proffitt et al. für den Porcupineinhibitor C59 ebenfalls in HEK293-Zellen und Chen et al. für Porcupineinhibitor IWP-2 in L-cells nachgewiesen (Chen et al. 2009; Proffitt et al. 2013).

Wie erwartet zeigte die Behandlung mit Wnt-Inhibitoren keinen Effekt auf die Zellinie U-2932 R2: Sowohl der $\beta$-Catenin- als auch der MYC-Gehalt waren konstant. Ursächlich ist die Translokation des MYC-Gens, durch die das Gen stetig exprimiert wird (Quentmeier et al. 2013), wodurch sich die Zelle einer WntRegulation, die proximal der Signalkette liegt, entzieht.

Für ein eindeutiges Ergebnis in OCl-Ly3 und U-2932 R1 bezüglich des $\beta$-CateninGehalts unter Inkubation mit Small Molecules wären weitere Experimente mit einem spezifischen Antikörper für aktives $\beta$-Catenin erforderlich.

\subsubsection{Reduktion von Zellwachstum und Klonogenität durch Small Molecules}

Wie bereits für andere Zelllinien beschrieben (Huang et al. 2009; Mo et al. 2013; Proffitt et al. 2013), konnte in dieser Arbeit gezeigt werden, dass durch Small Molecules das Wachstum von DLBCL-Zellen gehemmt und ihr klonogenes Potential reduziert wird. Hinsichtlich dessen zeigten sich zwischen den Inhibitoren jedoch deutliche Unterschiede: Während XAV939 eine signifikante Proliferationshemmung und Klonogenitätsreduktion erzielen konnte, zeigten sich beim Einsatz der Substanz C59 eher nur mäßige und für IWP-2 kaum relevante Effekte.

\subsubsection{Effektivität der Wnt-Inhibition durch XAV939}

Die Inkubation mit XAV939 führte zu signifikant verminderter Proliferation der Zellinien OCI-Ly3 und U-2932 R1. XAV939 inhibiert das Enzym Tankyrase, welches den Abbau von Axin, dem limitierenden Faktor des $\beta$-Catenin- 
Degradationskomplexes, fördert (Huang et al. 2009). Durch Inhibition dieses Enzyms wird demnach der Axinlevel in der Zelle und damit auch der Degradationskomplex stabilisiert. Spezifische Untersuchungen des $\beta$-CateninDegradationskomplexes führten $\mathrm{Li}$ et al. durch. Es wurde gezeigt, dass WntStimulation den Abbau von $\beta$-Catenin über Proteasomen durch Dissoziation von $\beta$-TrCP bremst, wodurch der Degradationskomplex nicht regeneriert werden kann (Li et al. 2012). Wird durch Tankyrasehemmung der Axingehalt der Zelle erhöht, können weitere Degradationskomplexe gebildet werden, die $\beta$-Catenin binden und damit die Migration des Mediators in den Nucleus unterbinden, wodurch die Endstrecke des Wnt-Signalwegs gehemmt wird.

Hinsichtlich der Klonogenität zeigte sich unter XAV939 eine verminderte Expansion der OCI-Ly3-Zellen, was in Zusammenschau mit den Ergebnissen der Proliferationsanalysen und des Westernblots schlussfolgern lässt, dass Lymphomzellen ohne genetische Alteration des Wnt-Signalwegs sensibel gegenüber XAV939 reagieren. Inwieweit diese Substanz einen potentiell neuen Ansatz in der DLBCL-Therapie darstellen kann, muss zunächst in weiteren Untersuchungen evaluiert werden. Für andere Malignome sind bereits weiterführende Daten vorhanden. Von der Arbeitsgruppe um Wu wurde kürzlich beschrieben, dass XAV939 die Chemosensibilität im Kolonkarzinom verbessern kann (Wu et al. 2016). Für Neuroblastomzellen wurde nachgewiesen, dass XAV939 eine erhöhte Apoptoserate erzielt (Tian et al. 2013), und im hepatozellulären Karzinom wurden erste In-vivo-Untersuchungen durchgeführt, die eine Tumorreduktion durch XAV939 nahelegen (Ma et al. 2015). Zusammenfassend lässt sich sagen, dass XAV939 ein effektiver Wnt-Inhibitor für Wnt-sensible Zellinien ist. Die von exogenem Wnt-Signal unabhängigen Zelllinien OCI-Ly1 und U-2932 R2 zeigten sich im Wachstum gegenüber dem Tankyraseinhibitor wie erwartet resistent.

\subsubsection{IWP-2 - Abgrenzung Wnt-spezifischer Effekte}

Für den Porcupineinhibitor IWP-2 ergaben sich in den Proliferationsanalysen nur geringe Effekte. OCl-Ly3-Zellen wuchsen unter IWP-2-Inkubation signifikant schlechter, für die Zelllinie U-2932 R1 ließ sich keine Wachstumseinschränkung nachweisen. Die Negativkontrollen OCI-Ly1 und U-2932 R2 blieben in den Proliferationsanalysen ohne signifikante Veränderung. Die Klonogenität von OCILy3-Zellen konnte durch Behandlung mit IWP-2 nicht reduziert werden. 
Der Einsatz von IWP-2 zeigte damit kein eindeutiges Ergebnis. Zudem muss berücksichtigt werden, dass Nebeneffekte der Porcupineinhibition bedeutend sein können. So zeigten Covey et al. für Mammakarzinomzellen, dass eine durch Knockdown von Porcupine hervorgerufene Proliferationshemmung mittels einer enzymatisch inaktiven Variante des Proteins ausgeglichen werden kann. Dies deutet darauf hin, dass Porcupine neben enzymatischen auch strukturelle Funktionen in der Zelle ausübt, die für die Zellproliferation ebenso bedeutend, aber unabhängig von intaktem Wnt-Signalweg sind (Covey et al. 2012). Solch strukturelle Funktionen von Porcupine sind bislang kaum untersucht worden. Würden diese aber entscheidend zur Proliferationshemmung durch IWP-2 beitragen, wäre zu erwarten, dass unabhängig von der Wnt-Abhängigkeit das Verhalten aller hier eingesetzten Zelllinien durch IWP-2 beeinflusst worden wäre.

Aufgrund der Ergebnisse im Westernblot kann wiederum bei OCl-Ly3 und U-2932 R1 durchaus eine Wnt-Inhibition diskutiert werden. Die isolierte Proliferationsreduktion für OCl-Ly3 lässt vermuten, dass diese Zelllinie sensibler als U-2932 R1 auf Wnt-Entzug reagiert, die Inhibition aber nicht effektiv genug ist, um auch die Klonogenität einzuschränken. Bei geringer Datenlage über die Funktion von Porcupine und anzunehmenden zahlreichen unspezifischen Effekten von IWP-2 bleibt die Interpretation spekulativ. Für eine eingehendere Analyse könnten Rescue-Experimente mittels Wnt-Gabe durchgeführt werden, worauf bei insgesamt eher geringen Effekten verzichtet wurde.

\subsubsection{Effektivität der Wnt-Inhibition durch C59}

Ebenso wie IWP-2 hemmt auch C59 das Enzym Porcupine. Auch hier wurde durch Inkubation mit C59 ausschließlich das Wachstum von OCI-Ly3 gehemmt. OCl-Ly1 und beide Klone von U-2932 zeigten keine Veränderungen. Im Gegensatz zu IWP-2 ist durch Inkubation mit C59 allerdings eine deutliche Reduktion des klonogenen Potentials für OCl-Ly3 gezeigt worden. Dies stützt die Hypothese, dass die Expansionsfähigkeit dieser Zelllinie stark Wnt-abhängig ist. Im Kolonie-Versuch kann die Zelle nur auf autokrine Wnt-Stimulation zurückgreifen. Ein effektiver Wnt-Entzug resultiert in stark reduzierter Klonogenität.

C59 wurde bislang nur wenig in Malignomen untersucht. Boulter et al. zeigten für das Cholangiokarzinom eine effektive Wnt-Inhibition durch den Porcupineinhibitor 
(Boulter et al. 2015). In mRNA-Analysen wurde gezeigt, dass MYC unter Behandlung mit C59 schwächer exprimiert wird, was in dieser Arbeit auch für Lymphomzellen in den Westernblotanalysen gezeigt werden konnte. Für HodgkinLymphomzellen konnte gezeigt werden, dass C59 die Migration der Zellen beeinflusst, aber die Proliferation nicht einschränken kann (Linke et al. 2017).

\subsubsection{Effekte auf die Zellzyklusprogression}

Die Proliferationseigenschaften unter Wnt-Inhibition wurden mittels Zellzyklusanalysen untersucht. Bei effektiver Wnt-Inhibition wurde erwartet, dass aufgrund reduzierten MYC-Levels ein verlangsamter Zellzyklus mittels Anstieg der G0/G1Phase nachgewiesen werden kann. Die schon in der Proliferationsmessung eher geringen Effekte der Porcupineinhibitoren scheinen jedoch zu nur marginalen Zellzyklusverschiebungen zu führen, die sich in der Zellzyklusanalyse kaum darstellen lassen oder aber sogar gegensätzliche Ergebnisse mit einer Abnahme der G0/G1-Population erzielten. Darüber hinaus führte auch die Behandlung mit XAV939 zu einer Zunahme der G2/M-Phase bei gleichzeitiger Abnahme der G1Phase. Diese Ergebnisse erscheinen zunächst widersprüchlich und bedürfen einer genaueren Betrachtung des Wnt-Signalwegs während der Mitose.

So muss bei der Zellzyklusanalyse berücksichtigt werden, dass der WntSignalweg nicht nur einen stimulierenden Effekt auf den Zellzyklus aufweist, sondern dass die Zellzyklusphasen auch umgekehrt den Signalweg beeinflussen (Niehrs und Acebron 2012). So konnte gezeigt werden, dass vor allem in der G2/M-Phase die Aktivität des Signalwegs besonders hoch ist, indem Corezeptoren wie LRP5/6 sensitiver als in anderen Phasen auf Wnt-Moleküle reagieren (Davidson et al. 2009). Die verstärkte Aktivität geht mit einem hohen Level von $\beta$ Catenin und Axin2 in der G2/M-Phase einher. Eben diese Komponenten steuern nicht nur mittels Gentranskription das Zellverhalten, sondern interagieren auch direkt mit den Mikrotubuli der Zelle und können damit die Mitose beeinflussen. Sowohl $\beta$-Catenin als auch GSK3 und Axin2 binden an die Zentrosomen und sorgen für den regelhaften Aufbau der Mitosespindel. Auch APC spielt eine Rolle für die korrekte Ausbildung der Mikrotubuli (Niehrs und Acebron 2012). Diese WntKomponenten spielen also unabhängig von der Gentranskription eine relevante Rolle für die Chromosomenstabilität und die regelrechte Zellteilung (Acebron et al. 2014). Wird durch Hemmung des Wnt-Signalwegs nun das Zusammenspiel der 
Komponenten gestört, ist anzunehmen, dass ein regelhafter Aufbau des Spindelapparats und damit auch die Segregation nicht möglich sind (Stolz und Bastians 2015).

Ein ergänzender Erklärungsansatz für die signifikante G2/M-Zunahme für den Einsatz von XAV939 ist in der besonderen Rolle der Tankyrase während der Mitose zu sehen. Dynek und Smith konnten zeigen, dass bei Inhibition des Enzyms die Trennung der Schwesterchromatiden an den Telomeren ausbleibt und die Zelle in der frühen Anaphase arretiert wird (Dynek und Smith 2004). Für die Verbindung an den Telomeren ist eine Interaktion zwischen telomeric-repeatbinding factor 1 (TRF-1) und der SA1-Untereinheit des Cohesinkomplexes verantwortlich. Um eine Trennung der Telomeren zu ermöglichen, muss TRF-1 vermutlich Tankyrase-abhängig von der DNA dissoziieren (Canudas et al. 2007). Daneben werden noch andere für die Mitose wichtige Proteine mittels Tankyrase enzymatisch verändert, sodass sich sagen lässt, dass die Tankyraseaktivität eine entscheidende Komponente für die erfolgreiche Zellteilung spielt, die zahlreichen Interaktionen allerdings noch nicht ausreichend untersucht worden sind (Lehtio et al. 2013).

\subsection{Effekte der Frizzledrezeptorblockierung auf die Wnt- Signalwegübermittlung in Lymphomzellen}

Das Peptid UM206 kann aufgrund seiner Wnt-3a-homologen Struktur an Frizzledrezeptoren binden und dabei als Wnt-Antagonist wirken. Dies ist vorrangig für die Frizzledrezeptoren 1 und 2 im Myokardgewebe beschrieben worden, wo durch UM206 das Wnt-geförderte Remodelling nach Myokardinfarkt eingeschränkt werden konnte (Laeremans et al. 2011; Uitterdijk et al. 2016). Bestätigen sich diese Ergebnisse, ist es durchaus möglich, dass UM206 in einigen Jahren therapeutisch nach Myokardinfarkt eingesetzt werden kann. Ob auch Lymphompatienten von einer Therapie mit UM206 profitieren würden, ist unbekannt und sollte daher in dieser Arbeit analysiert werden. UM206 wurde dabei sowohl in seiner aktiven, linearen Form als auch in der inaktiven Disulfidform untersucht. Dabei konnte nicht nachgewiesen werden, dass UM206 eine Inhibition des Wnt-Signalwegs in Lymphomzellen bewirken kann. Die Inkubation mit UM206 in linearer Form konnte kurzzeitig eine geringe Hemmung des Zellwachstums in serumfreier Suspensionskultur erzielen, jedoch zeigten sich 
keine signifikanten Verschiebungen im Zellzyklus. Durch die von Umgebungsfaktoren abhängige Proliferationshemmung kann ein kompetitiver Antagonismus postuliert werden: Wnt-Moleküle und UM206 konkurrieren um die Rezeptorbindung. In serumhaltiger und damit Wnt-reicher Umgebung können Wnt-Moleküle den Inhibitor größtenteils von den Rezeptoren verdrängen. Bei geringen WntKonzentrationen besteht dagegen ein Übergewicht an UM206 und damit eine verstärkte Blockade. Insgesamt scheint die inhibitorische Wirkung auf den WntSingalweg jedoch nur kurzzeitig zu bestehen und konnte nicht im Westernblot nachgewiesen werden. Auch im langfristigen Kolonie-Versuch zeigte sich keine Reduktion des klonogenen Potentials.

Trotz der vielversprechenden Ergebnisse im Myokard scheint UM206 kein potenter Wnt-Inhibitor in DLBCL zu sein. Für die ungenügende Inhibitionswirkung in Lymphomzellen können verschiedene Ursachen diskutiert werden: 1) Instabilität des Peptids: UM206 ist nur in linearer Form antagonistisch wirksam, kann aber durch Oxidation sehr schnell in die inaktive Disulfidform überführt werden. 2) Die Detektionsmethoden waren unzureichend. 3) Rezeptorausstattung der Zellen: UM206 inhibiert den Wnt-Signalweg vor allem über Frizzled-1 und -2, nicht aber über Frizzled-4 und -5 (Laeremans et al. 2011). 4) Rescue-Mechanismus der Zelle: Die kurzzeitige Wachstumshemmung mit konsekutiv verstärkter Proliferation lassen an einen Resistenzmechanismus der Zelle denken.

Eine Oxidationsproblematik ist nicht auszuschließen, jedoch konnte auch bei mehrfacher Gabe von UM206 kein positives Resultat erzielt werden. Ebenfalls unwahrscheinlich erscheint Punkt 2. Der konstante $\beta$-Catenin-Gehalt im Westernblot ist zwar, wie bereits in Kapitel 4.2.1 beschrieben, nicht aussagekräftig, jedoch erwies sich der Gehalt von MYC als downstream-Marker für einen aktiven Wnt-Signalweg als zuverlässig. Ein konstanter MYC-Gehalt lässt daher darauf schließen, dass keine effektive Wnt-Inhibition erzielt werden konnte. Diese Überlegungen führten zu dem Gedanken, dass die Rezeptorausstattung der Zelle für die Ineffektivität ursächlich sein könnte.

Laeremans et al. konnten zeigen, dass UM206 eine starke Affinität zu Frizzled-1 und -2 besitzt und die über diese Rezeptoren ausgelöste Wnt-Aktivität effektiv inhibieren kann, während die Blockade an Frizzled-4 und -5 zu keiner WntInhibition führt (Laeremans et al. 2011). Bei Untersuchung der Lymphomzelllinien 
zeigte sich, dass diese Frizzled-1 und -2 durchaus exprimieren, allerdings ein höheres Expressionsniveau für Frizzled-4 und -5 vorliegt. Auch über diese Rezeptoren wird der kanonische Wnt-Signalweg reguliert (Saitoh et al. 2001; Tickenbrock et al. 2008), sodass die Rezeptorausstattung bereits einen Erklärungsansatz für die Ineffektivität von UM206 in DLBCL bietet. Für die genauere Analyse der Bindung von UM206 an die Zelloberfläche wurden durchflusszytometrische Untersuchungen mit OCI-Ly1 und OCI-Ly3 durchgeführt, da diese aufgrund starker Rezeptorsignale in vorherigen Analysen für eine derartige Untersuchung besonders geeignet schienen. In der Durchflusszytometrie zeigte sich nach einstündiger Inkubation mit dem Peptid eine geringere Detektierbarkeit der Frizzledrezeptoren 1, 2, 4 und 5. Das Ergebnis spricht für eine Interaktion von UM206 und Rezeptoren, wodurch der Antikörper nicht mehr binden und daher kein Signal im Durchflusszytometer gemessen werden konnte. Eine signifikante Signalabnahme konnte nur für OCl-Ly3 und Frizzled-1 gemessen werden, jedoch ist für alle Messungen eine reduzierte Detektierbarkeit zu verzeichnen, weshalb bestätigt werden kann, dass UM206 eine starke Affinität zu Frizzled-1 zeigt, aber auch an alle anderen Frizzledrezeptoren binden kann.

Nach Sicherstellung der Bindung von UM206 an die Zelloberfläche war die zentrale Fragestellung nun, ob die Zelle einen Rescue-Mechanismus entwickelt, der es ihr erlaubt, sich der Wnt-Blockade zu entziehen. Zur Untersuchung dessen wurde das gleiche Experiment mit 24-stündiger UM206-Inkubation durchgeführt. Tatsächlich zeigte sich in der anschließenden Messung, dass die Rezeptordichte mindestens das Niveau von unbehandelten Zellen erreicht hat. Das Ergebnis lässt zwei Interpretationsmöglichkeiten zu: UM206 wurde abgebaut, sodass der Rezeptor für die Antikörperbindung wieder frei zugänglich war, oder die Behandlung von UM206 führt zu einer veränderten Proteinbiosynthese mit vermehrter Frizzledrezeptorexpression, wie es bereits für Frizzled-1 und -2 auf kardialen Myofibroblasten gezeigt worden ist (Laeremans et al. 2011). Ein Abbau von UM206 kann nicht ausgeschlossen werden; da aber die Zunahme der Frizzled-1-Expression auf der Oberfläche von OCI-Ly3 im Vergleich zu den Daten nach einer Stunde signifikant ist, scheint ebenso letzteres als RescueMechanismus der Zelle relevant zu sein. Für eine genauere Analyse der hier aufgestellten Hypothese müssten erneut Zellen mit UM206 inkubiert und die mRNA der Frizzledproteine gemessen werden. Da UM206 bei derart geringer 
Effektivität in Lymphomzellen jedoch als Inhibitor nicht von relevanter Bedeutung zu sein scheint, wurde von weiterführenden Untersuchungen abgesehen.

\subsection{Potenzierung der inhibitorischen Wirkung von sFRP4 auf die Wnt-Signalwegübermittlung}

Bei der Frage nach der effektivsten Methode zur Wnt-Inhibition wurden auch die physiologischen Wnt-Modulatoren der Familie der secreted frizzled-related proteins (sFRPs) einbezogen. SFRPs können als Wnt-Antagonisten den WntSignalweg modulieren und so Einfluss auf Prozesse in Wachstum und Entwicklung nehmen (Jones und Jomary 2002). Auch in Malignomen ist der WntAntagonismus für Proliferationseigenschaften und Therapieansprechen relevant (Horvath et al. 2007; Saran et al. 2012). Vorarbeiten unserer Arbeitsgruppe zeigten, dass sFRP4 besonders geeignet scheint, eine effektive Wnt-Inhibition in DLBCL bewirken zu können. In der von besonderer Klonogenität gekennzeichneten Side Population von DLBCL ist sFRP4 supprimiert, durch Reaktivierung bzw. Zugabe von sFRP4 kann die Side Population jedoch reduziert und die Expansionsfähigkeit der Tumorzellen eingeschränkt werden (Koch et al. 2014). SFRP4 scheint damit einen maßgeblichen Erfolg in der Hemmung von Tumorwachstum beitragen zu können, sodass dieses Protein für die Entwicklung eines neuen Mechanismus zur Unterdrückung des Wnt-Signalwegs in DLBCL ausgewählt wurde. Als lösliches Protein wird sFRP4 im Gewebe stets lediglich einen physiologischen Spiegel erreichen, sodass ein Mechanismus entwickelt werden musste, der die Akkumulation von sFRP4 an der Lymphomzelle erlaubt. Es entstand die Idee, den für B-Zellen spezifischen Oberflächenmarker CD20 als Anker zu verwenden und ein immunologisches Konstrukt aus sFRP4 und Rituximab zu entwickeln, welches den Wnt-Inhibitor gezielt zur Zelloberfläche der malignen B-Zellen transportiert. Im Sinne eines proof-of-concepts konnte diese Arbeit zeigen, dass sFRP4 erfolgreich an Rituximab-Fragmente gekoppelt und sowohl in vitro als auch in ovo an Lymphomzellen akkumuliert werden kann.

\subsubsection{Entwicklung eines SFRP4-F ${ }_{a b}-C D 20-I m m u n k o n j u g a t s$}

In der DLBCL-Therapie spielt Rituximab im Rahmen des R-CHOP-Schemas eine bedeutende Rolle für die Prognose der Patienten (Coiffier et al. 2010). Der vorwiegend über das $F_{c}$-Fragment vermittelte therapeutische Aspekt sollte jedoch in dieser Arbeit keine Rolle spielen, stattdessen wurden nur die antigenbindenden 
Anteile des Antikörpers zur Bindung an die Zelle und zur Überbrückung zum sFRP4-Molekül genutzt. Der Papainverdau ist eine etablierte Methode zur Spaltung von Antikörpern in ein $\mathrm{F}_{\mathrm{c}^{-}}$und $z$ wei $\mathrm{F}_{\mathrm{ab}}$-Fragmente und wurde auch in dieser Arbeit eingesetzt. Es konnte nachgewiesen werden, dass $F_{a b}$-Fragmente besser in Tumorgewebe penetrieren als komplette Antikörper (Muchekehu et al. 2013; Yokota et al. 1992). Entsprechend kann auch für Immunkonjugate postuliert werden, dass sich ein geringes Molekulargewicht vorteilhaft auf die Tumorpenetration auswirkt. Durch die Verwendung von $\mathrm{F}_{a b}$-Fragmenten in dieser Arbeit wurde daher die Voraussetzung für eine gute Tumorpenetration geschaffen. Darüber hinaus gilt für die meisten ADCs, dass sie internalisiert werden müssen, damit das häufig als Toxin fungierende Funktionsmolekül wirken kann (Perez et al. 2014). Im Fall des hier entwickelten Immunkonjugats ist eine Internalisierung nicht erwünscht, da sFRP4 als Wnt-Antagonist seine Wirkung an der Zelloberfläche ausübt. Es konnte nachgewiesen werden, dass die Internalisierung von Rituximab von der Interaktion zwischen dem $F_{c}$-Fragment des Antikörpers und dem $F_{c} \gamma R$ RllbRezeptor der Zelle abhängig ist (Lim et al. 2011), weshalb davon ausgegangen werden kann, dass ein fehlendes $F_{c}$-Fragment zu einer geringeren Aufnahme in die Zelle und einer verlängerten Verweildauer des Immunkonjugats auf der Zelloberfläche führt.

Für die Verlinkung von sFRP4 und $F_{a b}$-Fragmenten wurde eine Hydrazonverbindung ausgewählt. Bezüglich der Stabilität im Plasma deuten Untersuchungen zwar darauf hin, dass Hydrazone deutlich instabiler als zum Beispiel Thioetherverknüpfungen oder Dipeptidbindungen sind (Erickson et al. 2012; Hamann et al. 2002), jedoch sind Hydrazonverbindungen gut untersucht, zahlreich in der Entwicklung von Immunkonjugaten verwendet worden und darüber hinaus einfach herzustellen (Gordon et al. 2015).

Nach Verlinkung wurde zunächst im Dotblot nachgewiesen, dass sowohl sFRP4 als auch $\mathrm{F}_{\mathrm{ab}}$-Fragmente von Rituximab im Gemisch enthalten und die Möglichkeit der Immundetektion der einzelnen Proteine trotz veränderter Gruppen auch im verlinkten Zustand erhalten geblieben ist. Es war davon auszugehen, dass neben einem Fusionsprodukt auch nicht verlinkte Edukte im Gemisch enthalten waren, weshalb eine Flüssigchromatographie zur Auftrennung durchgeführt worden war. Nach Fraktionierung und Aufkonzentrierung wurde die Verifizierung der 
erfolgreichen Verlinkung im Westernblot und in der Durchflusszytometrie vorgenommen. Im Westernblot zeigte sich ein Protein von ca. $90 \mathrm{kDa}$, welches sowohl mit anti-Rituximab als auch mit anti-sFRP4 detektiert werden konnte. Da im Westernblot keine Bande auf der Höhe von 90 kDa für die Proben der Edukte zu verzeichnen war, kann die Hypothese aufgestellt werden, dass bei Detektion eines Moleküls dieser Größe mittels anti-sFRP4 und anti-Rituximab eine Verbindung von $\mathrm{F}_{\mathrm{ab}}$-Fragmenten mit sFRP4 stattgefunden haben muss. Des Weiteren konnte in durchflusszytometrischen Analysen von mit dem Fusionsprdukt behandelten Zellen sowohl der Nachweis von sFRP4 als auch von $\mathrm{F}_{\mathrm{ab}^{-}}$ Fragmenten von Rituximab erbracht werden, was die erfolgreiche Konjugation ebenfalls bekräftigt. Eine Konzentrationsbestimmung konnte mit etablierten Assays nicht erfolgen, weshalb diese nur semiquantitativ mittels Dotblot vorgenommen wurde.

\subsubsection{Akkumulation von sFRP4 mittels SFRP4-F $\mathrm{ab}_{\mathrm{a}}-\mathrm{CD} 20$ in vitro und in ovo}

Die Fluoreszenzmarkierung ist eine sehr sensitive Methode zur Darstellung von Zielstrukturen (Toseland 2013). In dieser Arbeit wurde sie genutzt, um die erfolgreiche Bindung von SFRP4- $\mathrm{F}_{\mathrm{ab}}-\mathrm{CD} 20$ sowie die daraus resultierende Akkumulation von sFRP4 mittels Durchflusszytometrie und Fluoreszenzmikroskopie nachzuweisen.

Vor Einsatz des immunlogischen Konstrukts wurden Vorversuche mit $\mathrm{F}_{\mathrm{ab}^{-}}$ Fragmenten und Rituximab durchgeführt, die die eingesetzte Methode zur FITCMarkierung von Proteinen verifizierten. Dabei wurde in Übereinstimmung mit anderen Arbeiten SU-DHL-4 aufgrund starker CD20-Expression als geeignete Zelllinie für Analysen von SFRP4-F ${ }_{a b}$ CD20 identifiziert (Teeling et al. 2004). Erste In-ovo-Versuche belegten zudem, dass FITC-markiertes Rituximab Lymphomgewebe penetrieren kann und nach 24 Stunden in der Fluoreszenzmikroskpie nachweisbar ist (Abb. 39).

Nach Validierung der Methoden wurden durchflusszytometrische Analysen von mit SFRP4-F $\mathrm{ab}_{\mathrm{b}}$-CD20 behandelten SU-DHL-4-Zellen durchgeführt, die eindrücklich zeigten, dass bei äquivalentem Einsatz von löslichem sFRP4 und Fusionsprodukt für die mit dem Fusionsprodukt behandelten Proben sFRP4 verstärkt auf der Zelloberfläche detektiert werden konnte. Die behandelten Zellen wiesen jeweils eine sFRP4-negative und eine sFRP4-positive Population auf, wobei auffällig ist, 
dass der Peak der negativen Zellen für SFRP4- $F_{a b}-C D 20$ deutlich geringer ausfiel als für die Probe mit löslichem sFRP4, was bedeutet, dass sFRP4 über CD20 mehr Zellen erreichte. Es kann daher entsprechend der Erwartung angenommen werden, dass bei gleicher Konzentration eine stärkere Bindung von sFRP4 bei Behandlung mit dem SFRP4- $F_{a b}$-CD20-Fusionsprodukt vorliegt und der neue Mechanismus geeignet ist, sFRP4 an der Zelle zu akkumulieren.

Eine Bindung des Fusionsproduktes an Tumorzellen konnten auch die In-ovoExperimente nachweisen. In der Fluoreszenzmikroskopie zeigte sich trotz sehr geringer Dosis der applizierten Substanz eine Anreicherung des FITC-markierten Proteins an der Zellmembran der Tumorzellen.

Ein weiterer Nachweis der Anreicherung im Primärtumor sollte in der Durchflusszytometrie erfolgen, was jedoch nur unzureichend gelang. Als Ursache kommen hier eine fehlende Anreicherung des Proteins an der Tumorzelle, eine zu geringe Konzentration des applizierten Fusionsproduktes oder eine Nichteignung der Nachweismethode in Frage. Eine unzureichende Akkumulation erscheint aufgrund der fluoreszenzmikroskopischen Ergebnisse und der In-vitro-Versuche unwahrscheinlich. Berücksichtigt man das Resultat der Positivkontrollen, so wird deutlich, dass auch hier bei geringer Dosis ( $2 \mu \mathrm{g} \mathrm{F}_{a b}$-Fragment) kaum ein Signal detektiert werden konnte. Für Rituximab in gleicher Konzentration zeigte sich dagegen ein starkes Signal, was an der größeren Molekülstruktur und damit auch einer höheren Anzahl an gebundenen FITC-Molekülen liegen könnte. Das Ergebnis der Rituximabproben bedeutet auch, dass die Durchflusszytometrie grundsätzlich geeignet ist, Analysen von primärem Tumorgewebe durchzuführen, aber für valide Aussagen höhere Konzentrationen der injizierten Lösung oder eine noch stärkere FITC-Markierung erforderlich sind. In dieser Arbeit wurden 24 Stunden nach Applikation der Substanzen Analysen an den Primärtumoren durchgeführt. Ergebnisse von Muchekehu et al. im Mausmodell zeigten allerdings, dass die maximale Konzentration von applizierten $F_{a b}$-Fragmenten in Tumorgewebe bereits nach ein bis zwei Stunden erreicht wird, sodass die Analysen möglicherweise früher hätten durchgeführt werden müssen (Muchekehu et al. 2013). 


\subsubsection{Evaluation des Konzepts}

Die Gesamtschau der Analysen lässt den Schluss zu, dass sFRP4 mittels eines Fusionsprodukts an malignen B-Zellen akkumuliert werden kann. Allerdings belegten die Untersuchungen die Funktionalität des Immunkonjugats nur unzureichend. Durch die ausgeprägte CD20-Expression schien SU-DHL-4 für die Akkumulationsanalysen besonders geeignet, im Klonogenitätsassay konnte jedoch nach Inkubation mit dem Immunkonjugat keine Reduktion des klonogenen Potentials nachgewiesen werden. SU-DHL-4 besitzt eine MYC-Amplifikation (Rabellino et al. 2016), was die Resistenz gegenüber Wnt-Modulation durch sFRP4 erklären kann. Für die Inkubation mit Rituximab wurde dagegen eine deutliche Reduktion der Kolonienzahl erreicht, was mit Ergebnissen anderer Arbeitsgruppen übereinstimmt, die nachwiesen, dass SU-DHL-4 Rituximabsensitiv ist (Kobayashi et al. 2013; Koivula et al. 2011). Dass Rituximab wiederum keine Wirkung auf die Koloniezahl der Zelllinie OCl-Ly3 hatte, entspricht ebenfalls Vorarbeiten (Koivula et al. 2011). Hier zeigte sich bezüglich SFRP4-Fab-CD20 ein interessantes Ergebnis: Eine von vier Proben konnte das klonogene Potential von OCl-Ly3 signifikant senken. Dies weist darauf hin, dass bei eben diesem Konjugationsvorgang ein sehr potenter Inhibitor entstanden sein könnte, wohingegen die weiteren Ansätze ebenfalls Fusionsprodukte, aber möglicherweise solche mit geringerer Effektivität produzierten. Genau hier besteht ein allgemeines Problem in der Herstellung von Immunkonjugaten: Die während der chemischen Reaktion entstehende und wenig zu beeinflussende Ratio zwischen Antikörper und Molekül führt zur Bildung eines sehr heterogenen Produktes mit unterschiedlichen Eigenschaften der Teilprodukte. Dabei führt eine geringe Ratio zwischen Antikörper und Molekül zu einem Verlust an Wirksamkeit, ein Antikörper mit zahlreichen funktionellen Molekülen büßt dagegen Stabilität ein (Hamblett et al. 2004). Einen weiteren Erklärungsansatz für heterogene Ergebnisse stellt die potentielle Veränderung der Struktur von sFRP4 durch die Verlinkung dar. Es ist nicht auszuschließen, dass funktionelle Gruppen von sFRP4 durch die Verlinkung nicht mehr zur Verfügung stehen und Affinität oder Stabilität verändert werden (Boylan et al. 2013), wobei in dieser Arbeit die Lokalisation der Verlinkung an sFRP4 nicht vorherzusagen war. Einen Lösungsversuch zur Produktion gezielter und homogener Immunkonjugate haben McDonagh et al. entwickelt. Von den acht Cysteinen, die an der Ausbildung der vier Disulfidbrücken eines Antikörpers 
beteiligt sind, ersetzte die Arbeitsgruppe vier durch Serin, womit noch vier Cysteine für eine mögliche Konjugation verbleiben. Es resultiert ein Konjugat aus Antikörper und vier funktionellen Molekülen. Neben einem festen Verhältnis von Antikörper zu Toxin erreichte man die Entstehung eines homogenen Produktes, da festgelegt werden konnte, welche Cysteine für eine Reaktion zur Verfügung stehen (McDonagh et al. 2006). Andere Möglichkeiten zur Produktion einer homogenen Substanz stellen enzymvermittelte seitenspezifische Konjugationsreaktionen dar (Axup et al. 2012). Dabei muss bedacht werden, dass für jede Art von Immunkonjugat ein individuelles Verhältnis gefunden werden muss, um das Maximum an Effektivität erreichen zu können (Schrama et al. 2006). Für die vorliegende Arbeit gilt, dass die differierenden Resultate im Kolonieversuch durchaus in der Heterogenität des Produkts begründet sein können.

Die Entwicklung einer homogenen Substanz mit maximaler Effektivität ginge über den Rahmen einer einzelnen Arbeit hinaus. Vielmehr sollte hier der proof-ofconcept für eine innovative Therapie erbracht werden. Für die Bestimmung der effektivsten Ratio zwischen sFRP4 und $F_{a b}$-Fragmenten, die Auswahl des besten Verlinkungsverfahrens und den Nachweis der Funktionalität sind weitere Untersuchungen erforderlich. Sollte dies gelingen, stellt SFRP4-Fab-CD20 ein potentielles Therapeutikum für DLBCL dar. 


\section{Zusammenfassung}

Deregulierte Wnt-3a-Signalwegaktivierung ist ein Mechanismus der intratumoralen Homöostase in diffusen großzelligen B-Zell-Lymphomen (DLBCL). Gegenstand dieser Arbeit war es, Antagonisten dieses Signalwegs erstmalig zu evaluieren, um Strategien zu einer individuell optimierten Therapie zu entwickeln.

Für die Wnt-Signalweginhibitoren XAV939, IWP-2 und C59 wurde im Westernblot eine Wnt-Inhibition in DLBCL-Zelllinien ohne genetische MYC-Alterationen nachgewiesen. Für XAV939 wurden zudem eine signifikante Proliferationshemmung und Klonogenitätsreduktion in vitro gezeigt, wohingegen diese Effekte für C59 schwächer und für IWP-2 kaum nachweisbar waren. Während IWP-2 aufgrund des Nebenwirkungsprofils ungeeignet für In-vivo-Untersuchungen erscheint, qualifiziert sich die Substanz C59 aufgrund ihrer Effektivität in der Klonogenitätshemmung für weitere Untersuchungen. XAV939 wirkt auf zwei Tankyrase-abhängige Vorgänge, die beide für die Krebstherapie interessant sind: Der Inhibitor bewirkt sowohl die Suppression des Wnt-Signalwegs als auch die Induktion eines Mitosearrests und sollte als vielversprechende Substanz weiterführend untersucht werden.

Trotz erfolgreicher Inhibition des Wnt-Signalwegs im Myokardgewebe scheint das Wnt-inhibitorische Peptid UM206 in DLBCL keine zytotoxische Wirkung zu haben, wofür am ehesten ein heterogenes Expressionsmuster von Isotypen des WntRezeptors Frizzled ursächlich ist.

Basierend auf der Beschreibung eines tumorsuppressiven Effekts des natürlichen Antagonisten sFRP4 wurde eine innovative Strategie zur Wnt-Inhibition in DLBCL verfolgt. Ein in dieser Arbeit entwickeltes Immunkonjugat aus variablen Anteilen von anti-CD20-Antikörpern und sFRP4 greift gezielt an Tumorzellen mit Stammzelleigenschaften an und könnte zu einem effektiven Therapeutikum für Wnt-regulierte DLBCL entwickelt werden. 


\section{Literaturverzeichnis}

Acebron SP, Karaulanov E, Berger BS, Huang YL, Niehrs C (2014): Mitotic wnt signaling promotes protein stabilization and regulates cell size. Mol Cell $\underline{54}, 663-674$

Alizadeh AA, Eisen MB, Davis RE, Ma C, Lossos IS, Rosenwald A, Boldrick JC, Sabet H, Tran T, Yu X (2000): Distinct types of diffuse large B-cell lymphoma identified by gene expression profiling. Nature $\underline{403}, 503-511$

Amini RM, Berglund M, Rosenquist R, Von Heideman A, Lagercrantz S, Thunberg U, Bergh J, Sundstrom C, Glimelius B, Enblad G (2002): A novel B-cell line (U-2932) established from a patient with diffuse large B-cell lymphoma following Hodgkin lymphoma. Leuk Lymphoma $\underline{43}, 2179-2189$

Aurlien E, Larsen RH, Kvalheim G, Bruland OS (2000): Demonstration of highly specific toxicity of the alpha-emitting radioimmunoconjugate(211)At-rituximab against non-Hodgkin's lymphoma cells. Br J Cancer $\underline{83}$, 1375-1379

Axup JY, Bajjuri KM, Ritland M, Hutchins BM, Kim CH, Kazane SA, Halder R, Forsyth JS, Santidrian AF, Stafin K (2012): Synthesis of site-specific antibody-drug conjugates using unnatural amino acids. Proc Natl Acad Sci U S A $\underline{109}, 16101-16106$

Bafico A, Gazit A, Pramila T, Finch PW, Yaniv A, Aaronson SA (1999): Interaction of frizzled related protein (FRP) with Wnt ligands and the frizzled receptor suggests alternative mechanisms for FRP inhibition of Wnt signaling. J Biol Chem 274, 16180-16187

Bellei B, Pacchiarotti A, Perez M, Faraggiana T (2004): Frequent beta-catenin overexpression without exon 3 mutation in cutaneous lymphomas. Mod Pathol 17, 1275-1281

Bhanot P, Brink M, Samos CH, Hsieh JC, Wang Y, Macke JP, Andrew D, Nathans J, Nusse R (1996): A new member of the frizzled family from Drosophila functions as a Wingless receptor. Nature $\underline{382}, 225-230$

Bienz M, Clevers H (2000): Linking colorectal cancer to Wnt signaling. Cell 103, 311-320

Bognar MK, Vincendeau M, Erdmann T, Seeholzer T, Grau M, Linnemann JR, Ruland J, Scheel CH, Lenz P, Ott G (2016): Oncogenic CARMA1 couples NF-kappaB and beta-catenin signaling in diffuse large B-cell lymphomas. Oncogene $\underline{35}$, 4269-4281

Bouchard C, Thieke K, Maier A, Saffrich R, Hanley-Hyde J, Ansorge W, Reed S, Sicinski P, Bartek J, Eilers M (1999): Direct induction of cyclin D2 by Myc contributes to cell cycle progression and sequestration of p27. EMBO J $18,5321-5333$

Bouchard C, Dittrich O, Kiermaier A, Dohmann K, Menkel A, Eilers M, Luscher B (2001): Regulation of cyclin D2 gene expression by the Myc/Max/Mad network: Myc-dependent TRRAP recruitment and histone acetylation at the cyclin D2 promoter. Genes Dev $\underline{15}$, 2042-2047

Boulter L, Guest RV, Kendall TJ, Wilson DH, Wojtacha D, Robson AJ, Ridgway RA, Samuel K, Van Rooijen N, Barry ST (2015): WNT signaling drives cholangiocarcinoma growth and can be pharmacologically inhibited. J Clin Invest $\underline{125}, 1269-1285$

Boylan NJ, Zhou W, Proos RJ, Tolbert TJ, Wolfe JL, Laurence JS (2013): Conjugation site heterogeneity causes variable electrostatic properties in Fc conjugates. Bioconjug Chem 24, 1008-1016

Bross PF, Beitz J, Chen G, Chen XH, Duffy E, Kieffer L, Roy S, Sridhara R, Rahman A, Williams G (2001): Approval summary: gemtuzumab ozogamicin in relapsed acute myeloid leukemia. Clin Cancer Res $\underline{7}, 1490-1496$ 
Bubien JK, Zhou LJ, Bell PD, Frizzell RA, Tedder TF (1993): Transfection of the CD20 cell surface molecule into ectopic cell types generates a $\mathrm{Ca} 2+$ conductance found constitutively in $\mathrm{B}$ lymphocytes. J Cell Biol 121, 1121-1132

Canudas S, Houghtaling BR, Kim JY, Dynek JN, Chang WG, Smith S (2007): Protein requirements for sister telomere association in human cells. EMBO J $\underline{26}, 4867-4878$

Carmon KS, Loose DS (2008): Secreted frizzled-related protein 4 regulates two Wnt7a signaling pathways and inhibits proliferation in endometrial cancer cells. Mol Cancer Res $\underline{6}, 1017-$ 1028

Chen B, Dodge ME, Tang W, Lu J, Ma Z, Fan CW, Wei S, Hao W, Kilgore J, Williams NS (2009): Small molecule-mediated disruption of Wnt-dependent signaling in tissue regeneration and cancer. Nat Chem Biol $\underline{5}, 100-107$

Clevers H, Nusse R (2012): Wnt/beta-catenin signaling and disease. Cell $\underline{149}, 1192-1205$

Coiffier B, Thieblemont C, Van Den Neste E, Lepeu G, Plantier I, Castaigne S, Lefort S, Marit G, Macro M, Sebban C (2010): Long-term outcome of patients in the LNH-98.5 trial, the first randomized study comparing rituximab-CHOP to standard CHOP chemotherapy in DLBCL patients: a study by the Groupe d'Etudes des Lymphomes de l'Adulte. Blood 116, 20402045

Coller HA, Grandori C, Tamayo P, Colbert T, Lander ES, Eisenman RN, Golub TR (2000): Expression analysis with oligonucleotide microarrays reveals that MYC regulates genes involved in growth, cell cycle, signaling, and adhesion. Proc Natl Acad Sci U S A 97, 32603265

Constantinou T, Baumann F, Lacher MD, Saurer S, Friis R, Dharmarajan A (2008): SFRP-4 abrogates Wnt-3a-induced beta-catenin and Akt/PKB signalling and reverses a Wnt-3aimposed inhibition of in vitro mammary differentiation. J Mol Signal $\underline{3}, 10$

Covey TM, Kaur S, Tan Ong T, Proffitt KD, Wu Y, Tan P, Virshup DM (2012): PORCN moonlights in a Wnt-independent pathway that regulates cancer cell proliferation. PLoS One $\underline{7}$, e34532

Croy HE, Fuller CN, Giannotti J, Robinson P, Foley AV, Yamulla RJ, Cosgriff S, Greaves BD, von Kleeck RA, An HH (2016): The Poly(ADP-ribose) Polymerase Enzyme Tankyrase Antagonizes Activity of the beta-Catenin Destruction Complex through ADP-ribosylation of Axin and APC2. J Biol Chem 291, 12747-12760

Dahle J, Borrebaek J, Jonasdottir TJ, Hjelmerud AK, Melhus KB, Bruland OS, Press OW, Larsen $\mathrm{RH}$ (2007): Targeted cancer therapy with a novel low-dose rate alpha-emitting radioimmunoconjugate. Blood $\underline{110}, 2049-2056$

Dahle J, Jonasdottir TJ, Heyerdahl H, Nesland JM, Borrebaek J, Hjelmerud AK, Larsen RH (2010): Assessment of long-term radiotoxicity after treatment with the low-dose-rate alpha-particleemitting radioimmunoconjugate (227)Th-rituximab. Eur J Nucl Med Mol Imaging 37, 93-102

Das SS, Hall AV, Wareham DW, Britton KE (2002): Infection imaging with radiopharmaceuticals in the 21st century. Brazilian Archives of Biology and Technology $\underline{45}, 25-37$

Davidson G, Shen J, Huang YL, Su Y, Karaulanov E, Bartscherer K, Hassler C, Stannek P, Boutros M, Niehrs C (2009): Cell cycle control of wnt receptor activation. Dev Cell 17, 788799

Davis RE, Ngo VN, Lenz G, Tolar P, Young RM, Romesser PB, Kohlhammer H, Lamy L, Zhao H, Yang Y (2010): Chronic active B-cell-receptor signalling in diffuse large B-cell lymphoma. Nature $\underline{463}, 88-92$

de Sanjose S, Benavente Y, Vajdic CM, Engels EA, Morton LM, Bracci PM, Spinelli JJ, Zheng T, Zhang Y, Franceschi S (2008): Hepatitis C and non-Hodgkin lymphoma among 4784 cases and 6269 controls from the International Lymphoma Epidemiology Consortium. Clin Gastroenterol Hepatol $\underline{6}$, 451-458 
Diamantis N, Banerji U (2016): Antibody-drug conjugates--an emerging class of cancer treatment. $\mathrm{Br} J$ Cancer 114, 362-367

Dodge ME, Moon J, Tuladhar R, Lu J, Jacob LS, Zhang LS, Shi H, Wang X, Moro E, Mongera A (2012): Diverse chemical scaffolds support direct inhibition of the membrane-bound Oacyltransferase porcupine. J Biol Chem 287, 23246-23254

Doronina SO, Toki BE, Torgov MY, Mendelsohn BA, Cerveny CG, Chace DF, DeBlanc RL, Gearing RP, Bovee TD, Siegall CB (2003): Development of potent monoclonal antibody auristatin conjugates for cancer therapy. Nat Biotechnol $\underline{21}, 778-784$

Dynek JN, Smith S (2004): Resolution of sister telomere association is required for progression through mitosis. Science $\underline{304}, 97-100$

Ekstrom Smedby K, Vajdic CM, Falster M, Engels EA, Martinez-Maza O, Turner J, Hjalgrim $\mathrm{H}$, Vineis P, Seniori Costantini A, Bracci PM (2008): Autoimmune disorders and risk of nonHodgkin lymphoma subtypes: a pooled analysis within the InterLymph Consortium. Blood 111, 4029-4038

Engel P, Boumsell L, Balderas R, Bensussan A, Gattei V, Horejsi V, Jin BQ, Malavasi F, Mortari F, Schwartz-Albiez R (2015): CD Nomenclature 2015: Human Leukocyte Differentiation Antigen Workshops as a Driving Force in Immunology. J Immunol 195, 4555-4563

Epstein AL, Herman MM, Kim H, Dorfman RF, Kaplan HS (1976): Biology of the human malignant lymphomas. III. Intracranial heterotransplantation in the nude, athymic mouse. Cancer $\underline{37}$, 2158-2176

Erickson HK, Lewis Phillips GD, Leipold DD, Provenzano CA, Mai E, Johnson HA, Gunter B, Audette CA, Gupta M, Pinkas J (2012): The effect of different linkers on target cell catabolism and pharmacokinetics/pharmacodynamics of trastuzumab maytansinoid conjugates. Mol Cancer Ther 11, 1133-1142

Francisco JA, Cerveny CG, Meyer DL, Mixan BJ, Klussman K, Chace DF, Rejniak SX, Gordon KA, DeBlanc R, Toki BE (2003): cAC10-vcMMAE, an anti-CD30-monomethyl auristatin E conjugate with potent and selective antitumor activity. Blood 102, 1458-1465

Freedman AS, Boyd AW, Anderson KC, Fisher DC, Pinkus GS, Schlossman SF, Nadler LM (1985): Immunologic heterogeneity of diffuse large cell lymphoma. Blood $\underline{65}, 630-637$

Gascoyne DM, Banham AH (2017): The significance of FOXP1 in diffuse large B-cell lymphoma. Leuk Lymphoma $\underline{58}, 1037-1051$

Ge X, Lv X, Feng L, Liu X, Wang X (2012): High expression and nuclear localization of betacatenin in diffuse large B-cell lymphoma. Mol Med Rep $\underline{5}, 1433-1437$

Gelebart P, Anand M, Armanious H, Peters AC, Dien Bard J, Amin HM, Lai R (2008): Constitutive activation of the Wnt canonical pathway in mantle cell lymphoma. Blood 112, 5171-5179

Glennie MJ, French RR, Cragg MS, Taylor RP (2007): Mechanisms of killing by anti-CD20 monoclonal antibodies. Mol Immunol 44, 3823-3837

Gordon MR, Canakci M, Li L, Zhuang J, Osborne B, Thayumanavan S (2015): Field Guide to Challenges and Opportunities in Antibody-Drug Conjugates for Chemists. Bioconjug Chem 26, 2198-2215

Grillo-Lopez AJ, Hedrick E, Rashford M, Benyunes M (2002): Rituximab: ongoing and future clinical development. Semin Oncol 29, 105-112

Gross JC, Chaudhary V, Bartscherer K, Boutros M (2012): Active Wnt proteins are secreted on exosomes. Nat Cell Biol 14, 1036-1045

Hamann PR, Hinman LM, Beyer CF, Lindh D, Upeslacis J, Flowers DA, Bernstein I (2002): An antiCD33 antibody-calicheamicin conjugate for treatment of acute myeloid leukemia. Choice of linker. Bioconjug Chem 13, 40-46 
Hamblett KJ, Senter PD, Chace DF, Sun MM, Lenox J, Cerveny CG, Kissler KM, Bernhardt SX, Kopcha AK, Zabinski RF (2004): Effects of drug loading on the antitumor activity of a monoclonal antibody drug conjugate. Clin Cancer Res $\underline{10}$, 7063-7070

Harper JW, Adami GR, Wei N, Keyomarsi K, Elledge SJ (1993): The p21 Cdk-interacting protein Cip1 is a potent inhibitor of G1 cyclin-dependent kinases. Cell $\underline{75}, 805-816$

He TC, Sparks AB, Rago C, Hermeking H, Zawel L, da Costa LT, Morin PJ, Vogelstein B, Kinzler KW (1998): Identification of C-MYC as a target of the APC pathway. Science 281, 15091512

Hermeking H, Rago C, Schuhmacher M, Li Q, Barrett JF, Obaya AJ, O'Connell BC, Mateyak MK, Tam W, Kohlhuber F (2000): Identification of CDK4 as a target of c-MYC. Proc Natl Acad Sci U S A $\underline{97}, 2229-2234$

Hoffman B, Amanullah A, Shafarenko M, Liebermann DA (2002): The proto-oncogene c-myc in hematopoietic development and leukemogenesis. Oncogene 21, 3414-3421

Horvath LG, Lelliott JE, Kench JG, Lee CS, Williams ED, Saunders DN, Grygiel JJ, Sutherland RL, Henshall SM (2007): Secreted frizzled-related protein 4 inhibits proliferation and metastatic potential in prostate cancer. Prostate $\underline{67}, 1081-1090$

Hsiao SJ, Smith S (2008): Tankyrase function at telomeres, spindle poles, and beyond. Biochimie 90, 83-92

Huang SM, Mishina YM, Liu S, Cheung A, Stegmeier F, Michaud GA, Charlat O, Wiellette E, Zhang Y, Wiessner S (2009): Tankyrase inhibition stabilizes axin and antagonizes Wnt signalling. Nature $\underline{461}, 614-620$

Jacob F, Ukegjini K, Nixdorf S, Ford CE, Olivier J, Caduff R, Scurry JP, Guertler R, Hornung D, Mueller R (2012): Loss of secreted frizzled-related protein 4 correlates with an aggressive phenotype and predicts poor outcome in ovarian cancer patients. PLoS One $\underline{7}$, e31885

Janda CY, Waghray D, Levin AM, Thomas C, Garcia KC (2012): Structural basis of Wnt recognition by Frizzled. Science $\underline{337}$, 59-64

Jaracz S, Chen J, Kuznetsova LV, Ojima I (2005): Recent advances in tumor-targeting anticancer drug conjugates. Bioorg Med Chem 13, 5043-5054

Jemal A, Bray F, Center MM, Ferlay J, Ward E, Forman D (2011): Global cancer statistics. CA Cancer J Clin $\underline{61}, 69-90$

Jho EH, Zhang T, Domon C, Joo CK, Freund JN, Costantini F (2002): Wnt/beta-catenin/Tcf signaling induces the transcription of Axin2, a negative regulator of the signaling pathway. Mol Cell Biol 22, 1172-1183

Jones SE, Jomary C (2002): Secreted Frizzled-related proteins: searching for relationships and patterns. Bioessays $\underline{24}, 811-820$

Kadowaki T, Wilder E, Klingensmith J, Zachary K, Perrimon N (1996): The segment polarity gene porcupine encodes a putative multitransmembrane protein involved in Wingless processing. Genes Dev 10, 3116-3128

Kaminker PG, Kim SH, Taylor RD, Zebarjadian Y, Funk WD, Morin GB, Yaswen P, Campisi J (2001): TANK2, a new TRF1-associated poly(ADP-ribose) polymerase, causes rapid induction of cell death upon overexpression. J Biol Chem 276, 35891-35899

Khramtsov Al, Khramtsova GF, Tretiakova M, Huo D, Olopade OI, Goss KH (2010): Wnt/betacatenin pathway activation is enriched in basal-like breast cancers and predicts poor outcome. Am J Pathol 176, 2911-2920

Kim W, Kim M, Jho EH (2013): Wnt/beta-catenin signalling: from plasma membrane to nucleus. Biochem J $\underline{450}, 9-21$ 
Kinzler KW, Nilbert MC, Su LK, Vogelstein B, Bryan TM, Levy DB, Smith KJ, Preisinger AC, Hedge $P$, McKechnie D (1991): Identification of FAP locus genes from chromosome 5q21. Science 253, 661-665

Kluk MJ, Chapuy B, Sinha P, Roy A, Dal Cin P, Neuberg DS, Monti S, Pinkus GS, Shipp MA, Rodig SJ (2012): Immunohistochemical detection of MYC-driven diffuse large B-cell lymphomas. PLoS One $\underline{7}$, e33813

Knop S, Jakob A, Kanz L, Hebart H, Bares R, Dohmen B (2004): 186Rhenium-labeled anti-CD20 antibody radioimmunotherapy followed by autologous peripheral blood stem cell transplantation in patients with relapsed or refractory non-Hodgkin lymphoma. Blood 103, 1175

Kobayashi H, Matsunaga Y, Uchiyama Y, Nagura K, Komatsu Y (2013): Novel humanized antiCD20 antibody BM-ca binds to a unique epitope and exerts stronger cellular activity than others. Cancer Med 2, $130-143$

Koch R, Demant M, Aung T, Diering N, Cicholas A, Chapuy B, Wenzel D, Lahmann M, Guntsch A, Kiecke $C$ (2014): Populational equilibrium through exosome-mediated Wnt signaling in tumor progression of diffuse large B-cell lymphoma. Blood 123, 2189-2198

Koivula S, Valo E, Raunio A, Hautaniemi S, Leppa S (2011): Rituximab regulates signaling pathways and alters gene expression associated with cell death and survival in diffuse large B-cell lymphoma. Oncol Rep 25, 1183-1190

Kreitman RJ (2006): Immunotoxins for targeted cancer therapy. AAPS J $\underline{8}$, E532-551

Kuijpers TW, Bende RJ, Baars PA, Grummels A, Derks IA, Dolman KM, Beaumont T, Tedder TF, van Noesel CJ, Eldering E (2010): CD20 deficiency in humans results in impaired T cellindependent antibody responses. J Clin Invest 120, 214-222

Laeremans H, Hackeng TM, van Zandvoort MA, Thijssen VL, Janssen BJ, Ottenheijm HC, Smits JF, Blankesteijn WM (2011): Blocking of frizzled signaling with a homologous peptide fragment of wnt3a/wnt5a reduces infarct expansion and prevents the development of heart failure after myocardial infarction. Circulation 124, 1626-1635

Lambert JM (2013): Drug-conjugated antibodies for the treatment of cancer. Br J Clin Pharmacol $\underline{76}, 248-262$

Lee E, Salic A, Kruger R, Heinrich R, Kirschner MW (2003): The roles of APC and Axin derived from experimental and theoretical analysis of the Wnt pathway. PLoS Biol 1, E10

Lehtio L, Chi NW, Krauss S (2013): Tankyrases as drug targets. FEBS J 르, 3576-3593

Lenz G, Staudt LM (2010): Aggressive lymphomas. N Engl J Med $\underline{362}$, 1417-1429

Lenz G, Davis RE, Ngo VN, Lam L, George TC, Wright GW, Dave SS, Zhao H, Xu W, Rosenwald A (2008a): Oncogenic CARD11 mutations in human diffuse large B cell lymphoma. Science $\underline{319}, 1676-1679$

Lenz G, Wright GW, Emre NC, Kohlhammer H, Dave SS, Davis RE, Carty S, Lam LT, Shaffer AL, Xiao W (2008b): Molecular subtypes of diffuse large B-cell lymphoma arise by distinct genetic pathways. Proc Natl Acad Sci U S A $\underline{105}$, 13520-13525

Leonard JP, Schuster SJ, Emmanouilides C, Couture F, Teoh N, Wegener WA, Coleman M, Goldenberg DM (2008): Durable complete responses from therapy with combined epratuzumab and rituximab: final results from an international multicenter, phase 2 study in recurrent, indolent, non-Hodgkin lymphoma. Cancer 113, 2714-2723

Lewis Phillips GD, Li G, Dugger DL, Crocker LM, Parsons KL, Mai E, Blattler WA, Lambert JM, Chari RV, Lutz RJ (2008): Targeting HER2-positive breast cancer with trastuzumab-DM1, an antibody-cytotoxic drug conjugate. Cancer Res $\underline{68}, 9280-9290$ 
Li VS, Ng SS, Boersema PJ, Low TY, Karthaus WR, Gerlach JP, Mohammed S, Heck AJ, Maurice MM, Mahmoudi T (2012): Wnt signaling through inhibition of beta-catenin degradation in an intact Axin1 complex. Cell 149, 1245-1256

Lim SH, Vaughan AT, Ashton-Key M, Williams EL, Dixon SV, Chan HT, Beers SA, French RR, Cox $\mathrm{KL}$, Davies AJ (2011): Fc gamma receptor Ilb on target $B$ cells promotes rituximab internalization and reduces clinical efficacy. Blood $\underline{118}, 2530-2540$

Linke F, Zaunig S, Nietert MM, von Bonin F, Lutz S, Dullin C, Janovska P, Beissbarth T, Alves F, Klapper W (2017): WNT5A: a motility-promoting factor in Hodgkin lymphoma. Oncogene $\underline{36}, 13-23$

Ma L, Wang X, Jia T, Wei W, Chua MS, So S (2015): Tankyrase inhibitors attenuate WNT/betacatenin signaling and inhibit growth of hepatocellular carcinoma cells. Oncotarget $\underline{6}$, 25390-25401

Maloney DG, Liles TM, Czerwinski DK, Waldichuk C, Rosenberg J, Grillo-Lopez A, Levy R (1994): Phase I clinical trial using escalating single-dose infusion of chimeric anti-CD20 monoclonal antibody (IDEC-C2B8) in patients with recurrent B-cell lymphoma. Blood $\underline{84}$, 2457-2466

McDonagh CF, Turcott E, Westendorf L, Webster JB, Alley SC, Kim K, Andreyka J, Stone I, Hamblett KJ, Francisco JA (2006): Engineered antibody-drug conjugates with defined sites and stoichiometries of drug attachment. Protein Eng Des Sel 19, 299-307

Mehra S, Messner H, Minden M, Chaganti RS (2002): Molecular cytogenetic characterization of non-Hodgkin lymphoma cell lines. Genes Chromosomes Cancer 33, 225-234

Meyer N, Penn LZ (2008): Reflecting on 25 years with MYC. Nat Rev Cancer $\underline{8}, 976-990$

Mo ML, Li MR, Chen Z, Liu XW, Sheng Q, Zhou HM (2013): Inhibition of the Wnt palmitoyltransferase porcupine suppresses cell growth and downregulates the Wnt/betacatenin pathway in gastric cancer. Oncol Lett $\underline{5}, 1719-1723$

Moldenhauer G, Salnikov AV, Luttgau S, Herr I, Anderl J, Faulstich H (2012): Therapeutic potential of amanitin-conjugated anti-epithelial cell adhesion molecule monoclonal antibody against pancreatic carcinoma. J Natl Cancer Inst $\underline{104}$, 622-634

Morin RD, Johnson NA, Severson TM, Mungall AJ, An J, Goya R, Paul JE, Boyle M, Woolcock BW, Kuchenbauer F (2010): Somatic mutations altering EZH2 (Tyr641) in follicular and diffuse large B-cell lymphomas of germinal-center origin. Nat Genet $\underline{42}, 181-185$

Motta G, Cea M, Moran E, Carbone F, Augusti V, Patrone F, Nencioni A (2010): Monoclonal antibodies for non-Hodgkin's lymphoma: state of the art and perspectives. Clin Dev Immunol 2010, 428253

Muchekehu R, Liu D, Horn M, Campbell L, Del Rosario J, Bacica M, Moskowitz H, Osothprarop T, Dirksen A, Doppalapudi V (2013): The Effect of Molecular Weight, PK, and Valency on Tumor Biodistribution and Efficacy of Antibody-Based Drugs. Transl Oncol $\underline{6}, 562-572$

Nesbit CE, Tersak JM, Prochownik EV (1999): MYC oncogenes and human neoplastic disease. Oncogene 18, 3004-3016

Niehrs C (2012): The complex world of WNT receptor signalling. Nat Rev Mol Cell Biol $\underline{13}$, 767-779

Niehrs C, Acebron SP (2012): Mitotic and mitogenic Wnt signalling. EMBO J $\underline{31}, 2705-2713$

Opelz G, Dohler B (2004): Lymphomas after solid organ transplantation: a collaborative transplant study report. Am J Transplant 4 , 222-230

Patel JH, Loboda AP, Showe MK, Showe LC, McMahon SB (2004): Analysis of genomic targets reveals complex functions of MYC. Nat Rev Cancer $\underline{4}, 562-568$ 
Perez HL, Cardarelli PM, Deshpande S, Gangwar S, Schroeder GM, Vite GD, Borzilleri RM (2014): Antibody-drug conjugates: current status and future directions. Drug Discov Today $\underline{19}, 869-$ 881

Phan RT, Dalla-Favera R (2004): The BCL6 proto-oncogene suppresses p53 expression in germinal-centre B cells. Nature $\underline{432}, 635-639$

Polito L, Bolognesi A, Tazzari PL, Farini V, Lubelli C, Zinzani PL, Ricci F, Stirpe F (2004): The conjugate Rituximab/saporin-S6 completely inhibits clonogenic growth of CD20-expressing cells and produces a synergistic toxic effect with Fludarabine. Leukemia 18, 1215-1222

Proffitt KD, Madan B, Ke Z, Pendharkar V, Ding L, Lee MA, Hannoush RN, Virshup DM (2013): Pharmacological inhibition of the Wnt acyltransferase PORCN prevents growth of WNTdriven mammary cancer. Cancer Res $\underline{73}, 502-507$

Quentmeier H, Amini RM, Berglund M, Dirks WG, Ehrentraut S, Geffers R, Macleod RA, Nagel S, Romani J, Scherr M (2013): U-2932: two clones in one cell line, a tool for the study of clonal evolution. Leukemia $27,1155-1164$

Rabellino A, Melegari M, Tompkins VS, Chen W, Van Ness BG, Teruya-Feldstein J, ConacciSorrell M, Janz S, Scaglioni PP (2016): PIAS1 Promotes Lymphomagenesis through MYC Upregulation. Cell Rep 15, 2266-2278

Rao PH, Houldsworth J, Dyomina K, Parsa NZ, Cigudosa JC, Louie DC, Popplewell L, Offit K, Jhanwar SC, Chaganti RS (1998): Chromosomal and gene amplification in diffuse large Bcell lymphoma. Blood 92, 234-240

Ricart AD (2011): Antibody-drug conjugates of calicheamicin derivative: gemtuzumab ozogamicin and inotuzumab ozogamicin. Clin Cancer Res 17, 6417-6427

Rimsza LM, Leblanc ML, Unger JM, Miller TP, Grogan TM, Persky DO, Martel RR, Sabalos CM, Seligmann B, Braziel RM (2008): Gene expression predicts overall survival in paraffinembedded tissues of diffuse large B-cell lymphoma treated with R-CHOP. Blood 112, 3425-3433

Rosenbruch M (1994): Frühe Entwicklungsstadien des bebrüteten Hühnereies als Modell in der experimentellen Biologie und Medizin. ALTEX 11, 199-206

Saito-Diaz K, Chen TW, Wang X, Thorne CA, Wallace HA, Page-McCaw A, Lee E (2013): The way Wnt works: components and mechanism. Growth Factors 31, 1-31

Saitoh T, Hirai M, Katoh M (2001): Molecular cloning and characterization of human Frizzled-5 gene on chromosome 2q33.3-q34 region. Int J Oncol $\underline{19}$, 105-110

Salahshor S, Woodgett JR (2005): The links between axin and carcinogenesis. J Clin Pathol $\underline{58}$, 225-236

Saran U, Arfuso F, Zeps N, Dharmarajan A (2012): Secreted frizzled-related protein 4 expression is positively associated with responsiveness to cisplatin of ovarian cancer cell lines in vitro and with lower tumour grade in mucinous ovarian cancers. BMC Cell Biol $\underline{13}, 25$

Savage KJ, Johnson NA, Ben-Neriah S, Connors JM, Sehn LH, Farinha P, Horsman DE, Gascoyne RD (2009): MYC gene rearrangements are associated with a poor prognosis in diffuse large B-cell lymphoma patients treated with R-CHOP chemotherapy. Blood $\underline{114}$, 3533-3537

Scherer WF, Syverton JT, Gey GO (1953): Studies on the propagation in vitro of poliomyelitis viruses. IV. Viral multiplication in a stable strain of human malignant epithelial cells (strain HeLa) derived from an epidermoid carcinoma of the cervix. J Exp Med 97, 695-710

Schrama D, Reisfeld RA, Becker JC (2006): Antibody targeted drugs as cancer therapeutics. Nat Rev Drug Discov $\underline{5}, 147-159$ 
Senter PD, Sievers EL (2012): The discovery and development of brentuximab vedotin for use in relapsed Hodgkin lymphoma and systemic anaplastic large cell lymphoma. Nat Biotechnol $\underline{30}, 631-637$

Shaffer AL, Yu X, He Y, Boldrick J, Chan EP, Staudt LM (2000): BCL-6 represses genes that function in lymphocyte differentiation, inflammation, and cell cycle control. Immunity $\underline{13}$, 199-212

Shankland KR, Armitage JO, Hancock BW (2012): Non-Hodgkin lymphoma. Lancet $\underline{380}$, 848-857

Siegfried E, Perrimon N (1994): Drosophila wingless: a paradigm for the function and mechanism of Wnt signaling. Bioessays $\underline{16}$, 395-404

Smith A, Howell D, Patmore R, Jack A, Roman E (2011): Incidence of haematological malignancy by sub-type: a report from the Haematological Malignancy Research Network. Br J Cancer $\underline{105}, 1684-1692$

Smith S, Giriat I, Schmitt A, de Lange T (1998): Tankyrase, a poly(ADP-ribose) polymerase at human telomeres. Science 282, 1484-1487

Srinivasan A, Mukherji SK (2011): Tositumomab and iodine I 131 tositumomab (Bexaar). AJNR Am J Neuroradiol $\underline{32}, 637-638$

Stasik CJ, Nitta H, Zhang W, Mosher CH, Cook JR, Tubbs RR, Unger JM, Brooks TA, Persky DO, Wilkinson ST (2010): Increased MYC gene copy number correlates with increased mRNA levels in diffuse large B-cell lymphoma. Haematologica $\underline{95}$, 597-603

Stolz A, Bastians H (2015): Fresh WNT into the regulation of mitosis. Cell Cycle 14, 2566-2570

Strebhardt K, Ullrich A (2008): Paul Ehrlich's magic bullet concept: 100 years of progress. Nat Rev Cancer $\underline{8}, 473-480$

Sukhdeo K, Mani M, Hideshima T, Takada K, Pena-Cruz V, Mendez G, Ito S, Anderson KC, Carrasco DR (2012): beta-catenin is dynamically stored and cleared in multiple myeloma by the proteasome-aggresome-autophagosome-lysosome pathway. Leukemia $\underline{26}, 1116-$ 1119

Surana R, Sikka S, Cai W, Shin EM, Warrier SR, Tan HJ, Arfuso F, Fox SA, Dharmarajan AM, Kumar AP (2014): Secreted frizzled related proteins: Implications in cancers. Biochim Biophys Acta 1845, 53-65

Takada R, Satomi Y, Kurata T, Ueno N, Norioka S, Kondoh H, Takao T, Takada S (2006): Monounsaturated fatty acid modification of Wnt protein: its role in Wnt secretion. Dev Cell $\underline{11}, 791-801$

Tedder TF, Engel P (1994): CD20: a regulator of cell-cycle progression of B lymphocytes. Immunol Today $\underline{15}, 450-454$

Tedder TF, Boyd AW, Freedman AS, Nadler LM, Schlossman SF (1985): The B cell surface molecule B1 is functionally linked with B cell activation and differentiation. J Immunol $\underline{135}$, 973-979

Teeling JL, French RR, Cragg MS, van den Brakel J, Pluyter M, Huang H, Chan C, Parren PW, Hack CE, Dechant M (2004): Characterization of new human CD20 monoclonal antibodies with potent cytolytic activity against non-Hodgkin lymphomas. Blood 104, 1793-1800

Tetsu O, McCormick F (1999): Beta-catenin regulates expression of cyclin D1 in colon carcinoma cells. Nature $\underline{398}, 422-426$

Tian XH, Hou WJ, Fang Y, Fan J, Tong H, Bai SL, Chen Q, Xu H, Li Y (2013): XAV939, a tankyrase 1 inhibitior, promotes cell apoptosis in neuroblastoma cell lines by inhibiting Wnt/beta-catenin signaling pathway. J Exp Clin Cancer Res $\underline{32}, 100$ 
Tickenbrock L, Hehn S, Sargin B, Choudhary C, Baumer N, Buerger H, Schulte B, Muller O, Berdel WE, Muller-Tidow C (2008): Activation of Wnt signalling in acute myeloid leukemia by induction of Frizzled-4. Int J Oncol $\underline{33}, 1215-1221$

Torre LA, Bray F, Siegel RL, Ferlay J, Lortet-Tieulent J, Jemal A (2015): Global cancer statistics, 2012. CA Cancer J Clin $\underline{65}, 87-108$

Toseland CP (2013): Fluorescent labeling and modification of proteins. J Chem Biol $\underline{6}, 85-95$

Tsukamoto AS, Grosschedl R, Guzman RC, Parslow T, Varmus HE (1988): Expression of the int-1 gene in transgenic mice is associated with mammary gland hyperplasia and adenocarcinomas in male and female mice. Cell $\underline{55}, 619-625$

Tuscano JM, Ma Y, Martin SM, Kato J, O'Donnell RT (2011): The Bs20x22 anti-CD20-CD22 bispecific antibody has more lymphomacidal activity than do the parent antibodies alone. Cancer Immunol Immunother $\underline{60}, 771-780$

Tweeddale ME, Lim B, Jamal N, Robinson J, Zalcberg J, Lockwood G, Minden MD, Messner HA (1987): The presence of clonogenic cells in high-grade malignant lymphoma: a prognostic factor. Blood $\underline{69}$, 1307-1314

Uitterdijk A, Hermans KC, de Wijs-Meijler DP, Daskalopoulos EP, Reiss IK, Duncker DJ, Matthijs Blankesteijn W, Merkus D (2016): UM206, a selective Frizzled antagonist, attenuates adverse remodeling after myocardial infarction in swine. Lab Invest $\underline{96}, 168-176$

Valkenburg KC, Graveel CR, Zylstra-Diegel CR, Zhong Z, Williams BO (2011): Wnt/beta-catenin Signaling in Normal and Cancer Stem Cells. Cancers (Basel) $\underline{3}$, 2050-2079

Verma S, Miles D, Gianni L, Krop IE, Welslau M, Baselga J, Pegram M, Oh DY, Dieras V, Guardino E (2012): Trastuzumab emtansine for HER2-positive advanced breast cancer. N Engl J Med $\underline{367}, 1783-1791$

Walker MP, Stopford CM, Cederlund M, Fang F, Jahn C, Rabinowitz AD, Goldfarb D, Graham DM, Yan F, Deal AM (2015): FOXP1 potentiates Wnt/beta-catenin signaling in diffuse large B cell lymphoma. Sci Signal $\underline{8}$, ra12

Wang SS, Slager SL, Brennan P, Holly EA, De Sanjose S, Bernstein L, Boffetta P, Cerhan JR, Maynadie M, Spinelli JJ (2007): Family history of hematopoietic malignancies and risk of non-Hodgkin lymphoma (NHL): a pooled analysis of 10211 cases and 11905 controls from the International Lymphoma Epidemiology Consortium (InterLymph). Blood $\underline{109}$, 3479-3488

Wang Y, Chang H, Rattner A, Nathans J (2016): Frizzled Receptors in Development and Disease. Curr Top Dev Biol 117, 113-139

Wawrzak D, Metioui M, Willems E, Hendrickx M, de Genst E, Leyns L (2007): Wnt3a binds to several sFRPs in the nanomolar range. Biochem Biophys Res Commun 357, 1119-1123

WHO, Swerdlow SH, International Agency for Research on Cancer: WHO classification of tumours of haematopoietic and lymphoid tissues [... reflects the views of a working group that convened for an Editorial and Consensus Conference at the International Agency for Research on Cancer (IARC), Lyon, October 25 - 27, 2007]. 4. Auflage, Internat. Agency for Research on Cancer, Lyon 2008

Willert K, Nusse R (1998): Beta-catenin: a key mediator of Wnt signaling. Curr Opin Genet Dev $\underline{8}$, 95-102

Witzig TE, Flinn IW, Gordon LI, Emmanouilides C, Czuczman MS, Saleh MN, Cripe L, Wiseman G, Olejnik T, Multani PS (2002): Treatment with ibritumomab tiuxetan radioimmunotherapy in patients with rituximab-refractory follicular non-Hodgkin's lymphoma. J Clin Oncol 20, 3262-3269 
Wu X, Luo F, Li J, Zhong X, Liu K (2016): Tankyrase 1 inhibitior XAV939 increases chemosensitivity in colon cancer cell lines via inhibition of the Wnt signaling pathway. Int $\mathrm{J}$ Oncol $\underline{48}, 1333-1340$

Xiao C, Srinivasan L, Calado DP, Patterson HC, Zhang B, Wang J, Henderson JM, Kutok JL, Rajewsky K (2008): Lymphoproliferative disease and autoimmunity in mice with increased miR-17-92 expression in lymphocytes. Nat Immunol $\underline{9}, 405-414$

Xuan C, Steward KK, Timmerman JM, Morrison SL (2010): Targeted delivery of interferon-alpha via fusion to anti-CD20 results in potent antitumor activity against B-cell lymphoma. Blood $\underline{115}, 2864-2871$

Yokota T, Milenic DE, Whitlow M, Schlom J (1992): Rapid tumor penetration of a single-chain Fv and comparison with other immunoglobulin forms. Cancer Res $\underline{52}, 3402-3408$

Zhang HW, Cheng NL, Chen ZW, Wang JF, Li SH, Bai W (2011): Clinical Impact of $t(14 ; 18)$ in Diffuse Large B-cell Lymphoma. Chin J Cancer Res $\underline{23}$, 160-164 


\section{Danksagung}

An dieser Stelle möchte ich mich ganz herzlich bei meinem Doktorvater Prof. Dr. Gerald G. Wulf und meinem Betreuer Dr. Raphael Koch für das Thema der Arbeit und die Betreuung bedanken. Ohne diese Unterstützung wäre die vorliegende Arbeit nicht möglich gewesen. Insbesondere möchte ich mich für die umfangreiche methodische Ausbildung durch Dr. Raphael Koch bedanken. Weiterhin danke ich Dr. Vivek Venkataramani für zahlreiche Denkanstöße.

Ebenfalls bedanke ich mich bei den MTAs Sabrina Becker, Ursula Sinzig und Christina Kiecke für die Unterstützung bei der Durchführung meiner Experimente sowie die tägliche Kollegialität im Labor.

Ich bedanke mich bei der Arbeitsgruppe um Dr. W. M. Blankesteijn der Universität Maastricht für die Bereitstellung des Peptids UM206.

Ebenfalls bedanke ich mich beim Zentrum Biochemie und Molekulare Zellbiologie Göttingen, insbesondere bei Klaus Neifer, für die Durchführung der Flüssigchromatographie.

Stellvertretend für das Institut der Pathologie Göttingen gilt mein Dank Stephan Küffer für die Anfertigung von Kryoschnitten und Gerätenutzung.

Für die Bereitstellung des Fluoreszenzmikroskops und die freundliche Einweisung bedanke ich mich bei der Arbeitsgruppe um Frau Prof. K. Guan in der Abteilung Kardiologie und Pneumologie, Göttingen, insbesondere gilt mein Dank Simin Chen. 